Biomarkers and mechanisms of natural disease resistance in dairy cows 


\section{Thesis committee}

\section{Promotor}

Prof. Dr H.F.J. Savelkoul

Professor of Cell Biology and Immunology

Wageningen University

\section{Co-promotor}

Dr. E.J. Tijhaar

Assistant professor, Cell Biology and Immunology Group

Wageningen University

\section{Other members}

Prof. Dr B. Kemp, Wageningen University

Prof. Dr F.G.M. Kroese, University Medical Centre Groningen

Prof. Dr A.C.M. van Hooijdonk, Wageningen University

Dr J.J. van der Poel, Wageningen University

This research was conducted under the auspices of the Graduate School of Wageningen Institute of Animal Sciences (WIAS). 


\title{
Biomarkers and mechanisms of natural disease resistance in dairy cows
}

\author{
S.E.C. van Altena
}

\section{Thesis}

submitted in fulfillment of the requirements for the degree of doctor at Wageningen University

by the authority of the Rector Magnificus

Prof. Dr A.P.J. Mol,

in the presence of the

Thesis Committee appointed by the Academic Board

to be defended in public

on Wednesday 6th of July 2016

at 1.30 p.m. in the Aula 
S.E.C. van Altena

Biomarkers and mechanisms of natural disease resistance in dairy cows 166 pages

PhD thesis, Wageningen University, Wageningen, NL (2016)

With references, with summaries in Dutch and English

ISBN 978-94-6257-800-5

DOI $10.18174 / 380150$ 
CONTENTS

Chapter $1 \quad$ General Introduction

Chapter 2 Identification of B-1 Cells in Veterinary Species

Chapter 3 Identification of B-1 cells in Cows

31

Chapter 4 Bovine Natural Antibodies in Antibody-

Dependent Bactericidal Activity Against

Escherichia coli and Salmonella Typhimurium

and Risk of Mastitis

.49

Chapter 5 A Proteomics-based Identification of Putative

Biomarkers for Disease in Bovine Milk

Chapter 6 General Discussion

Chapter $7 \quad$ Summary

Annex $1 \quad$ Maturation of the Immune Response

Annex 2 The Mucosal Factors Retinoic Acid and TGF- $\beta 1$ Induce Phenotypically and Functionally Distinct

Dendritic Cell Types

About me List of publications

Training 156

Dankwoord

CV 


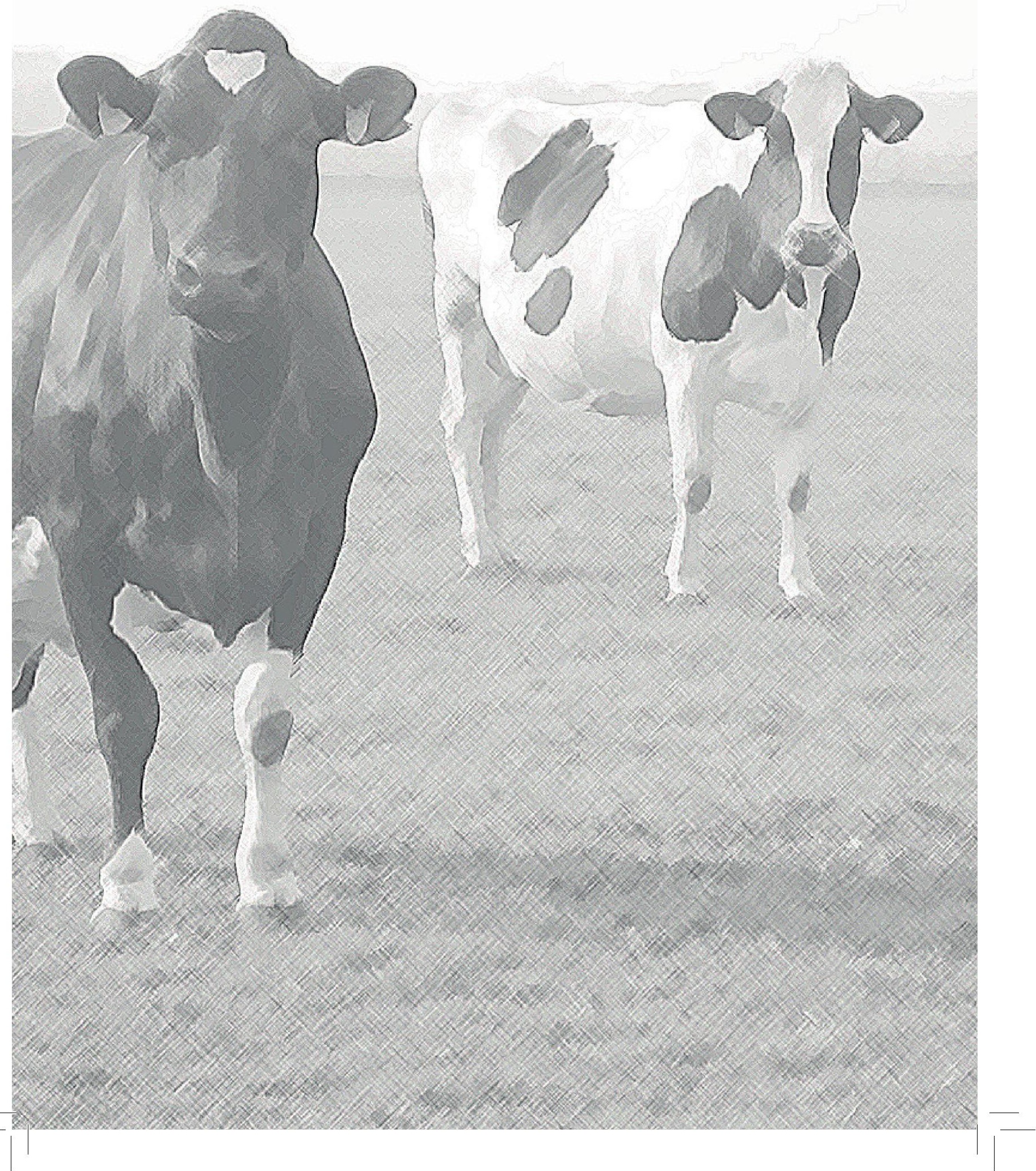




\section{Chapter 1}

General Introduction

Christine van Altena 
Chapter 1

Page | 1 


\section{Dairy farming in the Netherlands}

Dairy farming is an important and highly efficient industry in the Netherlands. The growth in dairy farming was initiated after the Second World War when the government decided to subsidise farmers in order to produce food for low prices and boost the rebuilding of the country. Large efficiency steps were made due to increased knowledge on genetics and diet regimes, but also technology such as stables and milking machines, which made it possible to manage more cows per person. The number of farms decreased, but the number of dairy cows and the production per cow increased strongly [1]. The last 20 years the number of dairy farms halved from 37,465 in 1995 to 18,300 farms in 2015. In the same period, the number of cows per farm almost doubled from 45.6 to 88.9 and the lifetime milk yield per cow increased with nearly $30 \%$ from $23,950 \mathrm{~kg}$ to $30,686 \mathrm{~kg}$. These improvements on milk production also have their drawbacks as it is accompanied with increased health problems and their associated costs $[2,3]$. The major health problems in dairy farming are mastitis, lameness and reduced fertility and these are important reasons for culling of dairy cows [4].

\section{Mastitis}

Mastitis is an inflammation of the udder caused by a microbial agent, which is accompanied with a decreased animal welfare, production loss and high costs [5-7]. Based on worldwide estimations, clinical mastitis costs about €61 - €97 per cow annually [8]. Mastitis is a multifactorial disease dependent on (mostly) bacterial exposure and the immune status of the cow, which is influenced by factors such as energy balance and milk production [9]. Since mastitis and (high) somatic cell counts (SCC) are strongly related, SSC is used as an indicator for mastitis in routine screening programmes. Major pathogens in mastitis are E. coli and the Streptococcus species [10]. Mastitis causing agents can be distinguished in environmental (e.g. E. coli) and contagious (e.g. Staphylococcus aureus) bacteria [9], which have their origin in the cows environment or are transmitted via infected quarters, respectively. Mastitis can be subdivided in clinical mastitis and subclinical mastitis. Clinical mastitis includes an inflammatory reaction in the udder with elevated SCC and changes in milk composition and occurs in either an acute or chronic form. Subclinical mastitis is asymptomatic and is indicated by SCC $>250,000$ cells per $\mathrm{ml}$ in multiparous cows and SCC $>150,000$ cells per $\mathrm{ml}$ in primiparous cows [11]. The risk of clinical mastitis is highest early in lactation [12], while the risk of subclinical mastitis increases during lactation [13]. The risk of both clinical and subclinical mastitis increases with age and are associated with an increased risk of culling [10]. Clinical mastitis incidence on Dutch conventional farms is about 33 cases per 100 cows per year [14], while others reported 47 cases per 100 cows per year in the UK [15]. The same group observed a subclinical mastitis incidence of 71 cases 100 cows per year in the UK, illustrating that mastitis is a major health problem in dairy farming.

\section{Lameness}

Lameness is the impairment of the cows` locomotion, which is caused by several leg and claw disorders. The most abundant causes of lameness are sole ulcers, white line defects 
(lesions in the junction between the foot sole and wall), digital dermatitis (Mortellaro disease) and foot rot [16-18]. The incidence of lameness is highly variable between farms and studies; one study reported an annual incidence of lameness per 100 cows ranging from 31.6 to 111.5 cases [16], in another study 10.7 to 170.1 cases were observed [19]. Claw problems are classified as infectious e.g. digital dermatitis and non-infectious e.g. trauma or white line defects and therefore have a different aetiology [20]. Infectious claw problems are often associated with a disbalance in the diet or energy balance and depression of the immune system [21]. Lameness does not only affect the cows' locomotion and welfare, but has also indirect consequences such as a reduced feed intake, milk production, fertility and energy balance and an increased risk of culling [21-25]. Risk factors for lameness are high milk production, acidosis (diet), season, animal housing, low body condition score (BCS) and (improper) management [17, 18, 26, 27].

\section{Fertility}

To initiate and maintain milk production in dairy cows, it is important that cows give birth to a calf about once a year. From the 1950 s a steady decline in fertility is observed in dairy cattle worldwide [28]. Cows fail to ovulate or lose their foetus early in pregnancy. The moment of insemination coincidences with peak lactation, when high milk production affects the nutritional need and energy balance of dairy cows and thereby impairs fertility [29]. Whether infertility is a direct consequence of high milk production or only inadequate management remains to be established [30]. Main factors contributing to impaired fertility are a too high or low body condition score (BCS $<2.5$ or $>3.5$ on a 5 -point scale), disbalance in feed macrominerals (e.g. $\mathrm{Ca}^{2+}$ and $\mathrm{Mg}^{+}$) and hormones, heat stress and diseases such as endometritis, mastitis, lameness and metabolic diseases [29, 31-34].

\section{Energy balance, diet and health problems}

The development of mastitis, lameness and fertility are all associated with a high milk yield, (negative) energy balance and diet of dairy cows [35]. This is also reflected by the main breeding goals in dairy farming across countries: production $(59.5 \%)$, durability $(28 \%)$ and health and reproduction $(12.5 \%)$, where production has much more interest than bovine health [36]. Modern dairy farming focusses on the diet and energy balance of cows, especially in the transition period, to prevent disease [37]. Still, after calving, high producing cows will come into a negative energy balance (NEB) as their feed intake does not meet their requirements and impairs the bovine immune system [35, 38]. Also the periparturient period itself is accompanied by immune suppression [39]. As a consequence, about $75 \%$ of the health problems in dairy cows occur the first month after calving [40].

\section{Immune system}

As in humans, the bovine immune system is divided in an innate and adaptive immune system. The innate immune system is characterised by fast responses based on recognition of conserved microbial structures by preformed receptors or immune proteins. Important players are different types of immune cells, and humoral factors like antimicrobial peptides and the complement system. Immune cells such as macrophages and neutrophils 
recognize and phagocytise microbes and produce cytokines in order to attract other immune cells and to induce an adaptive immune reaction. Antimicrobial peptides, such as lactoferrin, are amphipathic molecules of $<100$ amino acids long with antimicrobial and immunomodulatory functions [41]. They are produced by immune and epithelial cells and can kill among others by direct interaction and disruption of the bacterial membrane. The complement system involves a large set of proteins that can recognise microbes via three different pathways: the classical, the mannose-binding lectin and the alternative pathway. These pathways differ in the way of activation, but they all lead to the activation of key player $\mathrm{C} 3 \mathrm{~b}$ and subsequently opsonisation or lysing of microbes.

The adaptive immune system includes B- and T-cells, which are responsible for humoral (antibodies) and cell-mediated immunity, respectively. The B- and T-cell compartments include several cells with their own functions. Conventional B-cells (B-2 cells or follicular B-cells) are derived from the bone marrow. Upon interaction of the B-cell with a specific antigen and costimulation by T-cells, the B-cell becomes activated, starts proliferating and develops into plasma cells that secrete specific antibodies (SpAbs), mostly IgM (Figure 1). In addition, memory B-cells are formed which initiate a rapid antibody response upon a next encounter with the same antigen. In this secondary response B-cells undergo somatic hypermutation and class-switching to e.g. IgG1 and IgG2 subclasses leading to highly specific antibodies. T-cells are generally subdivided in $\mathrm{CD}^{+}$T-helper cells and $\mathrm{CD} 8^{+}$cytotoxic T-cells. $\mathrm{CD} 4^{+} \mathrm{T}$-cells are involved in B-cells activation and co-stimulation by the production of cytokines and cell-cell interactions. $\mathrm{CD} 8^{+} \mathrm{T}$-cells perform direct killing of virus-infected and tumour cells.

At the interplay of the innate and adaptive immune system are the $\gamma \delta$-T-cells, NKT-cells, marginal zone B-cells and B-1 cells [42]. These more innate-like cell types recognise a limited and more conserved repertoire of antigens than the conventional B- and T-cells. In addition, B-1 cells and $\gamma \delta$-T-cells recognise self-antigens [43], while conventional B- and T-cells are negatively selected for self-antigens. B- 1 and $\gamma \delta$-T-cells are both relatively more abundant in young individuals, particularly the $\gamma \delta$-T-cells that represent up to $60 \%$ of the peripheral blood mononuclear cells (PBMCs) in newborn calves [44].

\section{B-1 cells}

B-1 cells are well defined in mice, but sporadically described in cows. B-1 cells in cows were defined by the originally used murine markers CD5 and CD11b and subdivided in $\mathrm{CD}^{+} \mathrm{CD} 11 \mathrm{~b}^{-} \mathrm{B} 1 \mathrm{a}$ cells, $\mathrm{CD} 5^{-\mathrm{CD}} 11 \mathrm{~b}^{+} \mathrm{B} 1 \mathrm{~b}$ cells and $\mathrm{CD} 5^{-\mathrm{CD}} 11 \mathrm{~b}^{-}$conventional B-2 cells [45]. According to this classification, the total B-1 cell population would represent about 30 to $40 \%$ of the PBMCs and would increase up to $80 \%$ during a Trypanosoma congolense infection. Using these markers in humans, the B-1 cell population would represent about 10 to $30 \%$ of the PBMC. In contrast, murine B-1 cells are nearly absent in blood, but are enriched in the peritoneal and pleural cavities. These findings and additional research showed that the markers CD5 and CD11b are not suitable to identify B-1 cells only (Reviewed in chapter 2). B-1 cell identification in mice requires the following markers: $\mathrm{CD}^{+/}{ }^{+-}, \mathrm{CD}_{11 \mathrm{~b}^{+}}$, IgM ${ }^{\text {high }}$, IgD ${ }^{\text {low }}, \mathrm{B} 220^{\text {low }}, \mathrm{CD} 23^{-}$and $\mathrm{CD}^{2} 3^{+}[46,47]$.

Despite the fact that B-1 cells produce antibodies, they are more innate-like cells and 
from an evolutionary perspective, B-1 cells were present earlier than the conventional B-2 cells [48]. The major function of B-1 cells is the spontaneous production of Natural Antibodies (NAbs), while B-2 cells produce Specific Antibodies (SpAbs) upon interaction with a specific antigen and costimulatory signals. Additional functions of B-1 cells are the production of IL-10, (partial) production of intestinal IgA, phagocytosis and killing of microbes and subsequent induction of $\mathrm{CD}^{+}{ }^{+} \mathrm{T}$-cell responses [48-51].

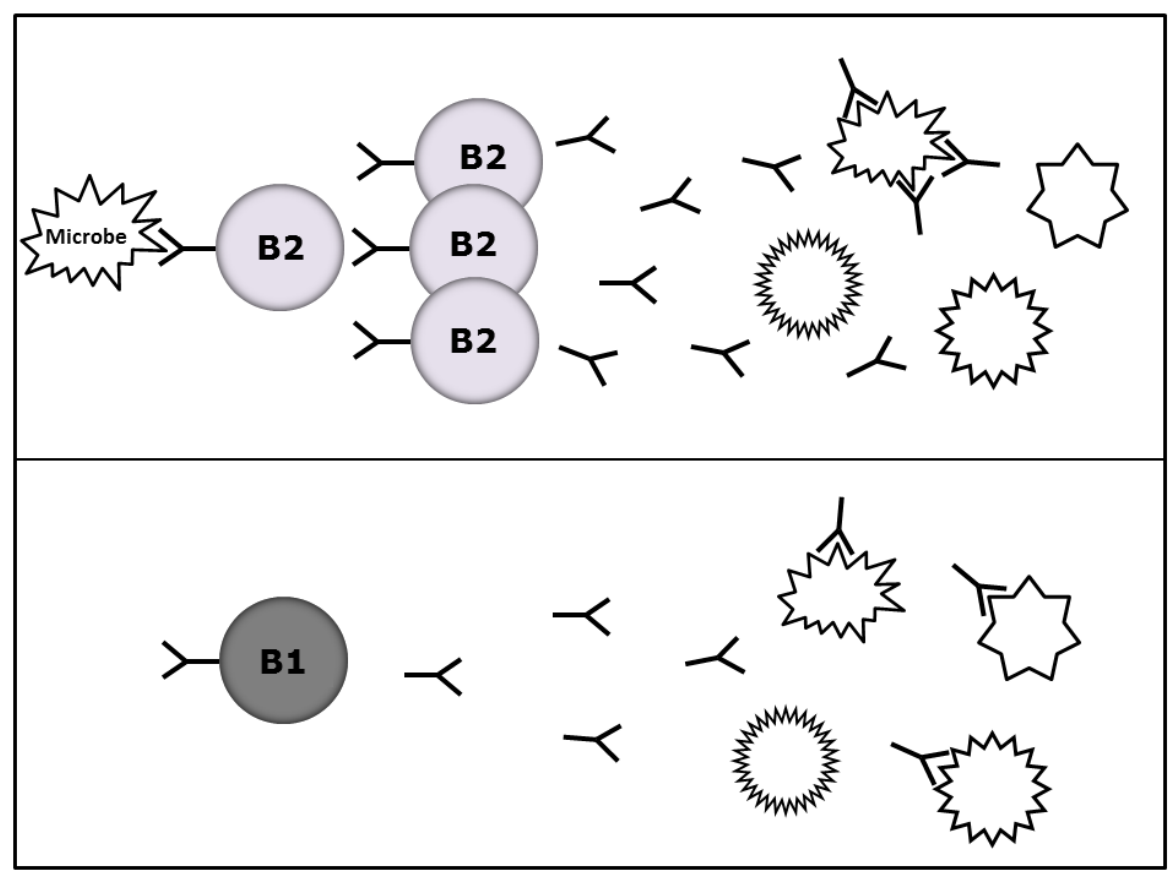

Figure 1: Antibody production by B-1 and B-2 cells

The conventional B-2 cells are activated by the interaction with a specific antigen (microbe) and costimulatory signalling. Activated B-2 cells start proliferating and produce specific antibodies (SpAbs) which bind to the antigen the B-2 interacted with and no other microbes. B-1 cells do not need the interaction with a specific antigen, but spontaneously produce natural antibodies (NAbs). These NAbs are mostly IgMs which bind to common microbial structures and auto-antigens.

\section{B-1 cell regulation}

B-1 cells are primarily formed before birth and maintained through life, while B-2 cells mainly develop around birth and strongly increase afterwards by clonal expansion [52]. In contrast to B-2 cells which proliferate upon B-cell receptor (BCR) stimulation, B-1 cells are hypo-responsive to $\mathrm{BCR}$ engagement showing no or little proliferation and increased apoptosis [53]. This BCR unresponsiveness maintains B-1 cell numbers since mutations in negative regulators of $\mathrm{BCR}$ signalling result in increased B-1 cell numbers and mutations in positive regulators lead to decreased B-1 cell numbers [47]. Because of their hyper- 
expression of the regulator gene c-myc, which encodes a transcription factor that induces cell cycle progression, B-1 cells show autonomous proliferation, unlike B-2 cells [54]. In addition, B-1 cells are able to spontaneously produce antibodies, which is different from antibody production in B-2 cells that requires BCR stimulation [55]. Antibody production in B-2 cells depends on several transcription factors such as B lymphocyte inducer of maturation program 1 (BLIMP-1) and paired box gene PAX-5 under control of key regulator interferon response factor 4 (IRF4). Peritoneal and splenic B-1 cells can produce low levels of NAbs independent of IRF4, however, high production of NAbs by splenic B-1 cells is IRF4-dependent. In addition, recent research suggests that B-1 cells from different sources have different functions [56]. Peritoneal B-1 cells are involved in inflammatory responses, while splenic (and bone marrow-derived) B-1 cells are the main producers of NAbs. They are also differently regulated since the number of peritoneal B-1 cells (and conventional B-2 cells) strongly decreased in the absence of secreted (natural) IgM, while splenic B-1 cells are unaffected and MZ cells even increased [57]. The absence of natural IgM resulted in antibody-mediated autoimmunity, implying an important role for B-1 cells in preventing autoimmunity. Furthermore, serum IgM levels were shown to control B-1 and MZ B-cell numbers at steady state [58].

\section{Natural antibodies}

Natural antibodies (NAbs) are defined as polyreactive antibodies, which are produced without prior antigenic stimulation [59]. These antibodies are often directed to common microbial structures (e.g. lipopolysaccharides (LPS), lipoteichoic acid (LTA), peptidoglycans (PGN)), auto-antigens (e.g. DNA, phosphatidylcholine (PtC)) and neo-antigens (e.g. keyhole limpet hemocyanin (KLH)) [60, 61]. The NAb repertoire is germline-like due to limited use of V-genes, somatic hypermutation and incorporation of $\mathrm{N}$-additions and is not further modified because of their lack of memory formation [59, 62]. Studies in mice and human showed that auto-reactive $\operatorname{IgM}$ and $\operatorname{IgG}$ (natural) antibodies are already present in newborns and individuals recognize a conserved collection of antigens [63]. The auto-reactive NAb repertoire develops and matures during early life, leading to some diversity, which is maintained during life. NAbs directed to common microbial structures were also shown to be conserved between species, since cross-reactivity was observed between mice, humans and rats [59]. The NAb repertoire consists of IgM, IgA, $\operatorname{IgG} 1$, and IgG2 antibodies, which are present in different amounts in species and body fluids. In mammalian blood, IgM is the most dominant NAb [64]. Due to its pentameric structure, natural IgM antibodies bind their target with low affinity, but high avidity. About $90 \%$ of total IgM levels in germ-free mice are natural antibodies [62]. In addition, NAbs in germ-free mice represent about $50 \%$ and $10 \%$ of the total $\operatorname{IgA}$ and $\operatorname{IgG}$ levels, respectively.

\section{Function NAbs}

Natural antibodies have different roles in the immune system and can act in similar ways as specific antibodies [65]. They are not able to eliminate pathogens by themselves [66], but cooperate with other cells and factors of the innate immune system to do so. However, NAbs can be considered part of the innate immune defence and are especially important in the initial phases of an immune response. Binding of NAbs to pathogens such as bacteria 
and viruses has different consequences. Firstly, NAbs result in neutralisation of the pathogen thereby preventing that the pathogen enters host cells or tissues. Agglutination of pathogens by NAbs provides a rapid reduction of infectious agents by creating antibodyantigen immune complexes with improved recognition by e.g. DCs via Fc receptors. Binding, or opsonisation, by NAbs also marks pathogens, leading to pathogen capture in the spleen or lymph nodes. When trapped in these secondary lymphoid organs, pathogens are unable to injure other organs [64]. Additionally, this antibody-antigen immune complex can be taken up by neutrophils, resident macrophages and dendritic cells, resulting in pathogen clearance and the induction of an immune response against the pathogen. The antibody-antigen immune complexes are also recognised by the complement system, mediating opsonisation, phagocytosis or direct killing by lysing the pathogen $[65,66]$. Especially IgM is a strong activator of the classical complement pathway by the binding of the constant region of IgM to complement factor C1q [64, 67]. Next to their role in innate and adaptive immunity, NAbs have some housekeeping functions as they contribute to the removal of oxidized lipids and apoptotic cells, and maintain intestinal homeostasis [68].

\section{NAbs and survival}

NAbs have a non-redundant role in the (humoral) innate immune system and are essential in the protection against viral and bacterial infections [66, 67, 69]. Mice suffering from an acute peritoneal infection had much higher mortality rates in the absence of NAbs; about $70 \%$ of the mice lacking secreted immunoglobulin type M (sIgM) died versus $20 \%$ of the wild-type mice [69]. Without NAbs, the mice were insufficiently protected during the first phases of the bacterial infection. Furthermore, NAbs were shown to have a predictive value for the risk of dying in laying hens [70]. The NAb titers to KLH and LPS in 20-weeks old laying hens were indicative for their survival; chickens having low $\mathrm{NAb}$ titres against KLH were more prone to die early. Also in Soay sheep, there was a positive correlation between autoreactive antibodies (NAbs) and survival [71]. The female Soay sheep with high anti-nuclear antibody levels were shown to be able to survive better during harsh winters than the ewes with low anti-nuclear antibody levels.

The effects of NAbs in mice, chicken, and sheep studies make it reasonable that NAbs have an important role in bovine immunity too. Indeed, this is strongly supported by the work of Ploegaert et al. [72]. She showed that the natural antibodies (type IgM and IgA) appear to have a considerable impact on the resistance to clinical mastitis in heifers with a good udder health history. Heifers with low NAb titres tend to have a higher risk to develop clinical mastitis than heifers with high NAb titres. In clinically healthy multiparous cows, the susceptibility for developing clinical mastitis significantly decreases by increasing IgG1 levels against KLH [72]. These findings indicate that NAbs might have a predictive value for the ability of a cow to resist certain infectious diseases. In addition, lactating cows with a negative energy balance were shown to have low NAb levels against KLH [38]. Based on these results, NAbs are a candidate biomarker for natural resistance in cows. 


\section{Resilient Cattle ("Weerbaar Vee")}

Dutch dairy farming is changing and, after years of focussing on milk yield, the animal welfare becomes of increasing importance. Dairy cows in the Netherlands live about 3.5 lactations [1], which means an average age of 5.5 years. This is relatively young since cows are able to reach an age of about 20 years. The main reasons for involuntary culling are health problems such as mastitis, lameness and fertility as mentioned before. Another concern in dairy farming is the use of antibiotics, and thereby the associated risk of emerging antibiotics resistance. The government urges to reduce the use of antibiotics in the whole livestock industry and decided to restrict the use of certain antibiotics for human diseases only. To increase the age and welfare of the Dutch dairy cows, projects are initiated such as Resilient Cattle. This project aims to answer the question whether the resilience of cows can be measured, to what extend this is hereditary and whether this resilience can be positively influenced.

The Resilient Cattle project is a cooperation between companies (GD and CRV), the University of Wageningen and initially 30 conventional dairy farmers spread over the Netherlands. Together they aim at increasing the health and age of dairy cows by decreasing the health problems. Different approaches were chosen to reach this goal. Previous research showed that Natural Antibodies (NAbs) are a suitable candidate biomarker for disease resistance in dairy cows. NAbs were represented as IgM antibodies binding to KLH. In the Resilient Cattle project, the potency of NAbs is further investigated on different levels. NAbs were determined in the bovine serum and milk samples and related to the development of periparturient diseases to establish the prognostic value of NAbs. In addition, to be able to use NAbs as a biomarker in practice, the relation between NAbs in blood and milk was determined since milk is much more feasible for routine screening. Also the heritability of NAb levels was calculated to test if selective breeding can influence NAbs. A field study was conducted on the 29 dairy farms involved in the project. Under supervision of a veterinarian, the health problems on each farm were investigated and approached with farm-specific management tools. The ultimate read-outs were a decrease in health problems, particularly in the periparturient period, and a change in NAb levels. In parallel, a lab-based approach was used to increase knowledge about the NAbs itself and their source, the B-1 cells. Additionally, a Proteomics approach was used to identify new potential biomarkers for disease resistance in milk.

\section{Resilient Cattle biobank}

During the Resilient Cattle project, a large biobank was created containing blood, serum and milk samples from the cows present on 29 of the 30 dairy farms involved. In 2011, 2012 and 2014 blood and serum samples were collected from the dairy cows and some of the calves. Also milk samples were collected: one in 2011, four in 2012/2013 and every 6-8 weeks in the period of December 2013 until March 2015. From each cow, 5 to 14 milk samples are stored in the Resilient Cattle biobank. Next to the biological samples, also milk production and registration data (MPR) are collected and thorough disease registration data were recorded. The MPR data are determined for each farm at a 6 to 8 week interval containing information about among others milk yield, somatic cell counts, percentage fat 
and protein. The disease registration data concerns all diseases and treatments the cows received including the moment and duration of disease. Diseases were categorised in: mastitis, other udder-related problems (e.g. trauma), metritis (all uterus-related problems), retained placenta (retention of the embryonic tissues for more than 24 hours after calving), respiratory diseases, lameness (includes all leg and claw problems), metabolic diseases (diseases such as milk fever and ketosis, which occur due an imbalance in macrominerals and a negative energy balance) and "other" (all diseases that did not fit the previous categories). During the project a special interest into the so-called production diseases emerged, which occur in the periparturient or transition period (about 3 weeks before and after calving) [73]. These production diseases include: metritis, retained placenta and the metabolic diseases.

\section{This thesis}

This thesis concerns biomarkers and mechanisms of natural disease resistance in dairy cows. Natural antibodies were implied to have a protective role in the bovine immune system as they were shown to be negatively associated to the risk of clinical mastitis in dairy cows. However, it remains to be established whether higher NAb levels are associated with an increased disease resistance in dairy cows and can be used as a biomarker for health. In addition, the underlying mechanism i.e. the functional and regulatory role of NAbs in the bovine immune system and how they contribute to disease resistance is currently not known. Studying NAbs in the bovine immune system is not straight forward, since both natural and specific antibodies are present in the cow and they are hard to distinguish from each other (Figure 1). Knockout models, as used for $\mathrm{NAb}$ research in mice, are not available for cows. An alternative way to study NAbs is to determine antibody binding to a naïve antigen. A naïve antigen, such as keyhole limpet hemocyanin $(\mathrm{KLH})$, is not encountered before and specific antibodies against KLH will be lacking in the cow. Antibodies binding to KLH should therefore, principally, be NAbs. Another approach is to study the cells that produce NAbs: the B-1 cells. In conjunction with NAbs, these B-1 cells may be a suitable biomarker. These cells also enable to study the regulation of NAb production as B-1 and (conventional) B-2 cells can be distinguished based on their phenotypes. Another advantage of B-1 cells is that B-1 cells can be used as a selection tool for calves at young age. Calves need to be selected at 2 to 3 weeks of age if they are suitable for rearing to become a dairy cow (replacement heifer) or to be sold as veal calf. Rearing of a calf costs about $€ 1700$, so it would be beneficial to be able to select a high-resistant dairy cow at young age. Measuring NAbs at this young age is not informative, since the serum antibodies mainly consist of maternal-derived antibodies and not NAbs produced by the calf. B-1 cells are most likely not transferred from cow to calf and might be a better reflection of the immune competence of the calf. The B-1 cells are well described in mice, but less studied in veterinary species. The B-1 cell phenotype described for veterinary species is mainly based on murine markers, which were shown to be not suitable. A better identification of bovine B-1 cells is therefore needed.

Since the potency of NAbs and B-1 cells as biomarker for disease resistance remains 
to be determined, also additional biomarkers for disease resistance are desired. Current biomarkers, such as SCC for mastitis, are disease-specific and can only be determined when the disease is already there. A predictive marker for disease resistance would be more valuable since it offers the opportunity to manage the cow at risk and thereby hopefully prevent disease. To monitor the disease resistance, a biomarker should be suitable for routine screening and therefore a milk protein marker is preferred.

In short, the main aims in this thesis are:

- Determining the role of NAbs in the bovine immune system

- Identification of bovine B-1 cells and their relevance to NAb production

- Identification of alternative biomarkers for disease resistance in bovine milk using Proteomics

These aims are addressed in the following chapters of this thesis. Chapter 2 encloses a review about the identification of B-1 cells in veterinary species. B-1 cells are well described in mice and humans. However, the phenotype of B-1 cells is shown to be variable between tissues in mice and the B-1 cell phenotype is still under debate in humans. In veterinary species, such as cows, B-1 cells are poorly described and their identification is based on markers, which were shown to be not suitable. The review gives an overview of the literature describing the B-1 cell phenotype, development and the existence of natural antibodies in veterinary species. Furthermore, this review is an introduction to the next chapter, since chapter 3 shows the identification of putative B-1 cells in cows. B-1 cells in cows might be a more clear marker for disease resistance in dairy cows than NAbs. In addition, B-1 cells can be determined at young age and are therefore suitable as a screening tool for young calves. Putative B-1 cells are identified using flow cytometry based on known markers described for mice and humans as far as possible since tools like monoclonal antibodies for cows are limited. These putative B-1 cells were quantified in blood of young calves before and after they received colostrum. Young animals have relatively more B-1 cells since B-2 cells enormously expand after birth while B-1 cell numbers are just maintained by self-renewal. The kinetics of B-1 cells during the first three weeks of life were correlated with the development of IgM antibodies binding to phosphatidylcholine (PtC), which is used as a marker for NAbs. In chapter 4 we investigated the role of NAbs in the bovine immune system i.e. their ability to recognise and kill bacteria. NAbs, were represented by IgM antibodies binding to KLH. Cows were selected from the Resilient Cattle biobank for having high and low NAbs in serum. Both groups were tested in ELISA for their IgM and IgG antibodies binding to common microbial structures (LPS, LTA and PGN) and intact, fixed bacteria (E. coli and S. typhimurium). The cows with high and low NAb levels were also compared for their ability to kill live E. coli and S. typhimurium bacteria via antibody-mediated complement killing in a newly developed serum bactericidal test. Additionally, the performance in the serum bactericidal test was related to the development of mastitis within one or five years after testing to 
determine the prognostic value of the serum bactericidal test. Chapter 5 addresses the search for new biomarkers for natural disease resistance of dairy cows. The proteins in milk of cows with recurrent diseases (low-resistant cows) and cows without health problems (high-resistant cows) were compared using Proteomics. Potential biomarkers obtained by Proteomics were validated with ELISA in a larger group of high- and lowresistant cows based on disease registration data. Moreover, the potential biomarker levels in milk were related to diseases the cows had suffered from and, finally, to culling in order to determine the association with specific diseases and to test the prognostic value. At the end of this thesis, limitations and future perspectives will be summarised and placed in the context of available literature in the general discussion (hapter 6). 


\section{References}

1. $\quad$ CRV, Jaarstatistieken: MPR statistiek 2015.

2. Rauw, W.M., et al., Undesirable side effects of selection for high production efficiency in farm animals: a review. Livestock Production Science, 1998. 56(1): p. 15-33.

3. Fleischer, P., et al., The relationship between milk yield and the incidence of some diseases in dairy cows. J Dairy Sci, 2001. 84(9): p. 2025-35.

4. Fetrow, J., K.V. Nordlund, and H.D. Norman, Invited review: Culling: nomenclature, definitions, and recommendations. J Dairy Sci, 2006. 89(6): p. 1896-905.

5. Carlén, E., E. Strandberg, and A. Roth, Genetic Parameters for Clinical Mastitis, Somatic Cell Score, and Production in the First Three Lactations of Swedish Holstein Cows. Journal of Dairy Science, 2004. 87(9): p. 3062-3070.

6. Huijps, K., T.J. Lam, and H. Hogeveen, Costs of mastitis: facts and perception. J Dairy Res, 2008. 75(1): p. 113-20.

7. Nielsen, C., et al., Economic consequences of mastitis and withdrawal of milk with high somatic cell count in Swedish dairy herds. Animal, 2010. 4(10): p. 1758-70.

8. Hogeveen, H., K. Huijps, and T. Lam, Economic aspects of mastitis: New developments. New Zealand Veterinary Journal, 2011. 59(1): p. 16-23.

9. $\quad$ Oviedo-Boyso, J., et al., Innate immune response of bovine mammary gland to pathogenic bacteria responsible for mastitis. Journal of Infection, 2007. 54(4): p. 399-409.

10. Hertl, J.A., et al., The effect of recurrent episodes of clinical mastitis caused by grampositive and gram-negative bacteria and other organisms on mortality and culling in Holstein dairy cows. Journal of Dairy Science, 2011. 94(10): p. 4863-4877.

11. Sampimon, O., et al., Effect of coagulase-negative staphylococci on somatic cell count in Dutch dairy herds. J Dairy Res, 2010. 77(3): p. 318-24.

12. Steeneveld, W., et al., The Influence of Cow Factors on the Incidence of Clinical Mastitis in Dairy Cows. Journal of Dairy Science, 2008. 91(4): p. 1391-1402.

13. Busato, A., et al., Udder health and risk factors for subclinical mastitis in organic dairy farms in Switzerland. Prev Vet Med, 2000. 44(3-4): p. 205-20.

14. Santman-Berends, I.M.G.A., et al., An estimation of the clinical mastitis incidence per 100 cows per year based on routinely collected herd data. Journal of Dairy Science, 2015. 98(10): p. 6965-6977.

15. Bradley, A., et al., Survey of the incidence and aetiology of mastitis on dairy farms in England and Wales. The Veterinary Record, 2007. 160: p. 253-258.

16. Hedges, J., et al., A Longitudinal Field Trial of the Effect of Biotin on Lameness in Dairy Cows. Journal of Dairy Science, 2001. 84(9): p. 1969-1975.

17. Hernandez, J., J.K. Shearer, and D.W. Webb, Effect of lameness on milk yield in dairy cows. Journal of the American Veterinary Medical Association, 2002. 220(5): p. 640-644.

18. Laven, R.A. and K.R. Lawrence, An evaluation of the seasonality of veterinary treatments for lameness in UK dairy cattle. J Dairy Sci, 2006. 89(10): p. 3858-65.

19. Clarkson, M.J., et al., Incidence and prevalence of lameness in dairy cattle. Vet Rec, 1996. 138(23): p. 563-7.

20. Cha, E., et al., The cost of different types of lameness in dairy cows calculated by dynamic programming. Preventive Veterinary Medicine, 2010. 97(1): p. 1-8.

21. Collard, B.L., et al., Relationships Between Energy Balance and Health Traits of Dairy Cattle in Early Lactation. Journal of Dairy Science, 2000. 83(11): p. 2683-2690.

22. Booth, C.J., et al., Effect of Lameness on Culling in Dairy Cows. Journal of Dairy Science, 2004. 87(12): p. 4115-4122. 
23. Barkema, H.W., et al., The effects of lameness on reproductive performance, milk production and culling in Dutch dairy farms. Preventive Veterinary Medicine, 1994. 20(4): p. 249-259.

24. Warnick, L.D., et al., The Effect of Lameness on Milk Production in Dairy Cows. Journal of Dairy Science, 2001. 84(9): p. 1988-1997.

25. Green, L.E., et al., The Impact of Clinical Lameness on the Milk Yield of Dairy Cows. Journal of Dairy Science, 2002. 85(9): p. 2250-2256.

26. Cook, N.B., Prevalence of lameness among dairy cattle in Wisconsin as a function of housing type and stall surface. J Am Vet Med Assoc, 2003. 223(9): p. 1324-8.

27. Randall, L.V., et al., Low body condition predisposes cattle to lameness: An 8-year study of one dairy herd. Journal of Dairy Science, 2015. 98(6): p. 3766-3777.

28. Lucy, M.C., Reproductive Loss in High-Producing Dairy Cattle: Where Will It End? Journal of Dairy Science, 2001. 84(6): p. 1277-1293.

29. Walsh, S.W., E.J. Williams, and A.C.O. Evans, A review of the causes of poor fertility in high milk producing dairy cows. Animal Reproduction Science, 2011. 123(3-4): p. $127-$ 138.

30. Leblanc, S., Assessing the Association of the Level of Milk Production with Reproductive Performance in Dairy Cattle. Journal of Reproduction and Development, 2010. 56(S): p. S1-S7.

31. Hernandez, J., J.K. Shearer, and D.W. Webb, Effect of lameness on the calving-toconception interval in dairy cows. Journal of the American veterinary medical association, 2001. 218(10): p. 1611-1614.

32. Huszenicza, G., et al., Effects of Clinical Mastitis on Ovarian Function in Post $\square$ partum Dairy Cows. Reproduction in Domestic Animals, 2005. 40(3): p. 199-204.

33. Roche, J.F., The effect of nutritional management of the dairy cow on reproductive efficiency. Animal Reproduction Science, 2006. 96(3-4): p. 282-296.

34. Garnsworthy, P., K. Sinclair, and R. Webb, Integration of physiological mechanisms that influence fertility in dairy cows. 2008.

35. Ingvartsen, K.L. and K. Moyes, Nutrition, immune function and health of dairy cattle. Animal, 2013. 7(Supplements1): p. 112-122.

36. Miglior, F., B.L. Muir, and B.J. Van Doormaal, Selection Indices in Holstein Cattle of Various Countries. Journal of Dairy Science, 2005. 88(3): p. 1255-1263.

37. Mulligan, F.J., et al., $A$ herd health approach to dairy cow nutrition and production diseases of the transition cow. Animal Reproduction Science, 2006. 96(3-4): p. 331-353.

38. van Knegsel, A.T.M., et al., Natural Antibodies Related to Energy Balance in Early Lactation Dairy Cows. Journal of Dairy Science, 2007. 90(12): p. 5490-5498.

39. Ingvartsen, K.L. and K.M. Moyes, Factors contributing to immunosuppression in the dairy cow during the periparturient period. Jpn J Vet Res, 2015. 63 Suppl 1: p. S15-24.

40. LeBlanc, S.J., et al., Major Advances in Disease Prevention in Dairy Cattle. Journal of Dairy Science, 2006. 89(4): p. 1267-1279.

41. Pasupuleti, M., A. Schmidtchen, and M. Malmsten, Antimicrobial peptides: key components of the innate immune system. Crit Rev Biotechnol, 2012. 32(2): p. 143-71.

42. Getz, G.S., Bridging the innate and adaptive immune systems. Journal of Lipid Research, 2005. 46(4): p. 619-622.

43. Vantourout, P. and A. Hayday, Six-of-the-best: unique contributions of [gamma][delta] T cells to immunology. 2013. 13(2): p. 88-100.

44. Clevers, H., et al., Identification of a bovine surface antigen uniquely expressed on CD4CD8- T cell receptor gamma/delta + T lymphocytes. Eur J Immunol, 1990. 20(4): p. 809- 
17.

45. Naessens, J. and D.J. Williams, Characterization and measurement of CD5+ B cells in normal and Trypanosoma congolense-infected cattle. Eur J Immunol, 1992. 22(7): p. 1713-8.

46. Hardy, R.R. and K. Hayakawa, B cell development pathways. Annu Rev Immunol, 2001. 19: p. 595-621.

47. Berland, R. and H.H. Wortis, Origins and functions of B-1 cells with notes on the role of CD5. Annu Rev Immunol, 2002. 20: p. 253-300.

48. Parra, D., et al., Pivotal advance: peritoneal cavity B-1 B cells have phagocytic and microbicidal capacities and present phagocytosed antigen to CD4+T cells. J Leukoc Biol, 2012. 91(4): p. 525-36.

49. Kroese, F.G., W.A. Ammerlaan, and A.B. Kantor, Evidence that intestinal IgA plasma cells in mu, kappa transgenic mice are derived from B-1 (Ly-1 B) cells. Int Immunol, 1993. 5(10): p. 1317-27.

50. Sindhava, V., et al., Interleukin-10 mediated autoregulation of murine B-1 B-cells and its role in Borrelia hermsii infection. PLoS One, 2010. 5(7): p. e11445.

51. Suzuki, K., et al., Roles of B-1 and B-2 cells in innate and acquired IgA-mediated immunity. Immunol Rev, 2010. 237(1): p. 180-90.

52. Montecino-Rodriguez, E. and K. Dorshkind, B-1 B cell development in the fetus and adult. Immunity, 2012. 36(1): p. 13-21.

53. Sindhava, V.J. and S. Bondada, Multiple Regulatory Mechanisms Control B-1 B Cell Activation. Frontiers in Immunology, 2012. 3: p. 372.

54. Mix, E., R. Goertsches, and U.K. Zett, Immunoglobulins--basic considerations. J Neurol, 2006. 253 Suppl 5: p. V9-17.

55. Holodick, N.E., J.R. Tumang, and T.L. Rothstein, Immunoglobulin secretion by B1 cells: differential intensity and IRF4-dependence of spontaneous IgM secretion by peritoneal and splenic B1 cells. Eur J Immunol, 2010. 40(11): p. 3007-16.

56. Baumgarth, N., E.E. Waffarn, and T.T.T. Nguyen, Natural and induced B-1 cell immunity to infections raises questions of nature versus nurture. Annals of the New York Academy of Sciences, 2015. 1362(1): p. 188-199.

57. Nguyen, T.T., R.A. Elsner, and N. Baumgarth, Natural IgM prevents autoimmunity by enforcing B cell central tolerance induction. J Immunol, 2015. 194(4): p. 1489-502.

58. Lino, A.C., E. Mohr, and J. Demengeot, Naturally secreted immunoglobulins limit B1 and MZ B-cell numbers through a microbiota-independent mechanism. Blood, 2013. 122(2): p. 209-218.

59. Avrameas, S., Natural autoantibodies: from 'horror autotoxicus' to 'gnothi seauton'. Immunol Today, 1991. 12(5): p. 154-9.

60. Ploegaert, T.C.W., et al., Genetic variation of natural antibodies in milk of Dutch HolsteinFriesian cows. Journal of Dairy Science, 2010. 93(11): p. 5467-5473.

61. Shaw, P.X., et al., Natural antibodies with the T15 idiotype may act in atherosclerosis, apoptotic clearance, and protective immunity. Journal of Clinical Investigation, 2000. 105(12): p. 1731-1740.

62. Baumgarth, N., J.W. Tung, and L.A. Herzenberg. Inherent specificities in natural antibodies: a key to immune defense against pathogen invasion. in Springer seminars in immunopathology. 2005. Springer.

63. Lacroix-Desmazes, S., et al., Stability of natural self-reactive antibody repertoires during aging. J Clin Immunol, 1999. 19(1): p. 26-34.

64. Boes, M., Role of natural and immune IgM antibodies in immune responses. Molecular 
immunology, 2000. 37(18): p. 1141-1149.

65. Hangartner, L., R.M. Zinkernagel, and H. Hengartner, Antiviral antibody responses: the two extremes of a wide spectrum. Nature Reviews Immunology, 2006. 6(3): p. 231-243.

66. Baumgarth, N., et al., B-1 and B-2 cell-derived immunoglobulin $M$ antibodies are nonredundant components of the protective response to influenza virus infection. J Exp Med, 2000. 192(2): p. 271-80.

67. Ehrenstein, M.R. and C.A. Notley, The importance of natural IgM: scavenger, protector and regulator. Nature Reviews Immunology, 2010. 10(11): p. 778-786.

68. Baumgarth, N., The double life of a B-1 cell: self-reactivity selects for protective effector functions. Nat Rev Immunol, 2011. 11(1): p. 34-46.

69. Boes, M., et al., A critical role of natural immunoglobulin M in immediate defense against systemic bacterial infection. The Journal of experimental medicine, 1998. 188(12): p. 2381-2386.

70. Star, L., et al., Natural humoral immune competence and survival in layers. Poult Sci, 2007. 86(6): p. 1090-9.

71. Graham, A.L., et al., Fitness correlates of heritable variation in antibody responsiveness in a wild mammal. Science, 2010. 330(6004): p. 662-665.

72. Ploegaert, T.C., et al., Natural antibodies in bovine milk and blood plasma: variability among cows, repeatability within cows, and relation between milk and plasma titers. Vet Immunol Immunopathol, 2011. 144(1-2): p. 88-94.

73. Drackley, J.K., Biology of dairy cows during the transition period: The final frontier? Journal of dairy science, 1999. 82(11): p. 2259-2273. 


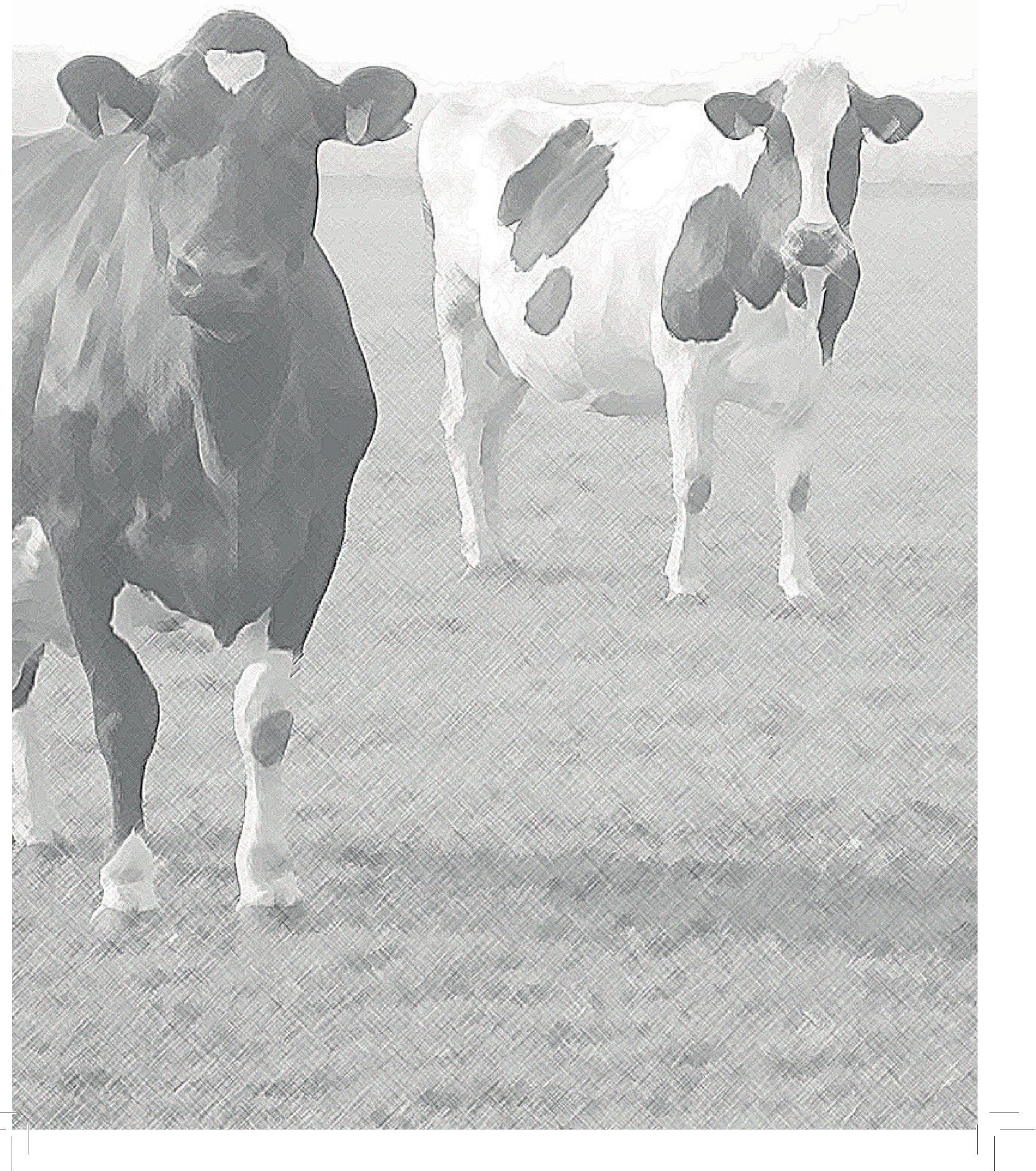




\section{Chapter 2}

\section{Identification of B-1 Cells in Veterinary Species}

\section{S.E.C. van Altena ${ }^{1}$, H.F.J. Savelkoul ${ }^{1}$, E.J. Tijhaar ${ }^{1}$}

${ }^{1}$ Cell Biology and Immunology Group, Department of Animal Sciences,

Wageningen University, PO box 338, Wageningen, the Netherlands

Submitted for publication 


\section{Abstract}

Text B-1 cells are well-established in mice in terms of their development, phenotype and functions. They have a unique role in the immune system and are responsible for the production of natural antibodies. The existence of B-1 cells in veterinary species is often discussed, but the true homologues of murine B-1 cells are not determined yet. Differences in surface marker expression and the lack of antibodies to detect cell markers in veterinary species challenges the identification of B-1 cells. However, similarities in foetal B-cell and antibody development between veterinary species and mice are consistent with the existence of both B-1 and the conventional B-2 cell populations. In this review, the existence of B-1 cells in veterinary species is discussed. 


\section{B-cell subsets}

Naïve B-cells from mice and humans can be divided in three major subsets: B-1, follicular and marginal zone (MZ) B-cells, based on their phenotype, localization and function [1, 2]. Follicular B-cells, or B-2 cells, are the conventional B-cells originating from the foetal liver and are maintained through life in the bone marrow. Peripheral B-2 cells are mainly located in the spleen and lymph nodes. B-2 cells produce specific antibodies upon antigen exposure and show somatic hypermutation and class-switching. B-1 and MZ B-cells are more innate-like B-cells, which share a distinct common progenitor [3] and emerge from foetal progenitors in the liver. B-1 cells are mainly located in the peritoneal cavity and marginal zone cells are located in the spleen. B-1 B-cells are maintained through life by self-renewal, while MZ B cells are long-lived. B-1 and MZ B cells rapidly respond to T-cell independent antigens and are able to produce natural antibodies [4]. Marginal zone B-cells can also perform T-cell dependent immune responses [5]. As the focus of this paper is B-1 cells, the follicular (B-2 cells) and MZ B-cells will no longer be discussed.

\section{B-1 cells}

B-1 cells were first described in mice as Ly-1 (CD5) positive cells involved in autoimmunity [6]. Nowadays, murine and human B-1 cells are well described in terms of development, regulation and their role in immunity, however, the B-1 cell phenotype is still highly debated in humans [7-11]. B-1 cells were mainly found in the mouse pleural and peritoneal cavity, intestine and in small numbers in the spleen, lymph nodes and peripheral blood [1214]. B-1 cells are the main producers of natural antibodies: polyreactive antibodies which are produced without prior stimulation by foreign antigens. These antibodies are mostly germ-line encoded IgMs and have an important role in the first phases of an immune response as they are present before the specifically-induced B-2 derived antibodies [15, 16]. Natural antibodies have a homeostatic role as they recognize self-antigens and mediate the clearance of apoptotic cells, but are therefore also related to auto-immunity $[17,18]$. B-1 cells are able to phagocytose and kill bacteria and induce CD4 ${ }^{+}$T-cell responses [19]. Furthermore, B-1 cells are potent producers of Il-10 upon TLR stimulation implying a regulatory role [20]. B-1 cells are considered to be an important link between the innate and adaptive immune system. From an evolutionary perspective, B-1 cells share characteristics, like phagocytosis and antimicrobial activity, with the "primitive" B-cells found in fish [19]. Unlike mice and humans, B-1 cells are hardly described in cows or other veterinary species.

\section{Identification B-1 cells based on marker expression}

Initially, B-1 cells were identified in mice by the expression of CD5 and CD11b or IgM ${ }^{\text {high }}$ and $\mathrm{IgD}^{\text {low }}$, thereby discriminating the $\mathrm{B} 1 \mathrm{a}\left(\mathrm{CD}^{+} \mathrm{CD} 11 \mathrm{~b}^{+}\right)$and $\mathrm{B} 1 \mathrm{~b}\left(\mathrm{CD} 5 \mathrm{CD}^{-} 1 \mathrm{~b}^{+}\right) \mathrm{B}$-cell subtypes [21]. B1a cells are the main producers of natural antibodies [11] and B1b cells are involved in the rapid induction of antibody responses to T-cell independent antigens that turned out to be long-lasting [22]. Several studies aimed to identify B-1 cells in nonmouse species based on the expression of CD5 and CD11b as described for murine B-1 cells [23-26]. The following species will be reviewed: sheep, pig and cow. 
In sheep, two different IgM positive cell populations with diverse characteristics could be identified in blood using CD5 and CD11b [24]. The ovine $\mathrm{CD}^{+/-} \mathrm{CD} 11 \mathrm{~b}^{+} \mathrm{B}$-cells were suggested to be B-1 cells as these cells under unstimulated conditions are larger in size, have a higher cell-cycle activity and a higher surface IgM expression than the $\mathrm{CD}^{-} \mathrm{CD}^{-} 1 \mathrm{~b}^{-}$ $\mathrm{B}$-cells. On the other hand, and contrary to the situation in mice, the $\mathrm{CD}^{+/-} \mathrm{CD} 11 \mathrm{~b}^{+} \mathrm{B}$ cells were most abundant in blood and proliferated upon surface $\operatorname{IgM}$ stimulation, indicating a B-2 cell phenotype. Consequently, these $\mathrm{CD}^{+/-} \mathrm{CD} 11 \mathrm{~b}^{+} \mathrm{B}$-cells were not considered true homologues of the murine B-1 cells. Another study proposed the ovine CD11 b ${ }^{+} / \mathrm{CD} 21^{-}$ and $\mathrm{CD} 11 \mathrm{~b} / \mathrm{CD} 21^{+}$cells populations as being B-1 and B-2 cells, respectively [27]. The $\mathrm{CD} 11 \mathrm{~b}^{+} / \mathrm{CD} 21^{-}$cells expressed high levels of IgM, like B-1 cells. On the other hand, the $\mathrm{CD}_{11} \mathrm{~b}^{+} / \mathrm{CD} 21^{-}$cells were scarcely present in neonates and increased with age, which better reflect B-2 cells than B-1 cells.

Porcine B-1 and B-2 cells were suggested to be discriminated by $\mathrm{CD}^{+}$and $\mathrm{CD} 5{ }^{-} \mathrm{B}-\mathrm{cells}$ [25]. Though, this statement was rejected by the same group a decade later, because the $\mathrm{CD}^{+}$and $\mathrm{CD} 5-\mathrm{B}-\mathrm{cell}$ populations did not differ in, among others, antibody isotypes and antibody repertoires, while B-1 derived antibodies are expected to be more germlinelike than B-2 derived antibodies [26].

In cows, $\mathrm{CD}^{+} \mathrm{CD} 11 \mathrm{~b}^{+} \mathrm{B}$-cells were shown to be present in blood and were suggested to resemble murine and human B-1 cells. During Trypanosoma congolense infections, increased levels of serum auto-antibodies were determined which were associated with a rise in $\mathrm{CD}^{+} \mathrm{CD} 11 \mathrm{~b}^{+}$cells $[23,28]$ and production of IgM against non-Trypanosoma antigens by $\mathrm{CD}^{+} \mathrm{B}$-cells [29]. Though the expansion of the $\mathrm{CD}^{+} \mathrm{B}$-cell population mainly occurred 7 to 10 days after the parasites were present in blood, which is more in favour of B-2 cells. Bovine leukaemia virus (BLV) induced B-cell lymphomas were also categorized in B-1 and B-2 cell-derived tumours based on the murine CD5 and CD11b expression [3032]. However, in contrast to what would be expected, one study reported higher surface IgM expression levels on the B-2 cell-derived lymphoma than on the B-1 cell-derived lymphoma [31]. Different B-cell populations can be distinguished in cows based on CD5 and CD11b, however, it is not if these are the true homologues of murine B-1 and B-2 cells.

In mice and humans it was shown that the combination of CD5 and CD11b was actually too limited to identify B-1 cells. CD5, an activation marker and negative regulator of BCR signalling, is also expressed on activated and anergic B-2 cells and thereby not a unique marker for B-1 cells [7, 14, 33-35]. In line with this, in pigs and cows CD5 expression is also upregulated on B-cells upon activation, indicating a B-2 cell phenotype $[25,36]$. Moreover, $\mathrm{CD}^{+} \mathrm{B}$-cells were absent in blood and the spleen of foetal calves [28] and represent only 1-2\% of the splenic B-cell population in foetal lambs [37], while B-1 cells in mice were shown to originate primarily during foetal development [38]. In addition, neonatal calves have low percentages of CD5 positive B-cells, which more than doubled at 7 months of life [39]. Taken into account that the number of B-cells per $\mathrm{mL}$ blood increased about 7-fold [40], this indicates a large increase in $\mathrm{CD}^{+} \mathrm{B}$-cells in cows after birth, indicative for B-2 cell expansion. In particular, the upregulation of CD5 on CD5 cells upon B-cell receptor crosslinking [36] makes CD5 as marker for B-1 cells in cows controversial $[39,41]$. Likewise, in humans CD5 is not a very discriminative 
marker as only $34 \pm 3 \%$ of the CD5 positive B-cells are B-1 cells [7].

Taken together, CD5 is not a very specific marker for B-1 cells in mice or in other species. The same is true for CD11b. Only half of the murine peritoneal B-1 cells express CD11b [42] and CD11b expression on B-1 cells declines after they leave the peritoneal cavity [43], implying that $\mathrm{CD} 11 \mathrm{~b}$ is not a stable B-1 cell marker. In contrast to mice, sheep and cows have very variable and high percentages of $\mathrm{CD} 11 \mathrm{~b}$ positive B-cells in blood $[23,24]$. Furthermore, the number of $\mathrm{CD} 11 \mathrm{~b}$ positive B-cells was shown to increase after birth since $\mathrm{CD} 11 \mathrm{~b}^{+}$B-cells were rare in neonates [27], while B-1 cells should be present after birth already. The previous results implies that the markers CD5 and CD11b+ are therefore not reliable markers for identifying B-1 cells in different species.

Alternative indicators for B-1 cells in mice are high IgM expression in combination with low IgD expression. In contrast, conventional B-2 cells express low levels of IgM and high levels of IgD. The existence of IgD was questioned for pigs, cows and sheep for a long time as the delta gene or surface $\operatorname{IgD}$ could not be detected $[28,44]$. Since $\operatorname{IgD}$ appeared to be lacking, some studies suggest that the whole B-cell population of cows and rabbits consists of B-1 cells $[28,45]$. A decade later, the delta genes were found and shown to be transcriptionally active in pigs, cows and sheep [46]. Recently, Xu et al. (2012) showed very low percentages of IgD positive B-cells $(1.2 \%$ of the peripheral blood lymphocytes) by surface staining with an IgD-specific antibody. Although, IgD positive B-cells were enriched in the bovine spleen, about $93 \%$ of the splenic B-cells were IgD negative [47], implying an unrealistic high percentage of B-1 cells in cows. This questions the use of IgM and IgD to distinguish B-1 and B-2 cells in cows.

In summary, the most useful markers to indicate B-1 cells in veterinary species, including cows, are still unknown. In summary, increasing evidence suggests that the commonly used B-1 marker CD5, alone or in combination with CD11b, is not unique nor suitable for B-1 cell identification, not even in mice and humans. Additional or alternative markers are described for mice and humans, but these are not applicable for veterinary species since the commercial antibody repertoire is limited. Although murine B-1 cells are welldefined, B-1 cells were not observed in the peritoneal cavity of many in- and outbred mouse strains except in the commonly used laboratory strains [48], supporting why it is hard to identify the true homologs of murine B-1 cells in other species.

\section{B-cell development with notes on B-1 cells}

Though the existence of B-1 cells in pigs is not established $[49,50]$, the foetal B-cell development during gestation (114 days) is well described and shows large similarities with mice (gestation 20 days). B-cell development in foetal mice was shown to occur in three different waves [38], where the first wave starts in the yolk sac and para aortic splanchopleural region at 9 days of gestation (dg) and consists of B-1 cell progenitors only [3]. These B-1 cells originate from hemogenic epithelial cells [51]. The second wave of B-cell development originates from the foetal liver and mainly results in B-1 cells, while the production of B-2 cells has just started [38]. The B-1 cell progenitors in the foetal liver were derived from resident hematopoietic stem cells and hemogenic epithelial cells, which were migrated from 
the yolk sac and para aortic splanchopleural region, and develop in parallel to mature B-1 cells [51]. Around birth, the third wave in B-cell development occurs from the bone marrow and gives rise to mainly B-2 cells. After birth, the number of B-2 cells strongly increases due to clonal expansion, while B-1 cells are maintained by self-renewal.

Also in pigs, the first indications for B-cell lymphopoiesis were found in the yolk sac from day 20 of gestation [50]. The yolk sac involutes around day 24 to 27, which is accompanied by the emergence of B-cell development in the foetal liver around day 30 . Later in gestation, the bone marrow develops, resulting in a strong increase in B-cell lymphopoiesis and the presence of B-cells in the periphery from day 40. From day 55, a CD5 positive B-cell population develops in the porcine thymus and is maintained after birth $[50,52]$. These B-cells are able to perform class-switching and produce IgG and IgA positive cells without exogenous stimulation [52, 53]. However, this B-cell population is unlikely to represent B-1 cells since they could be reconstituted by cells from the foetal liver as well as adult bone marrow, while in mice peritoneal B-1 cells can only be reconstituted from the foetal liver [54]. Like mice, B-cell lymphogenesis in pigs is maintained in the bone marrow throughout life [55].

Foetal B-cell development in cows (gestation 280 days) and sheep (gestation 150 days) appears to be comparable [56], although it is less studied than in mice and pigs. Unlike mice, gut associated lymphoid tissue (GALT) in the ileal Peyer's patches is the main location for B-cell development in cows and sheep and therefore often indicated as a primary lymphoid organ in these species [56, 57]. Foetal B-cells development in cows was hypothesized to occur in two waves [58]. During the first wave, bovine B-cells originate from progenitors in the bone marrow. The second wave of B-cell development is localised in the GALT and is characterized by a large expansion of the pre-immune B-cell pool. However, immature B-cells were already observed in the foetal spleen and lymph nodes $(60-85 \mathrm{dg})$ well before they were determined in the foetal bone marrow $(190-238 \mathrm{dg})$ [58], suggesting an earlier wave of B-cell development derived from the spleen [59]. B-cell lymphopoiesis is maintained in the foetal bone marrow, but is declined in adult bone marrow as shown by decreased recombination-activating genes (RAG) activity [60].

Comparable to cows, sheep $\operatorname{IgM}^{+}$cells were first observed in the foetal spleen at $48 \mathrm{dg}$ [61]. At $63 \mathrm{dg} \mathrm{IgM}^{+}$cells were present in the foetal spleen and lymph nodes and were expanding until $98 \mathrm{dg}$ [62]. The first $\operatorname{IgM}^{+}$cells in the ileal Peyer`s patches were observed from $70 \mathrm{dg}$ and significantly expand around $100 \mathrm{dg}$ [61]. Splenectomy at $56 \mathrm{dg}$ impaired B-cell development, although, it does not prevent total B-cell development [63], indicating that B-cells in sheep were not derived from the spleen only. Unlike mice, $\operatorname{IgM}^{+} \mathrm{B}$-cells were scarce $(<1 \%)$ in the liver of foetal lambs at different stages of gestation [37, 62]. Most likely, the first stages of B-cell development occur in the foetal spleen and other lymphoid tissues [64]. B-cell development is greatly reduced in foetal lambs by injecting anti-IgM at $63 \mathrm{dg}$ [65] and resulted in strongly diminished B-cell numbers in the secondary lymphoid tissues and B-cell absence in the ileal Peyer's patches. As B-cell development is seriously impaired with a single injection of anti-IgM, in contrast to repeated injections in mice, B-cell progenitors might originate in a small time-frame only or the ileal Peyer's patches can be seeded in a small time-frame [64]. Immature B-cells migrate from the 
spleen and seed the ileal Peyer's patches where they proliferate and the pre-immune B-cell repertoire is formed [66]. In the foetal spleen and ileal Peyer's patches, but not the foetal bone marrow, somatic hypermutation occurs in the absence of exogenous antigens and contributes to the diversity of the naive B cell repertoire [67].

Foetal B-cell development in pigs shows similarity to that of mice. Both mice and porcine B-cells originate from the same locations and in the same order, which might be an indication for the existence ofB-1 cells in pigs. However,B-cell development in theless-studied cows and sheep does not indicate two distinct B-1 and B-2 cell populations during foetal development. B-cell lymphopoiesis continues through life in mice, humans and pigs, but stops early in life in chickens, rabbits, sheep and cows $[60,68,69]$. This kinetics is consistent with B-1 development in mice and is suggestive for the presence of bovine B-1 cells [60].

\section{Natural antibodies}

As natural antibodies are produced without prior stimulation with foreign antigens, they are already present in newborns. Pre-suckled calves and piglets have low amounts of serum antibodies [53], consistent with the early presence of B-1 B-cells in utero. Both cows and pigs have epitheliochorial placentas, and as a consequence, no antibodies are transferred from mother to foetus during pregnancy [49]. The young animals are mainly dependent on antibodies derived from colostrum that are taken up during the first 24 to 36 hours after birth to provide passive immunity [70]. The prenatal antibody repertoire produced in the foetal pig are derived from B-cells originating from different locations, like the yolk sac and foetal liver [50]. Antibodies derived from the yolk sac and foetal liver were shown to have $100 \%$ and $>90 \%$ in-frame VDJ rearrangements, respectively, indicating germline-like antibodies as produced by B-1 cells [71]. However, the percentage in-frame rearrangements decreased to $71 \%$ after lymphopoiesis had started in the bone marrow, indicating the production of B-2 cell-derived antibodies. In line, antibody diversity due to $\mathrm{N}$-additions was determined in different organs of foetal calves by the expression of terminal deoxynucleotidyl transferase (TdT) [72]. About $41 \pm 13 \%$ of the bone marrow-derived B-cells in foetal calves express TdT, while only less than $0.05 \%$ of the B-cells express TdT in the foetal spleen, liver and ilial Peyer's patches. This indicates the production of different antibody repertoires in different locations in the foetal calf, suggesting the presence of B-2 cells in the foetal bone marrow and B-1 cells in the foetal liver and spleen, like mice and probably in pigs. Collectively, these data indicate that both B-1 and B-2 cell populations are present in the bovine system.

\section{B-1 cells: implications for cows}

Bovine B-1 cells were initially identified by CD5 and CD11b expression. As discussed in this review, these markers might not be the most useful markers for B-1 cell identification in cows since CD5 positive B-cells are scarce in the bovine foetus and CD5 expression is strongly increased after birth and upon B-cell stimulation both characteristic for B-2 cells. Some studies suggested that all bovine B-cells belong 
to the B-1 population due to the very low IgD expression on bovine B-cells and the cessation of B-cell lymphopoiesis in adults. This hypothesis seems unlikely as this would imply that all antibodies in cows are natural antibodies and antigen-specific reactions or vaccination are not possible, which is not the case. Future studies are needed to elucidate the existence and precise phenotyping of bovine B-1 cells.

\section{In conclusion}

The existence of B-1 cells in farm animals is often discussed, however, clear evidence is still lacking. Though the prenatal production of antibodies and the class-switching of a minority of B-cells without antigenic stimulation is in favour of the presence of B-1 cells. Differences between species in terms of marker expression and B-cell development hampers the identification of distinct B-1 and B-2 cell populations in species of veterinary interest.

\section{Acknowledgements}

This study is part of a joint project "Weerbaar Vee", funded by the Dutch Ministry of Economic Affairs (The Hague, the Netherlands), Dutch Dairy Product Board ("Productschap Zuivel", Zoetermeer, the Netherlands), Dutch Cooperative Cattle Improvement (CRV, Arnhem, the Netherlands), Dutch Federation of Agriculture and Horticulture ("LTO-Noord Fondsen", Zwolle, the Netherlands), GD Animal Health (Deventer, the Netherlands), and Wageningen University (Wageningen, the Netherlands). 


\section{References}

1. Allman, D. and S. Pillai, Peripheral B cell subsets. Current opinion in immunology, 2008. 20(2): p. 149-157.

2. Parra, D., F. Takizawa, and J.O. Sunyer, Evolution of B Cell Immunity. Annual review of animal biosciences, 2013. 1: p. 65-97.

3. Yoshimoto, M., et al., Embryonic day 9 yolk sac and intra-embryonic hemogenic endothelium independently generate a B-1 and marginal zone progenitor lacking B-2 potential. Proceedings of the National Academy of Sciences, 2011. 108(4): p. 1468-1473.

4. Martin, F., A.M. Oliver, and J.F. Kearney, Marginal Zone and B1 B Cells Unite in the Early Response against T-Independent Blood-Borne Particulate Antigens. Immunity, 2001. 14(5): p. 617-629.

5. Cerutti, A., M. Cols, and I. Puga, Marginal zone B cells: virtues of innatelike antibodyproducing lymphocytes. Nature reviews. Immunology, 2013. 13(2): p. 118-132.

6. Hayakawa, K., et al., The "Ly-1 B" cell subpopulation in normal immunodefective, and autoimmune mice. J Exp Med, 1983. 157(1): p. 202-18.

7. Griffin, D.O., N.E. Holodick, and T.L. Rothstein, Human B1 cells in umbilical cord and adult peripheral blood express the novel phenotype CD20+CD27+CD43+CD70. J Exp Med, 2011. 208(1): p. 67-80.

8. Descatoire, M., et al., A human equivalent of mouse B-1 cells? The Journal of Experimental Medicine, 2011. 208(13): p. 2563-2564.

9. Perez-Andres, M., et al., The nature of circulating CD27+CD43+B cells. The Journal of Experimental Medicine, 2011. 208(13): p. 2565-2566.

10. Griffin, D.O., N.E. Holodick, and T.L. Rothstein, Human B1 cells are CD3-: A reply to "A human equivalent of mouse B-1 cells?" and "The nature of circulating CD27+CD43+ $B$ cells". The Journal of Experimental Medicine, 2011. 208(13): p. 2566-2569.

11. Tangye, S.G., To B1 or not to B1: that really is still the question! Blood, 2013. 121(26): p. 5109-10.

12. Kroese, F.G., et al., Many of the IgA producing plasma cells in murine gut are derived from self-replenishing precursors in the peritoneal cavity. Int Immunol, 1989. 1(1): p. 75-84.

13. Kantor, A., A new nomenclature for B cells. Immunol Today, 1991. 12(11): p. 388.

14. Baumgarth, N., The double life of a B-1 cell: self-reactivity selects for protective effector functions. Nat Rev Immunol, 2011. 11(1): p. 34-46.

15. Ochsenbein, A.F., et al., Control of early viral and bacterial distribution and disease by natural antibodies. Science, 1999. 286(5447): p. 2156-2159.

16. Hangartner, L., R.M. Zinkernagel, and H. Hengartner, Antiviral antibody responses: the two extremes of a wide spectrum. Nature Reviews Immunology, 2006. 6(3): p. 231-243.

17. Zhang, M. and M.C. Carroll, Natural antibody mediated innate autoimmune response. Mol Immunol, 2007. 44(1-3): p. 103-10.

18. Vas, J., C. Gronwall, and G.J. Silverman, Fundamental roles of the innate-like repertoire of natural antibodies in immune homeostasis. Front Immunol, 2013. 4: p. 4.

19. Parra, D., et al., Pivotal advance: peritoneal cavity B-1 B cells have phagocytic and microbicidal capacities and present phagocytosed antigen to CD4+ T cells. J Leukoc Biol, 2012. 91(4): p. 525-36.

20. Sindhava, V., et al., Interleukin-10 mediated autoregulation of murine B-1 B-cells and its role in Borrelia hermsii infection. PLoS One, 2010. 5(7): p. e11445.

21. Kantor, A.B. and L.A. Herzenberg, Origin of murine B cell lineages. Annu Rev Immunol, 1993. 11: p. 501-38. 
22. Alugupalli, K.R., A distinct role for B1b lymphocytes in T cell-independent immunity. Curr Top Microbiol Immunol, 2008. 319: p. 105-30.

23. Naessens, J. and D.J. Williams, Characterization and measurement of CD5+ B cells in normal and Trypanosoma congolense-infected cattle. Eur J Immunol, 1992. 22(7): p. 1713-8.

24. Chevallier, N., et al., B-1-like cells exist in sheep. Characterization of their phenotype and behaviour. Immunology, 1998. 95(2): p. 178-184.

25. Appleyard, G.D. and B.N. Wilkie, Characterization of porcine CD5 and CD5(+) B cells. Clinical and Experimental Immunology, 1998. 111(1): p. 225-230.

26. Wilson, S.M. and B.N. Wilkie, B-1 and B-2 B-cells in the pig cannot be differentiated by expression of CD5. Vet Immunol Immunopathol, 2007. 115(1-2): p. 10-6.

27. Gupta, V.K., et al., Two B cell subpopulations have distinct recirculation characteristics. Eur J Immunol, 1998. 28(5): p. 1597-603.

28. Naessens, J., Surface Ig on B lymphocytes from cattle and sheep. Int Immunol, 1997. 9(3): p. 349-54.

29. Buza, J., et al., CD5+ B lymphocytes are the main source of antibodies reactive with nonparasite antigens in Trypanosoma congolense-infected cattle. Immunology, 1997. 92(2): p. 226-33.

30. Wu, D., et al., B-1a, B-1b and conventional B cell lymphoma from enzootic bovine leukosis. Vet Immunol Immunopathol, 1996. 55(1-3): p. 63-72.

31. Yin, S.A., et al., Relation between phenotype of tumor cells and clinicopathology in bovine leukosis. J Vet Med Sci, 2003. 65(5): p. 599-606.

32. Yamamoto, S., et al., Precursor B-1 B cell lymphoma in a newborn calf. J Vet Diagn Invest, 2007. 19(4): p. 447-50.

33. Ying-zi, C., E. Rabin, and H.H. Wortis, Treatment of murine CD5- B cells with anti-Ig, but not LPS, induces surface CD5: two B-cell activation pathways. International Immunology, 1991. 3(5): p. 467-476.

34. Hippen, K.L., L.E. Tze, and T.W. Behrens, CD5 maintains tolerance in anergic B cells. The Journal of experimental medicine, 2000. 191(5): p. 883-890.

35. Kaplan, D., et al., CD5 expression by B lymphocytes and its regulation upon Epstein-Barr virus transformation. Proceedings of the National Academy of Sciences, 2001. 98(24): p. 13850-13853.

36. Haas, K.M. and D.M. Estes, Activation of bovine B cells via surface immunoglobulin M cross-linking or CD40 ligation results in different B-cell phenotypes. Immunology, 2000. 99(2): p. 272-8.

37. Press, C.M., W.R. Hein, and T. Landsverk, Ontogeny of leucocyte populations in the spleen of fetal lambs with emphasis on the early prominence of B cells. Immunology, 1993. 80(4): p. 598-604.

38. Montecino-Rodriguez, E. and K. Dorshkind, B-1 B cell development in the fetus and adult. Immunity, 2012. 36(1): p. 13-21.

39. Chattha, K.S., et al., Expression of complement receptor 2 (CD21), membrane IgM and the inhibitory receptor CD32 (FcgammaRIIb) in the lymphoid tissues of neonatal calves. Vet Immunol Immunopathol, 2010. 137(1-2): p. 99-108.

40. Chattha, K.S., et al., Variation in expression of membrane IgM, CD21 (CR2) and CD32 (Fcgamma RIIB) on bovine lymphocytes with age: a longitudinal study. Dev Comp Immunol, 2010. 34(5): p. 510-7.

41. Haas, K.M. and D.M. Estes, The identification and characterization of a ligand for bovine CD5. J Immunol, 2001. 166(5): p. 3158-66. 
42. Ghosn, E.E., et al., CD11b expression distinguishes sequential stages of peritoneal B-1 development. Proc Natl Acad Sci U S A, 2008. 105(13): p. 5195-200.

43. Yang, Y., et al., Division and differentiation of natural antibody-producing cells in mouse spleen. Proceedings of the National Academy of Sciences, 2007. 104(11): p. 4542-4546.

44. Butler, J.E., J.-s. Sun, and P. Navarro, The swine Ig heavy chain locus has a single JH and no identifiable IgD. International Immunology, 1996. 8(12): p. 1897-1904.

45. Butler, J.E., Immunoglobulin diversity, B-cell and antibody repertoire development in large farm animals. Rev Sci Tech, 1998. 17(1): p. 43-70.

46. Zhao, Y., et al., Artiodactyl IgD: the missing link. The Journal of Immunology, 2002. 169(8): p. 4408-4416.

47. Xu, B., et al., Expressional Analysis of Immunoglobulin D in Cattle (Bos taurus), a Large Domesticated Ungulate. PLoS ONE, 2012. 7(9): p. e44719.

48. Thiriot, A., et al., The Bw cells, a novel B cell population conserved in the whole genus Mus. The Journal of Immunology, 2007. 179(10): p. 6568-6578.

49. Butler, J.E., et al., The piglet as a model for B cell and immune system development. Vet Immunol Immunopathol, 2009. 128(1-3): p. 147-70.

50. Sinkora, M. and J.E. Butler, The ontogeny of the porcine immune system. Dev Comp Immunol, 2009. 33(3): p. 273-83.

51. Yoshimoto, M., The first wave of B lymphopoiesis develops independently of stem cells in the murine embryo. Ann N Y Acad Sci, 2015. 1362(1): p. 16-22.

52. Cukrowska, B., et al., Thymic B cells of pig fetuses and germ-free pigs spontaneously produce IgM, IgG and IgA: detection by ELISPOT method. Immunology, 1996. 87(3): p. 487-92.

53. Butler, J.E., et al., Antibody repertoire development in fetal and neonatal piglets. IV. Switch recombination, primarily in fetal thymus, occurs independent of environmental antigen and is only weakly associated with repertoire diversification. J Immunol, 2001. 167(6): p. 3239-49.

54. Than, S., et al., Origin of thymic and peritoneal Ly-1 B cells. Eur J Immunol, 1992. 22(5): p. 1299-303.

55. Sinkora, M. and J. Sinkorova, B Cell Lymphogenesis in Swine Is Located in the Bone Marrow. The Journal of Immunology, 2014. 193(10): p. 5023-5032.

56. Yasuda, M., et al., The sheep and cattle Peyer's patch as a site of B-cell development. Vet Res, 2006. 37(3): p. 401-15.

57. Alitheen, N.B., S. McClure, and P. McCullagh, B-cell development: one problem, multiple solutions. Immunol Cell Biol, 2010. 88(4): p. 445-50.

58. $\quad$ Ekman, A., et al., B-cell development in bovine fetuses proceeds via a pre-B like cell in bone marrow and lymph nodes. Developmental \& Comparative Immunology, 2010. 34(8): p. 896-903.

59. Lucier, M.R., et al., Multiple sites of V lambda diversification in cattle. J Immunol, 1998. 161(10): p. 5438-44.

60. Ekman, A., M. Ilves, and A. Iivanainen, B lymphopoiesis is characterized by pre-B cell marker gene expression in fetal cattle and declines in adults. Developmental \& Comparative Immunology, 2012. 37(1): p. 39-49.

61. Press, C.M., M. Halleraker, and T. Landsverk, Ontogeny of leukocyte populations in the ileal Peyer's patch of sheep. Dev Comp Immunol, 1992. 16(2-3): p. 229-41.

62. Alitheen, N., S. McClure, and P. McCullagh, Detection and quantification of IgM+ lymphocytes in fetal lamb spleen, liver and lymph nodes by flow cytometry. 2007. 85(5): p. 391-393. 
63. Press, C.M., P. McCullagh, and T. Landsverk, Effect of early fetal splenectomy on prenatal $B$-cell development in sheep. Immunology, 2001. 102(2): p. 131-6.

64. McCullagh, P., et al., The Effect of Dosage, Gestational Age and Splenectomy on AntiIgM Interception of Prenatal B-cell Development in Sheep. Clinical and Developmental Immunology, 2003. 10(1): p. 19-26.

65. Press, C.M., et al., Fetal lambs are depleted of IgM+ cells following a single injection of an anti-IgM antibody early in gestation. Immunology, 1996. 88(1): p. 28-34.

66. Jenne, C.N., L.J. Kennedy, and J.D. Reynolds, Antibody repertoire development in the sheep. Developmental \& Comparative Immunology, 2006. 30(1-2): p. 165-174.

67. Liljavirta, J., et al., Activation-induced cytidine deaminase (AID) is strongly expressed in the fetal bovine ileal Peyer/'s patch and spleen and is associated with expansion of the primary antibody repertoire in the absence of exogenous antigens. 2013. 6(5): p. 942-949.

68. Weill, J.-C. and C.-A. Reynaud, Galt versus bone marrow models of B cell ontogeny. Developmental \& Comparative Immunology, 1998. 22(3): p. 379-385.

69. Jasper, P.J., et al., B lymphocyte development in rabbit: progenitor B cells and waning of B lymphopoiesis. J Immunol, 2003. 171(12): p. 6372-80.

70. Stott, G.H., et al., Colostral Immunoglobulin Transfer in Calves I. Period of Absorption1. Journal of Dairy Science, 1979. 62(10): p. 1632-1638.

71. Sinkora, M., et al., Antibody repertoire development in fetal and neonatal piglets. VI. B cell lymphogenesis occurs at multiple sites with differences in the frequency of in-frame rearrangements. J Immunol, 2003. 170(4): p. 1781-8.

72. Liljavirta, J., et al., Expansion of the Preimmune Antibody Repertoire by Junctional Diversity in Bos taurus. PLoS ONE, 2014. 9(6): p. e99808. 
Identification of B-1 Cells in Veterinary Species

\section{2}

Page | $\mathbf{3 0}$ 


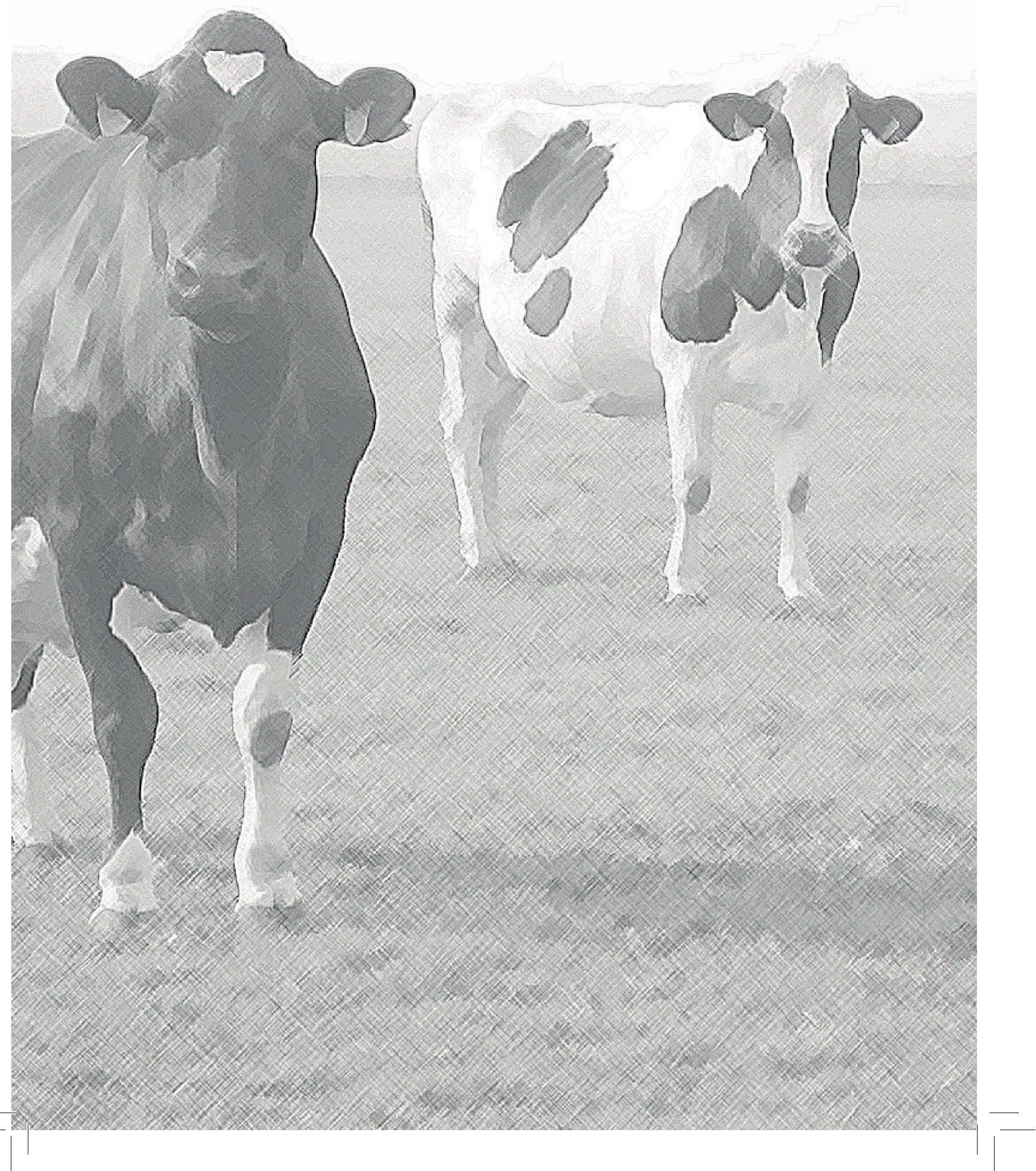




\section{Chapter 3}

\section{Identification of B-1 Cells in Cows}

S.E.C. van Altena ${ }^{1}{ }^{*}$, B. Meijer ${ }^{1}$, A.P. Koets ${ }^{2,3}$, H.F.J. Savelkoul ${ }^{1}$, E.J. Tijhaar ${ }^{1}$

${ }^{1}$ Cell Biology and Immunology Group, Department of Animal Sciences, Wageningen University, PO box 338, Wageningen, the Netherlands;

${ }^{2}$ Department of Bacteriology and Epidemiology, Central Veterinary Institute, part of Wageningen UR, PO box 65, Lelystad, the Netherlands;

${ }^{3}$ Department of Farm Animal Health, Faculty of Veterinary Medicine, Utrecht University, PO box 80151, Utrecht, the Netherlands;

Submitted for publication 


\section{Abstract}

B-1 cells are well-described in mice, but not in veterinary species such as cows. Currently, the bovine B-1 phenotype is still based on the cell surface markers CD5 and CD11b, which in mice and humans were shown to be not unique for B-1 cells. In this study, we identified B-1 cells in cows using a combination of the B-1 markers $\operatorname{IgM}^{++}$and $\mathrm{pSYK}^{++}$(a marker for constitutive intracellular signalling). Flow cytometric analysis showed a distinct cell population of $\operatorname{IgM}^{++} \mathrm{pSYK}^{++}$cells, indicating B-1 cells. This cell population has, similar to murine B-1 cells, a higher expression of CD80 compared to B-2 cells which are indicated by $\operatorname{IgM}^{+} \mathrm{pSYK}$. In addition, the postnatal development of the $\operatorname{IgM}^{++} \mathrm{pSYK}^{++}$cell correlates with the postnatal appearance of natural antibodies (NAbs) in serum, which are represented by $\mathrm{IgM}$ antibodies binding to phosphatidylcholine (PtC). Based on phenotypic markers (IgM and CD80) and functional markers (pSYK and production of NAbs), we identified $\mathrm{B}-1$ cells in cows. 


\section{Introduction}

B-1 cells were first identified in mice as $\mathrm{Ly}^{+} 1^{+}$(or $\left.\mathrm{CD}^{+}\right)$cells which were involved in autoimmunity [1]. Nowadays, B-1 cells are well-characterised in mice and humans and were shown to be an important link between innate and adaptive immunity [2]. The main characteristic of B-1 cells is the production of so-called natural antibodies (NAbs): polyreactive antibodies, mostly IgM, which are produced without prior antigenic stimulation [3]. Natural antibodies are germ-line encoded antibodies that are often directed to conserved microbial components and that are therefore important in the initial phases of an immune response [4]. They also have a homeostatic role as they can recognize self-antigens, such as phosphatidylcholine (PtC), which represents a cryptic determinant on senescent red blood cells [5]. In addition, NAbs mediate the clearance of apoptotic cells [6]. Other functions of B-1 cells are the ability to phagocytose bacteria and process and present bacterial antigens in the context of MHC class II to induce $\mathrm{CD} 4^{+}$T-cell responses [7] and the production of IL-10 [8].

As described for humans and mice, B-1 cells differ from conventional B-2 cells as B-1 cells spontaneously produce NAbs, while B-2 cells need antigenic stimulation and costimulation in order to produce specific antibodies. In addition, B-1 cells originate primarily before birth from the foetal liver and are maintained through life by self-renewal [9]. B-1 cell show constitutive intracellular signalling caused by active phosphorylation and dephosphorylation cycles of intracellular mediators such as spleen tyrosine kinase (SYK), and have increased CD80 (B7-1) and CD86 (B7-2) surface expression [10]. In contrast, B-2 cells originate from the (foetal) bone marrow and B-2 cell numbers strongly increase after birth due to clonal expansion after antigenic stimulation. Intracellular signalling in B-2 cells is only induced upon B-cell receptor stimulation and additionally, naïve B-2 cells have lower CD80 and CD86 surface expression levels than B-1 cells [10]. Furthermore, B-1 and B-2 cells also have distinct gene expression patterns of lineage specific transcription factors and regulators of B-cell function [11].

B-1 cells are well-characterised in mice and different markers are described to identify B-1 cells in different tissues [12]. Murine B-1 cells are mainly located in the peritoneal cavity and to a lesser extent in the spleen and can be discriminated from other cells using the following markers: $\mathrm{CD}^{+/}, \mathrm{CD} 11 \mathrm{~b}^{+}, \mathrm{IgM}^{\text {high }}, \mathrm{IgD}^{\text {low }}, \mathrm{B} 220^{\text {low }}, \mathrm{CD} 23^{-}$and $\mathrm{CD}^{2} 3^{+}[13$, 14]. In humans, $\mathrm{B}-1$ cells are identified in blood as: $\mathrm{CD} 20^{+} \mathrm{CD} 27^{+} \mathrm{CD} 43^{+} \mathrm{CD} 70^{-}$[15]. In less studied animals such as farm animals, B-1 cells are poorly described. Bovine B-1 cells were identified in blood based on the murine B-1 cell markers CD5 and CD11b (Naessens, EJI (1992)). However, using CD5 and CD11b does not solely identify B-1 cells in mice and might therefore not the best markers to identify B-1 cells in other animals. CD5 is expressed on the B1a subtype of B-1 cells, but also present on anergic B-2 cells and upregulated on activated B-2 cells in mice [15-19]. In calves, $\mathrm{CD}^{+} \mathrm{B}$-cells strongly increase after birth, which is more indicative for a B-2 cell expansion than a B-1 cell population maintained by self-renewal $[20,21]$. CD11b is shown to be expressed on only half of the peritoneal B-1 cell population and CD11b expression is lost upon extravasation of the peritoneal cavity in mice $[22,23]$. In contrast, bovine B-cells in blood express high and variable levels of CD11b [24, 25]. 
In this paper, we aimed to identify bovine B-1 cells based on (available) markers described for murine and human B-1 cells using flow cytometry. In addition to the phenotypic characteristics, we tested the B-1 cells for functional features such as constitutive intracellular signalling. Furthermore, we determined the relation between the development of B-1 cells and IgM antibodies binding to phosphatidylcholine in young calves. Lastly, we compared the $\mathrm{CD}^{+/-} \mathrm{CD} 11 \mathrm{~b}^{+}$cell population with the $\mathrm{B}-1$ cell population identified by our new B-1 cell markers in cows.

\section{Materials and Methods}

\section{Animals}

Blood and serum from four Holstein-Friesian calves were collected before (day 0) and after (day 4, 10 and 20) colostrum intake. These calves were housed at the dairy herd of Wageningen University and Research Centre (WUR) in Wageningen. Blood collection was approved by the Institutional Animal Care and Use Committee of Wageningen University and Research Centre (DEC2014005b). The adult dairy cows described in this paper were housed at the same facility (DEC2016001a).

Additionally, serum samples were collected from 28 calves before colostrum intake (day 0 ) and at 2, 6, 10, 18 and 26 weeks of age. These calves were housed at the Farm Animal Health department of the Faculty of Veterinary Medicine, Utrecht University, in Utrecht. Blood collection was approved by the Institutional Animal Care and Use Committee of Utrecht University (DEC0202080601).

\section{PBMC isolation}

Blood samples were collected in Vacutainer Sodium Heparin tubes (BD, Plymouth, UK). Peripheral blood mononuclear cells (PBMCs) were isolated from blood using Ficoll (GE Healthcare Bio Sciences, Uppsala, SE). In short, blood was diluted 1:1 in PhosphateBuffered Saline (PBS) (Lonza, Walkersville Inc, USA) and loaded on Ficoll (GE Healthcare Bio Sciences, Uppsala, SE). Tubes were centrifuged for 25 minutes at $450 \mathrm{G}$ at room temperature (RT). PBMCs were isolated and washed with PBS. The Ficoll separation was less clear in the youngest calves, therefore red blood cell (RBC) lysis was performed on all samples using ammonium chloride lysing buffer (Per litre: $8.3 \mathrm{~g} \mathrm{NH}_{4} \mathrm{Cl}, 1 \mathrm{~g} \mathrm{KHCO}, 0.04 \mathrm{~g}$ $\mathrm{Na}_{2}$ EDTA $\cdot \mathrm{H}_{2} \mathrm{O}, 2.5 \mathrm{~g}$ bovine serum albumin. All chemicals were obtained from Sigma, St. Louis, USA).

\section{Flow cytometry}

PBMCs were stained for extracellular markers using sheep anti-bovine IgM FITC, mouse anti-bovine CD80 PE (AbD Serotec, Raleigh, USA), mouse anti-human CD69 APC-Cy7 (BD, New Jersey, USA) and mouse anti-human CD14 Brilliant Violet 421 (eBioscience, San Diego, USA). Afterwards, dead PBMCs were gated out based on staining with Fixable Viability Dye eFluor 506 (Affymetrix eBiosciences, San Diego, USA) according to instructions provided. Constitutive intracellular signalling was assayed 
by the accumulation of phosphorylated spleen tyrosine kinase (pSYK) after phosphatase inhibition with pervanadate. Adapted from $[10,26]$ as follows. PBMCs were incubated with $6.25 \mu \mathrm{M}$ pervanadate $/ \mathrm{H}_{2} \mathrm{O}_{2}$ per $1 \times 10^{6}$ cells in RPMI without supplementation (Lonza, Walkersville Inc, USA) for 8 minutes at $37^{\circ} \mathrm{C}$. Spontaneous increase of pSYK was measured by incubating PBMCs in RPMI without supplementation or pervanadate for 8 minutes at $37^{\circ} \mathrm{C}$. Afterwards, the PBMCs were kept on ice for one minute and then immediately fixed with $4 \%$ paraformaldehyde (PFA, Sigma-Aldrich, Missouri, USA) for 10 minutes at $37^{\circ} \mathrm{C}$. PBMCs were permeabilised with FoxP3 / Transcription Factor Staining Buffer Set (Affymetrix eBioscience) for 30 minutes at RT. Intracellular pSYK was stained with mouse anti-human ZAP70 (PY319) / SYK (PY352) Alexa Fluor 647 or PE (BD Phosflow, New Jersey, USA) according to instructions provided.

Table 1: Flow cytometry antibodies

\begin{tabular}{llll}
\hline Antibody & Clone & Dilution & Company \\
\hline IgM & Polyclonal & $1: 1250$ & Serotec \\
CD14 & M5E2 & $1: 100$ & eBiosciences \\
CD69 & FN50 & $1: 20$ & BD \\
CD80 & Il-A159 & $1: 10$ & Serotec \\
pSYK & 17A/P-ZAP70 & $1: 10$ & BD \\
\hline
\end{tabular}

\section{ELISA}

The number of B-1 cells $\left(\operatorname{IgM}^{++} \mathrm{pSYK}{ }^{+}\right)$in cows was related to the binding of $\operatorname{IgM}$ to phosphatidylcholine (PtC), a NAb antigen. PtC (Sigma-Aldrich) was coated on flatbottom, high-binding ELISA plates (Greiner Bio-One, Frickenhausen, Germany) at 50 $\mu \mathrm{g} /$ $\mathrm{ml}$ in $100 \%$ ethanol and the ethanol was allowed to evaporate at RT. After evaporation was completed the plates were blocked with Casein Universal Diluent/Blocker (SDT, Baesweiler, Germany) for one hour at RT. Plates were washed three times with $0.05 \%$ Tween-20 (Thermo-Scientific, Waltham, USA) in PBS. Serum samples were 1:5 diluted in 1:3 Casein/PBS, incubated for one hour at RT and the plates were washed four times with $0.05 \%$ PBST. IgM antibodies binding PtC were detected using a mouse antibovine IgM Horse Radish Peroxidase (HRP) conjugated antibody (Bethyl Laboratories, Inc. Montgomery, USA) 1:5,000 times diluted in 1:3 Casein/PBS and incubated for one hour at RT. Afterwards, the wells were washed five times with $0.05 \%$ PBST and incubated with 3,3',5,5'-Tetramethylbenzidine (TMB) (SDT, Baesweiler, Germany) for 20 minutes at RT in the dark. The reaction was stopped using $2 \%$ hydrogen chloride $(\mathrm{HCl})$. Plates were measured with the Filtermax F5 Multimode ELISA plate reader (Molecular devices, Sunnyvale, USA) at $450 \mathrm{~nm}$ and corrected at $620 \mathrm{~nm}$.

Total IgM levels were determined using the Bovine IgM ELISA Quantitation Set following the manufacturers` instructions (Bethyl Laboratories). 


\section{Results}

\section{B-1 cell surface IgM expression}

We tested several markers that were described for these human and murine B-1 cells on bovine PBMCs (Supplementary table 1). Unfortunately, several markers were not available for cows, consequently, it was hard to combine a complete set of markers, such as $\mathrm{CD} 20^{+} \mathrm{CD} 27^{+} \mathrm{CD} 43^{+} \mathrm{CD} 70^{-}$which was described for human B-1 cells. Instead we started from another marker described for B-1 cells in mice and humans: $\operatorname{IgM}^{++}[10,15,16]$. Young individuals have relatively more B-1 cells as most B-1 cells originate before birth and the B-2 cell population is not fully expanded yet [9]. Comparing the IgM expression between young calves and adult cows showed a distinct IgM positive population in calves enriched for $\operatorname{IgM}^{++}$cells (Figure 1a). In contrast, $\operatorname{IgM}$ expression on adult B-cells showed a more continuous IgM expression, with more $\operatorname{IgM}^{+}$cells than young calves.

\section{IgM and pSYK markers for bovine B-1 cells}

The $\operatorname{IgM}^{++}$population in calves might identify a population enriched for B-1 cells, but it is not a distinctive marker. Another important B-1 cell feature is the continuous intracellular signalling caused by the constitutively active phosphorylation and dephosphorylation of, among others, spleen tyrosine kinase (SYK) [10]. In non-activated B-2 cells this cycling is not active and pervanadate-induced inhibition will result in no or low accumulation of phosphorylated SYK (pSYK). However, activated B-2 cells will also show pSYK accumulation. Therefore activated B-2 cells were discriminated from B-1 cells using the activation marker CD69 [27, 28]. Additionally is stained for CD14 and a fixable viability dye to exclude monocytes and dead cells, respectively. Combining the markers IgM and pSYK resulted in a distinct population of $\mathrm{IgM}^{++}$and $\mathrm{pSYK}^{++}$cells of B-1 cells. B-2 cells are represented by $\mathrm{IgM}^{+}$and $\mathrm{pSYK}^{-}$expression (Figure $1 \mathrm{~b}$ ). Intracellular staining for pSYK often results in a bimodal distribution of positive T-cells and highly positive B-cells.

\section{Higher CD80 expression on IgM $^{++} \mathrm{pSYK}^{++}$cells}

To support that bovine B-1 and B-2 cells could be discriminated using IgM and pSYK, these cell populations were additionally tested for CD80 expression as B-1 cells have a higher gene and surface expression of CD80 than B-2 cells [10,11]. Figure 1c shows the expression of CD80 on B-1 cells $\left(\operatorname{IgM}^{++} \mathrm{pSYK}{ }^{++}\right)$and $\mathrm{B}-2$ cells $\left(\mathrm{IgM}^{+} \mathrm{pSYK}\right)$. The bovine B-1 cells displayed a higher CD80 expression than B-2 cells. 


\section{A Calf}
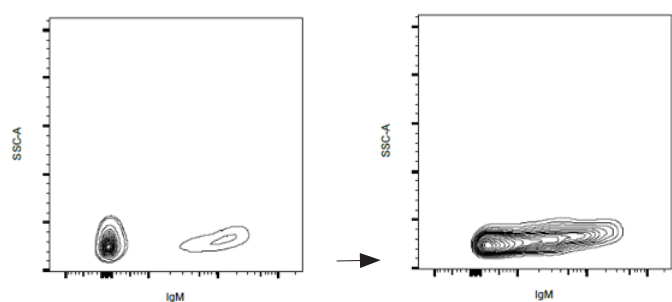

\section{B Cow}
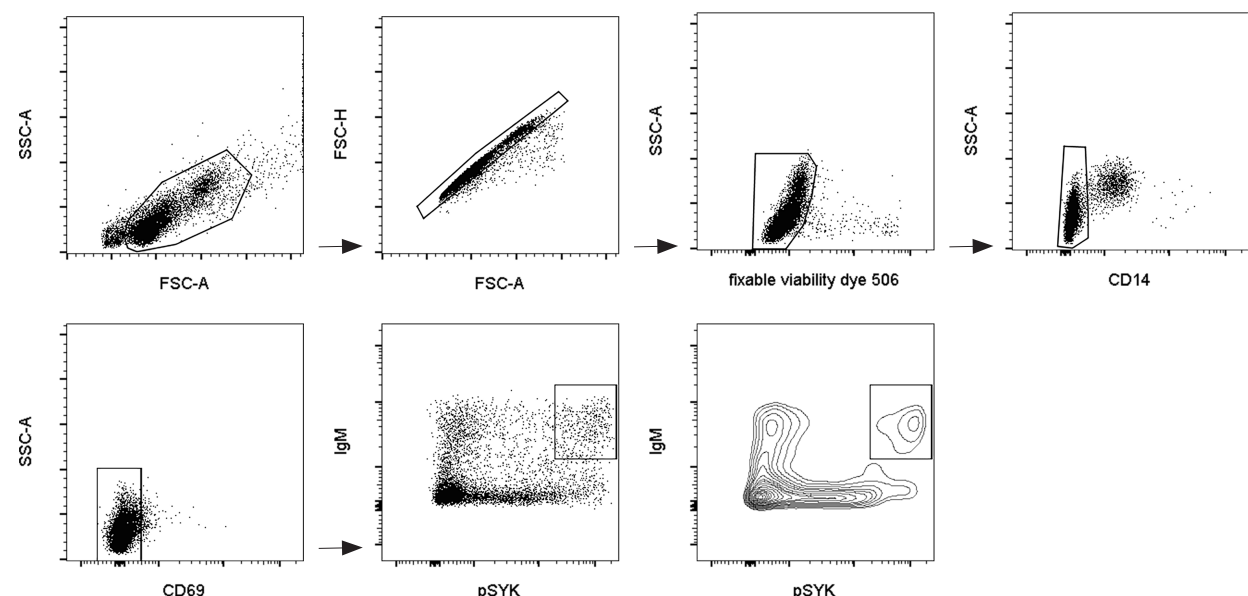

C

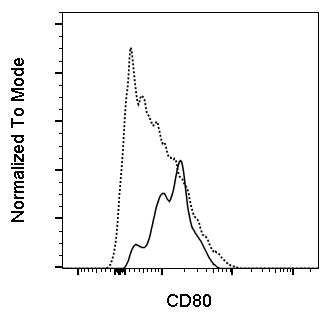

Figure 1: Combining IgM and pSYK results in a distinct cell population with increased CD80 expression The expression of IgM was determined in calves and cows. A representative picture is shown figure 1a where calves have a separate $\operatorname{IgM}^{++}$population, while adult cows show a more continuous IgM expression. Figure $1 \mathrm{~b}$ shows the gating strategy to identify bovine B-1 cells. Combing IgM with pSYK, which represents the continuous intracellular signalling in B-1 cells, results in a distinct $\mathrm{IgM}^{++} \mathrm{pSYK}^{++}$cell population which are the B-1 cells. The B- 2 cells are indicated by IgM ${ }^{+}$pSYK cells. Gating strategy: PBMCs $\rightarrow$ Single cells $\rightarrow$ viable cells $\rightarrow$ CD14- cells $\rightarrow$ CD69- cells $\rightarrow$ IgM versus $\mathrm{pSYK}$. Figure 1c shows a higher CD80 expression in the bovine B-1 cells $\left(\operatorname{IgM}^{++}\right.$pSYK $\left.{ }^{++}\right)$than the B-2 cells $\left(\operatorname{IgM}^{+}\right.$pSYK $)$. 


\section{$\operatorname{IgM}^{++} \mathrm{pSYK}^{++}$cells associated with anti-PtC IgM antibodies}

The further confirmation of this B-1 cell population is technically hampered by the inability to link the phenotypic characterisation to functional read-outs, like spontaneous IgM production, due to the chemical fixation of the cells required for the intracellular pSYK staining. Instead we determined natural antibody (NAb) levels in bovine sera and related these to the percentage of B-1 cells to validate our findings. Serum NAb levels were indicated by the levels of IgM binding to phosphatidylcholine (PtC), a well-known $\mathrm{NAb}$ antigen $[5,29]$. Blood samples were collected from 4 calves before colostrum intake (day 0 ) and at 4, 10 and 20 days afterwards to determine the percentage of B-1 cells (of total PBMCs) and anti-PtC IgM levels. During the first 20 days of life, the percentage of B-1 cells increased gradually from on average $0.25 \%$ to $1.0 \%$ of total PBMCs (Figure $2 \mathrm{a}$ ). The same kinetics was observed for the anti-PtC IgM levels with low anti-PtC IgM levels before colostrum intake and a gradual increase afterwards (Figure $2 \mathrm{~b}$ ). The percentage of B-1 cells and the levels of anti-PtC IgM showed a strong correlation (Pearson $r=0.768, p$ $=0.0008$ ) (Figure 2c).

A

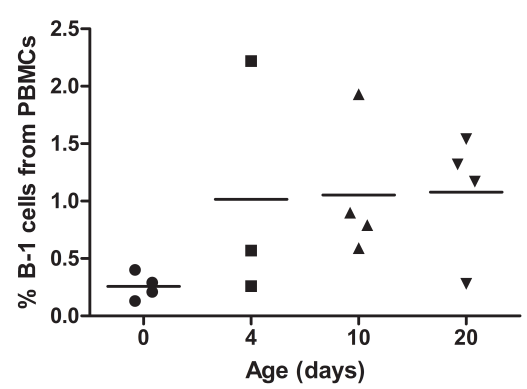

C

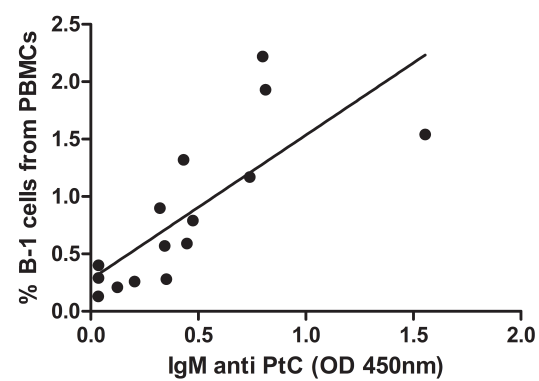

B

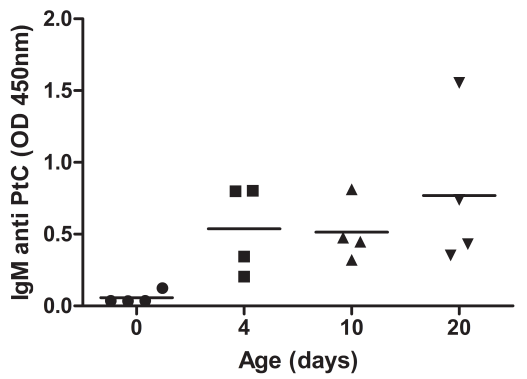

D

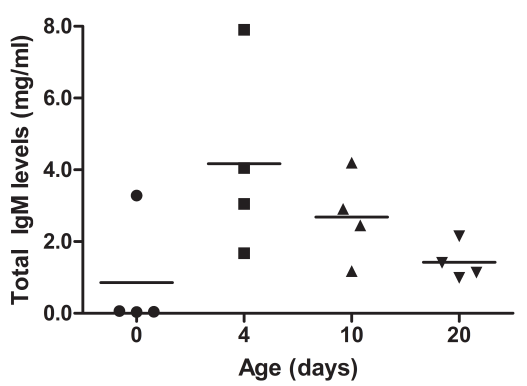

Figure 2: B-1 cells and NAbs before and after colostrum intake

The percentage of B-1 cells $\left(\operatorname{IgM}^{++} \mathrm{pSYK}^{++}\right.$) and NAbs (IgM binding phosphatidylcholine (PtC), OD 450nm $620 \mathrm{~nm}$ ) were measured in 4 calves before colostrum intake (day 0 ) and at 4,10 and 20 days afterwards (Figure 2 $\mathrm{a}$ and $\mathrm{b}$ ). Both B-1 cells and NAbs increase after colostrum intake and stabilise afterwards. One calf is missing at time-point 4 days as the B-1 cell identification failed due to technical problems. Figure $2 \mathrm{c}$ shows the correlation between presence of $B-1$ cells and NAbs (Pearson $r=0.768, p=0.0008$ ). Figure $2 d$ shows the total IgM levels in the calf serum samples in $\mathrm{mg} / \mathrm{ml}$. 
Since most antibodies in young calves are maternally-derived, we also determined the total IgM levels (Figure 2d) and related their kinetics to that of B-1 cells and anti-PtC IgM levels. As expected, the total IgM levels showed a sharp increase after colostrum intake and subsequently decreased. This kinetics was different from the gradual increase as observed for B-1 cells and anti-PtC IgM levels.

\section{Development PtC-binding IgM in calves}

The kinetics of B-1 cells, total IgM and PtC binding IgM levels were determined in four calves only in a period of three weeks. During this period, maternally derived antibodies are present in calf serum and represent the majority of all antibodies. Therefore, the IgM kinetics was also determined in a larger group of calves for a longer period. Total IgM levels and PtC-binding IgM levels were measured in a complete set of 15 calves sampled before colostrum intake (day 0) and at 2,6 10,18 and 26 weeks afterwards. Precolostral total IgM levels were low $(76 \mu \mathrm{g} / \mathrm{ml} \pm 160 \mu \mathrm{g} / \mathrm{ml})$ and rose sharply after colostrum intake $(0.98 \mathrm{mg} / \mathrm{ml} \pm 0.42 \mathrm{mg} / \mathrm{ml}$ at 2 weeks of age) (Figure 3a). The total IgM levels tended to decrease from 2 to 6 weeks of age, increased again from 6 to 18 weeks and stabilised from 18 weeks on to approximately $1.7 \mathrm{mg} / \mathrm{ml}$. In contrast, PtC-binding IgM levels increased from birth until 6 weeks of age and then stabilised (Figure $3 b$ ).

A

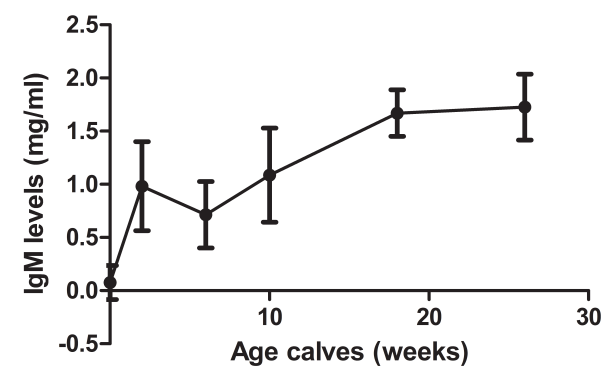

B

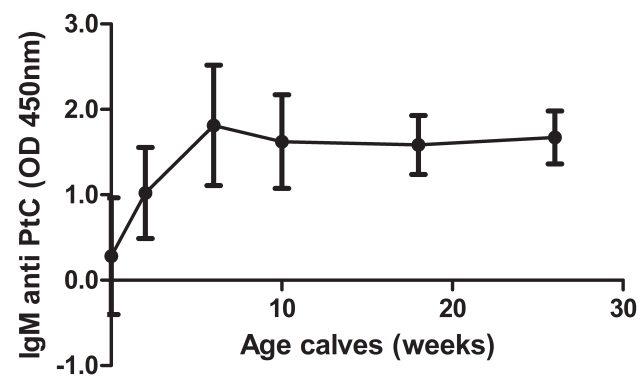

Figure 3: Total IgM levels and NAbs in serum before and after colostrum intake.

Figure 3 shows the total IgM levels (mg/ml) and NAbs (IgM anti PtC, OD 450nm - 620nm) in serum of 15 calves which were sampled before colostrum intake (day 0) and at 2, 6, 10, 18 and 26 weeks afterwards (Figure $3 a+b$ ). Results are represented as averages with bars indicating the standard deviations.

\section{IgM $^{++}$pSYK $^{++}$versus $\mathrm{CD5}^{+/} \mathrm{CD}^{-} 11 \mathrm{~b}^{+}$cells}

Bovine B-1 cells were previously indicated by $\mathrm{CD}^{+/}{ }^{+-} \mathrm{CD} 11 \mathrm{~b}^{+}$and could be subdivided in $\mathrm{CD}^{+} \mathrm{CD} 11 \mathrm{~b}^{+} \mathrm{B} 1 \mathrm{a}$ and $\mathrm{CD} 5{ }^{-} \mathrm{CD} 11 \mathrm{~b}^{+} \mathrm{B} 1 \mathrm{~b}$ cells $[24]$. The overlap between our $\mathrm{IgM}^{++} \mathrm{pSYK}^{++}$ and the former $\mathrm{CD}^{+/-} \mathrm{CD} 11 \mathrm{~b}^{+} \mathrm{B}-1$ cell populations was determined in 7 adult dairy cows. Within the $\operatorname{IgM}^{++}$pSYK ${ }^{++}$cell population, $42 \% \mathrm{CD}^{+} \mathrm{CD} 11 \mathrm{~b}^{+} \mathrm{B} 1 \mathrm{a}$ and $24 \% \mathrm{CD}^{-\mathrm{CD}} 11 \mathrm{~b}^{+}$ B1b cells were observed (Figure $4 \mathrm{a}$ ), which results in a proportion of approximately $2: 1 \mathrm{~B} 1 \mathrm{a}$ versus $\mathrm{B} 1 \mathrm{~b}$ cells. About $34 \%$ of the B-1 cells indicated by $\operatorname{IgM}^{++} \mathrm{pSYK}^{++}$were not identified 
by $\mathrm{CD}^{+/-} \mathrm{CD} 11 \mathrm{~b}^{+}$. The other way around, within the $\mathrm{CD}^{+/-} \mathrm{CD} 11 \mathrm{~b}^{+}$cell population only $23 \%$ of the cells was also indicated by $\operatorname{IgM}^{++} \mathrm{pSYK}^{++}$(Figure $4 \mathrm{~b}$ ).

The total percentage of B-1 cells in bovine blood indicated by $\operatorname{IgM}^{++} \mathrm{pSYK}^{++}$and $\mathrm{CD}^{+/-}$ $\mathrm{CD} 11 \mathrm{~b}^{+}$were $6 \%$ and $35 \%$ of the PBMCs, respectively.
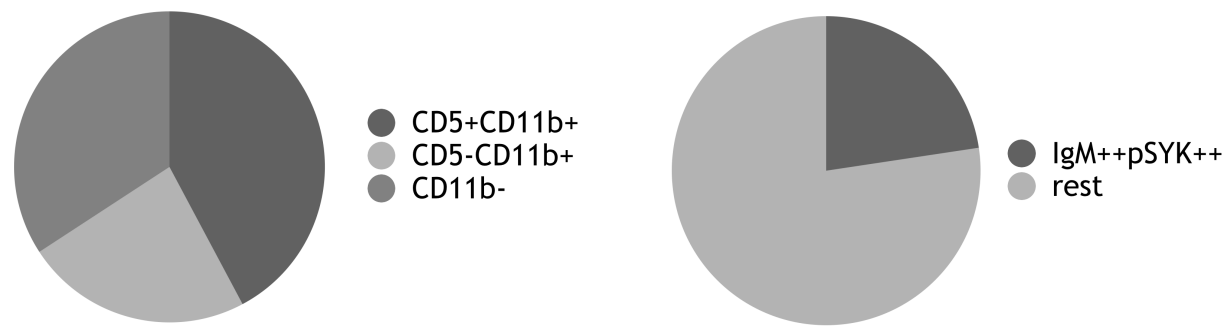

Figure 4: Comparison $\mathrm{CD}^{+/-} \mathrm{CD} 11 \mathrm{~b}^{-}$versus $\operatorname{IgM}^{++} \mathrm{pSYK}^{++}$cell populations

$\mathrm{B}-1$ cells were formerly indicated using $\mathrm{CD} 5$ and $\mathrm{CD} 11 \mathrm{~b}$ and subdivided into $\mathrm{B} 1 \mathrm{a} \mathrm{CD}^{+} \mathrm{CD} 11 \mathrm{~b}^{+}$and $\mathrm{B} 1 \mathrm{~b}$ CD5$\mathrm{CD}_{11 b^{+}}$cells. We identified B-1 cells using $\operatorname{IgM}^{++} \mathrm{pSYK}^{++}$. Figure $4 \mathrm{a}$ indicates the overlap between the B-1 cell populations as specified by $\operatorname{IgM}^{++} \mathrm{pSYK}^{++}$. Figure $4 \mathrm{~b}$ shows the overlap between the B-1 cell populations as specified by $\mathrm{CD}^{+/} \mathrm{CD} 11 \mathrm{~b}^{+}$. (Pictures based on the average percentage of $\mathrm{B}-1$ cells in 7 adult cows.) 


\section{Discussion}

In this paper, we aimed to identify bovine B-1 cells based on their phenotypic and functional characteristics. Combining the markers IgM and pSYK resulted in a distinct $\mathrm{IgM}^{++} \mathrm{pSYK}^{++}$cell population, which was consistent with murine B-1 markers and appeared to be B-1 cells in cows. Like murine and human B-1 cells, these B-1 cells in cows have a higher CD80 surface expression than the B-2 cells ( $\left.\operatorname{IgM}^{+} \mathrm{pSYK}^{-}\right)$. In addition, the development of B-1 cells in first three weeks of life was strongly correlated with the development of NAbs (anti-PtC IgM levels), but not to total IgM levels, since total IgM levels are mainly determined by maternal antibodies in these young calves. This difference in kinetics was maintained in calves up to an age of half a year. The NAbs increased until 6 weeks after birth and then stabilised. In contrast, the total IgM levels clearly showed the uptake and breakdown of maternally derived antibodies with subsequent endogenous IgM production, which increased up to 18 weeks of age. Comparing the B-1 cell populations identified by the formerly described $\mathrm{CD}^{+/-} \mathrm{CD} 11 \mathrm{~b}^{+}$and our $\operatorname{IgM}^{++} \mathrm{pSYK}^{++}$ markers showed a low overlap between these B-1 cell populations.

These B-1 cells in cows were identified starting from known markers described in mice and humans [13-15]. However, the required bovine-specific antibodies were only scarcely available and impeded the identification of bovine B-1 cells. Using a similar set of antibodies and antigens like in mice and humans was therefore not possible. Though, high expression of $\operatorname{IgM}$ and CD80 and the constitutive intracellular signalling reflected by pSYK were also described for murine and human B-1 cells $[10,15]$. Murine B-1 cells are mainly located in the peritoneal cavity, in lesser extent in the spleen and intestine and nearly absent in the peripheral blood [16, 30, 31]. However, similar to the situation in humans, we identified B-1 cells in peripheral blood, indicating that the distribution of B-1 cells is different for different species [15].

The human B-1 cells were debated, among others, due to their similarity with preplasmablasts $[32,33]$. In addition, our B-1 cells show tonic signalling and express high levels of IgM, like transitional B-cells in mice and humans [34]. Pre-plasmablasts and transitional B-cells are not described in the bovine system yet, so we cannot compare these cell populations to our B-1 cells. However, human and murine pre-plasmablasts and transitional B-cells express AA4.1 (CD93 or C1qR) [35] and this might therefore also be true for cows. Combining the IgM and pSYK staining with AA44.1 showed that this marker is lacking on our B-1 cells (data not shown). In humans, the development of transitional B-cells strictly depends on the signalling function of the B-cell receptor, a typical feature of B-2 cells. Furthermore, transitional B-cells do not produce PtC antibodies unless stimulated [5,36], which is contradictive with the strong correlation observed in our study between $\mathrm{IgM}^{++} \mathrm{pSYK}{ }^{++}$cells and IgM antibodies binding to PtC. This makes it unlikely that $\mathrm{IgM}^{++} \mathrm{pSYK}^{++}$cells represent pre-plasmablasts or transitional B-cells.

The B-1 cells and NAbs were shown to increase and stabilise simultaneously during the first 20 days of life. The larger group of 15 calves showed an increase in NAbs up to 6 weeks of age with a subsequent stabilisation. This prolonged rise in NAbs might be caused by individual differences between calves as indicated by the large standard deviations at 2, 6 and 10 weeks of age. However, the NAb kinetics fit the observation that murine B-1 
cell development continues during the first weeks after birth and is repressed by feedback inhibition at 4 to 8 weeks of age [37]. The total percentage of B-cells in calves strongly increased from birth up to 5 months of age and was mainly represented by B-2 cells [38]. In addition, the NAb kinetics did not correlate with the total IgM levels, which are mainly determined by maternally derived antibodies in combination with endogenous production by B-2 cells. Calves are born hypogammaglobulinaemic and mainly rely on colostrumderived antibodies for their immune defence and survival. These colostrum-derived antibodies are taken up in the first 24 to 36 hours of life [39] resulting in a peak IgM level at half a day of age. Total IgM levels subsequently decline with a half-life of 4 days and the lowest IgM levels occur around one month of age [40]. Meanwhile, the endogenous IgM production is initiated at approximately 8 to 16 days of age. Although, we did not monitor the IgM levels at such short intervals, we observed an overall similar kinetic of IgM levels. The overlap between the B-1 cell populations indicated by our $\operatorname{IgM}^{++} \mathrm{pSYK}^{++}$and the former $\mathrm{CD}^{+/}{ }^{-} \mathrm{CD} 11 b^{+}$B-1 cell markers was low since $66 \%$ of the B-1 cells indicated by our $\mathrm{IgM}^{++} \mathrm{pSYK}^{++}$were also indicated using the $\mathrm{CD}^{+/} \mathrm{CD}^{+1} \mathrm{~b}^{+}$markers. The other way around, the overlap was $23 \%$ only. Most B-1 cells are IgM positive, but using IgM as a marker limits the identification of B-1 cells that are IgA or IgG positive [41] and could be a reason for the incomplete overlap between the B-1 populations. More importantly, using the $\mathrm{CD}^{+/} \mathrm{CD} 11 \mathrm{~b}^{+}$markers revealed a much higher percentage of B-1 cells in bovine blood than using $\operatorname{IgM}^{++} \mathrm{pSYK}^{++}(35 \%$ versus $6 \%)$ and will therefore negatively influence the percentage of overlap as they have at least a $29 \%$ difference.

The percentage of bovine B-1 cells identified by $\mathrm{IgM}^{++} \mathrm{pSYK}^{++}$was similar to the percentage of human B-1 cells in blood [15], but much higher than in mice [16]. The proportion of $\mathrm{CD}^{+} \mathrm{B} 1 \mathrm{a}$ versus $\mathrm{CD} 5^{-} \mathrm{B} 1 \mathrm{~b}$ cells within the bovine $\mathrm{IgM}^{++} \mathrm{pSYK}^{++}$population is comparable to the proportion $\mathrm{B} 1 \mathrm{a}$ and $\mathrm{B} 1 \mathrm{~b}$ cells in mice, namely $2: 1$ [42].

Taken together, our findings demonstrate a novel identification of bovine B-1 cell population based on the combined surface expression of IgM and CD80, constitutive intracellular signalling as reflected by pSYK and the observed age-related relation between B-1 cells and occurrence of NAbs represented by IgM anti PtC in calves. 


\section{References}

1. Hayakawa, K., et al., The "Ly-1 B" cell subpopulation in normal immunodefective, and autoimmune mice. J Exp Med, 1983. 157(1): p. 202-18.

2. Getz, G.S., Bridging the innate and adaptive immune systems. Journal of Lipid Research, 2005. 46(4): p. 619-622.

3. Avrameas, S., Natural autoantibodies: from 'horror autotoxicus' to 'gnothi seauton'. Immunol Today, 1991. 12(5): p. 154-9.

4. Ochsenbein, A.F., et al., Control of early viral and bacterial distribution and disease by natural antibodies. Science, 1999. 286(5447): p. 2156-2159.

5. Rowley, B., et al., Autoreactive B-1 B cells: constraints on natural autoantibody B cell antigen receptors. J Autoimmun, 2007. 29(4): p. 236-45.

6. Shaw, P.X., et al., Natural antibodies with the T15 idiotype may act in atherosclerosis, apoptotic clearance, and protective immunity. Journal of Clinical Investigation, 2000. 105(12): p. 1731-1740.

7. Parra, D., et al., Pivotal advance: peritoneal cavity B-1 B cells have phagocytic and microbicidal capacities and present phagocytosed antigen to CD4 $+T$ cells. J Leukoc Biol, 2012. 91(4): p. 525-36.

8. Sindhava, V., et al., Interleukin-10 mediated autoregulation of murine B-1 B-cells and its role in Borrelia hermsii infection. PLoS One, 2010. 5(7): p. e11445.

9. Montecino-Rodriguez, E. and K. Dorshkind, B-1 B cell development in the fetus and adult. Immunity, 2012. 36(1): p. 13-21.

10. Holodick, N.E., J.R. Tumang, and T.L. Rothstein, Continual signaling is responsible for constitutive ERK phosphorylation in B-1a cells. Mol Immunol, 2009. 46(15): p. 3029-36.

11. Mabbott, N.A. and D. Gray, Identification of co-expressed gene signatures in mouse B1, marginal zone and B2 B-cell populations. Immunology, 2014. 141(1): p. 79-95.

12. Tumang, J.R., et al., Peritoneal and splenic B-1 cells are separable by phenotypic, functional, and transcriptomic characteristics. Eur J Immunol, 2004. 34(8): p. 2158-67.

13. Hardy, R.R. and K. Hayakawa, B cell development pathways. Annu Rev Immunol, 2001. 19: p. 595-621.

14. Berland, R. and H.H. Wortis, Origins and functions of B-1 cells with notes on the role of CD5. Annu Rev Immunol, 2002. 20: p. 253-300.

15. Griffin, D.O., N.E. Holodick, and T.L. Rothstein, Human B1 cells in umbilical cord and adult peripheral blood express the novel phenotype CD20+CD27+CD43+CD70. J Exp Med, 2011. 208(1): p. 67-80.

16. Baumgarth, N., The double life of a B-1 cell: self-reactivity selects for protective effector functions. Nat Rev Immunol, 2011. 11(1): p. 34-46.

17. Ying-zi, C., E. Rabin, and H.H. Wortis, Treatment of murine CD5-B cells with anti-Ig, but not LPS, induces surface CD5: two B-cell activation pathways. International Immunology, 1991. 3(5): p. 467-476.

18. Hippen, K.L., L.E. Tze, and T.W. Behrens, CD5 maintains tolerance in anergic B cells. The Journal of experimental medicine, 2000. 191(5): p. 883-890.

19. Kaplan, D., et al., CD5 expression by B lymphocytes and its regulation upon Epstein-Barr virus transformation. Proceedings of the National Academy of Sciences, 2001. 98(24): p. 13850-13853.

20. Chattha, K.S., et al., Expression of complement receptor 2 (CD21), membrane IgM and the inhibitory receptor CD32 (FcgammaRIIb) in the lymphoid tissues of neonatal calves. Vet Immunol Immunopathol, 2010. 137(1-2): p. 99-108. 
21. Chattha, K.S., et al., Variation in expression of membrane IgM, CD21 (CR2) and CD32 (Fcgamma RIIB) on bovine lymphocytes with age: a longitudinal study. Dev Comp Immunol, 2010. 34(5): p. 510-7.

22. Ghosn, E.E., et al., CD11b expression distinguishes sequential stages of peritoneal B-1 development. Proc Natl Acad Sci U S A, 2008. 105(13): p. 5195-200.

23. Yang, Y., et al., Division and differentiation of natural antibody-producing cells in mouse spleen. Proceedings of the National Academy of Sciences, 2007. 104(11): p. 4542-4546.

24. Naessens, J. and D.J. Williams, Characterization and measurement of CD5+B cells in normal and Trypanosoma congolense-infected cattle. Eur J Immunol, 1992. 22(7): p. 1713-8.

25. Chevallier, N., et al., B-1-like cells exist in sheep. Characterization of their phenotype and behaviour. Immunology, 1998. 95(2): p. 178-184.

26. Wienands, J., O. Larbolette, and M. Reth, Evidence for a preformed transducer complex organized by the B cell antigen receptor. Proceedings of the National Academy of Sciences of the United States of America, 1996. 93(15): p. 7865-7870.

27. Ahn, J.S., et al., Cloning of bovine CD69. Veterinary Immunology and Immunopathology, 2002. 88(1-2): p. 43-48.

28. Lauzurica, P., et al., Phenotypic and functional characteristics of hematopoietic cell lineages in CD69-deficient mice. Blood, 2000. 95(7): p. 2312-2320.

29. Arnold, L.W. and G. Haughton, Autoantibodies to phosphatidylcholine. The murine antibromelain RBC response. Ann N Y Acad Sci, 1992. 651: p. 354-9.

30. Kroese, F.G., et al., Many of the IgA producing plasma cells in murine gut are derived from self-replenishing precursors in the peritoneal cavity. Int Immunol, 1989. 1(1): p. 75-84.

31. Kantor, A., A new nomenclature for B cells. Immunol Today, 1991. 12(11): p. 388.

32. Covens, K., et al., Characterization of proposed human B-1 cells reveals pre-plasmablast phenotype. Blood, 2013. 121(26): p. 5176-83.

33. Covens, K., et al., Response: Extended analysis of microarray data does not contradict preplasmablast phenotype of human CD20+CD27+CD43+ cells. Blood, 2013. 122(22): p. 3693-4.

34. Cancro, M.P., Signalling crosstalk in B cells: managing worth and need. Nature reviews. Immunology, 2009. 9(9): p. 657-661.

35. Chevrier, S., et al., CD93 is required for maintenance of antibody secretion and persistence of plasma cells in the bone marrow niche. Proceedings of the National Academy of Sciences, 2009. 106(10): p. 3895-3900.

36. Capolunghi, F., et al., CpG drives human transitional B cells to terminal differentiation and production of natural antibodies. J Immunol, 2008. 180(2): p. 800-8.

37. Kantor, A.B. and L.A. Herzenberg, Origin of murine B cell lineages. Annu Rev Immunol, 1993. 11: p. 501-38.

38. Kampen, A.H., et al., Lymphocyte subpopulations and neutrophil function in calves during the first 6 months of life. Vet Immunol Immunopathol, 2006. 113(1-2): p. 53-63.

39. Stott, G.H., et al., Colostral Immunoglobulin Transfer in Calves I. Period of Absorption1. Journal of Dairy Science, 1979. 62(10): p. 1632-1638.

40. Husband, A.J., M.R. Brandon, and A.K. Lascelles, Absorption and endogenous production of immunoglobulins in calves. Aust J Exp Biol Med, 1972. 50(4): p. 491-498.

41. Baumgarth, N., J.W. Tung, and L.A. Herzenberg, Inherent specificities in natural antibodies: a key to immune defense against pathogen invasion. Springer Semin Immunopathol, 2005. 26(4): p. 347-62.

42. Cunningham, A.F., et al., B1b Cells Recognize Protective Antigens after Natural Infection 
and Vaccination. Frontiers in Immunology, 2014. 5: p. 535.

43. Xu, B., et al., Expressional Analysis of Immunoglobulin D in Cattle (Bos taurus), a Large Domesticated Ungulate. PLoS ONE, 2012. 7(9): p. e44719.

44. Sopp, P., L.S. Kwong, and C.J. Howard, Cross-reactivity with bovine cells of monoclonal antibodies submitted to the 6th International Workshop on Human Leukocyte Differentiation Antigens. Vet Immunol Immunopathol, 2001. 78(2): p. 197-206. 
Supplementary table 1: Markers for B-1 cell identification using flow cytometry

\begin{tabular}{|c|c|c|c|c|c|}
\hline Marker & Expression & Suitable for cow & Clone & Supplier & Notes \\
\hline \multicolumn{6}{|c|}{ Mouse } \\
\hline CD5 & + or - & + & $\mathrm{CC} 17$ & Serotec & $\begin{array}{l}\text { Discriminates B1a and } \\
\text { B1b cells }\end{array}$ \\
\hline CD11b & + & + & ICRF44 & Serotec & Tested \\
\hline IgM & High & + & $\mathrm{PC}$ & Serotec & Tested \\
\hline IgD & Low & N/A & - & - & $\begin{array}{l}\text { Described by [43] } \\
\text { Not tested }\end{array}$ \\
\hline CD23 & - & $?$ & 9P25 & - & $\begin{array}{l}\text { Cross-reactive ab [44]. } \\
\text { Not tested }\end{array}$ \\
\hline CD43 & + & - & CO.44B8 & Serotec & $\begin{array}{l}\text { Cross-reactive ab, but } \\
\text { not discriminative }\end{array}$ \\
\hline \multicolumn{6}{|l|}{ Human } \\
\hline CD20 & + & - & $\mathrm{PC}$ & Bioss & Not working, N/A \\
\hline CD27 & + & $?$ & $\begin{array}{l}\text { M-T271 } \\
\text { or PC }\end{array}$ & Bioss / BD & Cross-reactive ab [44] \\
\hline CD43 & + & - & CO.44B8 & Serotec & $\begin{array}{l}\text { Not in our hands } \\
\text { Cross-reactive ab, but } \\
\text { not discriminative }\end{array}$ \\
\hline CD70 & - & N/A & - & - & Activation marker \\
\hline \multicolumn{6}{|c|}{ Additionally described* } \\
\hline CD69 & - & + & FN50 & $\mathrm{BD}$ & $\begin{array}{l}\text { Activation marker } \\
\text { Cross-reactive ab }\end{array}$ \\
\hline pSYK & + & + & $\begin{array}{l}\text { 17A/P- } \\
\text { ZAP70 }\end{array}$ & $\mathrm{BD} /$ eBioscience & Cross-reactive ab \\
\hline CD24 & - & - & ML5 & $\mathrm{BD}$ & $\begin{array}{l}\text { Marker transitional } \\
\text { B-cells } \\
\text { Human ab not } \\
\text { cross-reactive }\end{array}$ \\
\hline CD93 & - & + & $\mathrm{PC}$ & Bioss & $\begin{array}{l}\text { Marker transitional } \\
\text { B-cells }\end{array}$ \\
\hline CD80 & High & + & IL-A159 & Serotec & Tested \\
\hline CD86 & High & $?$ & IL-A190 & Serotec & Not tested \\
\hline Il-10 & + & $?$ & CC318 & Serotec & Not tested \\
\hline
\end{tabular}

* These are additional markers which have been described. We tested these markers on bovine PBMCs as indicated. More markers have been described in literature, but were not tested in this study as indicated. N/A = not available. $\mathrm{PC}=$ polyclonal antibody. 


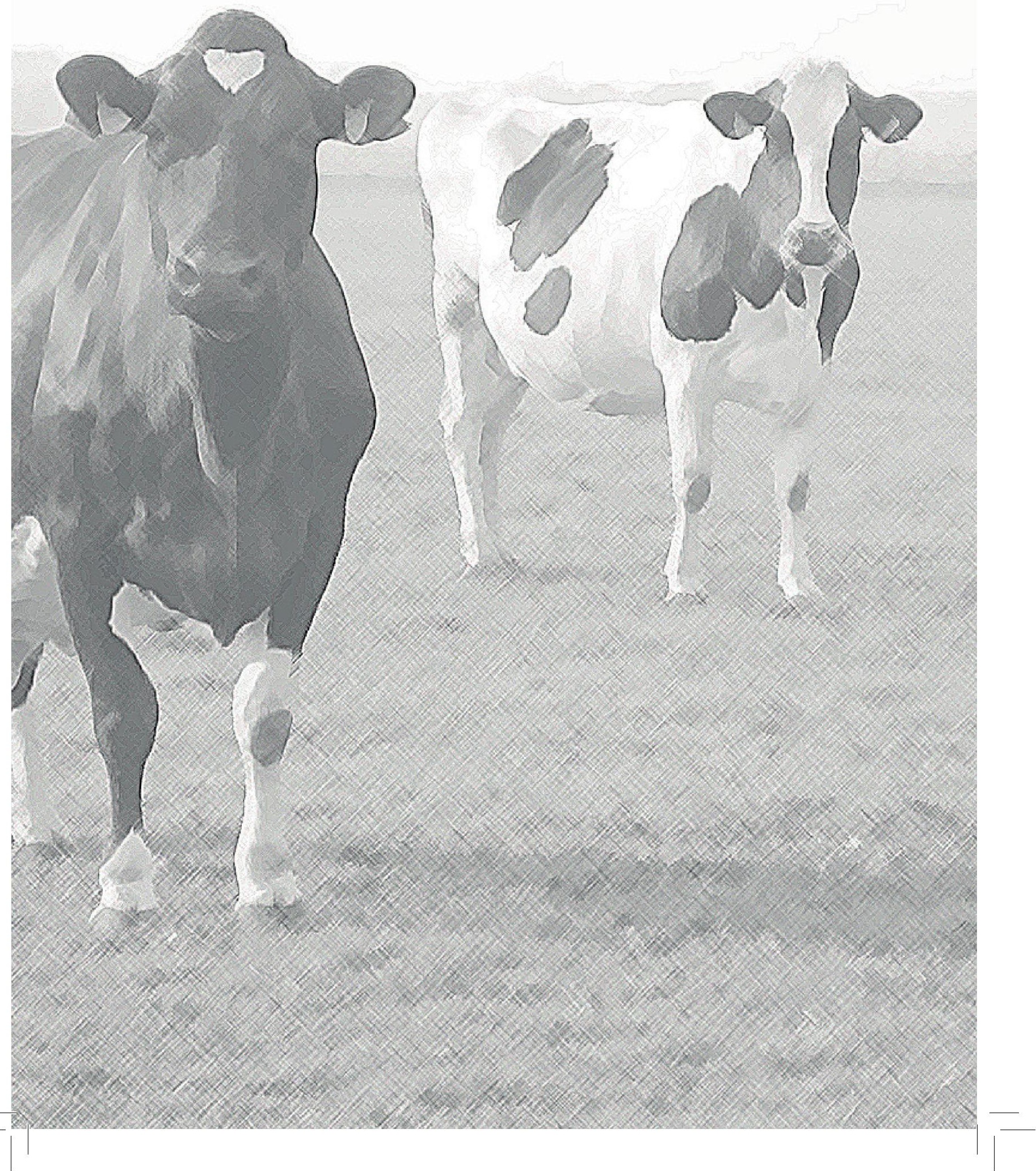




\title{
Chapter 4
}

\begin{abstract}
Bovine Natural Antibodies in Antibody-Dependent Bactericidal Activity Against Escherichia coli and Salmonella Typhimurium and Risk of Mastitis
\end{abstract}

S.E.C. van Altena ${ }^{1}$, M.A. Peen ${ }^{1}$, F.H. van der Linden ${ }^{1}$, H.K. Parmentier ${ }^{2}$, H.F.J. Savelkoul ${ }^{1}$, E.J. Tijhaar $^{1}$

${ }^{1}$ Cell Biology and Immunology Group, Department of Animal Sciences, Wageningen University, P.O. Box 338, Wageningen, the Netherlands

${ }^{2}$ Adaptation Physiology Group, Department of Animal Sciences, Wageningen University, P.O. Box 338, Wageningen, the Netherlands

Veterinary Immunology and Immunopathology (2016) 171:21-27 


\section{Abstract}

Natural antibodies (NAbs) are mostly IgM antibodies produced without antigenic stimulation and serve as a first line of defence of the immune system. As both natural and specific antibodies are present in animals, NAbs are studied by determining the IgM response to naïve antigens like keyhole limpet hemocyanin (KLH). In this study, we selected cows based on high and low anti-KLH IgM titers, reflecting high and low NAb titers, and determined if the anti-KLH IgM titers were indicative for the recognition of common microbial structures (lipopolysaccharide, lipoteichoic acid and peptidoglycan) and intact bacteria (Escherichia coli and Salmonella Typhimurium). Sera with high NAbs titers showed more IgM and IgG binding to common microbial structures and $S$. Typhimurium bacteria than sera with low NAbs titers. The same association was observed for IgM binding to $E$. coli, but not for IgG binding to $E$. coli. Antibody-mediated complement killing of $E$. coli and $S$. Typhimurium in a newly developed bactericidal test was equal between high and low NAb cows. However, relating the outcome of the bactericidal test to the development of mastitis within one and even four years after sampling showed a significant negative correlation implying cows that were less potent in bacterial killing had a higher chance on developing mastitis. In conclusion, sera with high NAbs titers had more antibodies binding to common microbial structures and intact bacteria. Furthermore, the bactericidal test might provide a useful prognostic tool for the development of mastitis.

Key words: Antibody-mediated complement killing, Natural antibodies, Dairy cattle 


\section{Introduction}

Natural antibodies (NAbs) are polyreactive antibodies that are produced without prior antigenic stimulation and mostly directed to auto-antigens and common microbial structures like Pathogen-Associated Molecular Patterns (PAMP) [1]. In mammals, NAbs are mostly IgM [2] and are produced by B1 B-cells [2, 3], performing a first line of defence against invading pathogens [4]. In contrast, specific antibodies (SpAbs) are produced by B2 B-cells in response to antigen exposure, and by consequence, are far more restricted in their epitope recognition compared to NAbs. Mouse studies showed that NAbs have a unique role in the immune system. NAbs can act in similar ways as SpAbs by initial recognition and opsonisation of pathogens, resulting in subsequent complementdependent killing or phagocytosis [5, 6]. Moreover, NAbs play a homeostatic role e.g. by clearing apoptotic cells and neo-epitopes [7, 8]. High serum NAb levels were associated with increased survival of laying hens [9] and sheep [10] and NAbs were essential in the survival of mice suffering from an induced acute peritonitis [11]. In cows, NAb levels in milk were suggested to be positively related with resistance to mastitis [12].

Binding of bovine serum antibodies to PAMP makes it hard to discriminate the role of NAbs from that of SpAbs. In other species, NAbs binding the naïve antigen Keyhole Limpet Hemocyanin (KLH) were studied. Dairy cows unlikely will have SpAbs to KLH, since KLH is derived from the Californian Pacific coast sea mollusc Megathura crenulata [13], but dairy cow do have NAbs binding KLH in milk and serum $[14,15]$.

The aim of the present study was threefold. First, it was studied whether NAbs in bovine serum, represented by anti-KLH IgM antibodies, were related with the levels of IgM and IgG serum antibodies binding lipopolysaccharide (LPS), lipoteichoic acid (LTA) and peptidoglycan (PGN) representing PAMP from Gram negative and Gram positive bacteria, and intact Escherichia coli (E. coli) and Salmonella enterica subspecies enterica serovar Typhimurium bacteria ( $S$. Typhimurium). These bacteria were chosen, as E. coli is a major pathogen in bovine infectious diseases in the udder $[16,17]$ and $S$. Typhimurium is an opportunistic bacterium that emerges when a cows' health status is compromised. The level of antibodies binding to $S$. Typhimurium is chosen as an indicator for natural immune competence. Such antibody-based indicator of natural immune competence was previously described in chickens $[18,19]$. Second, it was determined if high serum NAb titers resulted in higher microbial killing via antibody-mediated complement killing in a newly developed bactericidal test. Third, NAb titers and bactericidal activity of bovine serum were related with the future development of mastitis.

\section{Materials and methods}

\section{Animal selection}

Bovine serum samples were selected from the "Resilient Cattle" (Weerbaar Vee) biobank containing serum, blood and milk samples collected on 29 conventional, Dutch farms between 2011 and 2015. In total, 2032 and 3109 serum samples were collected during winter 2011 and spring 2012, respectively. Disease registration and 
milk recording data were collected. The disease registration data cover the type and numbers of disease, the date when disease occurred and treatments per cow.

Serum samples were tested for IgM and IgG antibodies binding to Keyhole Limpet Hemocyanin (KLH). Since the majority of NAbs are IgM antibodies [2], cows were selected on anti-KLH IgM titers and the following criteria: exclusion of cows with parity 0 , cows between 0 and 30 days in lactation and cows with elevated somatic cell counts (SCC) at the moment of sampling. Maximum SSC were $<150,000$ cells $/ \mathrm{mL}$ for primiparous cows and $<250,000$ cells $/ \mathrm{mL}$ for multiparous cows, respectively. Exclusion of cows by the aforementioned criteria resulted in 1494 and 2384 cows in winter 2011 and spring 2012, respectively (Fig. 1A and B).

\section{IgM and IgG antibodies binding KLH}

IgM and IgG antibody titers to KLH were determined using an enzyme-linked immunosorbent assay (ELISA) as described [20]. IgM and IgG levels binding to KLH were expressed as titer where the titer represented the $\log 2$ value of the dilution closest to $50 \%$ of $\mathrm{E}_{\max } . \mathrm{E}_{\max }$ is the highest value of the standard curve [21].

\section{IgM and IgG antibodies binding LPS, LTA and PGN}

IgM and IgG antibodies in serum binding to LPS, LTA and PGN were determined by ELISA. High-binding 96-wells plates were coated overnight at $4^{\circ} \mathrm{C}$ with $4 \mu \mathrm{g} / \mathrm{mL}$ LPS (from Escherichia coli O55:B5, Sigma-Aldrich Inc, Missouri, US), LTA or PGN (from Staphylococcus aureus, Sigma) in PBS. Plates were blocked using Casein (Casein Diluent, Stereospecific Detection Technologies, Baesweiler, Germany) for 1.5 hours (h) at room temperature (RT). Serum samples were diluted 10x, 25x and 1000x in 1:3 diluted Casein in PBS for PGN, LPS and LTA, respectively. Diluted sera were incubated for $1 \mathrm{~h}$ at RT. Plates were washed with PBS containing $0.05 \%$ Tween-20 and incubated with either sheep-anti-bovine IgM HRP or IgG HRP (Bethyl Laboratories Inc., Montgomery, US) 1:5000 diluted in 1:3 Casein/PBS for $1 \mathrm{~h}$ at RT. After washing, plates were incubated with 3,3',5,5'-tetramethylbenzidine (TMB) (SDT, Germany) for 20 minutes at RT and stopped using $2 \%$ hydrogen chloride $(\mathrm{HCl})$. OD-values were measured at $450 \mathrm{~nm}$ and blanc corrected using the Filtermax F5 plate reader (Molecular Devices, Sunnyvale, California).

\section{IgM and IgG antibodies binding Escherichia coli and Salmonella Typhimurium}

E. coli (JM109) and S. Typhimurium (SL3261) bacteria were grown overnight at $37^{\circ} \mathrm{C}$ in LB medium. The next day, bacteria were transferred to fresh LB medium and grown to log-phase $\left(\mathrm{OD}_{600 \mathrm{~mm}}=0.6-0.8\right)$. Bacteria were washed three times in 0.1 $\mathrm{M} \mathrm{Na}_{2} \mathrm{CO}_{3} / \mathrm{NaHCO}_{3}$ buffer ( $\mathrm{pH}$ 9.6).

Medium-binding plates were coated with $2 \times 10^{8}$ bacteria/mL in $0.1 \mathrm{M} \mathrm{Na}_{2} \mathrm{CO}_{3} /$ $\mathrm{NaHCO}_{3}$ buffer ( $\mathrm{pH} 9.6$ ) and incubated overnight at $4^{\circ} \mathrm{C}$. Bacteria were fixed using $4 \%$ paraformaldehyde for $2 \mathrm{~h}$ at RT. Plates were blocked using Casein for $1 \mathrm{~h}$ at RT. Serum samples were diluted 100 times in 1:3 Casein/PBS and incubated for $1 \mathrm{~h}$ at RT. After washing with PBS containing $0.05 \%$ Tween-20, IgM and IgG antibodies binding to $E$. coli or $S$. Typhimurium were detected as previously described (See IgM and IgG antibodies binding to LPS, LTA and PGN). 


\section{Bactericidal activity of bovine serum}

Serum samples containing high or low NAb titers were selected and tested for antibodymediated complement killing. Bacterial killing was expressed as the minimal inhibitory dose (MID), the highest serum dilution that inhibited bacterial growth (Supplementary Fig. 1), and was measured in a newly developed bactericidal test based on [22]. Bacteria (E. coli JM109 or S. Typhimurium SL3261) were inoculated in LB medium and grown to $\log$-phase. Serum samples were heat-inactivated (HI) for 30 minutes at $56^{\circ} \mathrm{C}$. The $\mathrm{HI}$ sera were diluted with PBS and titrated with two-step dilutions starting at 1:10 in $80 \mu \mathrm{L} /$ well in flat-bottom 96-wells culture plates (Greiner Bio-One, Frickenhausen, Germany). Next, $20 \mu \mathrm{L} /$ well untreated foetal calf serum (FCS, Thermo Fischer Scientific, MA) was added as fixed source for complement with low levels of endogenous antibodies. Bacteria were diluted to $4 \times 10^{6}$ bacteria $/ \mathrm{mL}$ in $\mathrm{LB}$ medium and $100 \mu \mathrm{L}$ bacteria were added to the diluted sera. Plates were measured at $595 \mathrm{~nm}$ using the Filtermax F5 microplate reader before and after overnight incubation at $37^{\circ} \mathrm{C}$ while shaking at $250 \mathrm{rpm}$.

The majority of NAbs in mice were shown to be IgM antibodies and only a minor part was $\operatorname{IgG}$ [2]. To minimize the influence of specific IgG antibodies in the test, cows were selected with low IgG levels to $E$. coli or $S$. Typhimurium in combination with high or low IgM antibody levels against these bacteria. This selection resulted in 20 high and 20 low cows for $E$. coli and for $S$. Typhimurium, which were compared in the bactericidal test.

\section{Statistical analysis}

Differences in IgM and IgG levels between cows with high- and low anti-KLH IgM titers were determined using the Mann-Whitney $U$ test since the samples were not normally distributed (GraphPad Prism 5). Normality was tested using the Shapiro-Wilk normality test. 


\section{Results}

High or low serum IgM titers against the naïve antigen KLH were defined as high or low NAb titers. In order to increase the contrast, cows were selected that had consistently the $15-20 \%$ highest or lowest NAb titers in two serum samples taken in successive years (Fig. 1A (2011) and B (2012)). Cows that were clinically ill around the moment of sampling were also excluded. This selection resulted in 79 serum samples high and 77 serum samples low in NAbs, as about $35 \%$ of the cows remained high or low NAb titers in two successive years. This selection was thus reflected in the serum anti-KLH IgM levels (Fig. 1C) and also in the total IgM antibody levels (Fig. 1D). The next experiments were performed with the serum samples obtained in the first winter of this study (2011)
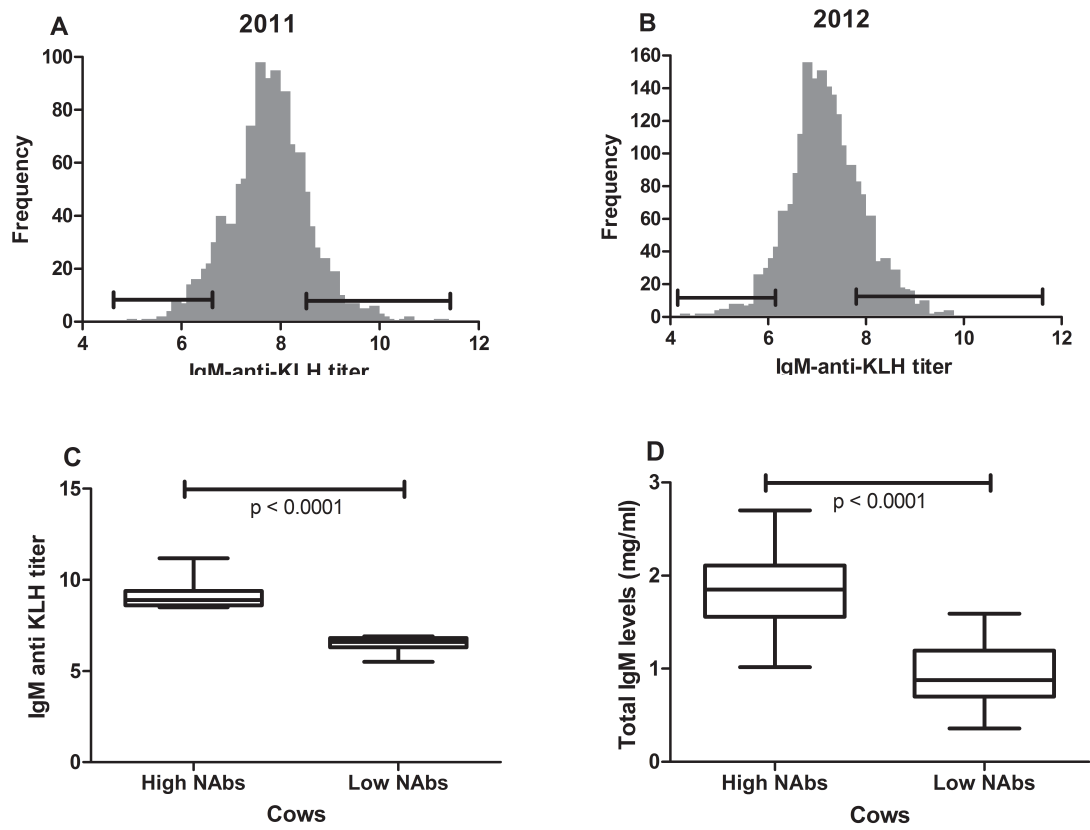

Figure 1: Frequency distribution and serum IgM anti KLH titers to determine high and low NAbs cows. (A) Frequency distribution of serum IgM anti KLH titers measured in 1494 cows obtained in Winter 2011. IgM anti KLH is a measure for natural antibodies (NAbs). The bars indicate the selection of cows with the $15 \%$ lowest and $15 \%$ highest NAb titers. (B) Frequency distribution of serum NAb titers measured in 2384 cows obtained in Spring 2012. The bars indicate the selection of cows with the $20 \%$ lowest and $20 \%$ highest NAb titers. Cows having the $15-20 \%$ highest and lowest NAb titers in both serum samples were selected, resulting in 79 high $\mathrm{NAb}$ and 77 low NAb cows. (C) Statistical analysis of the NAb titers in the high and low NAbs cows showed significant higher NAb titers in the high NAbs cows. (Mann-Whitney U test, $\mathrm{p}<0.0001$ ) (D) Total serum IgM levels $(\mathrm{mg} / \mathrm{mL})$ measured in cows high and low in NAb titers. Serum IgM levels $(\mathrm{mg} / \mathrm{mL})$ were significantly higher in the cows with high NAb titers. (Mann-Whitney U test, $\mathrm{p}<0.0001$ ) 


\section{Binding of serum antibodies to common microbial structures}

Sera with high and low NAb titers were tested for IgM and IgG binding to LPS, LTA and PGN, respectively (Fig. 2). As NAbs are often directed to common microbial structures, it was hypothesised that cows with higher NAb titers showed more binding to PAMPs (Fig. 2) and whole microbes (Fig. 3). Cows with high NAb titers had indeed higher IgM and IgG binding LPS, LTA and PGN than cows with low NAb titers (Fig. 2). Comparing the levels of IgM and IgG binding LPS of cows high and low in NAb titers showed significantly higher binding $(\mathrm{p}<0.0001)$ in high NAb cows (Fig. 2A). This large difference $(\mathrm{p}<0.0001)$ was also found for IgM and IgG binding LTA (Fig. 2B) and PGN (Fig. 2C).
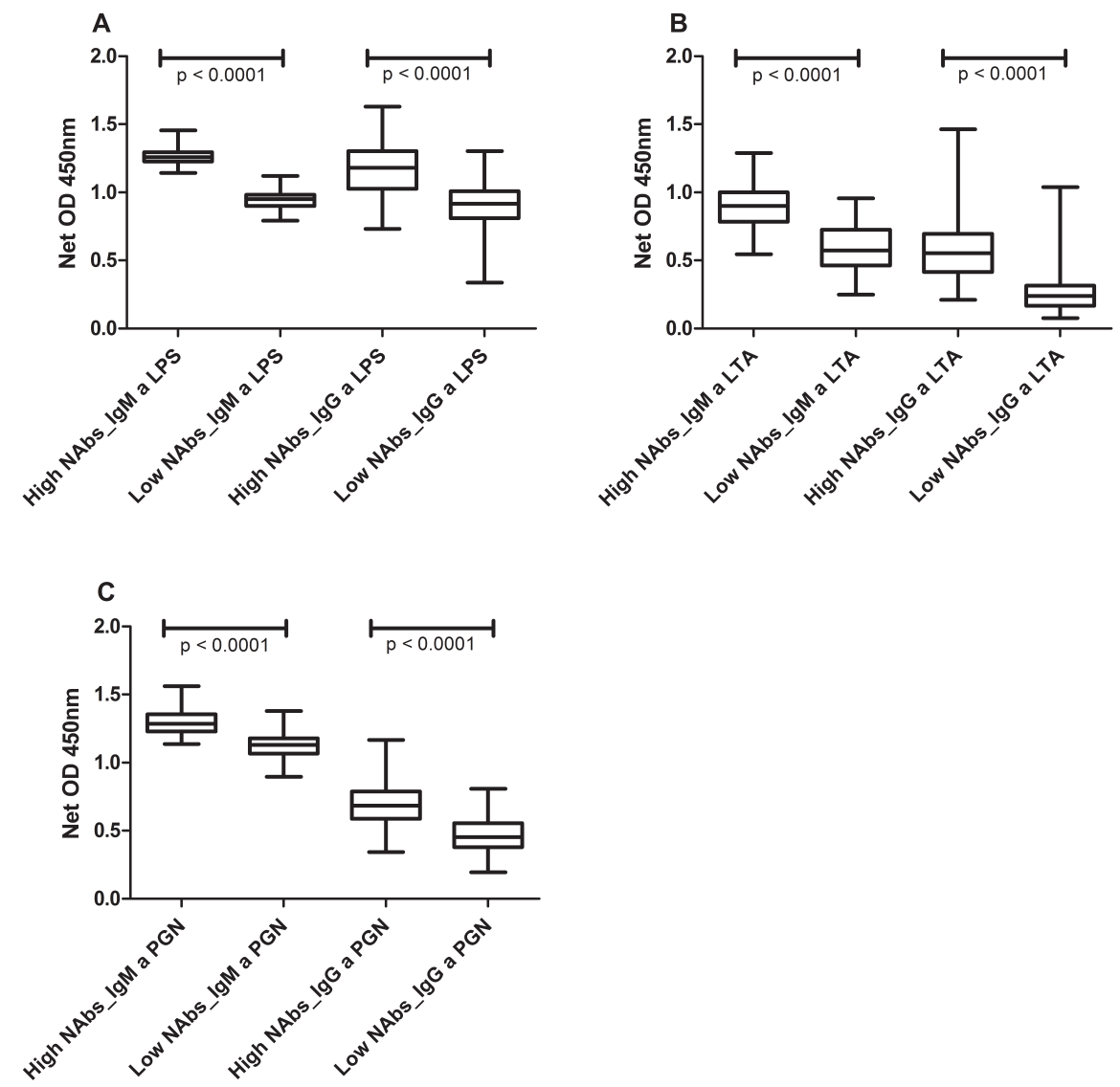

Figure 2: IgM and IgG response against LPS, LTA and PGN of cows high and low in NAbs

The IgM and IgG response against the PAMPs LPS (A), LTA (B) and PGN (C) were determined in bovine serum samples high and low in NAb titers, 79 and 77 samples respectively. IgM and IgG responses are represented as $\mathrm{OD}$-values $\left(\mathrm{OD}_{450 \mathrm{~nm}}-\mathrm{OD}_{620 \mathrm{~nm}}\right)$. The $\mathrm{OD}$-values are blanc-corrected. The IgM and $\mathrm{IgG}$ responses against the different PAMPs differed significantly between cows with high and low NAb titers (Mann-Whitney $\mathrm{U}$ test, $\mathrm{p}<$ $0.0001)$. 
Binding of serum antibodies to E. coli and S. Typhimurium

Levels of IgM and IgG binding E. coli and $S$. Typhimurium bacteria were significantly higher $(\mathrm{p}<0.0001)$ in bovine sera with high NAb titers compared to sera with low NAb titers except for the levels of IgG binding E. coli (Fig. 3A and B). The level of IgG binding $E$. coli was not significantly different between the cows with high or low NAb titers. This was reflected by the Spearman correlation for IgM and IgG antibodies binding to E. coli or $S$. Typhimurium, which was lower for E. coli, 0.430 and 0.685 , respectively (Fig. 3C and D).
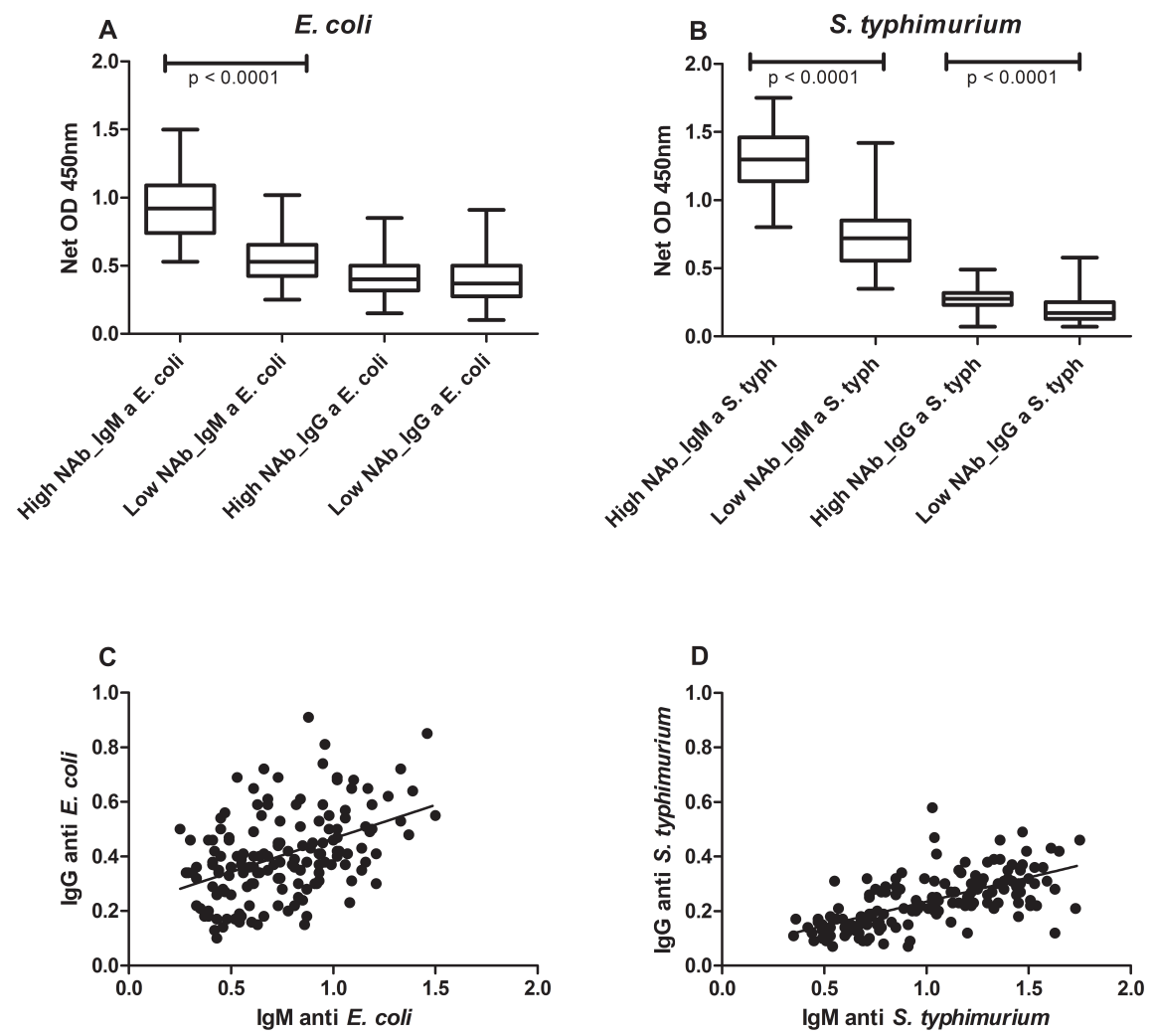

Figure 3: IgM and IgG responses to E. coli and S. Typhimurium in bovine sera with high and low NAb titers. Cows with high $(\mathrm{n}=79)$ and low $(\mathrm{n}=77)$ NAb titers were tested for their serum IgM and IgG responses to whole, fixed E.coli (A) and $S$. Typhimurium (B) bacteria in ELISA. One cow tested highly positive for $S$. Typhimurium and is removed from this selection, resulting in 78 high NAb cows and 77 low NAb cows in Fig. 3B and D. Reactivities are represented as OD-values $\left(\mathrm{OD}_{450 \mathrm{~mm}}-\mathrm{OD}_{620 \mathrm{~mm}}\right)$ and were corrected for the background signal. High $\mathrm{NAb}$ cows had significantly higher IgM responses against $E$. coli and $S$. Typhimurium than low NAb cows. (Mann-Whitney U test, $\mathrm{p}<0.0001$ ) A similar relation was observed for the $\operatorname{IgG}$ response to $S$. Typhimurium (Mann-Whitney U test, $\mathrm{p}<0.0001$ ), but not for E. coli. Spearman correlations were determined for IgM and IgG binding to $E$. coli $(0.430)$ and $S$. Typhimurium $(0.6848)$ and were highly significant $(\mathrm{p}<0.0001)$ (Fig. $3 \mathrm{C}$ and D). 


\section{Bactericidal activity of bovine serum}

The MID for $E$. coli and $S$. Typhimurium was determined via bactericidal activity in sera from the selected cows. Cows with high NAb titers were expected to have a higher MID than cows with low NAb titers. The frequency of serum dilutions indicating the MID were shown in Fig. 4A and B. These dilutions varied from 0 to 160 for E. coli and 20 to 80 for $S$. Typhimurium, respectively. No statistical differences were found between high and low NAb cows and killing of $E$. coli or $S$. Typhimurium (Fig. 4C and D). Besides, no relation was found for IgG and killing in the bactericidal test (data not shown).
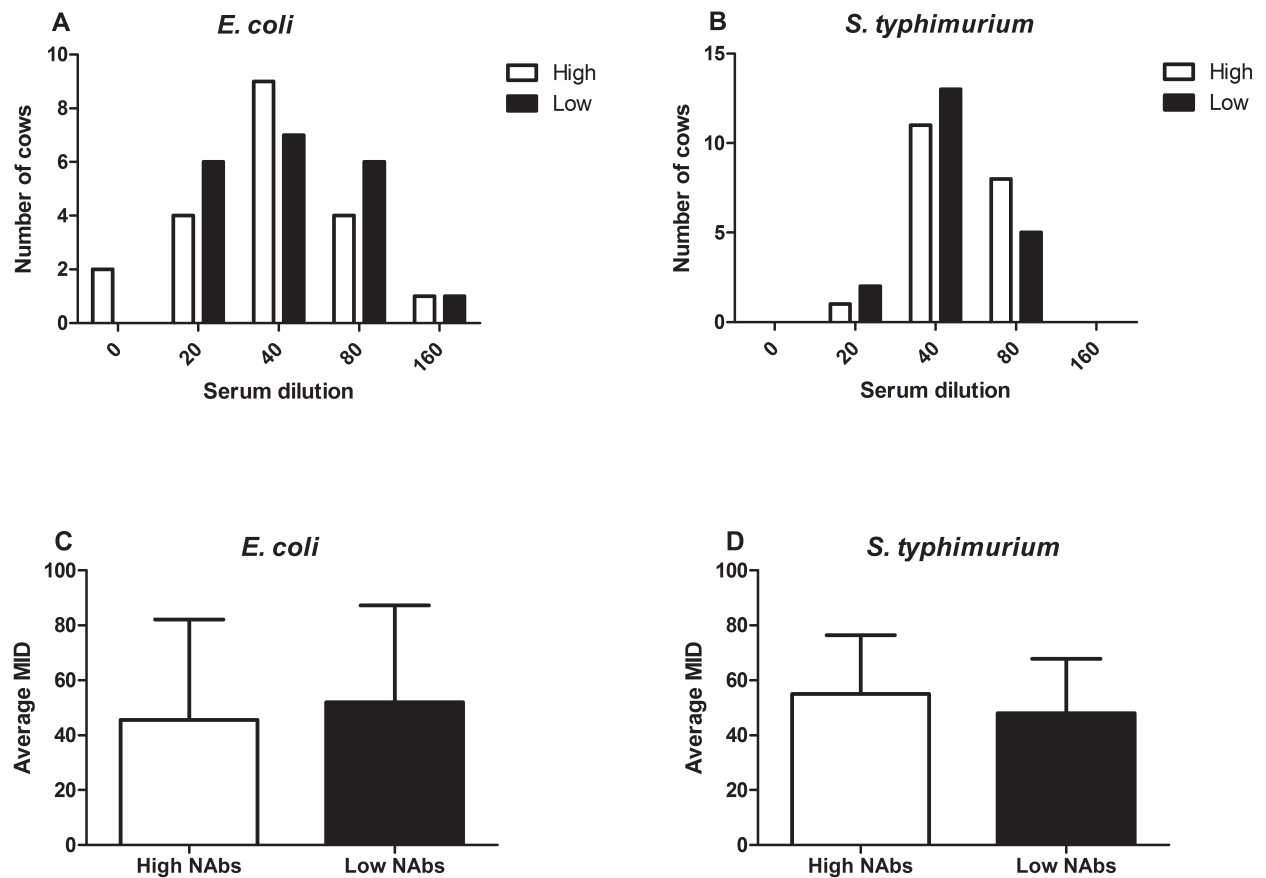

Figure 4: Minimal inhibitory dose for $E$. coli and $S$. Typhimurium in bovine sera with high and low NAb titers

The minimal inhibitory dose (MID) of different bovine sera is determined for 20 vs. 20 cows high vs. low in IgM against $E$. coli (A) or $S$. Typhimurium (B). The MID is determined as the highest serum dilution that still inhibits bacterial growth after 24 hours incubation and is represented as frequencies of cows with a specific MID. Open bars: cows high in IgM anti $E$. coli or $S$. Typhimurium, black bars: cows low in IgM anti $E$. coli or $S$. Typhimurium. Figure C and D show the average MID for cows high or low in IgM anti $E$. coli (C) or $S$. Typhimurium (D) with standard deviations. 


\section{Prognostic role of bactericidal test activity in serum}

Next, the bactericidal activity was related to the available disease registration data. Since $E$. coli and $S$. Typhimurium are important infectious agents in dairy cattle, we focussed on the occurrence of mastitis, independent of the NAb status of the cows. Cases of mastitis were recorded within a period of one (2012) and four (2015) years after sampling. It was hypothesised that cows developed mastitis were less able to kill bacteria i.e. had a lower MID.

Cows that did develop mastitis within one year after sampling had a lower MID in the $E$. coli and $S$. Typhimurium bactericidal tests (Fig. 5A and B). For the $S$. Typhimurium bactericidal test this relation still remained for a period up to four years after sampling, indicative of a true prognostic value of the outcome in the bactericidal test (Fig. $5 \mathrm{C}$ and D). A similar trend was found when the NAb status was taken into account, a lower MID for cows that developed mastitis within one year (Supplementary data Fig. 2).
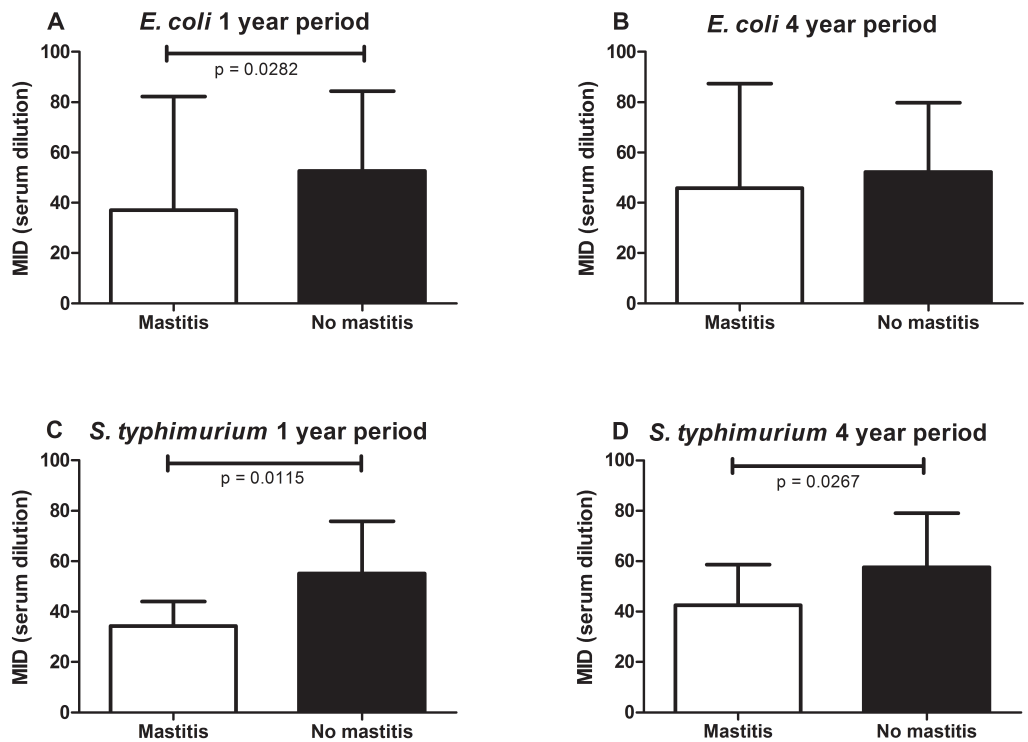

Figure 5: Predictive value bactericidal test for the development of mastitis

The performances in the E. coli and $S$. Typhimurium bactericidal test were represented by the MID and related to the development of mastitis one year after sampling (A and $\mathrm{C}$ ) and on the long term i.e. after 4 years (B and D). The bar graphs represent the average MID with standard deviations for cows that did develop mastitis (open bars) and those that did not develop mastitis (black bars) independent of their NAb status. Cows that developed mastitis within one year had a significantly lower MID in the E. coli (A) and $S$. Typhimurium (B) bactericidal test, Mann-Whitney $U$ test $\mathrm{p}=0.0282$ and $\mathrm{p}=0.0115$ respectively. On the long term, this relation still persists for the $S$. Typhimurium bactericidal test $(\mathrm{p}=0.0267)$, but not for the $E$. coli bactericidal test. 


\section{Discussion}

The present study showed that cows selected for high NAb titers in serum binding KLH, especially, represented by anti-KLH IgM antibodies, have a high binding capacity to PAMPs like LPS, LTA and PGN, respectively, as well as intact $E$. coli and $S$. Typhimurium bacteria. However, as determined in the bactericidal test, the higher binding capacity of cows with high NAb titers did not correspond with a higher antibody-mediated complement killing, which was shown to be equal between cows with high and low NAb titers. The MID determined in the E. coli and $S$. Typhimurium bactericidal tests was related mastitis incidence, independent of NAb-status. A lower MID was observed in cows that developed mastitis in one to even four years after sampling.

Anti-KLH IgM and IgG titers were used as indicator for NAbs in poultry [9] and dairy cattle [14], and were proposed to be a tool to determine the innate disease resistance of dairy cattle [15]. In this study, positive relations were found between serum anti-KLH IgM titers and the levels of antibodies in serum binding various PAMPs. NAbs have been shown to bind to conserved microbial structures and auto-antigens [1, 21]. In accordance, cows with high NAb titers also showed higher levels of IgM and IgG binding to whole $E$. coli and $S$. Typhimurium bacteria. Levels of $\operatorname{IgG}$ in serum binding to $E$. coli bacteria were equal between cows having high or low NAb titers. With respect to the different levels of IgG binding either E. coli or $S$. Typhimurium, it was suggested that the differences in LPS expression on the $E$. coli and $S$. Typhimurium strains used in the present study may have diminished the chance of cross-reactive antibodies between these bacteria [23]. E. coli expressed rough LPS, while $S$. Typhimurium expressed smooth LPS, which may have elicited an antibody response to both the rough core and smooth O-antigen [24].

NAbs were earlier shown to have an essential role in antibody-mediated complement killing $[25,26]$. This killing is mainly performed by (pentameric) IgM antibodies because of higher avidity with complement than (monomeric) IgG [27]. Despite higher levels of IgM binding to E. coli and $S$. Typhimurium whole bacteria in cows with high NAb titers, there was no difference between these cows and cows with low $\mathrm{NAb}$ titers in bactericidal activity. This suggested that bacterial killing was not only the results of antibody-mediated (classical) complement killing, but also by activation of the alternative or mannan-binding lectin complement pathways [28, 29] or, more importantly, anti-microbial proteins and peptides in serum [30]. Since the endogenous complement system was replaced by FCS-derived complement, which likely has lower complement levels [31], the killing potential of NAbs might be underestimated. NAbs were shown to be involved in various components of the immune system such as antigen neutralisation, opsonisation and trapping in secondary lymphoid tissues and thereby cooperating with immune cells to elicit an immune response $[5,6,32]$. Thus, a direct beneficial role for enhanced NAb titers in cows remains to be elucidated.

The bactericidal activity in sera showed relations with the occurrence of mastitis. Cows that developed mastitis within one or even four years after sampling, performed less in the bactericidal activity test i.e. they inhibited bacterial growth at lower serum dilutions. This suggested a prognostic value for the bactericidal test indicating those cows that are less powerful in combating microbes. Future studies should establish the actual prognostic value of this bactericidal test for the development of major diseases related to cow's health. 


\section{Conclusion}

Selected dairy cows with higher levels of IgM (natural) antibodies to KLH have higher levels of (natural) IgG antibodies to KLH, and higher levels of antibodies binding PAMP from Gram negative and Gram positive bacteria. In addition, also higher levels of antibodies binding to whole $E$. coli and $S$. Typhimurium bacteria were found in these cows. Bactericidal activity in serum to $E$. coli and $S$. Typhimurium were, however, not different in these cows suggesting that the NAb titers to KLH and antibodies to PAMPs measured were not involved in classical complement mediated killing. On the other hand, cows with a higher bactericidal activity in serum had a reduced chance to develop mastitis in the years after sampling. The developed bactericidal test could therefore be a promising tool to select dairy cows with increased resistance to mastitis.

\section{Conflict of interest statement}

None of the authors of this paper has a financial or personal relationship with other people or organisations that could inappropriately influence or bias the content of the paper.

\section{Acknowledgements}

This study is part of a joint project "Weerbaar Vee", funded by the Dutch Ministry of Economic Affairs (The Hague, the Netherlands), Dutch Dairy Product Board ("Productschap Zuivel", Zoetermeer, the Netherlands), Dutch Cooperative Cattle Improvement (CRV, Arnhem, the Netherlands), Dutch Federation of Agriculture and Horticulture ("LTO-Noord Fondsen", Zwolle, the Netherlands), GD Animal Health (Deventer, the Netherlands), and Wageningen University (Wageningen, the Netherlands). The authors also thank the herd owners for their collaboration. 


\section{References}

1. Avrameas, S., Natural autoantibodies: from 'horror autotoxicus' to 'gnothi seauton'. Immunol Today, 1991. 12(5): p. 154-9.

2. Baumgarth, N., J.W. Tung, and L.A. Herzenberg. Inherent specificities in natural antibodies: a key to immune defense against pathogen invasion. in Springer seminars in immunopathology. 2005. Springer.

3. Baumgarth, N., Innate-like B cells and their rules of engagement. Adv Exp Med Biol, 2013. 785: p. 57-66.

4. Ochsenbein, A.F. and R.M. Zinkernagel, Natural antibodies and complement link innate and acquired immunity. Immunol Today, 2000. 21(12): p. 624-30.

5. Hangartner, L., R.M. Zinkernagel, and H. Hengartner, Antiviral antibody responses: the two extremes of a wide spectrum. Nature Reviews Immunology, 2006. 6(3): p. 231-243.

6. Ehrenstein, M.R. and C.A. Notley, The importance of natural IgM: scavenger, protector and regulator. Nature Reviews Immunology, 2010. 10(11): p. 778-786.

7. Lutz, H.U., C.J. Binder, and S. Kaveri, Naturally occurring auto-antibodies in homeostasis and disease. Trends Immunol, 2009. 30(1): p. 43-51.

8. Grönwall, C., J. Vas, and G.J. Silverman, Protective Roles of Natural IgM Antibodies. Frontiers in Immunology, 2012. 3: p. 66.

9. Sun, Y., et al., Natural antibody isotypes as predictors of survival in laying hens. Poult Sci, 2011. 90(10): p. 2263-74.

10. Graham, A.L., et al., Fitness correlates of heritable variation in antibody responsiveness in a wild mammal. Science, 2010. 330(6004): p. 662-665.

11. Boes, M., et al., A critical role of natural immunoglobulin $M$ in immediate defense against systemic bacterial infection. The Journal of experimental medicine, 1998. 188(12): p. 2381-2386.

12. Ploegaert, T.C., et al. Parameters for natural resistance in bovine milk. in Proceedings of international conference 'Mastitis control, from science to practice. 2008.

13. Harris, J.R. and J. Markl, Keyhole limpet hemocyanin (KLH): a biomedical review. Micron, 1999. 30(6): p. 597-623.

14. van Knegsel, A.T.M., et al., Natural Antibodies Related to Energy Balance in Early Lactation Dairy Cows. Journal of Dairy Science, 2007. 90(12): p. 5490-5498.

15. Ploegaert, T.C., et al., Natural antibodies in bovine milk and blood plasma: variability among cows, repeatability within cows, and relation between milk and plasma titers. Vet Immunol Immunopathol, 2011. 144(1-2): p. 88-94.

16. Olde Riekerink, R.G., et al., Incidence rate of clinical mastitis on Canadian dairy farms. J Dairy Sci, 2008. 91(4): p. 1366-77.

17. Verbeke, J., et al., Pathogen-specific incidence rate of clinical mastitis in Flemish dairy herds, severity, and association with herd hygiene. J Dairy Sci, 2014. 97(11): p. 6926-34.

18. Star, L., et al., Natural humoral immune competence and survival in layers. Poult Sci, 2007. 86(6): p. 1090-9.

19. Star, L., et al., Effect of early life thermal conditioning and immune challenge on thermotolerance and humoral immune competence in adult laying hens. Poult Sci, 2009. 88(11): p. 2253-61.

20. de Klerk, B., et al., Phenotypic and genetic relationships of bovine natural antibodies binding keyhole limpet hemocyanin in plasma and milk. Journal of Dairy Science, 2015. 98(4): p. 2746-2752.

21. Ploegaert, T.C.W., et al., Genetic variation of natural antibodies in milk of Dutch Holstein- 
Friesian cows. Journal of Dairy Science, 2010. 93(11): p. 5467-5473.

22. Szabo, D., et al., The designer proline-rich antibacterial peptide A3-APO is effective against systemic Escherichia coli infections in different mouse models. International Journal of Antimicrobial Agents, 2010. 35(4): p. 357-361.

23. Conlan, J.W., et al., Salmonella landau as a live vaccine against Escherichia coli O157:H7 investigated in a mouse model of intestinal colonization. Can J Microbiol, 1999. 45(9): p. 723-31.

24. Currie, C.G., K. McCallum, and I.R. Poxton, Mucosal and systemic antibody responses to the lipopolysaccharide of Escherichia coli 0157 in health and disease*. Journal of medical microbiology, 2001. 50(4): p. 345-354.

25. Reid, R.R., et al., Endotoxin shock in antibody-deficient mice: unraveling the role of natural antibody and complement in the clearance of lipopolysaccharide. J Immunol, 1997. 159(2): p. 970-5.

26. Zhou, Z.-H., et al., The Broad Antibacterial Activity of the Natural Antibody Repertoire Is Due to Polyreactive Antibodies. Cell Host \& Microbe, 2007. 1(1): p. 51-61.

27. Melis, J.P.M., et al., Complement in therapy and disease: Regulating the complement system with antibody-based therapeutics. Molecular Immunology, 2015. 67(2, Part A): p. 117-130.

28. Warren, J., et al., Increased susceptibility of C1q-deficient mice to Salmonella enterica serovar Typhimurium infection. Infection and immunity, 2002. 70(2): p. 551-557.

29. Kilpi, M.K., J.T. Atosuo, and E.-M.E. Lilius, Bacteriolytic activity of the alternative pathway of complement differs kinetically from the classical pathway. Developmental \& Comparative Immunology, 2009. 33(10): p. 1102-1110.

30. Levy, O., Antimicrobial proteins and peptides of blood: templates for novel antimicrobial agents. Blood, 2000. 96(8): p. 2664-2672.

31. Triglia, R.P. and W.D. Linscott, Titers of nine complement components, conglutinin and C3b-inactivator in adult and fetal bovine sera. Molecular Immunology, 1980. 17(6): p. 741-748.

32. Ochsenbein, A.F., et al., Control of early viral and bacterial distribution and disease by natural antibodies. Science, 1999. 286(5447): p. 2156-2159. 


\begin{tabular}{|c|c|c|c|c|c|}
\hline & $\begin{array}{l}\text { bacte } \\
\text { cow } 1\end{array}$ & \multicolumn{2}{|c|}{ bacteria: 10,000 cells $/ \mathrm{ml}$} & $\begin{array}{l}\text { Ils/ml } \\
\text { cow } 4\end{array}$ \\
\hline \multirow{6}{*}{ 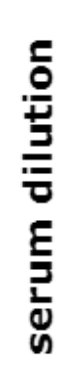 } & 10 & 0.01 & 0.01 & 0.00 & 0.01 \\
\hline & 20 & 0.00 & 0.00 & 0.19 & 0.00 \\
\hline & 40 & 0.01 & 0.00 & 0.27 & 0.01 \\
\hline & 80 & 0.37 & 0.01 & 0.40 & 0.01 \\
\hline & 160 & 0.43 & 0.37 & 0.48 & 0.37 \\
\hline & no serum & 0.59 & 0.55 & 0.55 & 0.55 \\
\hline
\end{tabular}

Supplementary data figure 1: Overview bactericidal test

Overview of bactericidal test. The different components, heat-inactivated serum, foetal calf serum and bacteria in LB-medium, are added in consecutive order. Serum samples are titrated in PBS to be able to determine the minimal inhibitory dose (MID). The MID is the highest serum dilution that still inhibits bacterial growth, here indicated by blue squares. 

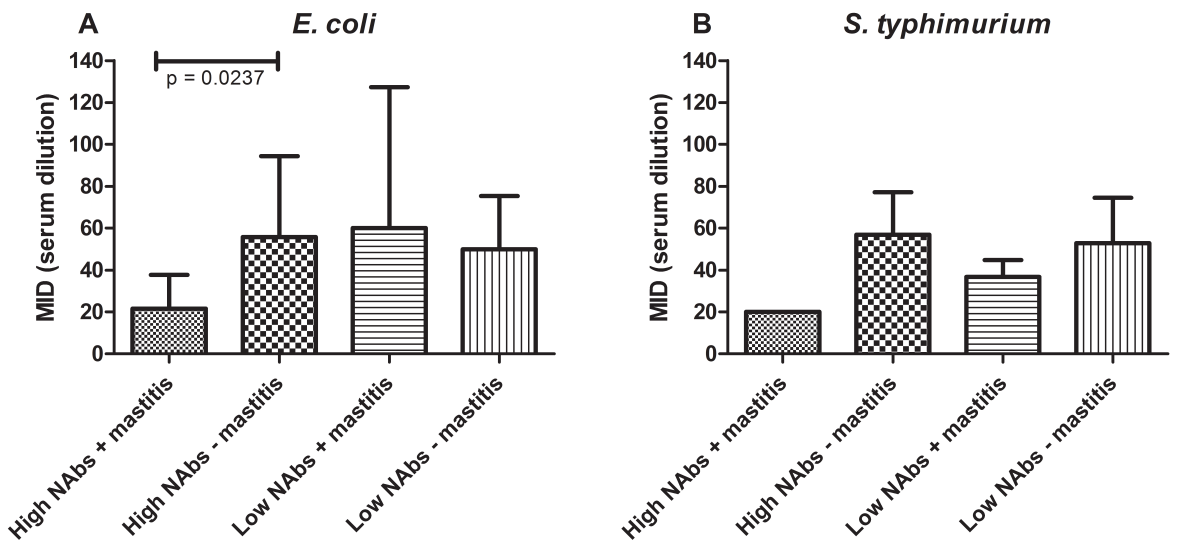

Supplementary data figure 2: MID and prognosis for disease development

Bactericidal tests with $E$. coli and $S$. Typhimurium were performed to determine the minimal inhibitory dose (MID) for bovine serum samples high and low in NAb titers. NAbs are defined as the IgM response to KLH. The average MIDs were related to the development of mastitis in the year after sampling. The bar graphs represent the average MID with standard deviations for cows high or low in NAb titers with and without mastitis (2A and B). Significant differences were found for cows high in NAb titers and the development of mastitis $(p=0.0237)$ in the $E$. coli bactericidal test. A similar trend was found $S$. Typhimurium. Significance was determined using the Mann-Whitney U test. 


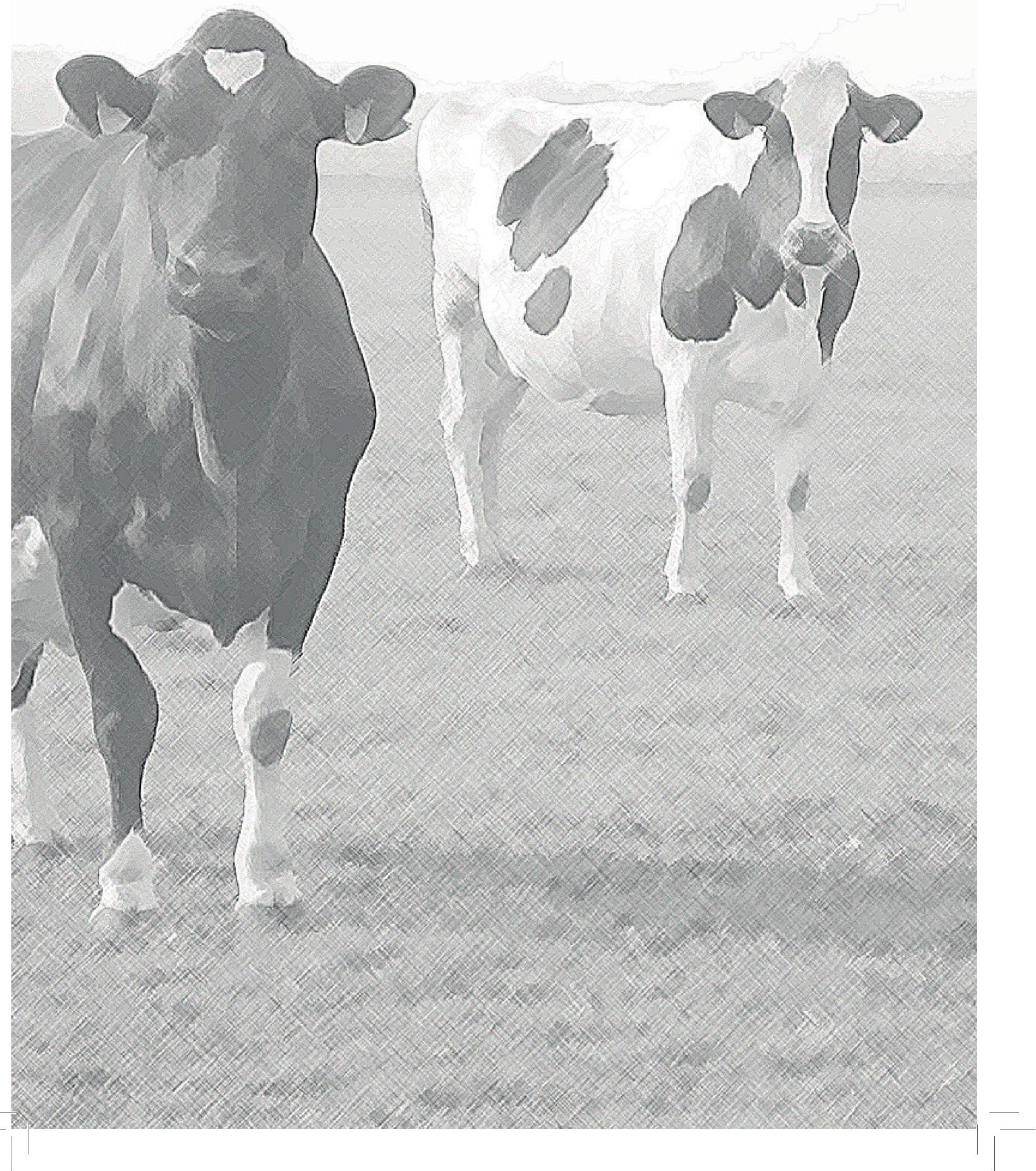




\section{Chapter 5}

\section{A Proteomics-based Identification of Putative Biomarkers for Disease in Bovine Milk}

S.E.C. van Altena ${ }^{1}$, B. de Klerk $^{2}$, K.A. Hettinga ${ }^{3}$, R.J.J. van Neerven ${ }^{1,4}$, S. Boeren $^{5}$, H.F.J. Savelkoul ${ }^{1}$, E.J. Tijhaar ${ }^{1}$

${ }^{1}$ Cell Biology and Immunology Group, Wageningen University, PO box 338, Wageningen, the Netherlands

${ }^{2}$ Animal Breeding and Genomics Centre, Wageningen University, PO box

338, Wageningen, the Netherlands

${ }^{3}$ Dairy Science and Technology Group, Wageningen University, 6700 EV,

Wageningen, the Netherlands

${ }^{4}$ FrieslandCampina, Stationsplein 4, 3818 LE Amersfoort, the Netherlands

${ }^{5}$ Laboratory of Biochemistry, Wageningen University, 6700 EV, Wageningen, the Netherlands

Veterinary Immunology and Immunopathology (2016) 174:11-18 


\section{Abstract}

The objective of this study was to identify and characterize potential biomarkers for disease resistance in bovine milk that can be used to indicate dairy cows at risk to develop future health problems. We selected high- and low-resistant cows i.e. cows that were less or more prone to develop diseases according to farmers` experience and notifications in the disease registration data. The protein composition of milk serum samples of these highand low-resistant cows were compared using NanoLC-MS/MS. In total 78 proteins were identified and quantified of which 13 were significantly more abundant in low-resistant cows than high-resistant cows. Quantification of one of these proteins, lactoferrin (LF), by ELISA in a new and much larger set of full fat milk samples confirmed higher LF levels in low- versus high-resistant cows. These high- and low-resistant cows were selected based on comprehensive disease registration and milk recording data, and absence of disease for at least 4 weeks. Relating the experienced diseases to LF levels in milk showed that lameness was associated with higher LF levels in milk. Analysis of the prognostic value of LF showed that low-resistant cows with higher LF levels in milk had a higher risk of being culled within one year after testing than high-resistant cows. In conclusion, LF in milk are higher in low-resistant cows, are associated with lameness and may be a prognostic marker for risk of premature culling.

Key words: dairy cattle, biomarker, lactoferrin, milk 


\section{Introduction}

The objective of this study was to identify biomarkers for disease resistance in bovine milk, thereby providing a prognostic tool to indicate dairy cows at risk to develop future health problems. The last decades dairy farming in the Netherlands has changed enormously and the number of cows per farm increased with $40 \%$ during the last 10 years [1]. Clinical mastitis, one of the major health problems in dairy farming, has an incidence of about 33 cases per 100 cows annually [2] with associated annual costs of approximately $€ 61$ to $€ 97$ per cow based on worldwide estimations [3]. Also fertility problems and lameness are important issues in dairy farming $[4,5]$. About $75 \%$ of the diseases in dairy cows occur in the first month after calving [6]. Around parturition, the immune system is compromised and the feed intake does not meet the energy requirements of the cow resulting in a negative energy balance (NEB), which makes the cow susceptible for diseases [6-8].

To monitor the health status of cows, several studies were performed to obtain specific biomarkers. For example the energy balance, and thereby the risk of developing disease, can be measured by the levels of not-esterified fatty acids (NEFA) and betahydroxybutyrate (BHBA) in blood [9]. Pre-partum NEFA serum levels were shown to be positively correlated with the risk of mastitis after parturition $[10,11]$. High postpartum NEFA levels are also a predictor for clinical ketosis, retained placenta, metritis and displaced abomasum [9]. Acute phase proteins (APP) in cows, like haptoglobin and serum amyloid, are common markers for infection and inflammation [12-14]. Haptoglobin and mammary-associated serum amyloid A (M-SAA3) were consistently increased in milk and subsequently in blood after a Staphylococcus aureus-induced subclinical mastitis $[12,15]$. In milk, an increase in somatic cell counts (SCC) or lactate dehydrogenase $(\mathrm{LDH})$ are markers for mastitis $[16,17]$ and are now routinely tested. Furthermore, ketosis can also be determined in milk by the rise in BHBA levels.

The risk for development of important diseases in dairy cattle can thus be monitored by the levels of some of these markers, which are used for regular screening in dairy farming already. A regularly used marker like SCC is specifically related to detection of mastitis, but does not indicate other diseases. Therefore, we are aiming for prognostic markers in bovine milk that are related to diseases different than mastitis. Markers in milk are preferred since milk samples are already collected regularly for routine screening, in contrast to blood samples. Nowadays, hundreds of unique proteins can be identified in different fractions of bovine milk by mass spectrometry $[18,19]$. This makes a proteomics approach a valuable tool for discovery of novel biomarkers [20, 21]. Here, we use shotgun proteomics (NanoLC-MS/MS) to compare milk samples of cows with a good health history (high-resistant cows) to milk samples of cows with a poorer health history (lowresistant cows). To exclude the detection of acute disease related markers, all samples were taken from cows that had not experienced health problems in the preceding 4 weeks. With this approach, we aimed to identify novel candidate biomarkers in milk for disease incidence in dairy cows, which were then evaluated in a larger number of milk samples from high- and low-resistant cows, selected on basis of comprehensive disease registration data collected during this study. 


\section{Materials and methods}

\section{Samples}

Milk samples were obtained from the Resilient Cattle ("Weerbaar Vee") biobank established in the Netherlands from 2010 until 2015. Cows from 29 conventional Dutch dairy farms were sampled multiple times during this period with the highest sampling frequency in 2014. In 2014, all full fat milk samples tested in the general milk recording and monitoring program were also stored in Resilient Cattle biobank at $-80^{\circ} \mathrm{C}$ (5 to 14 samples per cow). From 2010 until 2015 comprehensive disease registration data of these cows were collected. The disease registration data were carefully documented as instructed and supervised by one veterinarian and contained information about the diseases, applied treatments and medications the cows received including data about the duration of disease and treatment, vaccinations and hoof trimming. Diseases were categorized by the same veterinarian into: mastitis, other udder problems, lameness, retained placenta, metritis (uterus-related problems), respiratory diseases, metabolic diseases (e.g. ketosis) and "other" (diseases different than the previous categories for example trauma due to accidents).

First, milk serum samples used for proteomics analysis were selected based on the farmer`s opinion on perceived disease resistance of the cows in combination with disease registration data. Farmers were asked to identify their five highest and five lowest performing cows in terms of health problems, which are henceforward called high- and low-resistant cows. These cows were checked for health problems using the recorded disease registration data and milk recording data. Cows with somatic cell counts above 250,000 cells $/ \mathrm{ml}$ were excluded to reduce the chance on including cows with an ongoing mammary infection [22]. In addition, cows were excluded with annotations in the disease registration data within one month before or after the moment of sampling. High-resistant cows had no or only minor health problems, while low-resistant cows had recurrent health problems. Four high-resistant and four low-resistant cows were selected for proteomics analysis. These two group of cows were matched for age, parity, milk production, somatic cell counts (SCC), fat percentage, protein percentage and days in milk (DIM). At the moment of milk sampling all cows in both groups were clinically healthy based on disease registration and milk recording data. The individual milk serum samples were compared to a pooled of milk serum sample derived from 26 cows. This randomly chosen "average group" is matched to both groups of low-resistant and high-resistant individual samples in terms of age, parity, milk production, SCC, fat percentage, protein percentage and DIM.

The second and larger group of 43 high- and 36 low-resistant cows were selected based on the disease registration data obtained from the beginning of 2010 until summer 2014. Cows in the high- and low-resistant groups were matched for farm $(n=9)$, age, parity, milk production, SCC, fat percentage, protein percentage and DIM. Other inclusion criteria for the cows were: raised on the selected farms, born between 2008 and 2011, more than 30 days in lactation, production above the average production per farm and somatic cell count at sampling below 250,000 cells $/ \mathrm{ml}$. High-resistant cows had no annotations in the comprehensive disease registration data except for vaccinations. Farmers were carefully instructed and coached by the same veterinarian in keeping the disease registration accurate 
and up to date. Low-resistant cows had at least two annotations in the disease registration data (excepting regular vaccinations).

\section{NanoLC-MS/MS}

Milk serum samples were prepared by centrifugation at $1,500 \mathrm{~g}$ for 10 minutes at $10^{\circ} \mathrm{C}$. The supernatant was collected (without fat layer) and diluted 1:1 in $0.05 \mathrm{M}$ ammonium bicarbonate buffer $\mathrm{pH}=8.0$ ( $\mathrm{ABC}$ buffer, $\mathrm{NH}_{4} \mathrm{HCO}_{3}$ in water), then ultra-centrifuged at $100,000 \mathrm{~g}$ for 90 minutes at $30^{\circ} \mathrm{C}$. The clear supernatant (milk serum) was collected and prepared for proteomics analysis as described by [23]. Milk serum samples were treated using the filter-aided sample preparation (FASP) method [24] to clean the samples and perform trypsin digestion. After trypsin digestion, the resulting peptides were labelled by dimethyl labelling [25]. The amine-group of each peptide reacts with formaldehyde (for light label) or deuterated formaldehyde (for heavy label) forming a so called Schiff base, which is subsequently reduced by cyanoborohydride resulting in a light or heavy label attached to each peptide [26]. The milk serum samples from high- and low-resistant cows were individually labelled with a light label and compared to a pool of milk serum from 26 cows containing a heavy label. Protein quantity is expressed as a $\log _{2}$ ratio of the individual milk serum samples to the pooled milk serum sample. All eight individual samples can be compared with each other due to this labelling approach.

NanoLC-MS/MS analysis was performed as described by [27]. Full scan positive mode FTMS spectra were measured between m/z 380 and 1400 on a LTQ-Orbitrap XL (Thermo electron, San Jose, CA, USA) in the Orbitrap at high resolution (60000). CID fragmented MSMS scans of the four most abundant $2+$ and $3+$ charged peaks in the FTMS scan were recorded in data dependent mode in the linear trap (MSMS threshold $=5.000,45 \mathrm{~s}$ exclusion duration for the selected $\mathrm{m} / \mathrm{z}+/-25 \mathrm{ppm}$ ).

LCMS runs with all MSMS spectra obtained were analysed with MaxQuant 1.3.0.5 [28] using default settings for the Andromeda search engine [29] except that extra variable modifications were set for de-amidation of $\mathrm{N}$ and $\mathrm{Q}$.

A bovine database downloaded from Uniprot (http://www.uniprot.org) was used together with a contaminants database that contains sequences of common contaminants as for instance: BSA (P02769, bovine serum albumin precursor), Trypsin (P00760, bovine), Trypsin (P00761, porcine), Keratin K22E (P35908, human), Keratin K1C9 (P35527, human), Keratin K2C1 (P04264, human) and Keratin K1CI (P35527, human).

In the MaxQuant analysis, only peptides and proteins with a false discovery rate (FDR) of less than $1 \%$ were accepted. Reversed hits were deleted from the MaxQuant protein groups result table. The protein groups result was filtered further to keep only proteins with at least 2 identified peptides of which at least one should be unique and at least one should be unmodified.

\section{Lactoferrin ELISA}

The bovine lactoferrin ELISA was performed according to manufacturer instructions (Bovine Lactoferrin ELISA Quantitation Set, Bethyl Laboratories Inc., Montgomery USA). Milk samples were diluted 500, 1000 or 4000 times in Blocking Reagent (Roche Applied Science, Mannheim, Germany). All samples and standards were prepared and 
measured in duplicate at 450nm using a Filtermax F5 Plate Reader (Molecular Devices, Sunnyvale, California).

\section{Statistical analysis}

Groups of high- and low-resistant cows were matched for age, parity, milk production, SCC, fat percentage, protein percentage and DIM. The association of disease status or condition with LF levels were analysed with PROC MIXED in SAS 9.3 (SAS Inst. Inc. Cary, NC). To approximate normality, the natural logarithm (ln) of LF levels were calculated and analysed. Preliminary analyses indicated that the fixed continuous effect of a 305 days milk production in $\mathrm{kg}$, age of the cows in years, DIM, the interaction between age and DIM, and the random class effect of farms (farm 1 to 9) significantly affected LF levels. These effects were, therefore, maintained as correction factors within the models (base model). Inspection of the distribution of the residuals and the Q-Q plot indicated 2 possible outliers which were LF levels below the detection limit. These observations were, therefore, removed from the dataset, resulting in 43 high-resistant and 34 low-resistant cows.

To assess whether disease status or condition status was associated with LF levels, disease and condition variables were categorized into a limited set of different classes as some categories only had 1 observation. For mastitis, lameness, metabolic diseases and retained placenta the data were converted to a binary trait consisting of either having a condition (1) or not having a condition (0). For metritis the data was categorized in three classes consisting of having metritis once (1), having metritis more than once (2) or not having metritis (0). The fixed class effect of disease status or condition status was then individually added to the base model in separate analyses. To assess whether significant differences exist between cows that are not ill and cows that are ill with or without a certain condition, cows were categorized for each individual condition as either not ill, ill with a condition, or ill without a condition. These categories were individually added to the base model in separate analyses. Results are displayed in vertical scatter plots as the original individual observation (uncorrected LF level in $\mu \mathrm{g} / \mathrm{ml}$ ) for each disease status and/or condition. 


\section{Results}

Comparison of Milk Serum Samples of High- and Low-Resistant Cows by Proteomics To characterize potential biomarkers for disease resistance in dairy cows, differences in milk serum proteins between 4 high- and 4 low-resistant cows were determined by NanoLC-MS/MS. In total, 78 proteins were identified and quantified in these samples (Supplementary Table 1). Each protein is represented in Fig. 1 as a $\log _{2}$ ratio of the protein abundance in high-resistant versus low-resistant cows. $\log _{2}$ protein ratios between -1 and 1 were considered as natural variation, which may be caused by, for example, differences in cow genetics and individual farms. The proteins outside these limits may indicate true variation between high- and low-resistant cows. The expression of 10 proteins was significantly $(\mathrm{p}<0.05)$ different between the high- and low-resistant cows (open squares in Fig. 1). All 10 proteins were 2.3 to 6 times more abundant in milk serum of low-resistant than high-resistant cows (Table 1). To reduce the chance of missing potential biomarkers, while testing only a small number of cows, initially also proteins with $0.05<\mathrm{p}<0.07$ were included, which resulted in the inclusion of 3 additional proteins (open triangles in Fig. 1) and a total of 13 proteins. The cut-off at $p<0.07$ was chosen to include potential biomarkers, but still outside the natural variation between cows ( $\log _{2}$ protein ratios between -1 and 1$)$. The proteins that were selected were detected in at least 3 out of 4 cows per group.

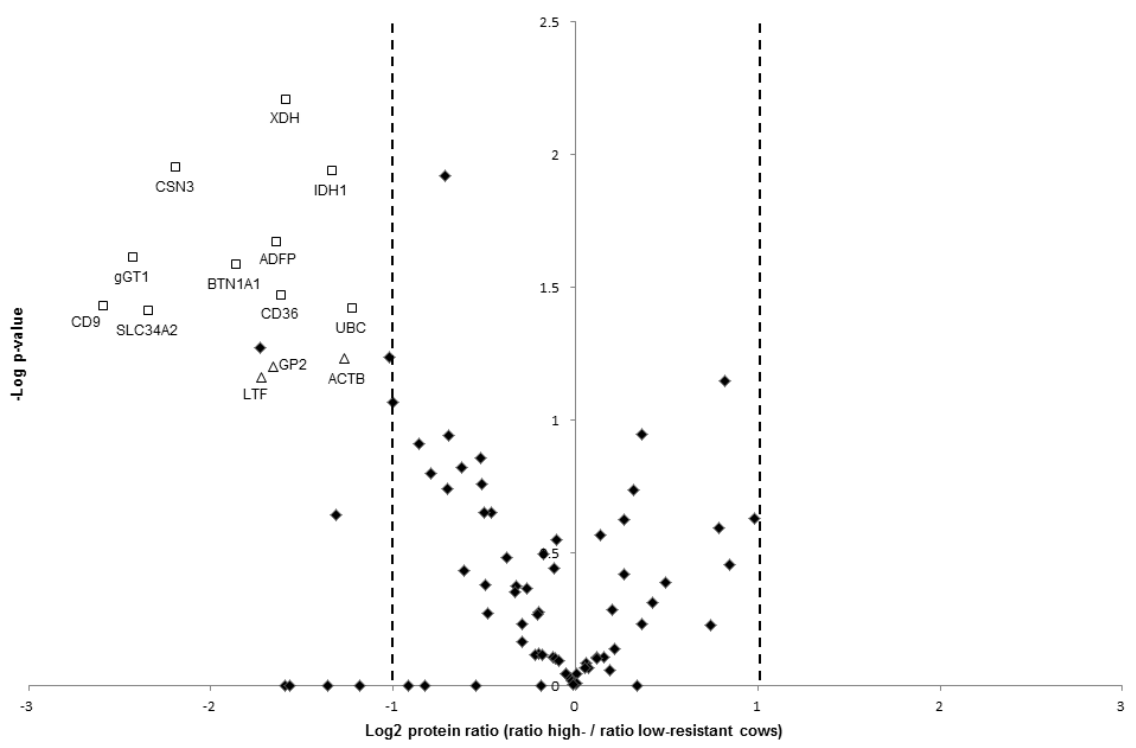

Figure 1: Ratio of milk serum proteins of high- to low-resistant cows

The diamonds, triangles and squares indicate the proteins found in milk serum samples from 4 high- and 4 lowresistant cows $(n=78)$. Proteins are represented as a $\log 2$ ratio of (ratio protein expression in high-resistant cows / protein expression in pooled milk sample) divided by (ratio protein expression in low-resistant cows / protein expression in pooled milk sample). Log2 protein ratios between -1 and 1 are considered as natural variation. Open squares: proteins that differ between high-and low-resistant cows $(\mathrm{p}<0.05)$. Open triangles: proteins that differ between high- and low-resistant cows $(0.05<\mathrm{p}<0.07)$. The abbreviations correspond to the proteins listed in Table 1. 


\section{Selection Potential Biomarkers}

The 13 proteins that differed between high- and low-resistant cows $(\mathrm{p}<0.07)$ were judged for their potential as a biomarker for bovine health. Most proteins were membranebound and were therefore less suitable as a biomarker since sample preparation and protein quantification with a high-throughput technique like ELISA is more difficult (Table 1). We therefore selected two soluble proteins for further investigation: gammaglutamyltranspeptidase 1 (gGT1) and lactoferrin (LF). Gamma-GT1 is an enzyme involved in the Meister glutamyl cycle and is responsible for the transfer of glutathione across the cell membrane to maintain homeostasis [30]. Furthermore, gGT1 levels in blood are related to liver performance and intoxication [31]. Gamma GT1 levels measured in urine can be an indicator for renal damage [32]. The association with disease and damage makes gGT1 in milk an interesting candidate marker for disease resistance. Lactoferrin is a glycoprotein produced by glandular epithelial cells and neutrophils and is present in all body fluids. It is part of the innate immune system and has antimicrobial, antiviral, antifungal, antiinflammatory and anti-oxidative properties, among others by iron sequestering [33, 34] and can also act as an acute phase protein [35].

\section{LF Levels in Milk of High- and Low-Resistant Cows, Selected on Disease Registration Data}

New, full fat milk samples were selected from the "Resilient cattle" biobank to determine if LF and gGT1 were suitable markers for health-related problems in cows. Milk samples of 43 high-resistant cows and 34 low-resistant cows were collected based on comprehensive disease registration data and milk recording data from January 2010 until July 2015. These cows did not have annotations the disease registration data in the month before and after sampling. LF and gGT1 levels were determined using commercially available ELISAs. The gGT1 levels in full fat milk samples were below the detection limit (data not shown) and were therefore not further investigated. Lactoferrin levels were detectable using ELISA and were expressed in $\mu \mathrm{g}$ per ml (Fig. 2). For statistical analysis, the LF levels were $\ln$ transformed and corrected for milk production, days in milk (DIM), age, farm and the interaction between DIM and age as these variables significantly influenced LF levels in milk. No association was found for LF levels and somatic cell counts (data not shown). The least squares means (corrected mean) for LF levels in full fat milk were 244 $\mu \mathrm{g} / \mathrm{ml}$ and $311 \mu \mathrm{g} / \mathrm{ml}$ for high- and low-resistant cows, respectively, and were significantly higher in low-resistant cows $(\mathrm{p}=0.047)$ (Fig. 2). This is consistent with the previous results obtained by NanoLC-MS/MS for the 8 milk serum samples. This implies that being high- or low-resistant is significantly associated with LF levels in full fat milk, even after correction for milk production, DIM, age, farm and the interaction between DIM and age. 


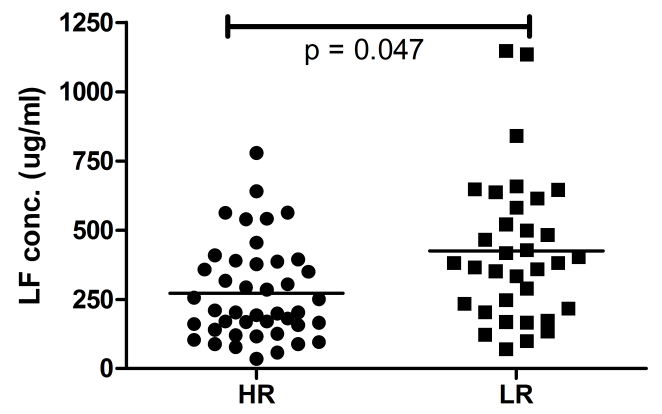

Figure 2: LF levels in full fat milk samples of high- versus low-resistant cows

LF levels were measured in full fat milk samples from 43 high- and 34 low-resistant cows using ELISA. LF levels were expressed as the original LF concentration in $\mu \mathrm{g} / \mathrm{ml}$. The horizontal line indicates the mean. Statistics were performed on the $\ln$ transformed and corrected data. (Correction for farm, 305 days production, age, days in milk (DIM) and the interaction between age and DIM.) LF levels were significantly higher in low-resistant cows than high-resistant cows $(\mathrm{p}=0.047)$.

\section{Association of LF Levels in Milk and Specific Diseases}

Next, we determined if the LF levels in full fat milk were associated with specific classes of diseases, independent of the resistance status of the cows. Cow performance was monitored by disease registration data and milk recording data. Diseases were categorised in: mastitis, other udder problems, lameness, retained placenta, metritis, respiratory diseases, metabolic diseases and "other" (diseases different than the previous categories or e.g. trauma). Cows with high disease resistance had none of the aforementioned health problems, while the low-resistant cows had at least two times an annotation in the disease registration data. Based on disease incidence, the association with LF levels in milk was determined for the following health-related problems in cows: mastitis, metabolic diseases, lameness, metritis and retained placenta (Supplementary Fig. 1).

We did not observe a significant difference in LF levels in milk between cows that had mastitis, metabolic diseases, metritis or a retained placenta in the past and cows without these particular diseases (Supplementary Fig. 1a-d). Nevertheless, cows that had suffered from lameness $(\mathrm{n}=14)$ were significantly different from cows without lameness $(\mathrm{p}=$ 0.024 ) as cows with lameness had higher LF levels in their milk (Supplementary Fig. 1e).

\section{Association of LF levels in Milk with Mastitis and Lameness in High- and Low- Resistant Cows}

Independent of being high- or low-resistant, LF levels were determined with respect to the different diseases. When the high- and low-resistance status was taken into account, the low-resistant cows that had suffered from mastitis showed similar LF levels in milk as the low-resistant cows without mastitis (Fig. 3a). Low-resistant cows with lameness had significantly higher LF levels in milk compared to high-resistant cows without lameness ( $p$ 
$=0.014)$ (Fig. 3b). LF levels appeared to be higher in low-resistant cows that had suffered from lameness compared to low-resistant cows without lameness, although, this difference was not significant $(\mathrm{p}=0.13)$ (Fig. $3 b)$.
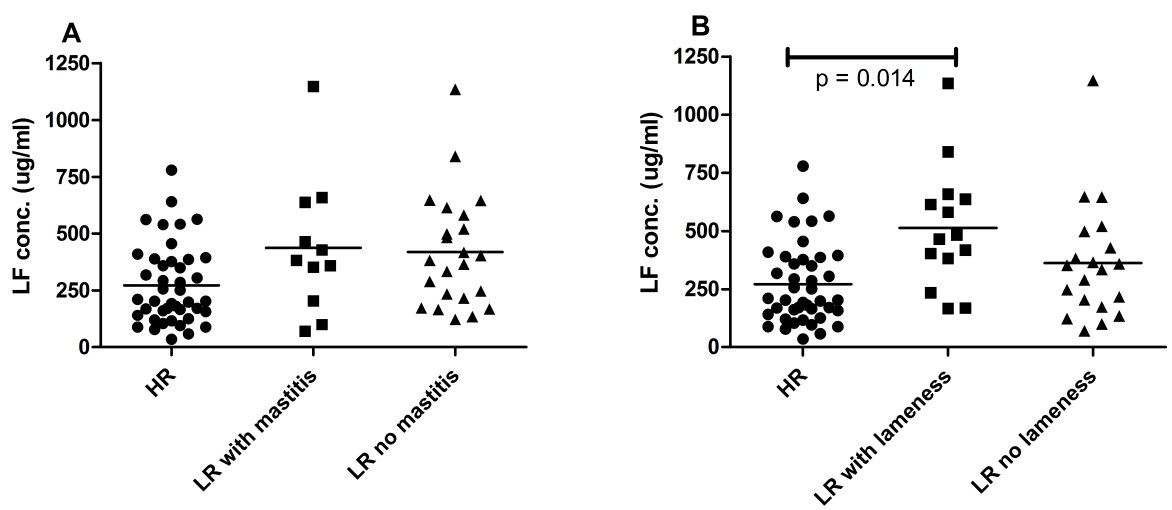

Figure 3: LF levels in full fat milk related to mastitis and lameness

LF levels were determined in full fat milk samples and related to disease thereby comparing high-resistant cows, low-resistant cows which had suffered from a specific disease and low-resistant cows without that particular disease. Individual LF levels were expressed in $\mu \mathrm{g} / \mathrm{ml}$. Statistics were performed on the $\mathrm{ln}$ transformed and corrected data. 3A. High resistant cows, low-resistant cows which had suffered from mastitis and low-resistant cows which had suffered from other diseases than mastitis had similar LF levels in milk. 3B. Low-resistant cows which had suffered from lameness had significantly higher LF levels in milk compared to high-resistant cows $(\mathrm{p}=0.014)$.

\section{Prognostic Value Lactoferrin}

The LF levels were measured in milk samples collected during the summer of 2014. One year later, summer 2015, we investigated which of the high-and low-resistant cows were culled or not as an indicator for cow performance. Figure 4 shows the LF levels in full fat milk of high- and low-resistant cows that were still alive and those that were culled within one year. The low-resistant cows that were culled within one year after sampling had on average higher LF levels (least squares means $=394.0 \mu \mathrm{g} / \mathrm{ml}$ ) than high-resistant cows that were alive $(265.2 \mu \mathrm{g} / \mathrm{ml})$, high-resistant cows that were culled $(166.1 \mu \mathrm{g} / \mathrm{ml})$ and lowresistant cows that were still alive $(288.6 \mu \mathrm{g} / \mathrm{ml})$. This difference was significant between high-resistant cows that were still on the farm and low-resistant cows that were culled within one year $(\mathrm{p}=0.035)$ and between high- and low-resistant cows that were culled ( $\mathrm{p}$ $=0.0017$ ) (Fig. 4). A similar trend was observed for low-resistant cows that were still alive and those that were culled $(\mathrm{p}=0.10)$. In addition, high-resistant cows that were culled had lower LF levels in milk compared to high-resistant cows that were still alive ( $p=$ $0.041)$ and low-resistant cows that were still alive $(p=0.017)$. Taken together, these results indicate that low-resistant cows with higher LF levels had a higher chance of being culled. 


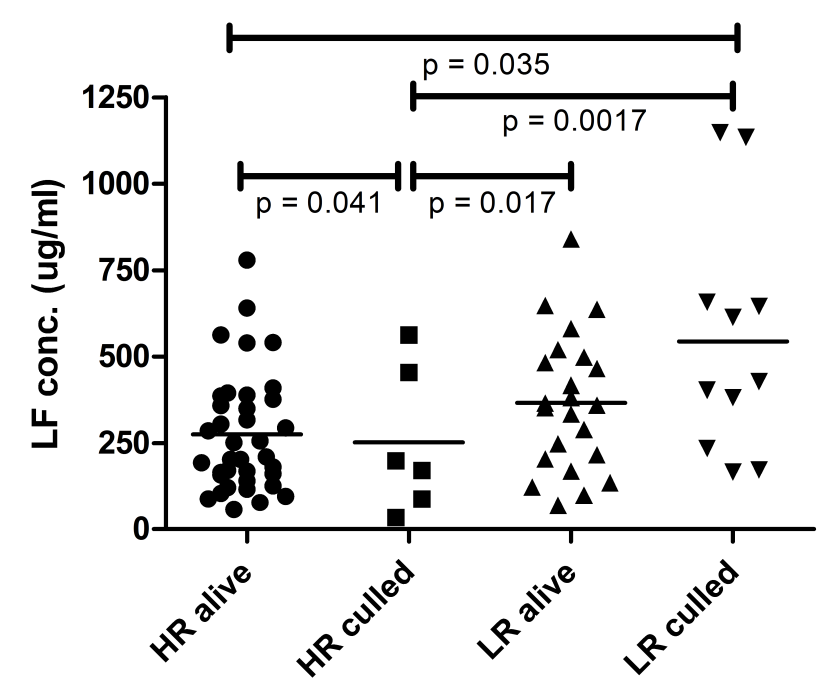

Figure 4: LF levels in full fat milk and culling

To determine the prognostic role of LF, LF levels in milk were related to culling. LF levels in milk were determined in high- and low-resistant cows that were culled or alive one year after sampling. Individual LF levels were expressed in $\mu \mathrm{g} / \mathrm{ml}$. Statistics were performed on the $\ln$ transformed and corrected data. LF levels were lower in high-resistant cows which were culled compared to high-resistant cows that were still alive ( $\mathrm{p}=$ $0.041)$ or low-resistant cows that were still alive $(\mathrm{p}=0.017)$. Low-resistant cows that were culled had higher LF levels in milk than high-resistant cows which were still alive $(\mathrm{p}=0.035)$ or culled $(\mathrm{p}=0.0017)$. 


\section{Discussion}

In this study we identified LF as a putative marker for lameness with prognostic value for early culling. Potential biomarkers were characterised in milk to indicate cows that are at risk to develop disease using a proteomics-based approach. The initial comparison of milk serum samples from 4 high- versus 4 low- disease-resistant cows revealed 13 proteins that were differentially expressed between both groups (ten $p<0.05$ and three $p$ $<0.07)$. These proteins were all more abundantly detected by proteomics in milk serum of low-resistant cows compared to high-resistant cows. Using ELISA we confirmed in a much larger set of full fat milk samples that the levels of one of these proteins, LF, were significantly increased in low-resistant cows. A positive association was observed between LF levels in milk and cows that had suffered from lameness. No significant associations were found for LF levels and metabolic disease, metritis, retained placenta or mastitis. The LF levels were also associated with culling and had a prognostic value for culling as lowresistant cows that were culled within one year had higher LF levels in milk.

The two potential biomarkers, gGT1 and LF, were selected from the proteins that were significantly different between high- and low-resistant cows, because these were soluble proteins which were related to disease in practice and literature. Elevated gGT1 levels in blood is an indicator for cholestasis and liver failure and is already used in practice. In literature, enhanced gGT1 activity in serum of Rathi cattle is a marker for stress and metabolic dysfunction [36]. Increased gGT1 levels in urine were related with renal injury [32]. Additionally, gGT1 levels were used as an indicator for colostrum uptake in young calves and lambs [37]. Unfortunately, the gGT1 levels in milk were below the detection limit of the available capture ELISA, therefore the relevance of gGT1 levels in milk for bovine health could not be determined in this study. LF levels were shown to be significantly higher in low-resistant cows. Lactoferrin has different functions [3335 ] and plays e.g. an important role in the induction of innate immunity by sequestering iron and thereby limiting the availability of free iron, which is essential for bacterial growth. Therefore, it might appear counterintuitive that a protective agent like LF is increased in low-resistant cows, since higher LF levels imply a better protection against disease. However, a similar situation is seen for SCC. A higher SCC is usually caused by an influx of neutrophils in the udder to fight a (starting) bacterial infection [38]. Similar to LF, the higher SCC level helps to control the infection, which is favourable for the cow. At the same time the higher SCC level is an indication of a recent or ongoing infection, which will occur more often in low-resistant cows.

Lactoferrin levels were significantly associated with lameness i.e. cows that had suffered from lameness in the past had higher LF levels in milk. Other studies showed relations between lameness and elevated levels of the acute phase proteins serum amyloid A, haptoglobin and fibrinogen in serum $[39,40]$. However, in our milk samples these proteins were not significantly different in high- and low-resistant cows or were not detected at all by NanoLC-MS/MS (Supplementary data 1), suggesting that LF was not produced due to an acute phase response. As we excluded cows with annotations in the months before and after sampling, this implies that LF could indicate lameness on a long term in contrast to e.g. serum amyloid A which indicates an ongoing infection. 
Lactoferrin in milk is released by neutrophils and epithelial cells and its production is positively related with the influx of neutrophils and SCC [41]. Since SCC were on average equal between high- and low-resistant cows (data not shown), it is less likely that LF levels were increased due to neutrophil infiltration in the udder. Lactoferrin and haptoglobin levels in milk were also associated with the energy status of cows [42]. Cows with higher serum NEFAs levels around parturition, an indicator for increased fat mobilisation and a negative energy balance (NEB), had significantly higher LF and haptoglobin levels in milk for several weeks afterwards. Moreover, cows with more metabolic stress after calving had more health disorders [43]ular, like lameness [44]. In line with this, the low-resistant cows in our study had higher LF levels in milk, suffered at least two times from periparturient diseases, and showed a significant association between LF levels and lameness. Unfortunately, data on the cows' energy status was lacking in our study and a significant association between LF levels in milk and periparturient diseases was not observed (data not shown).

In contrast to other studies, no association was observed between LF levels in milk and SCC [45-47]. However, we selected for cows with SCC below 250.000 cells $/ \mathrm{ml}$ and excluded cows with annotations in the disease registration datain themonth before and aftersampling, thereby excluding an association with mastitis. In addition, we found an increase in CD36, BTN1A1, IDH1 and kappa-casein in milk of low-resistant cows, while others showed these proteins to be decreased in milk from cows with ongoing mastitis $[48,49]$. This supports the notion that the increased LF levels observed in this study were not caused by mastitis.

Initially, we found an association between LF levels and disease-resistance in cows in retrospect, but a prognostic marker for disease-resistance would be more valuable. The prognostic value of LF was studied based on culling rates one year after our analysis. LF levels were significantly higher in low-resistant cows that were culled within one year compared to high-resistant cows. A similar trend was observed comparing low-resistant cows which were culled or still alive. This suggest that LF is an indicator for culling risk and might be a result of repeated health problems. High-resistant cows that were culled within one year surprisingly had significantly lower LF levels compared to the high-resistant cows that were still alive, suggesting that these cows were culled for other reasons than low-resistant cows. Although, it should be taken into account that the number of high-resistant that were culled were low $(n=6)$. Despite the variability in basal LF levels between cows [50] and the short half-life of LF in milk [51], we did show an association between LF levels in milk and lameness and culling. These results warrant larger studies to validate LF as a (prognostic) biomarker for the health status of dairy cattle and the risk of premature culling. 


\section{Conclusion}

In conclusion, using a proteomics approach, we have established a potential biomarker for cows with health problems. Low-resistant cows have higher lactoferrin levels in milk even though these cows were clinically healthy at the moment of sampling. The LF levels were positively associated with lameness and may be a long term indicator for this disease. Moreover, cows with high LF levels were more likely to have been culled one year after sampling, indicating that LF has potential as a prognostic biomarker for premature culling.

\section{Conflict of interest}

RJJvN is an employee of FrieslandCampina. FrieslandCampina was not involved in this study.

\section{Acknowledgement}

This study is part of a joint project Weerbaar Vee, which is funded by the Dutch Ministry of Economic Affairs (The Hague, the Netherlands), Dutch Dairy Product Board ("Productschap Zuivel", Zoetermeer, the Netherlands), Dutch Cooperative Cattle Improvement (CRV, Arnhem, the Netherlands), Dutch Federation of Agriculture and Horticulture ("LTO-Noord Fondsen", Zwolle, the Netherlands), GD Animal Health (Deventer, the Netherlands), and Wageningen University (Wageningen, the Netherlands). The authors also thank the herd owners for their collaboration and Danny de Koning for his excellent support in the statistical analysis of the data. 


\section{References}

1. CRV, Jaarstatistieken: MPR statistiek 2015.

2. Santman-Berends, I.M.G.A., et al., An estimation of the clinical mastitis incidence per 100 cows per year based on routinely collected herd data. Journal of Dairy Science, 2015. 98(10): p. 6965-6977.

3. Hogeveen, H., K. Huijps, and T. Lam, Economic aspects of mastitis: New developments. New Zealand Veterinary Journal, 2011. 59(1): p. 16-23.

4. Weaver, M.D.J., G.S.; Steiner, A., Lameness, in Bovine Surgery and Lameness. 2007, Blackwell Publishing Ltd. p. 208-268.

5. Huxley, J.N., Impact of lameness and claw lesions in cows on health and production. Livestock Science, 2013. 156(1-3): p. 64-70.

6. $\quad$ LeBlanc, S.J., et al., Major Advances in Disease Prevention in Dairy Cattle. Journal of Dairy Science, 2006. 89(4): p. 1267-1279.

7. van Knegsel, A.T., et al., Natural antibodies related to energy balance in early lactation dairy cows. J Dairy Sci, 2007. 90(12): p. 5490-8.

8. Ingvartsen, K.L. and K. Moyes, Nutrition, immune function and health of dairy cattle. Animal, 2013. 7(Supplements1): p. 112-122.

9. Ospina, P.A., et al., Evaluation of nonesterified fatty acids and $\beta$-hydroxybutyrate in transition dairy cattle in the northeastern United States: Critical thresholds for prediction of clinical diseases. Journal of Dairy Science, 2010. 93(2): p. 546-554.

10. Holtenius, K., et al., Metabolic parameters and blood leukocyte profiles in cows from herds with high or low mastitis incidence. The Veterinary Journal, 2004. 168(1): p. 65-73.

11. Moyes, K.M., et al., Identification of potential markers in blood for the development of subclinical and clinical mastitis in dairy cattle at parturition and during early lactation. Journal of Dairy Science, 2009. 92(11): p. 5419-5428.

12. Eckersall, P.D., et al., Acute Phase Proteins in Bovine Milk in an Experimental Model of Staphylococcus aureus Subclinical Mastitis. Journal of Dairy Science, 2006. 89(5): p. 1488-1501.

13. Eckersall, P.D. and R. Bell, Acute phase proteins: Biomarkers of infection and inflammation in veterinary medicine. The Veterinary Journal, 2010. 185(1): p. 23-27.

14. Ceciliani, F., et al., Acute phase proteins in ruminants. Journal of Proteomics, 2012. 75(14): p. 4207-4231.

15. Eckersall, P.D., et al., Acute phase proteins in serum and milk from dairy cows with clinical mastitis. Veterinary Record, 2001. 148(2): p. 35-41.

16. Hiss, S., et al., Haptoglobin and lactate dehydrogenase measurements in milk for the identification of subclinically diseased udder quarters. Veterinarni Medicina, 2007. 52(6): p. 245-252.

17. Åkerstedt, M., et al., Natural variation in biomarkers indicating mastitis in healthy cows. Journal of Dairy Research, 2011. 78(01): p. 88-96.

18. Hettinga, K., et al., The host defense proteome of human and bovine milk. PLoS One, 2011. 6(4): p. e19433.

19. Nissen, A., et al., Expanding the bovine milk proteome through extensive fractionation. J Dairy Sci, 2013. 96(12): p. 7854-66.

20. Boehmer, J.L., et al., The proteomic advantage: label-free quantification of proteins expressed in bovine milk during experimentally induced coliform mastitis. Vet Immunol Immunopathol, 2010. 138(4): p. 252-66.

21. Ferreira, A.M., et al., The mammary gland in domestic ruminants: A systems biology 
perspective. Journal of Proteomics, 2013. 94: p. 110-123.

22. Sampimon, O., et al., Effect of coagulase-negative staphylococci on somatic cell count in Dutch dairy herds. J Dairy Res, 2010. 77(3): p. 318-24.

23. Zhang, L., et al., Bovine Milk Proteome in the First 9 Days: Protein Interactions in Maturation of the Immune and Digestive System of the Newborn. PLoS ONE, 2015. 10(2): p. e0116710.

24. Wisniewski, J.R., et al., Universal sample preparation method for proteome analysis. Nat Methods, 2009. 6(5): p. 359-62.

25. Lu, J., et al., Filter-aided sample preparation with dimethyl labeling to identify and quantify milk fat globule membrane proteins. J Proteomics, 2011. 75(1): p. 34-43.

26. Boersema, P.J., et al., Multiplex peptide stable isotope dimethyl labeling for quantitative proteomics. 2009. 4(4): p. 484-494.

27. Zhang, L., et al., A proteomic perspective on the changes in milk proteins due to high somatic cell count. J Dairy Sci, 2015a. 98(8): p. 5339-51.

28. Cox, J. and M. Mann, MaxQuant enables high peptide identification rates, individualized ppb-range mass accuracies and proteome-wide protein quantification. Nature biotechnology, 2008. 26(12): p. 1367-1372.

29. Cox, J., et al., Andromeda: a peptide search engine integrated into the MaxQuant environment. Journal of proteome research, 2011. 10(4): p. 1794-1805.

30. Meister, A.a. and M.E. Anderson, Glutathione. Annual Review of Biochemistry, 1983. 52(1): p. 711-760.

31. Pompella, A., et al., $\gamma$-Glutamyltransferase, redox regulation and cancer drug resistance. Current Opinion in Pharmacology, 2007. 7(4): p. 360-366.

32. Ferguson, M.A., V.S. Vaidya, and J.V. Bonventre, Biomarkers of nephrotoxic acute kidney injury. Toxicology, 2008. 245(3): p. 182-193.

33. García-Montoya, I.A., et al., Lactoferrin a multiple bioactive protein: An overview. Biochimica et Biophysica Acta (BBA) - General Subjects, 2012. 1820(3): p. 226-236.

34. Kanwar, J.R., et al., Multifunctional Iron Bound Lactoferrin and Nanomedicinal Approaches to Enhance Its Bioactive Functions. Molecules, 2015. 20(6): p. 9703-9731.

35. Tothova, C., et al., Acute phase proteins and their use in the diagnosis of diseases in ruminants: a review. Vet Med-Czech, 2014. 59: p. 163-180.

36. Kataria, N. and A. Kataria, Use of serum gamma glutamyl transferase as a biomarker of stress and metabolic dysfunctions in Rathi cattle of arid tract in India. Journal of Stress Physiology \& Biochemistry, 2012. 8(3).

37. Maden, M., et al., Blood and colostrum/milk serum gamma-glutamyltransferase activity as a predictor of passive transfer status in lambs. J Vet Med B Infect Dis Vet Public Health, 2003. 50(3): p. 128-31.

38. Paape, M., et al., Defense of the bovine mammary gland by polymorphonuclear neutrophil leukocytes. J Mammary Gland Biol Neoplasia, 2002. 7(2): p. 109-21.

39. Kujala, M., T. Orro, and T. Soveri, Serum acute phase proteins as a marker of inflammation in dairy cattle with hoof diseases. Vet Rec, 2010. 166(8): p. 240-1.

40. Tóthová, C., et al., The influence of hoof diseases on the concentrations of some acute phase proteins and other variables of the protein profile in heifers. Acta veterinaria, 2011. 61(2-3): p. 141-150.

41. Lindmark-Månsson, H., et al., Relationship between somatic cell count, individual leukocyte populations and milk components in bovine udder quarter milk. International Dairy Journal, 2006. 16(7): p. 717-727.

42. Hiss, S., et al., Short communication: Relationship between metabolic status and the 
milk concentrations of haptoglobin and lactoferrin in dairy cows during early lactation. Journal of Dairy Science, 2009. 92(9): p. 4439-4443.

43. Gross, J., et al., Performance and metabolic profile of dairy cows during a lactational and deliberately induced negative energy balance with subsequent realimentation. Journal of Dairy Science, 2011. 94(4): p. 1820-1830.

44. Collard, B.L., et al., Relationships between energy balance and health traits of dairy cattle in early lactation. J Dairy Sci, 2000. 83(11): p. 2683-90.

45. Cheng, J.B., et al., Factors Affecting the Lactoferrin Concentration in Bovine Milk. Journal of Dairy Science, 2008. 91(3): p. 970-976.

46. Liu, G., et al., Canonical correlation of milk immunoglobulins, lactoferrin concentration and Dairy Herd Improvement data of Chinese Holstein cows. Livestock Science, 2010. 128(1-3): p. 197-200.

47. Chaneton, L., et al., Milk lactoferrin in heifers: Influence of health status and stage of lactation. Journal of Dairy Science, 2013. 96(8): p. 4977-4982.

48. Moyes, K.M., et al., Gene network and pathway analysis of bovine mammary tissue challenged with Streptococcus uberis reveals induction of cell proliferation and inhibition of PPAR $\gamma$ signaling as potential mechanism for the negative relationships between immune response and lipid metabolism. BMC genomics, 2009. 10(1): p. 542.

49. Huang, J., et al., iTRAQ-proteomics and bioinformatics analyses of mammary tissue from cows with clinical mastitis due to natural infection with Staphylococci aureus. BMC genomics, 2014. 15(1): p. 839.

50. Stelwagen, K., et al., Immune components of bovine colostrum and milk. J Anim Sci, 2009. 87(13 Suppl): p. 3-9.

51. Kutila, T., et al., Disposition kinetics of lactoferrin in milk after intramammary administration. J Vet Pharmacol Ther, 2002. 25(2): p. 129-33. 

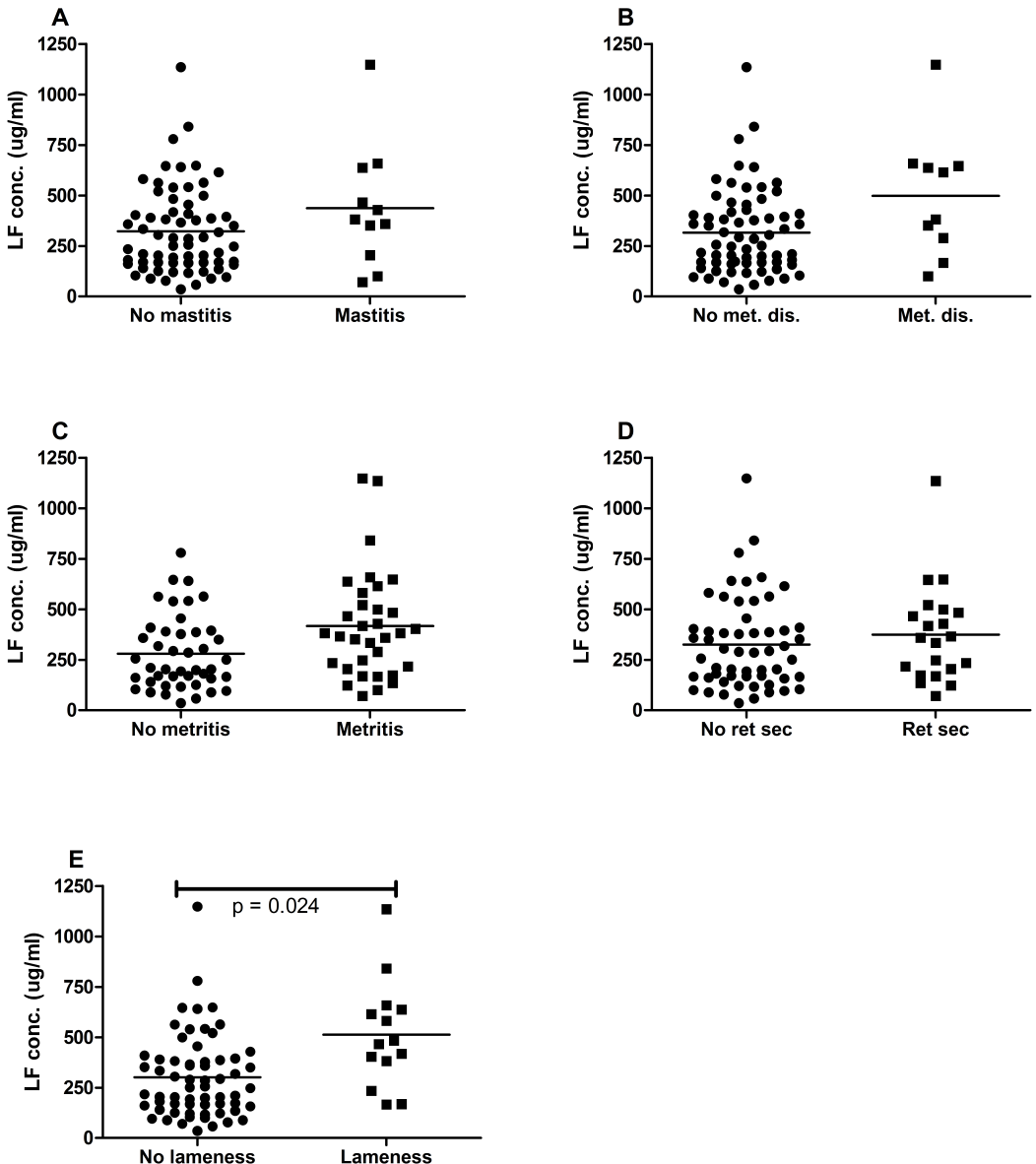

Supplementary figure 1: LF levels in full fat milk and associations with disease

The relevance of individual diseases on LF levels in full fat milk was determined by comparing the LF levels in cows with a particular disease versus all other cows. (High- and low-resistance classification was not taken into account.) Individual LF levels in milk were expressed in $\mu \mathrm{g} / \mathrm{ml}$. The horizontal line indicates the mean. Statistics were performed on the $\ln$ transformed and corrected data. Diseases were classified into: A. mastitis, B. metabolic diseases (met. dis.), C. metritis, D. retained placenta (ret sec) and E. lameness. Cows which had suffered from mastitis, metabolic diseases, metritis or retained placenta were not significantly different from the other cows. However, cows which had suffered from lameness had significant higher LF levels in milk $(\mathrm{p}=0.024)$. 


\section{Table}

Table 1: Milk serum proteins that differ between high- and low-resistant cows

\begin{tabular}{|c|c|c|c|c|c|}
\hline Protein & Full name & Uniprot ID & $\begin{array}{l}\text { Subcellular } \\
\text { location }\end{array}$ & $\begin{array}{l}\text { Fold } \\
\text { change }\end{array}$ & p-value \\
\hline CD9 & CD9 antigen & P30932 & M & 6.0 & 0.037 \\
\hline GGT1 & $\begin{array}{l}\text { Uncharacterised protein; } \\
\text { Gamma-glutamyl transpeptidase 1, gamma- } \\
\text { glutamyltransferase } 1\end{array}$ & G3N2D8 & $\mathrm{M}, \mathrm{S}$ & 5.4 & 0.024 \\
\hline SLC34A2 & $\begin{array}{l}\text { Solute carrier family } 34 \text { (sodium-dependent } \\
\text { phosphate transport protein } 2 \mathrm{~B} \text { ) member } 2\end{array}$ & F1N6D4 & M & 5.1 & 0.039 \\
\hline CSN3 & Casein kappa & P02668 & $\mathrm{E}$ & 4.6 & 0.011 \\
\hline BTN1A1 & Butyrophilin subfamily 1 member A1 & P18892 & M & 3.6 & 0.026 \\
\hline LTF & Lactotransferrin & P24627 & $\mathrm{E}, \mathrm{S}$ & 3.3 & 0.069 \\
\hline GP2 & $\begin{array}{l}\text { Uncharacterised protein; Glycoprotein } 2 \text {, } \\
\text { zymogen granule membrane, pancreatic } \\
\text { secretory granule membrane major } \\
\text { glycoprotein }\end{array}$ & F1N726 & $\mathrm{E}, \mathrm{S}$ & 3.1 & 0.063 \\
\hline $\begin{array}{l}\text { PLIN2 / } \\
\text { ADFP }\end{array}$ & $\begin{array}{l}\text { Perilipin 2, adipophilin, adipose } \\
\text { differentiation-related protein }\end{array}$ & F1N1N6 & M & 3.1 & 0.021 \\
\hline CD36 & $\begin{array}{l}\text { CD36 molecule, platelet glycoprotein IV, } \\
\text { thrombospondin receptor }\end{array}$ & P26201 & M & 3.1 & 0.034 \\
\hline $\mathrm{XDH}$ & Xanthine dehydrogenase/oxidase & F1MUT3 & $\mathrm{C}, \mathrm{E}$ & 3.0 & 0.006 \\
\hline IDH1 & Isocitrate dehydrogenase 1 (NADP+) & Q9XSG3 & $\mathrm{C}$ & 2.5 & 0.011 \\
\hline ACTB & Actin, cytoplasmic 1 & P60712 & $\mathrm{C}$ & 2.4 & 0.060 \\
\hline UBC & Polyubiquitin & $\mathrm{P} 0 \mathrm{CH} 28$ & $\mathrm{C}$ & 2.3 & 0.037 \\
\hline
\end{tabular}

$\mathrm{C}=$ cytosol, $\mathrm{E}=$ extra-cellular space, $\mathrm{M}=$ membrane, $\mathrm{S}=$ secreted 


\section{Supplementary table}

Table 1: Proteins identified in milk serum samples from 4 high- and 4 low-resistant cows using NanoLC-MS/MS

\begin{tabular}{|c|c|c|}
\hline Uniprot ID & Protein name & Gene name \\
\hline P80195 & Glycosylation-dependent cell adhesion molecule 1 & GLYCAM1 \\
\hline Q3SZR3 & Alpha-1-acid glycoprotein & ORM-like \\
\hline G5E5H7 & Uncharacterized protein & PAEP \\
\hline E1BGW1 & Mucin-15 & MUC15 \\
\hline Q3ZCH5 & Zinc-alpha-2-glycoprotein & AZGP1 \\
\hline F1N3Q7 & Apolipoprotein A-IV & APOA4 \\
\hline Q2KJF1 & Alpha-1B-glycoprotein & A1BG \\
\hline O46375 & Transthyretin & TTR \\
\hline Q0IIA2 & Odorant-binding protein-like & MGC151921 \\
\hline Q03247 & Apolipoprotein E & APOE \\
\hline $\mathrm{P} 02754$ & Beta-lactoglobulin & LGB \\
\hline Q0IIH5 & Nucleobindin 2 & NUCB2 \\
\hline E1BH06 & Uncharacterized protein & LOC617696 \\
\hline P50448 & Factor XIIa inhibitor & $\mathrm{N} / \mathrm{A}$ \\
\hline F1MXP8 & Proactivator polypeptide & PSAP \\
\hline P31096 & Osteopontin & SPP1 \\
\hline F1MSZ6 & Antithrombin-III & SERPINC1 \\
\hline Q3ZBZ1 & $45 \mathrm{kDa}$ calcium-binding protein & SDF4 \\
\hline F1MH40 & Uncharacterized protein & Bt.57604 \\
\hline Q32KV6 & Nucleotide exchange factor SIL1 & SIL1 \\
\hline P00711 & Alpha-lactalbumin & LALBA \\
\hline Q3MHN2 & Complement component C9 & C9 \\
\hline P15497 & Apolipoprotein A-I & APOA1 \\
\hline P81187 & Complement factor B & CFB \\
\hline G8JKW7 & Uncharacterized protein & SERPINA3 \\
\hline A8YXY3 & $15 \mathrm{kDa}$ selenoprotein & SEP15 \\
\hline P12763 & Alpha-2-HS-glycoprotein & AHSG \\
\hline Q0P569 & Nucleobindin-1 & NUCB1 \\
\hline A6QR11 & Protein kinase C-binding protein & NELL2 \\
\hline F1MPE1 & Uncharacterized protein & CD109 \\
\hline P17690 & Beta-2-glycoprotein 1 & $\mathrm{APOH}$ \\
\hline F1N5M2 & Vitamin D-binding protein & GC \\
\hline P10790 & Fatty acid-binding protein, heart & FABP3 \\
\hline P08037 & Beta-1,4-galactosyltransferase 1 & B4GALT1 \\
\hline F1MBN5 & Folate receptor alpha & FOLR1 \\
\hline P02666 & Beta-casein & $\mathrm{CSN} 2$ \\
\hline Q9MZ06 & Fibroblast growth factor-binding protein 1 & FGFBP1 \\
\hline
\end{tabular}




\begin{tabular}{|c|c|c|}
\hline P80025 & Lactoperoxidase & LPO \\
\hline Q29443 & Serotransferrin & $\mathrm{TF}$ \\
\hline Q2KIS7 & Tetranectin & CLEC3B \\
\hline A6QNL0 & Monocyte differentiation antigen CD14 & CD14 \\
\hline P34955 & Alpha-1-antiproteinase & SERPINA1 \\
\hline E1BND5 & Uncharacterized protein & NCOA6 \\
\hline P01044 & Kininogen-1 & KNG1 \\
\hline P12799 & Fibrinogen gamma-B chain & FGG \\
\hline F1N045 & Complement component $\mathrm{C} 7$ & $\mathrm{C} 7$ \\
\hline A1L528 & RAB1A, member RAS oncogene family & RAB1A \\
\hline P17697 & Clusterin & CLU \\
\hline F1MLW7 & Uncharacterized protein & IGLL1 \\
\hline P79345 & Epididymal secretory protein E1 & NPC2 \\
\hline A5PJE3 & Fibrinogen alpha chain & FGA \\
\hline G3X7A5 & Complement $\mathrm{C} 3 \mathrm{~b}$ alpha chain & $\mathrm{C} 3$ \\
\hline P02662 & Alpha-S1-casein & CSN1S1 \\
\hline F1MAV0 & Fibrinogen beta chain & FGB \\
\hline P81265 & Polymeric immunoglobulin receptor & PIGR \\
\hline P11151 & Lipoprotein lipase & LPL \\
\hline P02663 & Alpha-S2-casein & CSN1S2 \\
\hline F6R3I5 & Uncharacterized protein & CRISP3 \\
\hline P19120 & Heat shock cognate $71 \mathrm{kDa}$ protein & HSPA8 \\
\hline $\mathrm{P} 0 \mathrm{CH} 28$ & Polyubiquitin-C & $\mathrm{UBC}$ \\
\hline P60712 & Actin, cytoplasmic 1 & ACTB \\
\hline F1MXX6 & Lactadherin & MFGE8 \\
\hline Q9XSG3 & Isocitrate dehydrogenase [NADP] cytoplasmic & IDH1 \\
\hline G5E5V1 & Uncharacterized protein & N/A \\
\hline Q05927 & 5-nucleotidase & NT5E \\
\hline P61823 & Ribonuclease pancreatic & RNASE1 \\
\hline F1MUT3 & Xanthine dehydrogenase/oxidase & $\mathrm{XDH}$ \\
\hline P26201 & Platelet glycoprotein 4 & CD36 \\
\hline F1N1N6 & Perilipin-2 & PLIN2 \\
\hline F1N726 & Uncharacterized protein & GP2 \\
\hline P24627 & Lactotransferrin & LTF \\
\hline Q2KJ93 & Cell division control protein 42 homolog & $\mathrm{CDC} 42$ \\
\hline P18892 & Butyrophilin subfamily 1 member A1 & BTN1A1 \\
\hline P02668 & Kappa-casein & CSN3 \\
\hline F1N6D4 & Sodium-dependent phosphate transport protein $2 \mathrm{~B}$ & SLC34A2 \\
\hline G3N2D8 & Uncharacterized protein & GGT1 \\
\hline P30932 & CD9 antigen & CD9 \\
\hline
\end{tabular}




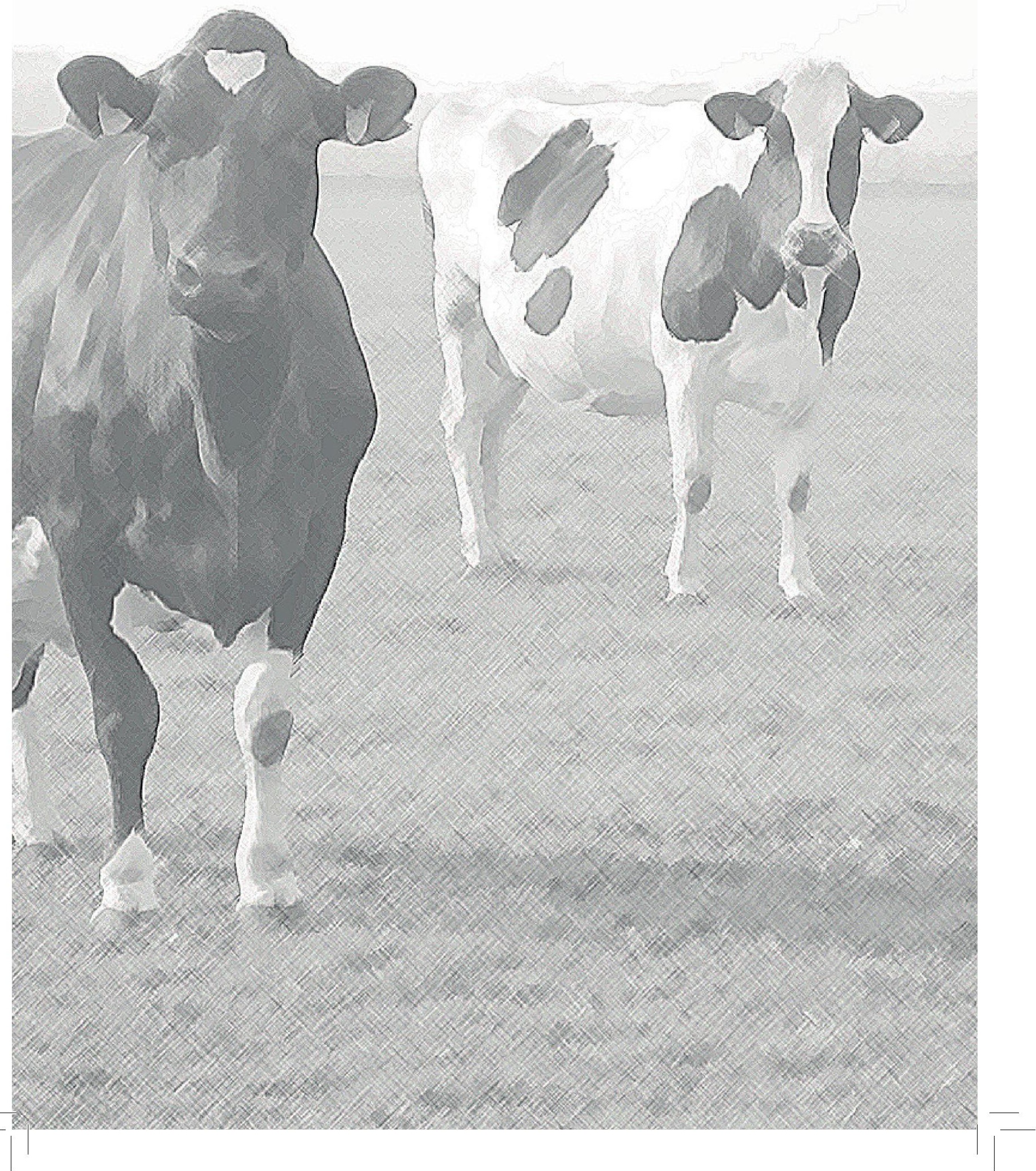




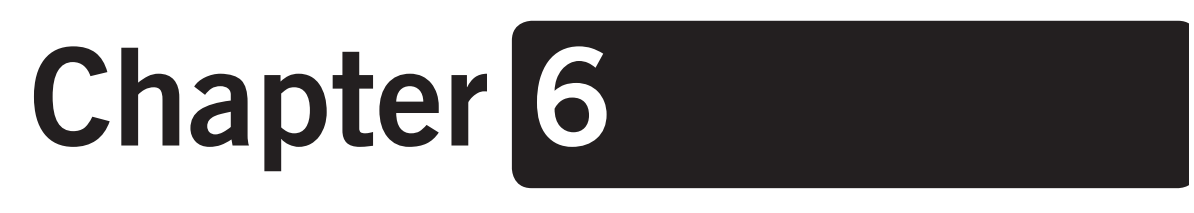

General Discussion 


\section{General discussion}

The aim of this thesis was to study biomarkers and mechanisms of disease resistance in dairy cows. The milk production on dairy farms is strongly increased and is associated with an increase in health problems in dairy cows. As the use of antibiotics is restricted, it is important to improve disease resistance as an alternative to prevent cows from falling ill. In this thesis, we studied known and identified new (candidate) biomarkers for disease resistance. A true prognostic biomarker indicates cows at risk for disease and offers the opportunity to adapt the management of these cows at risk for disease and prevent them from developing disease. Such biomarkers can additionally be used as an early selection tool to rear calves with a better disease resistance that eventually become high disease resistant dairy cows. One such a candidate biomarker that is used in our research are Natural Antibodies (NAbs). In chapter 4, we studied the role of NAbs in the bovine immune system in terms of bacterial recognition and killing. These NAbs are produced by B-1 cells, a B-cell subset. Basic immunological aspects of these B-1 cells are reviewed in chapter 2. We identified these bovine B-1 cells and their functional capacity in chapter 3. We also performed initial studies to the potential of these B-1 cells to be used as an alternative marker for disease resistance, which might be implemented at a young age. An alternative approach to identify new biomarkers for disease resistance in milk is based on proteomics and this is described in chapter 5. In chapter 6 (General Discussion), we elaborate on the potential biomarkers that were described in this thesis with a focus on NAbs as indicated by IgM antibodies binding to KLH. Furthermore, the $\operatorname{IgM}^{++} \mathrm{pSYK}^{++}$ B-1 cells are compared to the previously described $\mathrm{CD}^{++-} \mathrm{CD} 11 \mathrm{~b}^{+}$cells and their role in the bovine immune system is discussed. Lastly, the difference between high and low disease resistance cows is investigated based on the differences in the milk proteome.

\section{Biomarkers}

In this thesis, we studied existing and newly selected biomarkers associated with disease in dairy cows. A biomarker is defined as a biological characteristic that can be objectively measured as an indicator of normal biologic processes, or a response to a therapeutic or husbandry and diet-based intervention. Biomarkers are used for diagnosis and staging of disease, and as indicators of disease prognosis. Most diseases in dairy cows occur in the periparturient period and are also called production diseases as they have a strong association with high milk production and energy balance of the cows [1]. Such potential biomarkers are studied in this thesis, including:

- B-1 cells and serum NAb levels to indicate general disease resistance

- Serum bactericidal test as a prognostic test for presence of (sub)clinical mastitis

- Lactoferrin levels in milk as indicator for lameness and risk of culling in the near future

These potential biomarkers are not yet recognised to be useful in daily management of dairy cows. A biomarker should display the following characteristics: specific, be measurable in an easy, consistent and robust manner, variable between cows and over time, and repeatable 
within cows $[2,3]$. Here I discuss to what extent the candidate biomarkers studied in this thesis meet the criteria of a biomarker for disease resistance.

\section{Serum Natural Antibody levels as indicator for general disease resistance}

Two types of antibodies derived from different subsets of B-cells exist: natural antibodies (NAbs) produced by B-1 cells, which is present in an organism without prior antigenic contact and is part of the first-line innate defence; and specific antibodies (SpAbs) produced by B-2 cells, which develops after antigenic challenge. NAbs have a significant function in maintaining tissue homeostasis, promoting phagocytic clearance of apoptotic cells and preventing infectious and autoimmune diseases, and in recognizing and removing cancer cells [4]. Natural Antibodies, represented by anti-KLH IgM antibodies, were suggested to be a candidate biomarker for disease resistance in dairy cows before [2]. The author showed that NAbs can be conveniently measured in serum and in milk using ELISA, underscoring that NAb levels are variable between cows and repeatable within cows [5]. Additionally, NAbs were suggested to be related with the risk of developing clinical mastitis in heifers with a good udder health history, whereby higher NAb levels in milk appear to be protective against the development of clinical mastitis [2]. However, when studying heifers this association was only a trend and not a significant correlation, and thus the association between NAbs and natural disease resistance still had to be established. The observed trend was, however, in line with studies in mice and chicken and underscored a protective role for NAbs [6, 7]. In a small dataset consisting of cows with high $(\mathrm{n}=20)$ or low $(\mathrm{n}=20)$ serum NAbs levels (Chapter 4$)$, the measured KLH-binding NAb levels were associated with mastitis, lameness and periparturient diseases using PCA statistical analysis. In this group of cows, periparturient diseases covered metritis, placenta retention and metabolic diseases. From our results it is clear that having high or low serum NAbs was not associated with diseases the cows had suffered from in the past period. However, analysis on the whole "Resilient Cattle" biobank (by I. den Uijl) showed that NAb levels measured in one milk sample before calving was indicative for the risk of periparturient diseases after calving. In this case, higher NAb levels were associated with a higher risk of future health problems (data not published). In line with these results, milk NAb levels were positively correlated with plasma levels of non-esterified fatty acids (NEFA), which is an indicator for lipolysis and a negative energy balance (NEB) [8]. In contrast, plasma $\mathrm{NAb}$ levels were negatively correlated with plasma NEFA levels [9]. All together, these data show ambiguous relations between NAbs and several aspects of disease resistance and it cannot be concluded that NAbs are a true biomarker for disease resistance under all conditions. It appears that different factors, such as disease history, presence in plasma or milk, influence the relationship of NAb levels with disease resistance which impacts on their use as single marker in practical management of dairy cows.

\section{B-1 cells as indicator for general disease resistance}

Subsequently, B-1 cells, being responsible for NAb production, were studied as an alternative marker for disease resistance in cows. Also in cows it is not easy to clearly distinguish NAbs and SpAbs, but B-1 and B-2 cells have distinct phenotypes and could 
therefore be related to different immune parameters. In addition, serum NAbs measured in young calves ( $<$ one month) mainly represent maternally-derived NAbs instead of endogenously produced NAbs. Therefore, measuring NAbs in young calves does not accurately indicate the immune competence of the calf itself. In contrast, B-1 cells are of endogenous origin since they are produced mainly before and around birth [10]. For these reasons, numbers and activity of B-1 cells might be a more reliable marker for immune competence than the presence of NAbs per se, which partly consist of maternal antibodies. We identified the B-1 cells in cows (chapter 3 ) and observed that the percentage of B-1 cells is variable between cows (personal observations). In chapter 3 is shown that B-1 cells in calves appear to increase after colostrum intake (day 4) and stabilise afterwards (day 4 to day 20). Though, the percentages B-1 cells slightly increase in older calves (personal observations). The stability of B-1 cell numbers in adult cows and their value as biomarker for disease resistance is not determined yet. However, B-1 cells can have an added value for selecting young calves as replacement heifers or for the veal industry. It is costly to rear calves to replacement heifers and therefore a suitable test at a young age, in this case $<2$ weeks, would be economically beneficial. B-1 cells could be determined at a young age, though, it is too early to implement B-1 cells as biomarker for disease resistance as prospective cohort studies should first be performed.

\section{Serum bactericidal test as a prognostic test for presence of (sub)clinical mastitis}

Chapter 4 describes the serum bactericidal test for its prognostic value predicting the development of mastitis. This serum bactericidal test is based upon antibody-mediated complement killing. Cows that performed less in the serum bactericidal test, i.e. the serum could only stop bacterial growth at lower dilutions, were more likely to develop mastitis afterwards. This relation was significant for those cows that developed mastitis within one year after blood collection when using E. coli in the bactericidal test. When using $S$. Typhimurium, this relation was significant for even up to 4 years after sampling. As shown in chapter 4 differences between cows were observed and the test has a prognostic value for the development of mastitis. The relation between bacterial killing and mastitis was specific; no or ambiguous relations were found with lameness, production diseases or culling (data not shown). In addition, having high or low serum NAbs as such was not related to bacterial killing. Since we used the same batch of foetal calf serum (FCS) to replace the complement system in each individual serum sample, the relation between bacterial killing and development of mastitis appears to be based on microbial recognition by (total) serum antibodies. Antibody-mediated complement killing is most likely the mechanisms underlying this bacterial killing as heat-inactivated serum was unable to kill bacteria in the absence of complement. In addition, FCS was unable to kill bacteria by itself in the dilution $(1: 10)$ that was used in the bactericidal test. Interestingly, the antibody repertoire in serum and milk is not exactly the same due to selective receptor-mediated transport of antibodies from blood to the udder and local production of antibodies in the udder [11]. Still, the serum bactericidal test does show a predictive value for udder health. The application of this serum bactericidal test in routine screening, however, is still far away due to technical and practical limitations. These issues should be resolved 
as the test is potentially of great value since it is prognostic for up to 4 years. The test needs further standardisation as a constant source of FCS is needed. Furthermore, the effect of age, stage of lactation and other cow-related factors are currently not known and for practical implementation of the serum bactericidal test also cut-off values need to be established. Specifically, it would also be interesting to determine the applicability of the serum bactericidal test in young calves in order to use this test as a selection tool. In short, the serum bactericidal test, despite its current limitations, remains a promising predictive test for the risk to develop mastitis.

\section{Lactoferrin levels in milk as indicator for lameness and risk of culling}

Subsequently, we identified lactoferrin (LF) as a candidate biomarker for lameness and involuntary culling using a contemporary proteomics approach with added bioinformatics analysis (Chapter 5). The comparison of milk samples from high and low disease resistant cows revealed 13 candidate biomarkers. These proteins were more abundant in lowresistant cows than high-resistant cows. We confirmed in a new and larger group of high- and low disease resistant cows selected based on disease registration data and milk recording data that LF was more abundant in low-resistant cows. LF levels are variable between, but also within cows [11] among others due to a short half-life [12]. In addition, LF levels are dependent on the stage of lactation, milk production, age and SCC and are associated with mastitis [13-16]. We also observed an association between individual farm and LF levels, which might be caused by the different environments and infection status on farms. Correction for age, days in milk, production and farm showed that LF levels in milk were higher in cows that suffered from lameness. Despite the pleiotropic roles of LF, this association was not described in literature before. Since LF is not associated with lameness only, but also related to e.g. stage of lactation and mastitis, LF is less suitable as biomarker specific for lameness. More importantly, LF levels were higher in cows that had clinical manifestations of lameness, meaning that lameness was already detected. However, LF had a prognostic value for culling i.e. cows with higher LF levels in milk had a higher risk of being culled within the near future. Due to positive associations of LF levels in milk with disease in general and age, it is very likely that culling is associated with higher LF levels. However, culling of dairy cows is not a good read-out to monitor disease resistance [17] since culling is dependent on various factors such health status, production and management, and, in addition, has a strong economic incentive [18]. The increase of LF levels in milk is associated with mastitis and lameness. Therefore, LF may be a biomarker for health problems in dairy cows instead of disease resistance. LF levels in milk are relatively easy to measure using a commercially available ELISA test, but implementation of LF as biomarker for health problems requires regular monitoring of LF levels in milk with correction for factors such as milk production. Based on our data, a clear cut-off value for LF levels in milk could not yet be determined, but is required to use LF as a biomarker in milk. 
Innate and adaptive immunity: role of B-1 cells and Natural Antibodies in cows

According to the prevailing dogma, also cows have an innate and adaptive immune system with separate mediators and functions. The innate immune system consists of cells such as neutrophils and macrophages, the complement system, cytokines and anti-microbial components, including lactoferrin. Together they can act in a fast way and are able to clear most invading microbes [19]. When the innate immune system is unable to solve a microbial attack, the adaptive immune system is activated. The adaptive immune system mainly consists of SpAbs produced by activated B-2 cells and T-cells (T-helper, T-regulatory and cytotoxic T-cells) (Annex 1 and 2). They act in an antigen-specific manner and develop immunological memory. B-1 cells and NAbs have characteristics of both the innate and adaptive immune system. They could belong to the adaptive immune system like the conventional B-2 cells and SpAbs, however, B-1 cells and NAbs also have clear innate-like functions. B-1 cells produce NAbs without prior antigenic stimulation, these NAbs are directed to common microbial structures and auto-antigens [20]. Therefore, B-1 cells and NAbs are often indicated as a link between innate and adaptive immunity [2123]. Interestingly, also $\gamma \delta$ T-cells act at the borderline of the innate and adaptive immune systems and they can constitute up to $60 \%$ of the PBMCs in newborn calves [24]. In adult cows, $\gamma \delta$ T-cells represent about 10 to $20 \%$ of the circulating lymphocytes, which is still high compared to human and murine $\gamma \delta$ T-cells which represent 5 to $10 \%$ [25]. Both B-1 cells and $\gamma \delta$ T-cells are innate-like lymphocytes which develop during the first wave of immune cell development in the foetus according to the layered immune system theory [26]. B-1 cells are subdivided in B1a and B1b cells and $\gamma \delta$ T-cells can be subdivided in $\mathrm{WC1}^{+}$and $\mathrm{WC1}^{-}$cells. The more "innate-like" B1a cells and $\mathrm{WC}^{+} \gamma \delta$ T-cells recognise a limited repertoire of antigens including self-antigens [22, 27]. B1b cells and $\mathrm{WC}^{-} \gamma \delta$ T-cells are more "adaptive" cells as they both have a broader repertoire, and in addition, $\mathrm{B} 1 \mathrm{~b}$ cells develop T-cell independent memory and $\mathrm{WC1}^{-} \gamma \delta \mathrm{T}$-cells undergo clonal expansion $[27,28]$. B- 1 cells and $\gamma \delta$ T-cells can both take up antigens and induce CD4 ${ }^{+}$ T-cells responses [29-31]. Furthermore, a subset of $\gamma \delta$ T-cells express and produce IL-10 [32], similar to B-1 cells [33]. B-1 cells and $\gamma \delta$ T-cells have similar characteristics, but also interact with each other e.g. NAb production by B-1 cells can be induced by noncognate help of $\gamma \delta$ T-cells [34]. Furthermore, $\gamma \delta$ T-cells regulate B-1 cell numbers by the production of IL-4 [35]. B-1 cells and $\gamma \delta$ T-cells share some characteristics and interact with each other. Therefore it would be interesting to study the interplay between B-1 cells and $\gamma \delta$ T-cells in cows.

\section{Natural antibodies as studied by IgM antibodies binding to KLH}

NAbs (and SpAbs) are studied in cows by determining antibody binding (preferably IgM) to naïve antigens (e.g. KLH), common microbial structures (e.g. LPS) and auto-antigens (e.g. PtC). However, during life cows encounter microbes that express e.g. LPS and also develop SpAbs to common microbial structures. KLH is a large protein derived from haemolymph of the sea mollusc Megathura crenulata, that lives off the Pacific coast [36]. In addition, KLH might share some antigens or show cross-reactivity with snails that cows encounter while grazing on the pasture. More importantly, KLH is a large and highly 
glycosylated protein, which is cross-reactive with phosphorylcholine (PC; hydrophilic, polar head of PtC) and E. coli-derived LPS (O55:B5) [37]. As NAbs in cows were shown to increase with age $[8,38]$, it is questionable if binding to KLH reflects pure NAb levels or rather a combination of NAbs and SpAbs. NAbs (IgM anti-KLH) appear to have a protective role in heifers with a good udder health history, but this trend disappeared with the inclusion of heifers which suffered from udder health problems or by studying multiparous cows [2]. This suggests that IgM antibodies binding to KLH represent a combination of NAbs and SpAbs dependent on the antigens the cow encounters during life. NAbs can still play a protective role, however, over time they are progressively mixed up or even overwhelmed by SpAbs representing "reactive" antibodies as they are produced in response to an antigen. The "Resilient Cattle" dataset showed that cows with higher milk IgM levels binding to KLH before calving had more health problems after calving. This might indicate that cows with higher IgM anti-KLH levels where less able to clear pathogens or were more challenged by pathogens and had more IgM SpAbs that can also bind to KLH. Chapter 4 of this thesis describes that cows with high levels of serum IgM against KLH also show high IgM (and IgG) binding to LPS, LTA, PGN and whole bacteria. In addition, cows with high NAb levels also have higher total IgM levels than cows with low NAb levels. This supports that IgM binding to KLH might not indicate pure NAbs only, but appears to be an indicator for total IgM levels representing a mixture of NAbs and SpAbs. 
A

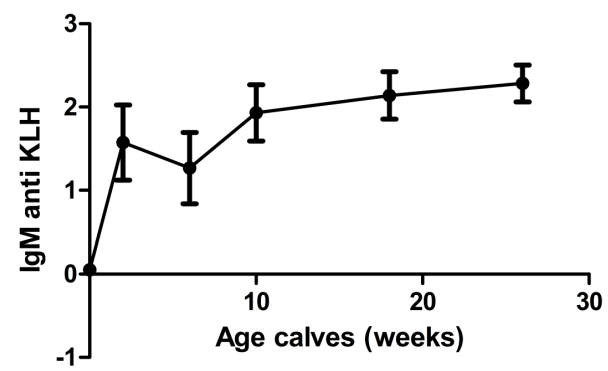

C

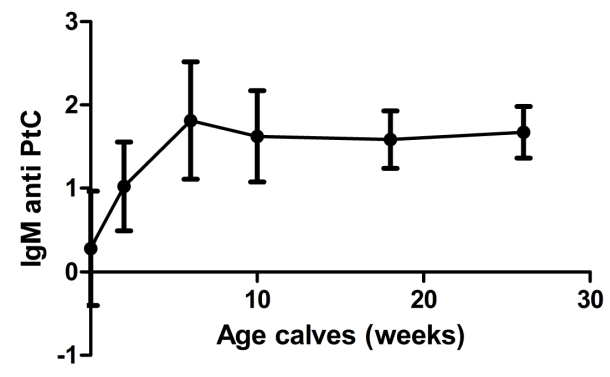

E

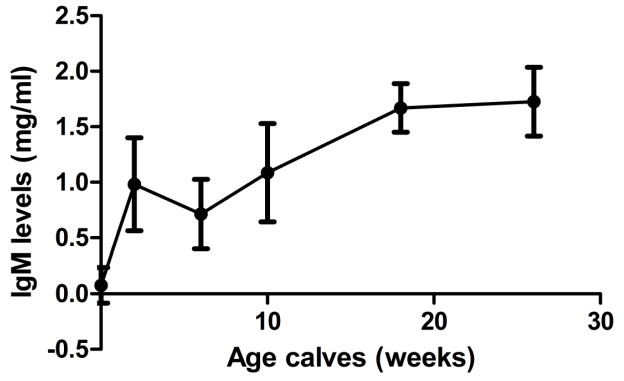

B

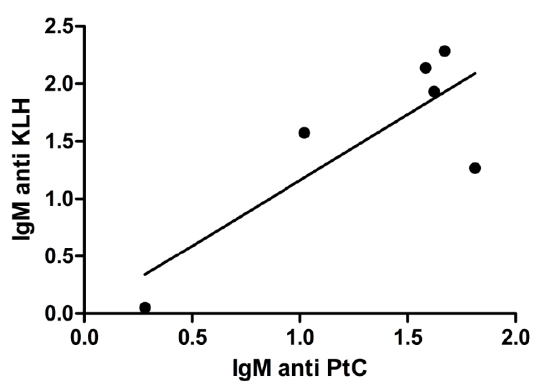

D

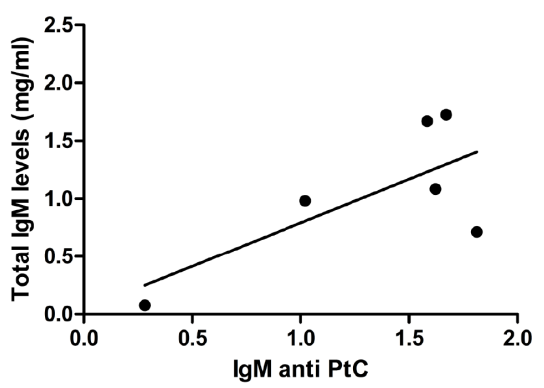

$\mathbf{F}$

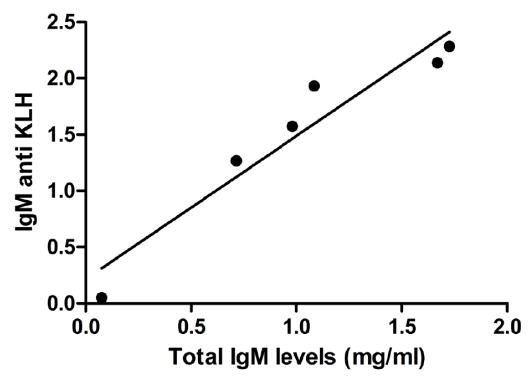

Figure 1: Development of IgM anti KLH, PtC and total IgM levels during the first 6 months of life Left: Serum IgM antibodies binding to KLH and PtC (expressed as OD-value at $450 \mathrm{~nm}$ ) and total IgM levels $(\mathrm{mg} / \mathrm{ml})$ were determined in 15 calves at 0 (before colostrum), 2, 6, 10,18 and 26 weeks of age. The graphs show average values (black dot) with standard deviations (bars) at each time point. Right: The correlation between the average levels of IgM binding to KLH versus IgM binding to PtC at 0, 2, 6, 10, 18 and 26 weeks of age (Pearson $\mathrm{r}=0.812, \mathrm{p}=0.049)$. The same for total IgM levels versus IgM binding to PtC (Pearson $\mathrm{r}=0.711, \mathrm{p}=0.11$ ) and IgM binding to KLH versus total IgM levels (Pearson $r=0.959, p=0.0025)$. 
To test the hypothesis that IgM anti KLH is an indicator for total IgM levels, we studied the development of IgM against KLH, IgM against PtC and total IgM levels in 15 calves before colostrum intake until half a year of age (Figure 1, see also chapter 3). The IgM antibodies binding to PtC and total IgM levels are not significantly related (Pearson $\mathrm{r}=$ $0.711, \mathrm{p}=0.11$ ). IgM binding to KLH and $\operatorname{IgM}$ binding to PtC are related (Pearson $\mathrm{r}=$ $0.812, p=0.049$ ), but the strongest correlation is observed between IgM binding to KLH and total IgM levels (Pearson $r=0.959, p=0.0025$ ). This strong correlation is mainly caused by the clear bimodal development of total $\operatorname{IgM}$ antibodies and $\operatorname{IgM}$ antibodies binding to KLH in calves representing the uptake and breakdown of maternally derived $\operatorname{IgM}$ and the endogenous IgM production. Probably, the difference with IgM binding to $\mathrm{PtC}$ would have been more extreme when the calves were sampled at half a day of age and at 4 weeks of age. These time points represent the peak levels of maternally-derived IgM and the drop in serum IgM levels between maternally-derived $\operatorname{IgM}$ and the initiation of endogenous $\operatorname{IgM}$ production $[39,40]$.

In summary, the cross-reactivity between KLH and common antigens such as LPS [37] and the strong correlation between IgM binding to KLH and total IgM levels imply that IgM against KLH better reflect total IgM levels than NAbs. The inability to distinguish NAbs and SpAbs binding to KLH hampers to determine the role of true NAbs in disease resistance.

\section{Comparison of B-1 cell populations indicated by $\mathrm{CD5}^{+} \backslash \mathrm{CD}^{-} 11 \mathrm{~b}^{+}$and $\operatorname{IgM}^{++} \mathrm{pSYK}^{++}$}

Chapter 2 reviews the literature on B-1 cells in veterinary species and one of the main conclusions is that CD5 and CD11b alone are not suitable markers to identify B-1 cells in cows. Therefore, other markers described for B-1 cells in other species were used to test for their capacity to identify B-1 cells in cows: $\operatorname{IgM}^{++} \mathrm{pSYK}^{++}$(Chapter 3 ). In mice, a proportion of the $\mathrm{B}-1$ cells is shown to express CD5 and/or CD11b, but additional markers are required for the exact identification of B-1 cells [41, 42]. B-1 cells in mice are enriched in the pleural and peritoneal cavity and represent about $35-70 \%$ of the CD19+ B-cells, while in blood B-1 cells represent only $0.3-0.5 \%$ of the CD19+ B-cells [43]. Within these $\mathrm{B}-1$ cells, the presence between $\mathrm{CD} 5$ determines the difference between $\mathrm{B} 1 \mathrm{a}$ and $\mathrm{B} 1 \mathrm{~b}$ cells. The ratio of $\mathrm{B} 1 \mathrm{a}\left(\mathrm{CD}^{+} \mathrm{CD} 11 \mathrm{~b}^{+}\right)$and $\mathrm{B} 1 \mathrm{~b}\left(\mathrm{CD} 5-\mathrm{CD} 11 \mathrm{~b}^{+}\right)$cells is approximately 2:1 [44].

In an experiment using seven adult cows, the overlap between the previously used $\mathrm{CD}^{+} / \mathrm{CD} 11 \mathrm{~b}^{+}$markers and our newly defined markers $\operatorname{IgM}^{++} \mathrm{pSYK}^{++}$were assessed in blood (Figure 2). About $50 \%$ of the $\mathrm{IgM}^{++} \mathrm{pSYK}^{++}$cell population turned out to be $\mathrm{CD}^{+}$ indicating a proportion of $\mathrm{B} 1 \mathrm{a}$ and $\mathrm{B} 1 \mathrm{~b}$ cells of $1: 1$ (Figure $2 \mathrm{a}$ ). When using both CD5 and $\mathrm{CD} 11 \mathrm{~b}$, this reveals $42 \% \mathrm{CD}^{+} \mathrm{CD} 11 \mathrm{~b}^{+} \mathrm{B} 1 \mathrm{a}$ cells and $24 \% \mathrm{CD} 5-\mathrm{CD} 11 \mathrm{~b}^{+} \mathrm{B} 1 \mathrm{~b}$ cells, resulting in a proportion of approximately $2: 1 \mathrm{~B} 1 \mathrm{a}$ versus B1b cells (Figure 2b), which is similar to mice [44]. Furthermore, this indicates an incomplete (about 66\%) overlap between the $\mathrm{CD}^{+} / \mathrm{CD}^{-} 1 \mathrm{~b}^{+}$and $\mathrm{IgM}^{++} \mathrm{pSYK}{ }^{++} \mathrm{B}-1$ cell populations. The other $34 \%$ of the B-1 cells identified by $\operatorname{IgM}^{++} \mathrm{pSYK}^{++}$is $\mathrm{CD} 11 \mathrm{~b}-$, which might be explained by the loss of CD11b by B-1 cells after leaving the peritoneal cavity as shown in mice [45], although this is, as yet, speculation. Comparing the $\mathrm{CD}^{+} / \mathrm{CD}^{-} 1 \mathrm{~b}^{+}$and $\mathrm{IgM}^{++} \mathrm{pSYK}^{++}$cell populations the other way around reveals that $\operatorname{IgM}^{++} \mathrm{pSYK}^{++}$cells represent only $23 \%$ of the B-1 cells indicated by $\mathrm{CD}^{+} / \mathrm{CD}^{-} 1 \mathrm{~b}^{+}$(Figure $2 \mathrm{c}$ ). This indicates that the overlap between the 
previously used (murine) markers to identify bovine B-1 cells and our putative B-1 cells in cows is low. One important reason is that we observed much lower percentages of putative B-1 cells in blood when using our marker combination as compared to using the $\mathrm{CD}^{+} /-\mathrm{CD} 11 \mathrm{~b}^{+}$markers, i.e. $6 \%$ versus $35 \%$ of PBMCs [46], respectively. In humans adults, the $\mathrm{CD} 20^{+} \mathrm{CD} 27^{+} \mathrm{CD} 43^{+} \mathrm{B}-1$ cell population represents $12.7 \%$ of the $\mathrm{CD} 20^{+} \mathrm{B}$-cells and within this B-1 population the ratio B1a versus B1b cells is 3:1 [47]. In addition, the $\mathrm{CD} 20^{+} \mathrm{CD} 27^{+} \mathrm{CD} 43^{+} \mathrm{B}-1$ cell population represents about $33 \%$ of the $\mathrm{CD} 20^{+} \mathrm{CD}^{+}$cell population. This suggests a larger overlap using the human and murine markers (33\%) as compared to our study between bovine and murine $(23 \%)$ markers. However, CD11 b was unfortunately not included in the comparison between human and murine markers. Our results show that identification of B-1 cells by $\operatorname{IgM}^{++} \mathrm{pSYK}^{++}$results in a ratio B1a/ $\mathrm{B} 1 \mathrm{~b}$ cells comparable to mice, however, the percentage of total bovine B-1 cells is more comparable to those in humans.

A

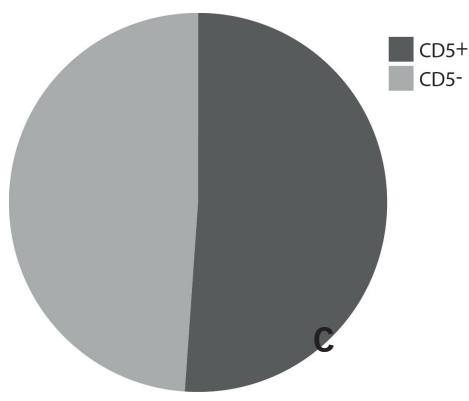

B

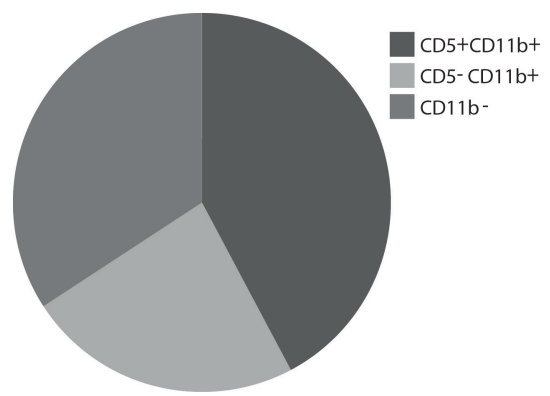

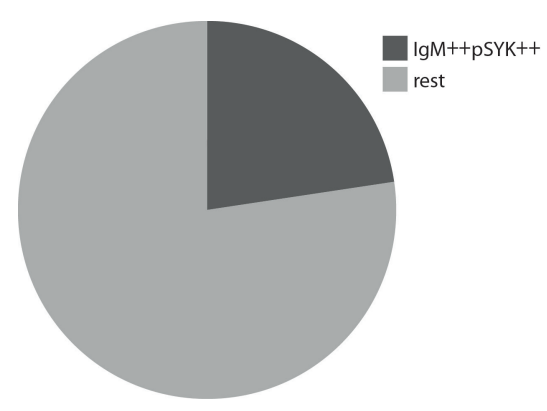

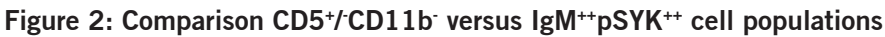

B-1 cells were indicated before using CD5 and CD11b and subdivided into B1a CD5 ${ }^{+} \mathrm{CD} 11 \mathrm{~b}^{+}$and B1b CD5$\mathrm{CD}_{11} \mathrm{~b}^{+}$cells. We identified putative B-1 cells using $\mathrm{IgM}^{++} \mathrm{pSYK}^{++}$. Figure $2 \mathrm{a}$ shows the proportion of $\mathrm{CD}^{+}$ and $\mathrm{CD}^{-}$cells within the $\mathrm{IgM}^{++} \mathrm{pSYK}^{++} \mathrm{B}-1$ population. Figure $2 \mathrm{~b}$ indicates the overlap between the B-1 cell populations as specified by $\operatorname{IgM}^{++} \mathrm{pSYK}^{++}$. Figure $2 \mathrm{c}$ shows the overlap between the B-1 cell populations as 
specified by $\mathrm{CD}^{+} / \mathrm{CD} 11 \mathrm{~b}^{+}$. (Pictures based on the average percentage of B-1 cells in 7 adult cows.)

\section{High versus low disease resistant cows}

Chapter 5 describes the identification of additional biomarkers for natural disease resistance in cows. The initial division into high and low disease resistant cows was based on the opinion of the farmers, which inevitably is not purely objective. Additional features of cows, such as production and individual character, might have affected the farmers ' decision. However, the farmer has daily contact with the cows and will have a total view of the herd. Due to inclusion of additional data obtained from disease registration and milk recording data, the farmers' bias was reduced in the final selection for high and low disease resistant cows. It is questionable if the cows are really "low" disease resistant since they are still in production and not already culled. In general, about $80 \%$ of the cows are culled for health-related reasons [48], emphasising the importance of health status in dairy cows. Probably, the comparison between high versus low disease resistant cows made in chapter 5 was better defined by high versus moderate disease resistant cows.

Table 1

\begin{tabular}{ll}
\hline Cellular function & Proteins involved \\
\hline Lipid metabolism & APOE, SERPING1, APOA4, NCOA6, APOH, APOA1, XDH, CLU, BTN1A1, \\
& PMP2, CDC42, IDH1, LF, PLIN2, LPL, CFB, FABP4, SERPINA1, FABP3, GC, \\
& TTR, C3, SPP1, AHSG, CD36, LALBA, SLC34A2, GGT1, AZGP1, HSPA8, \\
& KNG1, SERPINC1, CD9, B4GALT1, NUCB2, CD14, PSAP, NPC2 \\
\hline Molecular & APOE, APOA4, APOH, NCOA6, APOA1, XDH, CLU, FOLR2, PMP2, BTN1A1, \\
transport & CDC42, IDH1, LF, PLIN2, LPL, CFB, FABP4, FABP3, GC, TTR, C3, SPP1, \\
& RAB13, AHSG, RAB10, CD36, RAB8A, LALBA, SLC34A2, AZGP1, PIGR, \\
& FOLR1, HSPA8, KNG1, SERPINC1, ORM1, TF, B4GALT1, CSN2, CD14, NUCB2, \\
& PSAP, NPC2 \\
\hline Small molecule & APOE, SERPING1, APOA4, NCOA6, APOH, APOA1, XDH, CLU, FOLR2, \\
biochemistry & BTN1A1, PMP2, CDC42, IDH1, LF, PLIN2, LPL, CFB, FABP4, SERPINA1, \\
& FABP3, GC, TTR, SPP1, C3, LPO, AHSG, CD36, LALBA, SLC34A2, GGT1, \\
& AZGP1, FOLR1, HSPA8, KNG1, SERPINC1, TF, CD9, B4GALT1, NT5E, PSAP, \\
& NUCB2, CD14, NPC2 \\
\hline
\end{tabular}

The top three functions of the milk proteins obtained by proteomics were determined using Ingenuity and listed in Table 1. The bold abbreviations indicate the proteins that were significantly different between the high and low disease resistant dairy cows as identified by proteomics.

To put the proteomics results in a broader perspective, the proteins obtained were analysed using the Ingenuity networking software. The milk proteins that are most differentially expressed between high and low resistant cows as detected by proteomics, were, based on this network analysis, functionally involved in lipid metabolism, molecular transport and small molecule biochemistry. This is not surprisingly based on the high metabolic activity in the udder [49]. The lipid metabolism is an important issue in dairy farming as it is associated with the (negative) energy balance of cows (Figure 3). Under homeostatic 
conditions, the feed intake of dairy cows meets the energy requirements for the cows' maintenance and milk production. However, after calving cows develop a NEB due to decreased dry matter intake (DMI) and increased milk production [50]. This energy deficit is "solved" by lipid mobilisation from the peripheral tissues [51]. The NEB lasts about 8 weeks implying a high demand on the bovine metabolism [52]. During the NEB, also the lipid metabolism in the udder changes [53,54]. Milk fat is derived from the diet or body fat (mostly long-chain fatty acids $\geq 16$ carbons) or locally synthesised by mammary epithelial cells (mostly short-chain fatty acids $\leq 16$ carbons) [55]. Body fat accounts for less than $10 \%$ of the fatty acids in milk fat, but can increase proportionally with a NEB. We did not measure the milk fat composition in high- and low-resistant cows, but found proteins involved in lipid metabolism which were significantly more abundant in low-resistant cows $(\mathrm{p}<0.07)$. These proteins are xanthine dehydrogenase/oxidase $(\mathrm{XDH})$, butyrophilin (BTN1A1), cell division control protein 42 homolog (CDC42), isocitrate dehydrogenase [NADP] cytoplasmic (IDH1), lactoferrin (LF), perilipin-2 or adipophilin (PLIN2 or ADFP), platelet glycoprotein 4 (CD36), sodium-dependent phosphate transport protein 2B (SL34A2), gamma-glutamyltransferase 1 (GGT1) and CD9 antigen (CD9). (Table 1). CD36 is present on mammary epithelial cells and is involved in uptake and translocation of dietary and body fat-derived fatty acids to the udder [56]. Isocitrate dehydrogenase is a key enzyme in the de novo fatty acid synthesis in the bovine udder [57]. Butyrophilin, adipophilin and xanthine dehydrogenase/oxidase are involved in the formation of lipid droplets in milk [58, 59]. The increased abundance of CD36, IDH1, BTN1A1, XDH and ADFP in milk from low-resistant cows compared to high-resistant cows suggests increased (de novo) lipogenesis in low-resistant cows. This is consistent with increased lipid droplet formation by cells in response to oxidative stress [60,61]. Oxidative stress and weight loss are enhanced in the periparturient period due to a higher metabolic rate and lipolysis [62]. Furthermore, weight loss by lipolysis increases the levels of plasma NEFAs, which repress immune functioning [63]. In vitro studies show that NEFAs increase the levels of CD36 mRNA in mammary epithelial cells and is also accompanied by an increase in lipid droplet formation [56]. A persistent NEB increases both NEFAs and BHBA, the last one is a substrate for de novo fatty acid synthesis [64]. The increase of proteins involved in de novo lipogenesis in low-resistant cows might therefore be caused by a failure to maintain their energy balance, which is accompanied by e.g. increased oxidative stress. Since the cows included in this study passed the transition period, their decreased disease resistance might be related to metabolism and oxidative stress levels of the cows [65], suggesting an inability to return to homeostasis during their lactation. 


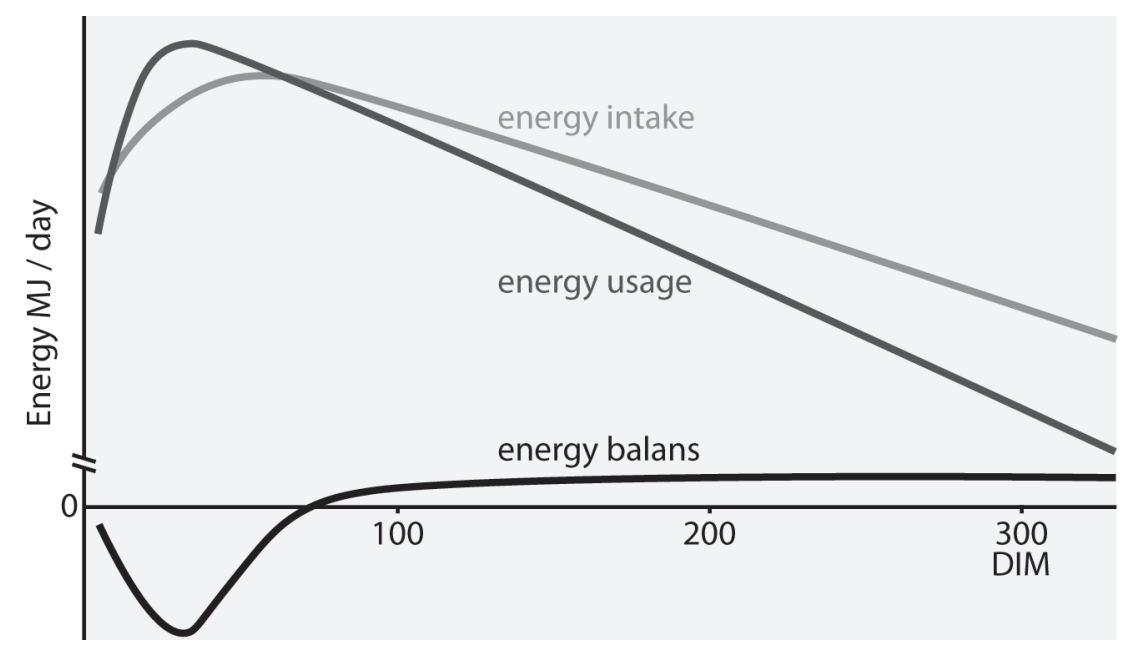

Figure 3: Energy balance of dairy cows

The energy balance of dairy cows depends on the energy intake by feed intake and energy usage for selfmaintenance and milk production. At peak lactation, the energy intake does not meet the energy usage leading to a NEB, which lasts for approximately the first 8 weeks of lactation. Later in lactation the energy balance stabilises since the cow needs extra energy for her growing calf during pregnancy.

Also, the elevated levels of gGT1 and LF in low-resistant cows fit the theory of increased oxidative stress in these animals. On the one hand, gGT1 contributes to the antioxidant defence mechanism of cells by maintaining the intracellular glutathione levels, while on the other hand gGT1 has been shown to induce oxidative stress by the catabolism of glutathione [66, 67]. In Rathi cows, serum gGT1 levels were shown to be an indicator for (oxidative) stress and metabolic dysfunction e.g. caused by acidosis [68]. LF has antioxidative properties by metal binding, e.g. iron, thereby preventing lipid oxidation [69]. gGT1 can be a cause or a result of oxidative stress, however, these data suggest that gGT1 and LF are produced in response to oxidative stress to prevent damage.

The phosphate transporter SLC34A2, better known as NaPi-IIb, is suggested to be a mammary gland differentiation marker in cows [70]. In goats is shown that SLC34A2 is responsible for the phosphate reuptake into mammary epithelial cells and its expression is dependent on the phosphate requirements for ATP synthesis [71]. Interestingly, the SLC34A2 expression in the murine intestine is upregulated by metabolic acidosis in order to adjust to homeostasis [72]. Unfortunately, SLC34A2 expression was not determined in the mammary gland. In cows, metabolic acidosis is accompanied by oxidative stress [73]. So, increased SLC34A2 expression due to oxidative stress would fit the theory that lowresistant cows have metabolic problems and increased oxidative stress levels.

Based on the Proteomics results and available literature, the difference between the highand low- disease resistant cows appears mostly to be related to the energy balance of the cows. The low-resistant cows appear to be unable to reach a stable homeostasis during 
their lactation making the cows more vulnerable to develop disease. In cows, the energy balance, diet and immune system are strongly related $[8,74,75]$ and a deficiency in one will have consequences for the other two. Naturally, additional factors such as genetics and management of the cows will play a role too.

\section{Future recommendations}

When studying bovine health and immune system, it is important to realise that dairy cows do not represent a "normal" physiological situation, but more that of a well-trained athlete [76]. The dairy cows' metabolism is primed at converting feed into milk and in early lactation milk production precedes at the expense of the cows' maintenance, which is reflected by a NEB [77] (Figure 3). Another important feature is the status of immunosuppression around calving [78], which is characterised by e.g. reduced migration and killing by neutrophils $[79,80]$ making the cows vulnerable to bacterial infections. Natural immunosuppression occurs due to hormonal changes, among others by an increase in glucocorticoids such as cortisol around calving [81]. In addition, cows have low serum glucose levels after parturition, which is the main fuel for immune cells [78]. After calving, the high energy requirements lead to more ROS production, lipolysis and NEB which exaggerate the immunosuppressive status of the cow $[65,78,82]$. So, even when a cow has a perfect immune system, she will have a harsh time around calving and therefore, not surprisingly, most diseases occur in the periparturient period. It is a challenging period for the cow and farmer and requires adequate management. Future research into bovine disease resistance and identification and use of biomarkers should therefore focus at this period, because there is still room for improvement and substantial (economic) gain. It is important to be able to determine the cows at risk before disease occurs, which indicates the need for prognostic biomarkers. Interestingly, some cows are more vulnerable to develop disease than other cows and investigation of the differences between those individual cows would be a good starting point, as we applied in chapter 5 . We compared the protein presence and abundance in milk samples of only 4 high- and 4 low-disease resistant cows, but a higher number of cows would be appreciated. During the "Resilient Cattle" project a biobank is established consisting of milk and serum samples and disease registration and milk recording data. From this biobank, the high- and lowdisease resistant cows could be selected as these cows "proved" their disease resistance during the last years. As milk composition can strongly differ due factors such as feed, stage of lactation and breed [83], a strict selection of cows is recommended.

Our study has provided suitable markers for bovine B-1 cell identification thereby permitting basic immunological studies into the formation of NAbs, their regulation at perinatal age and their potential relation to resilience against infections and predictive value for the development of future diseases. Studying B-1 cells in cows is quite a challenge due to the lack of commercially available tools. The staining for IgM and internal pSYK using flow cytometry discriminates B-1 cells from other cells, but this protocol is not easy to implement in routine screening. Therefore the use of B-1 cells as a potential biomarker is not achievable at this moment and an easier screening methods for B-1 cells are recommended. The use of surface expressed markers to identify 
bovine B-1 cells would improve the screening of B-1 cells and gives the opportunity to determine NAb production by individual B-1 cells. B-1 and B-2 cells could be FACS sorted using the current IgM and pSYK markers in order to perform transcriptomics and determine unique surface markers for both cell populations. In this way, B-1 cell numbers and activity (i.e. NAb production) could be monitored in the periparturient period to determine the relation between B-1 cells and disease resistance in dairy cows.

Lactoferrin levels in milk as biomarker for disease resistance is still an interesting candidate due to its relation with mastitis, lameness and subsequent involuntary culling, but also by its applicability. We expect a similar relation of LF levels with infectious diseases as SSC has with mastitis. SSC are increased with mastitis and, although this is a normal physiological reaction to fight against invading microbes, high SSC are not preferred in practice. Also LF appears to increase as a physiological reaction to mastitis and (probably) infectious forms of lameness. Therefore, it would be worthwhile to implement the detection and quantification of LF levels in milk in an automated milking system to gain more knowledge on the (circadian) rhythm, basic levels and differences within and between cows in LF levels. In addition, by inclusion of disease registration data, the relationship between LF levels and the development of disease could be determined more precisely. Deviations in milk LF levels could be an early indicator for disease in individual cows.

We focussed on biomarkers for disease resistance in dairy cows which are already in lactation. However, it would be ideal to be able to select high-resistant dairy cows at a young age since rearing a calf is costly and prediction of its health development would be of great value. Therefore, longitudinal prospective studies are warranted to determine biomarkers or factors in young calves that are related to high disease resistant cows. It is important to record health and performance of the individual animals with disease registration data and milk recording data, but also data on e.g. growth. In the context of this thesis, B-1 cell numbers or activity, as reflected by the production of NAbs, could be determined at a regular basis in a large group of calves from birth to adulthood. These data on B-1 cells and NAbs could then be related to disease resistance in dairy cows as reflected by the annotations in the disease registration data. 


\section{In conclusion}

Determining the role of NAbs in the bovine immune system

We determined that cows with high serum NAb levels, represented by IgM binding to $\mathrm{KLH}$, also show a higher binding to common microbial structures (including PtC) and whole bacteria. This implies that cows with high NAbs are better in recognising invading microbes. However, this hypothesis could not be confirmed in the serum bactericidal test, which was based upon antibody-mediated complement killing. It is still possible that cows with high NAbs are better at fighting microbes via other routes. Additionally, we showed that the serum bactericidal test is a predictive test for the risk of mastitis.

\section{Identification of bovine B-1 cells and their relevance to NAb production}

B-1 cells in cows are identified using the markers $\operatorname{IgM}^{++} \mathrm{pSYK}^{++}$. This staining results in a distinct cell population in calves and cows. Young calves $(<3$ weeks) have about $1 \%$ of B-1 cells (from PBMCs) in blood, while adult cows have about 6\% B-1 cells. In young calves, the percentage of B-1 cells correlated with the levels of IgM antibodies binding to phosphatidylcholine. In contrast, IgM antibodies binding to KLH showed a different age-related kinetics.

Identification of alternative biomarkers for disease resistance in bovine milk using proteomics

Using Proteomics, several candidate biomarkers were identified in milk that were more abundant in low-resistant cows. We confirmed in an independent set of milk samples that LF is more abundant in low-disease resistant cows. In addition, LF levels were associated with lameness and were predictive for the risk of culling. 


\section{References}

1. Mulligan, F.J. and M.L. Doherty, Production diseases of the transition cow. The Veterinary Journal, 2008. 176(1): p. 3-9.

2. Ploegaert, T.C.W., Parameters for natural resistance in bovine milk. 2010.

3. Bosch, R.J., X. Zhang, and N.G. Sandler, Study design issues in evaluating immune biomarkers. Curr Opin HIV AIDS, 2013. 8(2): p. 147-54.

4. Ehrenstein, M.R. and C.A. Notley, The importance of natural IgM: scavenger, protector and regulator. Nature Reviews Immunology, 2010. 10(11): p. 778-786.

5. Ploegaert, T.C., et al., Natural antibodies in bovine milk and blood plasma: variability among cows, repeatability within cows, and relation between milk and plasma titers. Vet Immunol Immunopathol, 2011. 144(1-2): p. 88-94.

6. Boes, M., et al., A critical role of natural immunoglobulin $M$ in immediate defense against systemic bacterial infection. The Journal of experimental medicine, 1998. 188(12): p. 2381-2386.

7. Star, L., et al., Natural humoral immune competence and survival in layers. Poult Sci, 2007. 86(6): p. 1090-9.

8. $\quad$ van Knegsel, A.T., et al., Natural antibodies related to energy balance in early lactation dairy cows. J Dairy Sci, 2007. 90(12): p. 5490-8.

9. $\quad$ van Knegsel, A.T., et al., Natural antibodies related to metabolic and mammary health in dairy cows. Prev Vet Med, 2012. 103(4): p. 287-97.

10. Montecino-Rodriguez, E. and K. Dorshkind, B-1 B cell development in the fetus and adult. Immunity, 2012. 36(1): p. 13-21.

11. Stelwagen, K., et al., Immune components of bovine colostrum and milk. J Anim Sci, 2009. 87(13 Suppl): p. 3-9.

12. Kutila, T., et al., Disposition kinetics of lactoferrin in milk after intramammary administration. J Vet Pharmacol Ther, 2002. 25(2): p. 129-33.

13. Hagiwara, S., et al., Lactoferrin concentrations in milk from normal and subclinical mastitic cows. J Vet Med Sci, 2003. 65(3): p. 319-23.

14. Cheng, J.B., et al., Factors Affecting the Lactoferrin Concentration in Bovine Milk. Journal of Dairy Science, 2008. 91(3): p. 970-976.

15. Liu, G., et al., Canonical correlation of milk immunoglobulins, lactoferrin concentration and Dairy Herd Improvement data of Chinese Holstein cows. Livestock Science, 2010. 128(1-3): p. 197-200.

16. Chaneton, L., et al., Milk lactoferrin in heifers: Influence of health status and stage of lactation. Journal of Dairy Science, 2013. 96(8): p. 4977-4982.

17. Fetrow, J., K.V. Nordlund, and H.D. Norman, Invited review: Culling: nomenclature, definitions, and recommendations. J Dairy Sci, 2006. 89(6): p. 1896-905.

18. Beaudeau, F., et al. Effect of health disorders on culling in dairy cows: a review and a critical discussion. in Annales de zootechnie. 2000. EDP Sciences.

19. Bertoni, G., A. Minuti, and E. Trevisi, Immune system, inflammation and nutrition in dairy cattle. Animal Production Science, 2015. 55(7): p. 943-948.

20. Avrameas, S., Natural autoantibodies: from 'horror autotoxicus' to 'gnothi seauton'. Immunol Today, 1991. 12(5): p. 154-9.

21. Ochsenbein, A.F. and R.M. Zinkernagel, Natural antibodies and complement link innate and acquired immunity. Immunol Today, 2000. 21(12): p. 624-30. 
22. Getz, G.S., Bridging the innate and adaptive immune systems. Journal of Lipid Research, 2005. 46(4): p. 619-622.

23. Panda, S. and J.L. Ding, Natural antibodies bridge innate and adaptive immunity. The Journal of Immunology, 2015. 194(1): p. 13-20.

24. Clevers, H., et al., Identification of a bovine surface antigen uniquely expressed on CD4CD8- T cell receptor gamma/delta ${ }^{+}$T lymphocytes. Eur J Immunol, 1990. 20(4): p. 80917.

25. McGill, J.L., et al., The role of gamma delta T cells in immunity to Mycobacterium bovis infection in cattle. Veterinary Immunology and Immunopathology, 2014. 159(3-4): p. 133-143.

26. Mold, J.E. and J.M. McCune, At the crossroads between tolerance and aggression: Revisiting the "layered immune system" hypothesis. Chimerism, 2011. 2(2): p. 35-41.

27. Baldwin, C.L. and J.C. Telfer, The bovine model for elucidating the role of gammadelta $T$ cells in controlling infectious diseases of importance to cattle and humans. Mol Immunol, 2015. 66(1): p. 35-47.

28. Alugupalli, K.R., A distinct role for B1b lymphocytes in T cell-independent immunity. Curr Top Microbiol Immunol, 2008. 319: p. 105-30.

29. Collins, R.A., et al., Gammadelta $T$ cells present antigen to $C D 4^{+}$alphabeta $T$ cells. J Leukoc Biol, 1998. 63(6): p. 707-14.

30. Parra, D., et al., Pivotal advance: peritoneal cavity B-1 B cells have phagocytic and microbicidal capacities and present phagocytosed antigen to $C D 4^{+} T$ cells. J Leukoc Biol, 2012. 91(4): p. 525-36.

31. Holderness, J., et al., Comparative biology of gammadelta T cell function in humans, mice, and domestic animals. Annu Rev Anim Biosci, 2013. 1: p. 99-124.

32. Guzman, E., et al., Bovine $\gamma \delta$ T Cells Are a Major Regulatory T Cell Subset. The Journal of Immunology, 2014. 193(1): p. 208-222.

33. Sindhava, V., et al., Interleukin-10 mediated autoregulation of murine B-1 B-cells and its role in Borrelia hermsii infection. PLoS One, 2010. 5(7): p. e11445.

34. Watanabe, N., et al., Migration and differentiation of autoreactive B-1 cells induced by activated gamma/delta T cells in antierythrocyte immunoglobulin transgenic mice. J Exp Med, 2000. 192(11): p. 1577-86.

35. Huang, Y., et al., $\gamma \delta$ T Cells Shape Preimmune Peripheral B Cell Populations. The Journal of Immunology, 2016. 196(1): p. 217-231.

36. Harris, J.R. and J. Markl, Keyhole limpet hemocyanin (KLH): a biomedical review. Micron, 1999. 30(6): p. 597-623.

37. May, R.J., D.O. Beenhouwer, and M.D. Scharff, Antibodies to Keyhole Limpet Hemocyanin Cross-React with an Epitope on the Polysaccharide Capsule of Cryptococcus neoformans and Other Carbohydrates: Implications for Vaccine Development. The Journal of Immunology, 2003. 171(9): p. 4905-4912.

38. Srinivasan, A., Y. Ni, and I. Tizard, Specificity and prevalence of natural bovine antimannan antibodies. Clin Diagn Lab Immunol, 1999. 6(6): p. 946-52.

39. Husband, A.J., M.R. Brandon, and A.K. Lascelles, Absorption and endogenous production of immunoglobulins in calves. Aust J Exp Biol Med, 1972. 50(4): p. 491-498.

40. Rajala, P. and H. Castrén, Serum immunoglobulin concentrations and health of dairy calves in two management systems from birth to 12 weeks of age. Journal of dairy science, 1995. 78(12): p. 2737-2744. 
41. Hardy, R.R. and K. Hayakawa, B cell development pathways. Annu Rev Immunol, 2001. 19: p. 595-621.

42. Berland, R. and H.H. Wortis, Origins and functions of B-1 cells with notes on the role of CD5. Annu Rev Immunol, 2002. 20: p. 253-300.

43. Baumgarth, N., The double life of a B-1 cell: self-reactivity selects for protective effector functions. Nat Rev Immunol, 2011. 11(1): p. 34-46.

44. Cunningham, A.F., et al., B1b Cells Recognize Protective Antigens after Natural Infection and Vaccination. Frontiers in Immunology, 2014. 5: p. 535.

45. Yang, Y., et al., Division and differentiation of natural antibody-producing cells in mouse spleen. Proceedings of the National Academy of Sciences, 2007. 104(11): p. 4542-4546.

46. Naessens, J. and D.J. Williams, Characterization and measurement of $C D 5^{+} B$ cells in normal and Trypanosoma congolense-infected cattle. Eur J Immunol, 1992. 22(7): p. 1713-8.

47. Griffin, D.O., N.E. Holodick, and T.L. Rothstein, Human B1 cells in umbilical cord and adult peripheral blood express the novel phenotype $C D 20^{+} C D 27^{+} C D 43^{+} C D 70$. J Exp Med, 2011. 208(1): p. 67-80.

48. Hadley, G.L., C.A. Wolf, and S.B. Harsh, Dairy Cattle Culling Patterns, Explanations, and Implications. Journal of Dairy Science, 2006. 89(6): p. 2286-2296.

49. Thivierge, M.C., et al., Variations in Mammary Protein Metabolism During the Natural Filling of the Udder with Milk over a 12-h Period Between Two Milkings: Leucine Kinetics $<$ sup $>1</$ sup $>$. Journal of Dairy Science, 2002. 85(11): p. 2974-2985.

50. Grummer, R.R., D.G. Mashek, and A. Hayirli, Dry matter intake and energy balance in the transition period. Vet Clin North Am Food Anim Pract, 2004. 20(3): p. 447-70.

51. Drackley, J.K., Biology of dairy cows during the transition period: The final frontier? Journal of dairy science, 1999. 82(11): p. 2259-2273.

52. Block, S.S., et al., Decreased concentration of plasma leptin in periparturient dairy cows is caused by negative energy balance. J Endocrinol, 2001. 171(2): p. 339-48.

53. Stoop, W.M., et al., Effect of lactation stage and energy status on milk fat composition of Holstein-Friesian cows. J Dairy Sci, 2009. 92(4): p. 1469-78.

54. Nogalski, Z., et al., The Effect of Body Energy Reserve Mobilization on the Fatty Acid Profile of Milk in High-yielding Cows. Asian-Australas J Anim Sci, 2012. 25(12): p. 171220.

55. Bauman, D.E. and J.M. Griinari, Nutritional regulation of milk fat synthesis. Annual review of nutrition, 2003. 23(1): p. 203-227.

56. Yonezawa, T., et al., Effects of long-chain fatty acids on cytosolic triacylglycerol accumulation and lipid droplet formation in primary cultured bovine mammary epithelial cells. J Dairy Sci, 2004. 87(8): p. 2527-34.

57. Laliotis, G.P., I. Bizelis, and E. Rogdakis, Comparative Approach of the de novo Fatty Acid Synthesis (Lipogenesis) between Ruminant and Non Ruminant Mammalian Species: From Biochemical Level to the Main Regulatory Lipogenic Genes. Current Genomics, 2010. 11(3): p. 168-183.

58. Ogg, S.L., et al., Expression of butyrophilin (Btn1a1) in lactating mammary gland is essential for the regulated secretion of milk-lipid droplets. Proc Natl Acad Sci U S A, 2004. 101(27): p. 10084-9.

59. Lu, J., et al., Identification of lipid synthesis and secretion proteins in bovine milk. J Dairy Res, 2014. 81(1): p. 65-72.

60. Khatchadourian, A. and D. Maysinger, Lipid Droplets: Their Role in NanoparticleInduced Oxidative Stress. Molecular Pharmaceutics, 2009. 6(4): p. 1125-1137. 
61. Lee, S.-J., et al., Mitochondrial Dysfunction Induces Formation of Lipid Droplets as a Generalized Response to Stress. Oxidative Medicine and Cellular Longevity, 2013. 2013: p. 10.

62. Bernabucci, U., et al., Influence of Body Condition Score on Relationships Between Metabolic Status and Oxidative Stress in Periparturient Dairy Cows*. Journal of Dairy Science, 2005. 88(6): p. 2017-2026.

63. Contreras, G.A. and L.M. Sordillo, Lipid mobilization and inflammatory responses during the transition period of dairy cows. Comparative Immunology, Microbiology and Infectious Diseases, 2011. 34(3): p. 281-289.

64. Zhang, M., et al., $\beta$-Hydroxybutyrate Facilitates Fatty Acids Synthesis Mediated by Sterol Regulatory Element-Binding Protein1 in Bovine Mammary Epithelial Cells. Cellular Physiology and Biochemistry, 2015. 37(6): p. 2115-2124.

65. Sordillo, L.M. and S.L. Aitken, Impact of oxidative stress on the health and immune function of dairy cattle. Veterinary Immunology and Immunopathology, 2009. 128(1-3): p. 104-109.

66. Pompella, A., et al., $\gamma$-Glutamyltransferase, redox regulation and cancer drug resistance. Current Opinion in Pharmacology, 2007. 7(4): p. 360-366.

67. Dominici, S., et al., Prooxidant Reactions Promoted by Soluble and Cell-Bound $\gamma$-Glutamyltransferase Activity. Methods in enzymology, 2005. 401: p. 484-501.

68. Kataria, N. and A. Kataria, Use of serum gamma glutamyl transferase as a biomarker of stress and metabolic dysfunctions in Rathi cattle of arid tract in India. Journal of Stress Physiology \& Biochemistry, 2012. 8(3).

69. Satué-Gracia, M.T., et al., Lactoferrin in Infant Formulas: Effect on Oxidation. Journal of Agricultural and Food Chemistry, 2000. 48(10): p. 4984-4990.

70. Baik, M., et al., Gene Expression Profiling of Liver and Mammary Tissues of Lactating Dairy Cows. Asian Australas. J. Anim. Sci, 2009. 22(6): p. 871-884.

71. Muscher, A., G. Breves, and K. Huber, Modulation of apical Na $/$ Pi cotransporter type IIb expression in epithelial cells of goat mammary glands. Journal of Animal Physiology and Animal Nutrition, 2009. 93(4): p. 477-485.

72. Stauber, A., et al., Regulation of intestinal phosphate transport. II. Metabolic acidosis stimulates $\mathrm{Na}\left({ }^{+}\right)$-dependent phosphate absorption and expression of the $\mathrm{Na}\left({ }^{+}\right)-\mathrm{P}(\mathrm{i})$ cotransporter NaPi-IIb in small intestine. Am J Physiol Gastrointest Liver Physiol, 2005. 288(3): p. G501-6.

73. Guo, Y., et al., Changes in feed intake, nutrient digestion, plasma metabolites, and oxidative stress parameters in dairy cows with subacute ruminal acidosis and its regulation with pelleted beet pulp. Journal of Animal Science and Biotechnology, 2013. 4(1): p. 31-31.

74. LeBlanc, S.J., et al., Major Advances in Disease Prevention in Dairy Cattle. Journal of Dairy Science, 2006. 89(4): p. 1267-1279.

75. Ingvartsen, K.L. and K. Moyes, Nutrition, immune function and health of dairy cattle. Animal, 2013. 7(Supplements1): p. 112-122.

76. Opsomer, G., et al., High milk production and good fertility in modern dairy cows: the results of some recent research items. Slov Vet Res, 2006. 43: p. 31-39.

77. Leroy, J.L., et al., Nutrient prioritization in dairy cows early postpartum: mismatch between metabolism and fertility? Reprod Domest Anim, 2008. 43 Suppl 2: p. 96-103.

78. Ingvartsen, K.L. and K.M. Moyes, Factors contributing to immunosuppression in the dairy cow during the periparturient period. Jpn J Vet Res, 2015. 63 Suppl 1: p. S15-24.

79. Kehrli, M.E., Jr., B.J. Nonnecke, and J.A. Roth, Alterations in bovine neutrophil function during the periparturient period. Am J Vet Res, 1989. 50(2): p. 207-14. 
80. Dosogne, H., et al., Pregnancy-associated glycoprotein and decreased polymorphonuclear leukocyte function in early post-partum dairy cows. Veterinary Immunology and Immunopathology, 1999. 67(1): p. 47-54.

81. Burton, J.L., et al., Gene expression signatures in neutrophils exposed to glucocorticoids: A new paradigm to help explain "neutrophil dysfunction" in parturient dairy cows. Veterinary Immunology and Immunopathology, 2005. 105(3-4): p. 197-219.

82. Hammon, D.S., et al., Neutrophil function and energy status in Holstein cows with uterine health disorders. Veterinary Immunology and Immunopathology, 2006. 113(1-2): p. 2129.

83. Tacoma, R., et al., Characterization of the bovine milk proteome in early-lactation Holstein and Jersey breeds of dairy cows. Journal of Proteomics, 2016. 130: p. 200-210. 


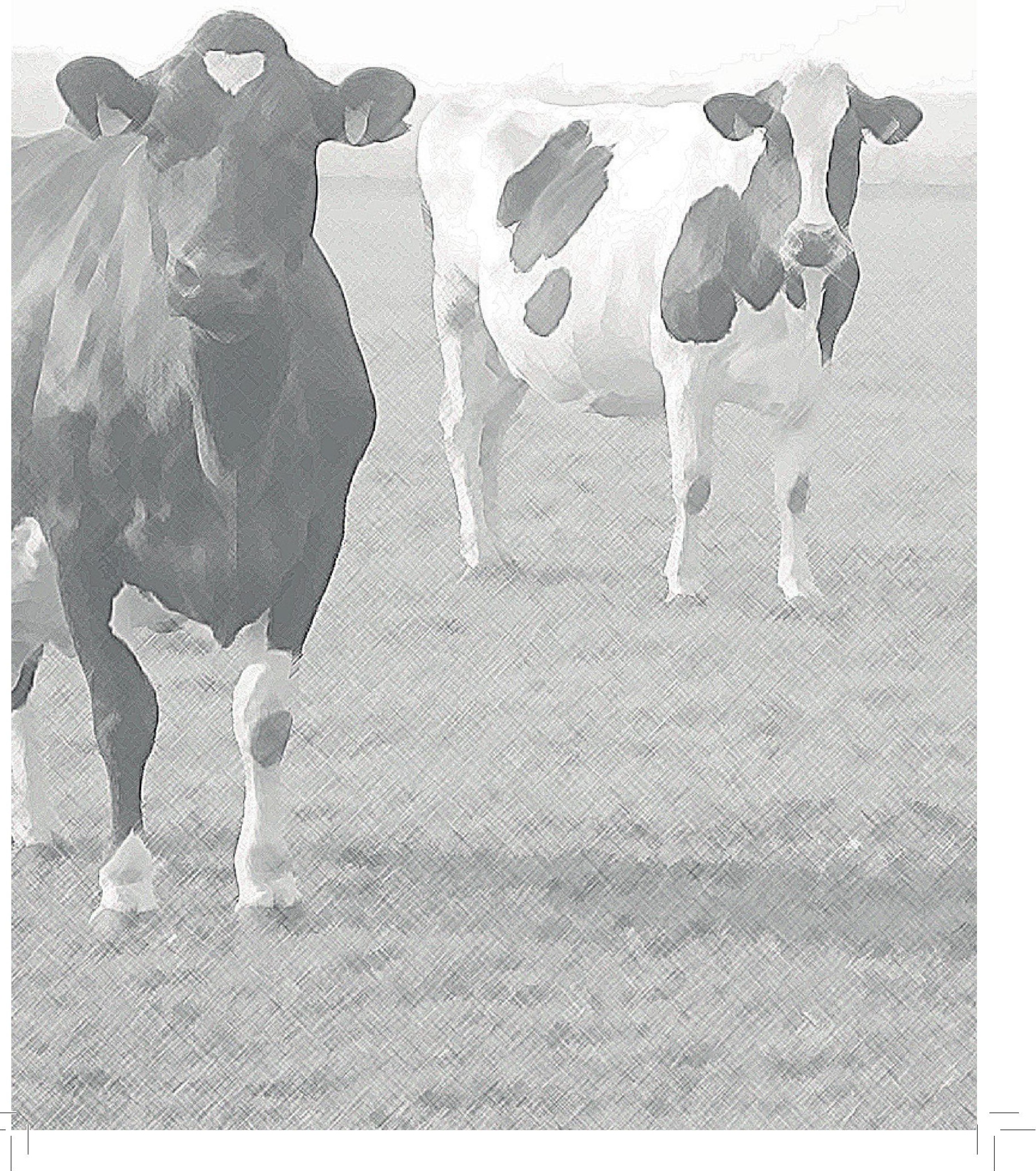




\section{Summary}

Samenvatting 


\section{Summary}

The aim of this thesis was to define and test biomarkers for disease resistance in dairy cows and to determine the underlying mechanism in natural disease resistance. The health status of the cows is an important issue in dairy farming. Due to the mandatory reduction in the use of antibiotics, alternatives are required to prevent the development and expression of illness in dairy cows. The identification of biomarkers associated with such disease offers the opportunity to adapt the management of cows at risk, and in this way, prevent them from developing overt disease. Previously, natural antibodies (NAbs) in serum and milk were used as candidate biomarkers for natural disease resistance in cows. In this thesis, we continue on the occurrence and mode of action of NAbs and also focus on their source: the B-1 cells. We performed a literature study on the identification and function of B-1 cells in different species and defined the limitations in the current identification of these cells in pigs, sheep and cows (Chapter 2). B-1 cells were described in cows by using widely accepted cell surface markers CD5 and CD11b. However, in literature several findings suggest that these cell surface markers are not unique markers for B-1 identification. The similarities between mice and veterinary animals in foetal B-cell development and antibody production, implies that B-1 cells are present in cows. In chapter 3 , we carefully studied new markers to selectively identify B-1 cells in cows. The combination of B-1 cell markers $\operatorname{IgM}^{++}$and $\mathrm{pSYK}^{++}$(indicator constitutive intracellular signalling) identifies a distinct cell population with essential B-1 characteristics such as high CD80 expression. In addition, the development of these B-1 cells in calves before colostrum intake and 3 weeks afterwards shows the same kinetics as the development of NAbs represented by IgM antibodies binding to the well-accepted NAb-antigen phosphatidylcholine (PtC). In calves up to half a year of age, it is shown that the production of such NAbs increases from birth and stabilises from 6 weeks onwards. This implies an endogenous NAb production, which follows the same age-related kinetics as can be expected from B-1 cell development. In contrast, the development of total IgM antibody levels in calves shows a bimodal distribution, which is caused by the uptake and breakdown of maternallyderived IgM and simultaneous endogenous production of specific and natural IgM. Chapter 4 describes the role of such NAbs in bovine immunity. NAbs were represented by the binding of IgM to the naïve antigen keyhole limpet hemocyanin (KLH). Cows with high serum NAb levels were shown to have more IgM and IgG antibodies binding to common microbial structures LPS, LTA and PGN, than cows with low serum NAb levels. In addition, they also have more IgM antibodies binding to intact, fixed $E$. coli and $S$. Typhimurium bacteria. However, the killing of live E. coli and $S$. Typhimurium bacteria via antibody-mediated complement killing does not differ between cows with high and low NAb levels. The antibody-mediated complement killing was determined in a newly developed serum bactericidal test. Cows that performed less in the bactericidal test were more likely to develop mastitis in the future. This association was observed for the killing of $E$. coli and $S$. Typhimurium and the development of mastitis within the next one year. For $S$. Typhimurium the association was still present for the cases of mastitis occurring within four years after testing. Alternative biomarkers for disease resistance in cows were defined in chapter 5 by using a contemporary proteomics approach. Milk samples from 
high and low disease resistant cows were selected from the "Resilient Cattle" (Weerbaar Vee) biobank. Comparing the spectrum of milk proteins of high and low disease-resistant cows showed potential candidate biomarkers that were elevated in the milk of low-resistant cows. Two candidate marker proteins were validated with ELISA in a new and larger group of high- and low-resistant cows. Lactoferrin (LF) levels were significantly increased in milk of low-resistant cows. In addition, LF levels in milk were associated with clinical manifestations of lameness and had a predictive value for subsequent culling.

In conclusion, we found that also in cows NAbs are produced by B-1 cells that can be identified based on the combined expression of cell surface IgM and internal pSYK. In addition, the frequency of these B-1 cells after birth follows a similar kinetics as described before in mice. These NAbs can be more precisely identified based on their PtC binding ability and their functional activity in a bactericidal test. However, the true predictive value of B-1 cells and NAbs for the health status and immunocompetence of dairy cattle remains to be established. Proteomics turned out to be a useful approach for identifying potential new biomarkers for health and disease in milk of cows. Application and further development of their predictive capacity is dependent on the availability of robust, sensitive and quantitative assays. This project was part of the "Resilient Cattle" project providing biological samples and essential data on the health status during respective lactation periods of individual dairy cows. The impact of this research now requires translation into management tools and principles for the individual farmer impacting on the overall health status and economic performance of his herd of dairy cattle. 


\section{Samenvatting}

De gezondheidsstatus van melkkoeien is een belangrijk speerpunt in de melkveehouderij, aangezien ziekte vaak gepaard gaat met pijn en stress voor de koe en hoge kosten en vermindert werkplezier voor de veehouder. Vanuit de overheid is bepaald dat het gebruik van antibiotica in de dierhouderij sterk verminderd moet worden om antibioticaresistentie te voorkomen. Dit vraagt om alternatieve methoden om de gezondheid van melkkoeien op peil te houden en legt meer focus op het voorkomen van ziekten in plaats van genezen. In het voorkomen van ziekten kunnen (voorspellende) biomarkers een belangrijke rol gaan spelen. Een biomarker die aangeeft dat een koe 'at risk' is voor het ontwikkelen van ziekte stelt de veehouder in staat om met managementmaatregelen (bijv. door het voerregime aan te passen) te voorkomen dat de koe daadwerkelijk ziek wordt. Uit eerder onderzoek is een kandidaat biomarker voor de weerstand van koeien gekomen: natuurlijke antilichamen (NAbs) in serum en melk. NAbs zijn antilichamen die worden gevormd zonder specifieke stimulatie door bijvoorbeeld bacteriën of vaccinatie. Ze zijn vaak gericht tegen structuren die veel op bacteriën voorkomen en daardoor zijn NAbs belangrijk in de eerste fase van een immuunreactie. In deze thesis wordt verder ingegaan op de NAbs door te onderzoeken hoe NAbs kunnen bijdragen aan een betere weerstand van melkkoeien en het identificeren van de bron van NAbs in koeien: de B-1 cellen. Verder is er in dit onderzoek gezocht naar alternatieve biomarkers voor weerstand in melkkoeien.

Hoofdstuk 2 omvat een review over de (potentiële) markers van B-1 cellen in varkens, schapen en koeien en de beperkingen van deze markers voor het identificeren van B-1 cellen in deze dieren. B-1 cellen zijn gedefinieerd op basis van de markers CD5 en CD11b. Deze markers zijn van origine beschreven voor B-1 cellen in de muis, maar inmiddels is aangetoond dat deze markers niet specifiek genoeg zijn om puur B-1 cellen in de muis te identificeren. In het review wordt bediscussieerd dat deze markers waarschijnlijk ook niet geschikt zijn voor het identificeren van B-1 cellen in varkens, schapen en koeien. De overeenkomsten in de foetale B-1 cel ontwikkeling en antilichaamproductie tussen muis en varkens, schapen en koeien impliceert overigens dat B-1 cellen wel aanwezig zijn in deze dieren. In hoofdstuk 3 zijn nieuwe markers getest om B-1 cellen in koeien te identificeren. Flow cytometry met de marker combinatie van IgM++ en pSYK++ resulteert in een aparte celpopulatie met B-1 karakteristieken, zoals een hoge CD80 expressie. Verder correleren het percentage van deze B-1 cellen in het bloed van jonge kalveren, voor en tot 3 weken na biestinname, met de NAb niveaus (gedefinieerd als IgM dat bindt aan phosphatidylcholine (PtC)). In kalveren tot 6 maanden oud nemen de NAb niveaus in serum toe tot een leeftijd van ongeveer 6 weken, waarna ze stabiliseren. Dit impliceert dat de NAbs door het kalf zelf zijn geproduceerd en niet via de biest zijn ontvangen. De ontwikkeling van de totale hoeveelheid IgM in serum vertoont daarentegen wel duidelijk 2 pieken; een toename veroorzaakt door opname van maternaal $\operatorname{IgM}$ vanuit de biest en een tweede piek veroorzaakt door IgM productie (specifiek en natuurlijk IgM) door het kalf zelf. De NAb ontwikkeling verloopt volgens dezelfde kinetiek als van B-1 cellen verwacht kan worden, zoals eerder aangetoond voor de muis. Hoofdstuk $\underline{4}$ beschrijft de rol van NAbs in de koe. NAbs zijn hier gedefinieerd als IgM antilichamen die binden aan het naïeve antigeen "keyhole limpet hemocyanin" (KLH). Koeien met 
hoge NAb niveaus in hun serum hebben ook meer IgM en IgG antilichamen die binden aan microbiële componenten zoals lipopolysaccharide (LPS), lipoteichoic acid (LTA) en peptidoglycanen (PGN), dan koeien met lage NAb niveaus. Verder vertoonden koeien met hoge NAb niveaus ook meer IgM binding aan intacte E. coli en S. Typhimurium bacteriën. Echter, het doden van E. coli en S. Typhimurium bacteriën via antilichaam-gemedieerde complement killing in een bactericide test verschilt niet tussen koeien met hoge of lage $\mathrm{NAb}$ niveaus. Wel bleek dat de koeien die slecht scoorden in de bactericide test een grotere kans hadden op het ontwikkelen van mastitis in de toekomst. Deze associatie tussen de bactericide test en mastitis was voorspellend op een termijn van een jaar wanneer E. coli bacteriën in de bactericide test werden gebruikt. Voor S. Typhimurium was deze associatie voorspellend voor een termijn van zelfs 4 jaar. Hoofdstuk 5 beschrijft de identificatie van alternatieve biomarkers voor weerstand tegen ziekten in melkkoeien met behulp van proteomics. Melkmonsters van hoog en laag weerbare koeien werden geselecteerd uit de "Weerbaar Vee" biobank. Deze monsters werden vergeleken op basis van welke eiwitten en hoeveel van deze eiwitten aanwezig waren in melk van hoog versus laag weerbare koeien. Potentiele biomarkers bleken in een verhoogde concentratie aanwezig in de melk van laag weerbare koeien. Twee potentiele biomarkers werden gevalideerd met ELISA in een nieuwe en grotere set melkmonsters. Lactoferrine levels waren significant verhoogd in de melk van laag weerbare koeien en bleken geassocieerd te zijn met klauwproblemen en een voorspellende waarde te hebben voor het afvoeren van de koe. In conclusie, NAbs in koeien worden geproduceerd door B-1 cellen die gekarakteriseerd zijn door (hoge) expressie van IgM en pSYK. Het percentage B-1 cellen in bloed correleert met de NAb niveaus in jonge kalveren. NAbs kunnen bepaald worden aan de hand van de IgM binding aan PtC. De voorspellende waarde van B-1 cellen voor de gezondheidsstatus en weerbaarheid van melkkoeien moet echter nog bepaald worden. Proteomics is een geschikte techniek om potentiële biomarkers voor de weerstand van melkkoeien te identificeren. Lactoferrine bleek een biomarker voor laag weerbare koeien en was geassocieerd met klauwproblemen en een grotere kans op het afvoeren van de melkkoe. 


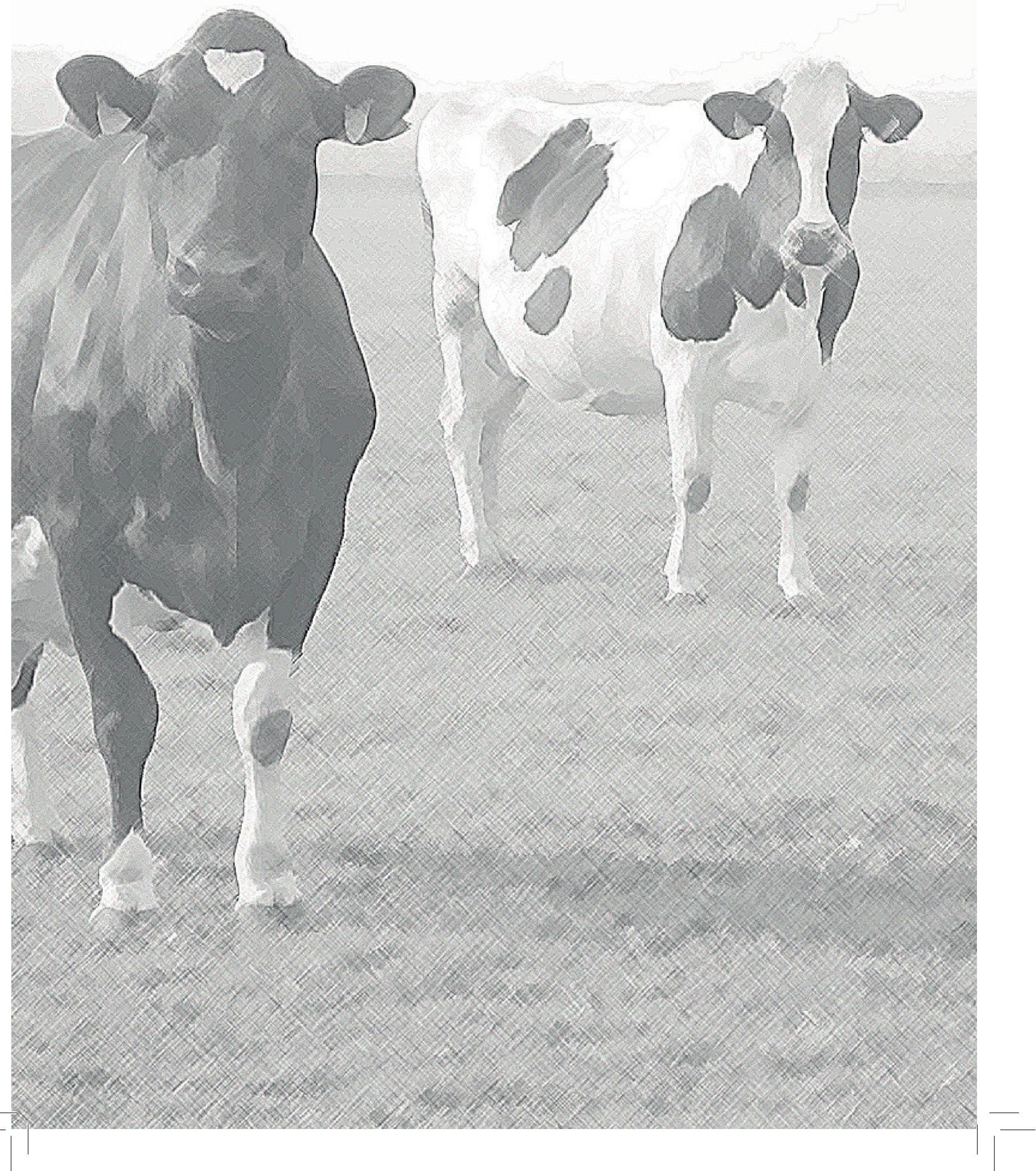




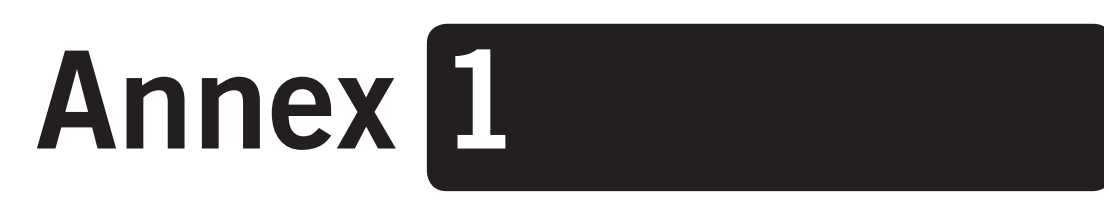

\title{
Maturation of the Immune Response
}

\author{
S.E.C. van Altena ${ }^{1}$, B. Meijer ${ }^{1}$, H.F.J. Savelkoul ${ }^{1}$ \\ ${ }^{1}$ Cell Biology and Immunology Group, Department of Animal Sciences, \\ Wageningen University, P.O. Box 338, Wageningen, the Netherlands
}

Encyclopedia of Immunotoxicology (2014) 1-11 


\section{Definitions}

\section{Innate immunity}

The innate immune system depends on features like extracellular and intracellular pattern recognition receptors (PRR) that recognize general molecular patterns. Different types of PRR have been described, identifying microbe-, pathogen- and dangerassociated molecular patterns (abbreviated as MAMP, PAMP and DAMP respectively). PRR enhance ligation and phagocytosis of microbes or have signaling ability allowing activation of the cell. Ligation of extracellular toll like receptors (TLR) by bacterial ligands like lipopolysaccharide (LPS) (binds to TLR4), peptidoglycan (PGN) (TLR2) and flagellin (TLR5) results in MyD88-dependent production of inflammatory cytokines like interleukin (IL)-1ß, IL-6, IL-8, and partly TNF- $\alpha$. The expression of TLRs is vast as they are found on the cell membranes of innate immune cells (dendritic cells (DC), macrophages, natural killer cells), cells of the adaptive immunity ( $\mathrm{T}$ and $\mathrm{B}$ lymphocytes) and non immune cells (epithelial and endothelial cells, fibroblasts).

A complex network of specialized DC subsets is involved in on the one hand inducing acute inflammatory responses upon invasion by pathogens, and on the other hand in inducing tolerance to harmless dietary and inhaled antigens and commensal microbiota [1]. Since DC's control many T-cell responses they have been useful tools to beneficially manipulate the $\mathrm{T}$ cell responses to recognize specific antigens (mostly viral or tumor antigens) in vitro or in vivo. Direct isolation of DC's from peripheral blood mononuclear cells results in extremely low yields $(0.1 \%)$. However large amounts of DC's can be generated from peripheral blood mononuclear cells (PBMC), bone marrow cells or monocytes cultured in vitro in the presence of GM-CSF and IL-4. Complete activation and differentiation of $\mathrm{T}$ cells in contact with antigen presenting DCs is determined by expression levels of co-stimulatory molecules like CD80 and CD86, and the production of cytokines (TNF- $\alpha$, IL-10, IL-12) and other soluble factors (e.g. retinoic acid).

\section{T-cell immune maturation}

In mammals, approximately $40-80 \%$ of lymphocytes in the blood account for T-cells. The peptide-binding $\mathrm{T}$ cell antigen receptor (TCR) complex is an important structure on the surface of the T-lymphocyte that contains many different proteins. These proteins can function in antigen binding for signal transduction and usually have a cluster of differentiation designation (CD). CD3 for example is a signal transducer that acts when an antigen binds the TCR and is therefore found on all T cells. CD4 is expressed on the surface of $\mathrm{T}$ helper cells that, as previously described, recognize processed exogenous antigen-derived peptides in combination with major histocompatibility (MHC) class II molecules on the surface of APC's. CD8 is predominantly found on the surface of cytotoxic $\mathrm{T}$ - cells that recognize processed endogenous antigen-derived peptides in combination with MHC class I molecules. In humans, $60-70 \%$ of T cells are $\mathrm{CD} 4^{+} \mathrm{CD} 8$ and $30-40 \%$ are $\mathrm{CD} 4 \mathrm{CD}^{+}$. The remaining $5-10 \%$ of $\mathrm{T}$ cells are said to be double negative.

Both $\mathrm{CD}^{+}$and $\mathrm{CD}^{+} \mathrm{T}$ cells can be differentiated in subpopulations that can be distinguished by their cytokine secretion profile $[2,3]$. This is best established for $\mathrm{CD}^{+} \mathrm{T}$ cells. Upon activation by a processed antigen that is presented by APC's, the naive CD $4^{+}$ 
Th cells begin to produce IL-2 and depending on the cytokines present in the environment, they continue to differentiate to designated Th1, Th2 or Th17 cells. Th1 cells express transcription factor t-bet, produce IL-2, IFN- $\gamma$ and lymphotoxin and support cell-mediated immune responses. Th2 cells express the transcription factor GATA-3, produce IL-4, IL-5, IL-9, IL-13 and GM-CSF and support humoral and allergic responses. Th17 cells produce IL-17, characterized by the transcription factor RORgT and seem to play a key role in many autoimmune diseases. Although Th1 and Th2 cells often work together in an immune response, the response can become dominantly Th1 or Th2-like. These Th1 and Th2 subsets appear to be extremes in cytokine production profiles and within these polarized subsets, individual Th cells exhibit differential rather than coordinated cytokine gene expression. The Th1 and Th2 subsets appear to cross-regulate each other's cytokine production profiles, mainly through IFN- $\gamma$ and IL-10. From this concept it was rationalized that disturbances in the balance of between these two subsets may result in different clinical manifestations. IL-12 is a dominant factor promoting Th1 differentiation, and is produced by dendritic cells and macrophages. Moreover, IL-12 induces IFN- $\gamma$ production by T cells and natural killer (NK) cells and IL-18 acts synergistically with IL-12 to induce Th1 development. Polarization of Th2 cells is critically dependent on the presence of IL-4 produced by Th cells, basophils and mast cells. APC-derived IL-6 has also been shown to induce small amounts of IL-4 in developing Th cells. IL-10 and prostaglandin E2 (PGE2), both produced by APC inhibit IL-12 production and Th1 priming.

Within the $\mathrm{CD}^{+}$cell population, regulatory $\mathrm{T}$ cells expressing the transcription factor FOXP3 and the surface protein CD25 (the interleukin-2 (IL-2) receptor a-chain) are naturally present. $\mathrm{CD} 4^{+} \mathrm{CD} 25^{+} \mathrm{FOXP} 3^{+}$Treg cells have a regulatory function by suppressing the activation, proliferation and cytokine production of many immune cells, including $\mathrm{CD}^{+}$cells $\mathrm{CD}^{+}$and APCs. Their dysfunction can result in autoimmune disease, immunopathology and allergy. In addition, IL-10 secreting Tr1 cells, and transforming growth factor- $\beta$ (TGF- $\beta$ ) secreting Th3 cells are adaptively regulatory: they acquire regulatory functions after specific antigenic stimulation [4]. As mentioned before, regulatory $\mathrm{T}$ cells have been isolated from in vitro cultures, which appeared to produce low levels of IL-2, no IL-4, but high levels of IL-10 and TGF- $\beta$. This demonstrates the importance of cytokines in regulating and dampening the immune response [5].

To study effects on the maturation potential of the immune response (e.g. under conditions of immune-mediated diseases like allergy or by interaction with environmental factors like diet), it is presumed that human DCs generated from peripheral blood monocytes (moDCs) in vitro, resemble DC produced in vivo [6]. These DCs have been used to determine the attribution of allergenic or dietary proteins for driving the polarization of the immune system. Therefore, we propose to first investigate the immunomodulatory effects on maturation markers and cytokine profiles of human moDCs stimulated with different protein preparations and subsequently use co-cultures of moDC with purified $\mathrm{CD}^{+} \mathrm{T}$ cells for their polarizing capabilities in donors.

\section{B cell immune maturation}

Before an efficient B cell response is mounted, B cells need to mature either from naïve B 
cells or pre-activated B cells. Humoral immunity is part of the adaptive immune system and involves the production of specific antibody molecules (immunoglobulin's (Ig)) in response to an antigen, which is mediated by B cells. Naive B cells produce IgM, but can undergo antibody heavy-chain isotype class switching to $\operatorname{IgG}, \operatorname{IgE}$ or $\operatorname{IgA}$ after activation. Activation of $\mathrm{B}$ cells and isotype switching requires activation of AID and is regulated by activated Th cells expressing CD40 ligand and by cytokines produced by the Th cells. IL-4 and IL-13, produced by Th2 cells, mediates isotype switching towards IgE. Th2 cells can also induce IgG4 in humans. IgG4 production is initiated by the presence of IL-10 from Treg, which inhibits IgE production [7, 8].

To be functionally active on mucosal surfaces that are exposed to the external milieu, transport over the epithelium is required. Several Fc domain-binding receptors have been identified, with different affinities and isotype specificities. IgA is bound by the FcaR (CD89), IgE by the high or low affinity FceR (CD23) and IgG by Fc $\gamma$ RI-III (CD66, CD32, CD16, respectively) [9, 10]. Monocyte derived DCs may preferentially express the low affinity receptor CD32, whereas monocytes also express CD89, some of the high affinity receptor CD64 and minor levels of CD16. Expression of CD16 is more prominent on neutrophils, which can become activated upon binding of immune complexes. It is important to note that not all IgG subclasses are bound by the Fc gamma receptors. Mainly IgG1 and IgG3 are bound, which are therefore called cytophilic IgG. IgG2 and especially IgG4 are well-known for their relatively tolerogenic features, which could be explained by the lack binding of those subclasses by Fc receptors.

\section{Measurement of immune response maturation}

\section{Maturation of dendritic cells}

The mechanism for regulation of innate immunity or the induction of immunomodulation by food components is largely unknown. The most widely studied mechanism is the uptake of proteins by pinocytosis and presentation of peptides to $\mathrm{T}$ helper cells. The majority of food proteins is (partly) digested and hence presented as peptides to the innate immune system. Alternatively, the exposure to environmental and food-derived potentially toxic compounds relies on the interaction with cells of the innate immune system of which dendritic cells are prototypical examples. Upon intracellular processing by professional APCs, peptides are presented on the MHC II class (signal 1) and co-stimulatory molecules can be up regulated (signal 2) next to the induction of cytokine secretion (signal 3). These factors together determine if and how the Th cell becomes activated. 

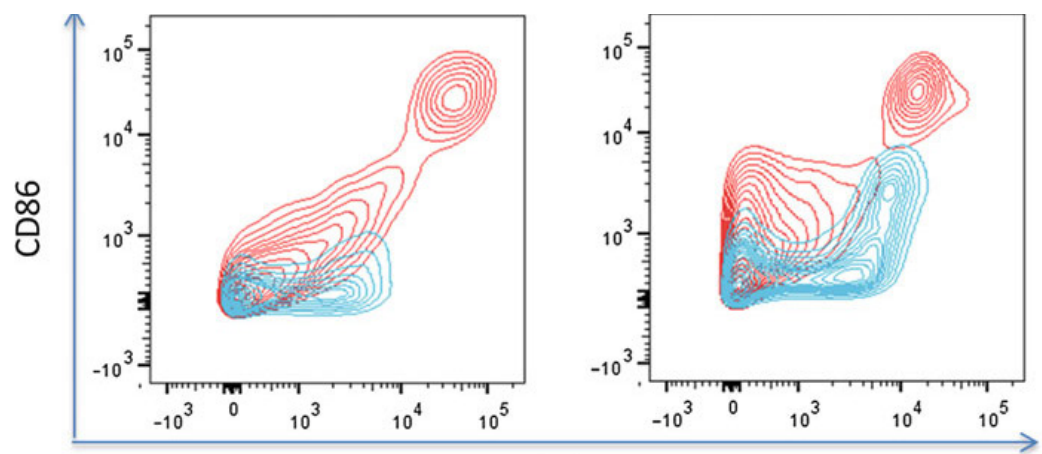

MHC class II
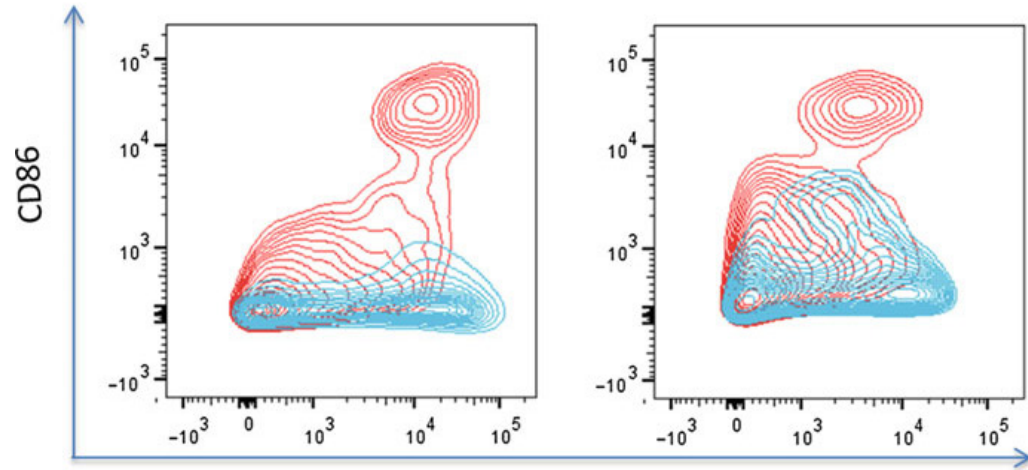

CD11c
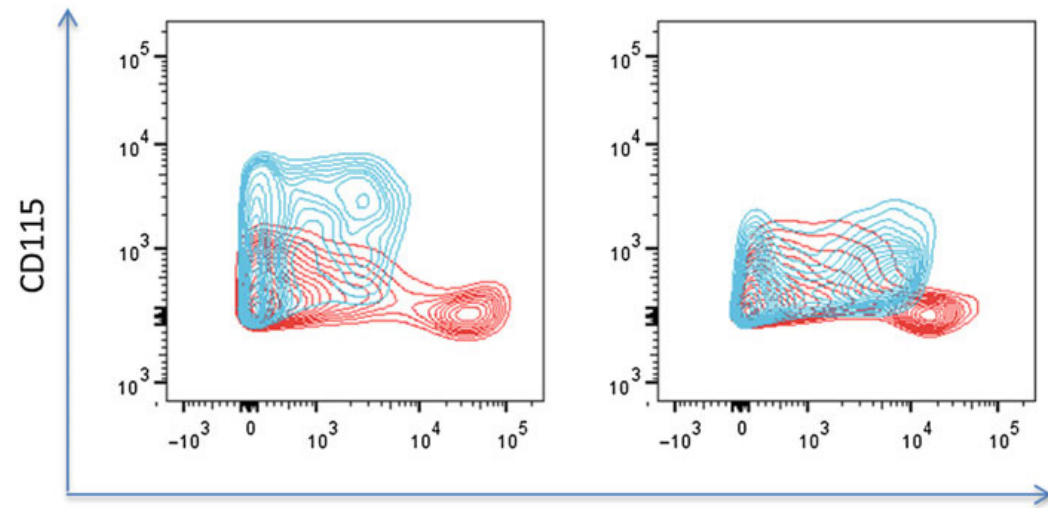

MHC class II

Figure 1.Immature monocyte-derived DC were analyzed directly for surface marker expression and also after 24 of maturation by stimulation with LPS or a probiotic bacterium. Upper panel: CD86 vs MHC class II expression; middle panel: CD86 vs CD11c expression; and lower panel: CD115 vs MHC class II expression. MHC class II expression (HLA-DR) and CD86 are markers for mature DC representing antigen presentation capacity and co-stimulatory activity, respectively. CD115 is a marker for DC precursor and immature cells. Blue is negative control and red represents the $24 \mathrm{hr}$ stimulated culture. 
Activation and maturation status of APC's is usually determined by flow cytometric analysis of expression levels of CD80 and CD86 respectively CD83 and the precursor marker CD115. CD80 (B7-1) and CD86 (B70-2) are co-stimulatory molecules expressed on APCs and hybridize with CD28 expressed on Th cells. APC dependent activation of Th cells finally is mediated by the production of inflammatory cytokines like IL-1ß, IL-6 and TNF- $\alpha$, and the regulatory cytokine IL-10. Expression of these co-stimulatory molecules and cytokines can be inhibited by IL-10, resulting in reduced activation of Th2 cells. Production of the Th1 skewing cytokine IL-12 is also inhibited by IL10. Next to absolute production levels, the ratio between IL-10 and IL-12 is used to identify if a stimulus is skewing towards Th1 or Th2. Precise evaluation of the cytokine production requires both absolute production levels and cytokine ratios. Tolerance is essential to prevent chronic inflammatory diseases or allergy. Key players in tolerance induction are $\mathrm{T}$ regulatory cells and this is a key feature of mucosal tissue, to prevent massive inflammation upon antigen challenges that are non-pathogenic.

Peripheral blood mononuclear cells (PBMCs) obtained from buffy coats of healthy blood donors were isolated by gradient centrifugation on Ficoll-Paque PLUS. Monocytes were labeled with MicroBeads conjugated to mouse anti human CD14 monoclonal antibodies, and isolated using the MACS. Isolated monocytes were cultured in RPMI to which recombinant human GM-CSF and IL-4 were added. On day 6, expression of surface markers was analyzed using flow cytometry. Subsequently, these immature DCs were stimulated for 1 day with LPS or selected probiotic bacteria to become fully mature DC based on maturation marker expression. DCs were stained with antibodies against CD14 (marker for monocytes and macrophages, but not DC), CD115 (marker for precursors and immature DC), HLA-DR (MHC class II), CD11c, CD83, and CD86. These monocytederived dendritic cells (moDC) are characterized by their expression of HLA-DR, CD1a, CD11b, CD11c, CD86, CD83, CD115 and CD32 (Figure 1). MoDCs were described to constitute the main population of DC present under inflammatory conditions and strongly able to capture, process and present antigens in the T-cell area, LPS-treated MoDCs displayed a mature DC phenotype as shown by up-regulation of the maturation marker CD83 and the co-stimulatory molecule CD86 necessary for antigen presentation to T cells. Addition to MoDCs of probiotic bacteria also induced (slightly less profound) maturation phenotype [11]. 


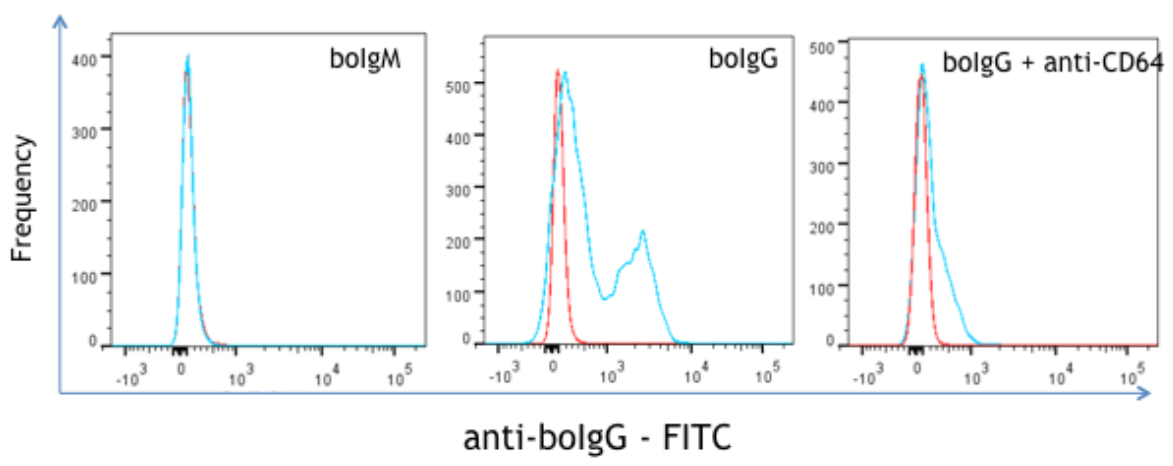

Figure 2. Binding of monomeric bovine $\operatorname{IgG}$ (boIgG) but not boIgM (left panel) purified from cow's milk to human monocyte-derived immature DC (middle panel). Staining is performed by using FITC labeled anti-bovine IgG monoclonal antibodies. Pre-incubation of DC with IgG could be completely blocked by the competitive inhibition with anti-CD64 (FcgRI) antibodies (right panel). Data from one representative donor of two is shown.

\section{Functional activity of mature dendritic cells}

An example of dietary immunomodulation is by consumption of bovine milk, which contains $\operatorname{IgM}, \operatorname{IgG}$ and $\operatorname{IgA}$ that can bind to pathogens and allergens that are also encountered by humans [12-14]. Milk-derived and purified bovine IgG, IgA, and IgM did not bind significantly to freshly isolated human monocytes (data not shown). In contrast, bovine IgG, but not IgM, from milk as well as purified immunoglobulins did clearly bind to immature monocyte-derived DC (Figure 2, left and middle panel). Incubation of DC with IgG could be completely blocked by the competitive inhibition with antiCD64 (FcgRI) antibodies (Figure 2, right panel), indicating that the high affinity FcgRI is responsible for binding of the monomeric IgG to DC. IgG that formed complexes with LPS, resulted in increased binding of bovine IgG to human moDC compared to monomeric bovine IgG, suggesting binding of immune complexes (Figure 3, upper panel). There is an optimal ratio between antigen and $\mathrm{IgG}$ for the formation of immune complexes. This binding of bovine IgG could partially be inhibited by blocking monoclonal antibodies $(\mathrm{mAb})$ directed at the low affinity Fc $\gamma \mathrm{RII}(\mathrm{CD} 32)$, but also by mAb to the high affinity Fc $\gamma \mathrm{RI}$ (CD64) (Figure 3, lower panel). These data suggest that monomeric bovine IgG can bind to the high affinity human Fc $\gamma$ RI, and that bovine IgG immune complexes could bind to the human low affinity FcyRII. Depending on the expression levels of activating and inhibitory $\mathrm{F} c \gamma \mathrm{R}$, inflammatory or non-inflammatory downstream immune responses may be initiated leading to the production of protective IgG antibodies. This may be influenced by the type of DC the Fc $\gamma \mathrm{R}$ is expressed. 

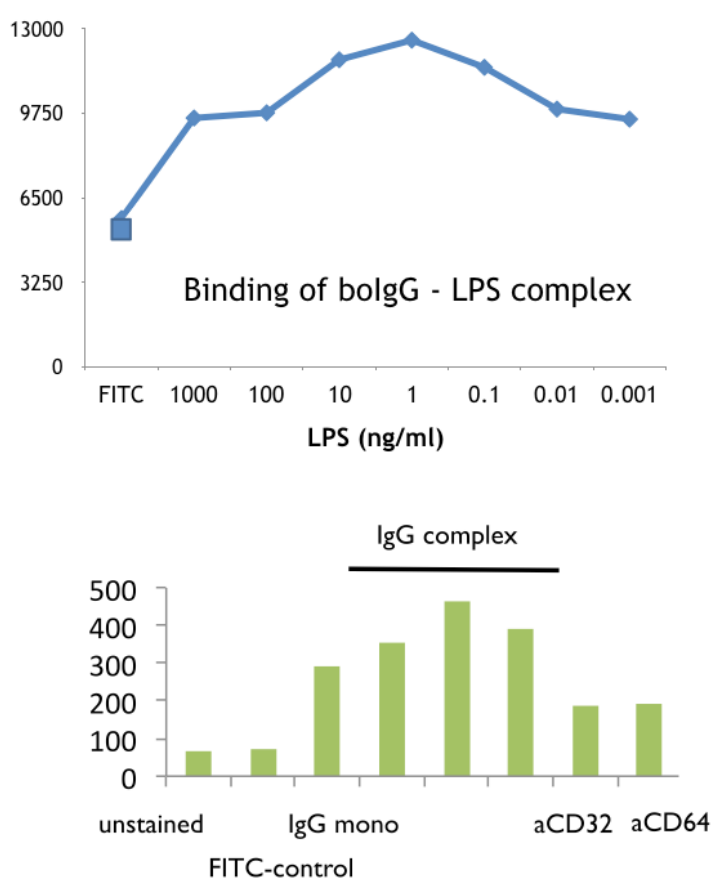

Figure 3. Binding of bovine IgG-LPS immune complexes to human moDCs. IgG was incubated with different doses of LPS and subsequently added to moDCs (upper panel). IgG -LPS immune complexes in three different ratios were added to moDC in the presence or absence of IgG receptor blocking antibodies (lower panel). Unstained and FITC control show background staining, IgG mono is monomeric bovine $\operatorname{IgG}$ and $\operatorname{IgG}$ complex shows bovine IgG pre-incubated with LPS (in three different concentrations) prior to addition to the DCs. Blocking of LPS-IgG complexes by anti (a) CD32 and aCD64 was performed with specific monoclonal antibodies.

\section{Polarization of T-cells in allergy}

Dendritic cells are professional antigen-presenting cells and are the key players in the initial stage of the interaction of e.g. allergens and the immune system that shapes the differentiation of naïve $\mathrm{T}$ cells. DCs display inherent plasticity and depending on their functional state, induce or inhibit $T$ cell responses. The differentiation of naïve $\mathrm{T}$ cells into committed effector and regulator cells depends on complex interactions between the antigen, the antigen-presenting cell, and the milieu of cytokines in the immediate environment and expression of cell surface receptors. As described, allergy is widely considered a Th2 mediated immune maturation disease with a disturbed Th1-Th2 balance resulting in excessive amounts of $\operatorname{IgE}$ antibodies $[7,8]$.

Typically, systemic T cells are isolated from peripheral blood mononuclear cells (human) or spleen and peripheral lymph nodes (mouse) by preparing single cell suspensions from these lymphoid organs. Naïve (CD62 $\mathrm{L}^{\text {high }}$ ) $\mathrm{T}$ cells are purified by magnetic beads coupled with anti-CD4 antibodies and using magnetic activated cell sorting (MACS) or, alternatively, labeling of the cells by anti-CD4 antibodies coupled to a fluorochrome 
(e.g. FITC or PE) and using flow cytometric cell sorting (FACS) [4]. Isolated T cells can be obtained with relatively high purity $(>95 \%)$ using both methodologies.

$\mathrm{T}$ cell polarization is obtained by culturing purified $\mathrm{CD}^{+} \mathrm{T}$-cells in vitro and stimulating these cells by anti-CD3 and anti-CD28 monoclonal antibodies. All cells are cultured in the presence of IL-2 for maximal proliferation (neutral condition). For maximal Th1 development cells are cultured in the presence of IL-12, IFN- $\gamma$, and anti-IL-4 antibodies, while maximal Th2 development is obtained by stimulation in the presence of IL-4 and anti-IL-12 and anti-IFN- $\gamma$ antibodies. Cells are stimulated under Th0-like conditions in the presence of monensin for 5 hours if intracellular cytokine staining (ICS) analysis will be required, or alternatively, cell supernatants are harvested 48 or 96 hours after secondary stimulation in the absence of monensin treatment [15].

Polarized T cells are pelleted and stained for surface molecules in a fluorescent activated cell-sorting (FACS) buffer. Following this, cells are fixed in paraformaldehyde and permeabilized with saponin. Cells are stained for intracellular cytokines with anti- IL-4-PE and anti-IFN- $\gamma$-FITC. Unlabeled antibody of the same clones is utilized at 10 times excess to set negative gates to control for non-specific staining. Cells are suspended in FACS buffer and then 10000 events in the live cell gate (dead cells excluded by propidium iodine staining) will be analyzed on a flow cytometer (Figure 4). The use of propidium iodine (PI) staining of fixed and permeabilized cells provides a useful tool for setting the life cell inclusion gate for subsequent analysis of intracellular cytokine staining. This method of setting of stringent live cell gates is essential, as the use of un-stimulated cells alone does not adequately control for changes in auto-fluorescence following activation due to the inevitable increase in forward/sideward scatter in the flow cytometric analysis. Due to cell fixation and permeabilization, there is an inherent amount of non-specific staining which must be controlled for. Typically, the gates are set so that only $1 \%$ of cells are positive for the cytokine of interest in the labeled/unlabeled negative control. In order to detect intracellular cytokines, a Golgi trans- port inhibitor must be used on in vitro stimulated cells. This inhibitor affects the release or display of rapidly produced cytokines as well as other surface molecules. The concentration range in which the Golgi transport inhibitors can be used is relatively small, due to their inherent cytotoxicity. Therefore, cells must be activated to rapidly produce cytokines (hence the use of PMA and calcium ionophore) within a narrow 2-hour window for brefeldin A and a 5-hour window for monensin. 


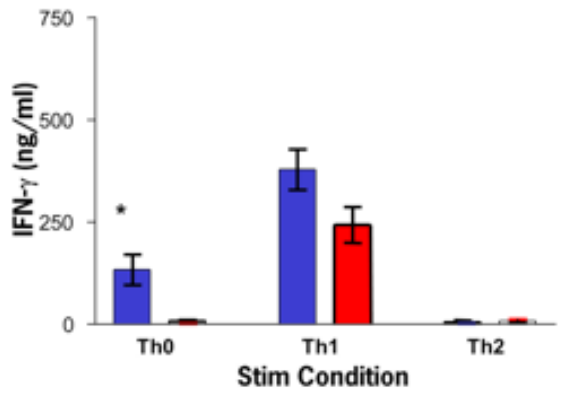

Allergy

$\mathrm{HC}$

${ }^{*} \mathrm{p}=0.0037 \mathrm{t}$ test,

paired,2 tailed

( $n=10$ SEM)

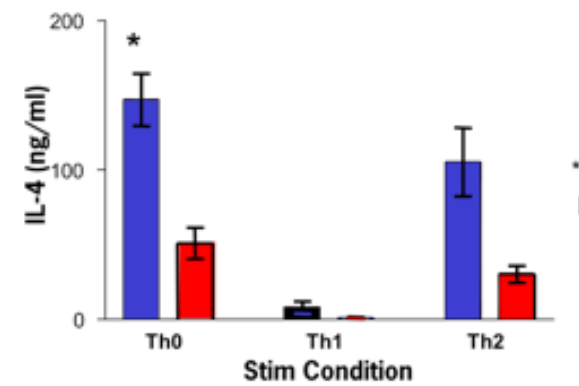

Allergic

HC

* $p=0.0013 \mathrm{t}$ test

paired, 2 tailed

( $n=10$ SEM)

\section{Th1 vs Th2 polarisation in allergic patients}

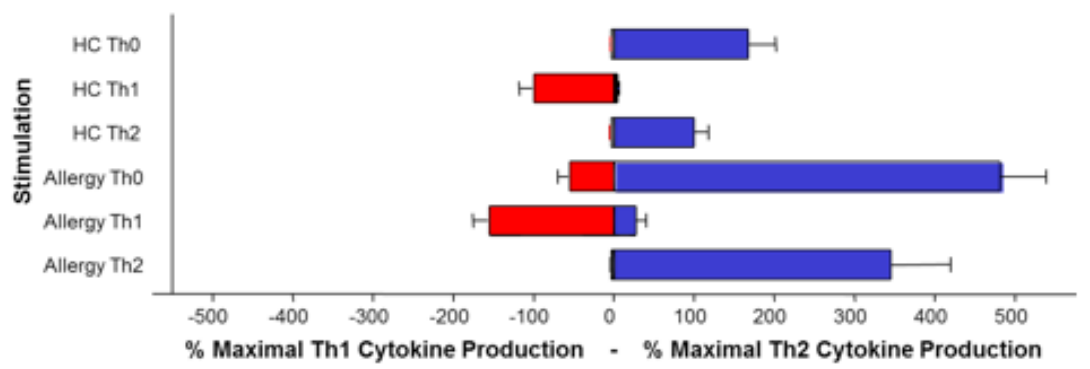

Allergy: allergic hay-fever patient; HC: non-allergic healthy control

Figure 4. Maturation of the Immune Response. Absolute cytokine production of interferon- $\gamma$ (upper panel) and interleukin-4 (middle panel) by T helper cells isolated from healthy control ( $\mathrm{HC}$ ) and allergic individuals, as detected by ELISA (detection limit $7.5 \mathrm{pg} / \mathrm{ml}$ ) under different in vitro polarizing conditions, including Th0, Th1 and Th2 conditions. Relative cytokine production of T helper type 1 versus T helper type 2 cells (lower panel). Absolute production is converted into a relative percentage by dividing interferon- $\gamma$ or interleukin IL-4 production values by the mean IFN- $\gamma$ or IL-4 concentration following Th1 or Th2 polarization, respectively, of $\mathrm{CD}^{+} \mathrm{T}$ cells from healthy control (HC) or allergic individuals. 


\section{Preclinical Relevance}

Utilization of the DC maturation analysis and a $\mathrm{T}$ cell polarization pulse, followed by comparison of relative cytokine production by intracellular cytokine staining under polarized conditions allows ex vivo assessment of the $\mathrm{DC}$ and $\mathrm{T}$ cell polarization state in vivo. Immature or semi-mature DC can prime naïve $\mathrm{T}$ cell to differentiate into Treg cells rather than effector $\mathrm{T}$ cells, which enables them to promote tolerance instead of immunity. Ex vivo systems have the advantage of their natural origin, however donor viability and high individual variation can make analyses and interpretation of results more complex.

Since strong and clear T cell polarization typically takes place in chronic disease states or exposure to (potentially toxic) agents [16], this technique provides an assessment whether the current direction of polarization in the DC and T cells are heading towards acute responses, on a population basis via relative cytokine production, and on a cell-by-cell basis via ICS. Most importantly, the comparison of cytokine production by enzyme-linked immunosorbent assay (ELISA) must be made on a relative scale, as outlined since the potency of the key Th1 and Th2 cytokines, IFN- $\gamma$ and IL-4 respectively, may not necessarily be equal. Similar relative comparisons have been made during microarray analysis of Th1 and Th2 gene transcripts. Additionally, all polarizations must be compared to the results obtained from $\mathrm{CD} 4^{+} \mathrm{T}$ cells isolated from a healthy controls polarized under identical conditions. The rationale for this is apparent when looking at the data, because some individuals are naturally Th2 biased in their cytokine profile, while others are naturally Th1 biased.

The addition of ICS to this method most importantly allows for further assessment of the $\mathrm{T}$ helper population in experimental groups, to determine if a mixed cytokine profile detected via ELISA and comparison of relative cytokine production truly represents an un-differentiated Th0 response of naive cells, or rather if it is indicative of a heterogeneous population of simultaneously differentiating Th1 and Th2 cells. Additionally, it can allow for further characterization of the cytokine-producing subsets $[17,18]$.

\section{Clinical Relevance}

Polarization of $\mathrm{T}$ helper cells is important in disease models associated with chronic immune stimulation, where the outcome depends on the type of immune response induced and relative amount of cytokines released. Many diseases such as leprosy, allergy, multiple sclerosis, and responses to immunotoxic agents have pathology associated with aberrant Th1 and Th2 (and Th17) polarization along with disturbed Treg formation $(1,2)$. The importance of $\mathrm{T}$ cell polarization in a disease such as leprosy is immediately obvious since the infection by Mycobacterium leprae can be resolved by a strong cell mediated Th1 response, while continued infection is associated with a humoral Th2 response.

It is hard to determine polarization of $\mathrm{T}$ helper subsets during an acute response since real distinct populations only arise after chronic exposure to a particular antigen. However, many in vivo and in vitro experiments have a limited duration that does not reflect more chronic effects. It is therefore paramount to try to determine in which direction the cell population is polarizing. For this reason we perform two secondary ex vivo stimulations under polarizing conditions in our system, in order to determine how 
far our stimulated cells can be pushed in each direction, Th1 and Th2. Using purified human $\mathrm{T}$ cells for analysis in these polarization assays, generally up to four rounds of stimulation are used before the final analysis of the polarization state can be performed. Moreover, un-polarized Th0 cells can be pushed in any direction in culture by addition of exogenous polarizing cytokines in concert with neutralizing antibodies to polarizing cytokines in the opposite direction, such as IL-4 and IFN- $\gamma$. Resistance to this directional polarization, or co-expression of IFN- $\gamma$ or IL-4 in the supernatant under opposite polarizing conditions, however, indicates a shift towards differentiated $\mathrm{T}$ helper cell populations. Naturally, these analyses need to be performed on highly purified populations of $\mathrm{CD}^{+} \mathrm{T}$ cells obtained from circulation or isolated lymphoid organs.

Several techniques can be used to try to determine the direction of polarization [19]. Firstly, quantitative reverse transcription polymerase chain reactions (RT-PCR) can be used to determine the number and nature of cytokine mRNA transcripts of stimulated cells, and can even be performed on a single cell level. This has certain disadvantages, since the actual production and release of cytokines cannot be directly measured and many of the cytokines of interest are subject to post-transcription regulatory mechanisms. Determination of cytokine production via direct protein detection in supernatant of cultured cells can be done by ELISA. ELISA determination is a valuable tool for measuring the average overall cytokine response accumulated over time, of a heterogeneous population of stimulated cells. However, this method alone is unable to distinguish whether a mixed Th0 cytokine pattern is due to the release of diverse cytokines from naive Th0 cells, or due to the production of cytokines by heterogeneous subpopulations of Th1 and Th2 cells. Additionally, this method does not allow determination of which proportion of the cells is responsible for this skewing. To work around this limitation and to identify cells producing more than one cytokine, an ICS method is used. This method makes it possible to concurrently check the presence of different cytokines in each cell. When combined with ELISA results, an impression of the proportion of cytokine producing cells, as well as the combined cytokine profile of the cell population, can be assessed. This approach gives invaluable insight into the direction of $\mathrm{T}$ helper cell polarization.

\section{Relevance to Humans}

Dendritic cells in their immature and mature state present unique characteristics to investigate and to permit the estimation of the immunomodulating effects of food compounds. Health of human and animals is strongly related to a proper balance of immune functions, which can be directly mediated by diets or exposure to environmental and food-derived toxins, also called "immune-modulation". As cells in vivo always work as a network, co-culture systems in in vitro or ex vivo conditions may present a step forward to mimic the in vivo situation. Subsequently, co-culture of dendritic cells and T-cells are essential to further elucidate such immunomodulatory activities of food components and potentially toxic compounds [20].

Properties of many diseases, particularly systemic autoimmune disease, strongly support the involvement of helper T lymphocytes. For example, pathogenic autoantibody responses 
generally are of high-affinity IgG class, after having undergone affinity maturation, which requires helper $\mathrm{T}$ cells. The protein antigens to which many autoantibodies are directed generally require $\mathrm{T}$ cell help. Besides roles as helpers, $\mathrm{T}$ cells may directly provoke cellular injury during inflammatory phases of the disease process. T cells, and in particular $\mathrm{CD}^{+}$helper $\mathrm{T}$ cells produces effector molecules, called cytokines, upon activation. A multiplicity of cytokine abnormalities has been associated with various autoimmune and immune-mediated diseases. It is thus becoming common practice to analyze the role of helper $\mathrm{T}$ cells and the cytokines they produce in studying the immunpathologic basis of particular diseases, to aid in the unambiguous diagnosis of the disease, and to provide parameters to monitor the efficacy of treatment.

\section{Regulatory Environment}

Toxicity to the immune system encompasses a variety of adverse effects. These include suppression or enhancement of the immune response. Suppression of the immune response can lead to decreased host resistance to infectious agents or tumor cells. Enhancing the immune response can exaggerate autoimmune diseases or hypersensitivity. Toxic compounds (whether environmentally derived, drugs or food compounds) or toxinprotein adducts might also be recognized as foreign and stimulate an anti-toxin response. Subsequent exposures to the toxin can lead to hypersensitivity (allergic) reactions. Much of the science and method development and validation efforts in the past have been focused on evaluating drug development candidates for their potential for either immunosuppression or contact sensitization. No standard approaches for human pharmaceuticals are currently available for testing for respiratory or systemic allergenicity (antigenicity) or drug-specific autoimmunity; testing for these endpoints is not currently required in any region.

In addition, there are no direct guidelines determining the testing of human $T$ cell polarization in vivo under neutral or diseased conditions. However, since the methodology of dendritic cell maturation analysis and T-cell polarization cultures is now more elaborately employed and standardization is proposed to apply this methodology in pharmaceutical and research conditions. 


\section{References}

1. Banchereau J, Briere F, Caux C, Davoust J, Lebecque S, Liu YJ, Pulendran B, Palucka K. Immunobiology of dendritic cells. Annual review of immunology 2000;18:767-811.

2. Infante-Duarte C, Kamradt T (1999) Th1/Th2 balance in infection. Semin Immunopathol 21:317-338 .

3. Abbas AK, Murphy KM, Sher A (1996) Functional diversity of helper T lymphocytes. Nature 383:787-793

4. Barrat FJ, Cua DJ, Boonstra A, Richards DF, Crain C, Savelkoul HF, de Waal Malefyt R, Coffman RL, Hawrylowicz CM, O’Garra A (2002) In Vitro Generation of Interleukin 10 - producing Regulatory CD4 ${ }^{+} \mathrm{T}$ Cells Is Induced by Immunosuppressive Drugs and Inhibited by T Helper Type 1 (Th1)_and Th2-inducing Cytokines. J Exp Med 195: 603616.

5. Li MO, Flavell RA. Contextual regulation of inflammation: a duet by transforming growth factor-beta and interleukin-10. Immunity 2008;28:468-76.

6. Lutz MB, Schuler G. Immature, semi-mature and fully mature dendritic cells: which signals induce tolerance or immunity? Trends Immunol 2002;23:445-9.

7. Jutel M, Akdis CA. T-cell subset regulation in atopy. Curr Allergy Asthma Rep 2011;11:139-145.

8. Akdis M, Akdis CA. (2012) IgE class switching and cellular memory. Nat Immunol. 13(4):312-4.

9. Shields RL, (2001) High Resolution Mapping of the Binding Site on Human IgG1 for Fc $\gamma$ RI, Fc $\gamma$ RII, Fc $\gamma$ RIII, and FcRn and Design of IgG1 Variants with Improved Binding to the Fc $\gamma$ R. Journal of Biological Chemistry. 276(9): 6591-6604.

10. Ravetch JV, Bolland S (2001) IgG Fc receptors. Annual Review of Immunology. 19: $275-$ 290.

11. Snel J, Vissers YM, Smit BM, Jongen JMJ, Van der Meulen ET, Zwijsen R, RuinemansKoerts J, Kleerenbezem M, Savelkoul HFJ. (2011) Strain $\square$ specific immunomodulatory effects of Lactobacillus plantarum strains on birch $\square$ pollen $\square$ allergic subjects out of season. Clinical \& Experimental Allergy 41 (2), 232-242.

12. Greer FR, Sicherer SH, Burks AW. Effects of early nutritional interventions on the development of atopic disease in infants and children: the role of maternal dietary restriction, breastfeeding, timing of introduction of complementary foods, and hydrolyzed formulas. Pediatrics. 2008;121:183-91.

13. Den Hartog G, Savelkoul HFJ, Schoemaker R, Tijhaar E, Westphal AH, de Ruiter T, van de Weg-Schrijver E, van Neerven RJJ. (2011) Modulation of human immune responses by bovine interleukin-10. PLoS One 6(3):e18188.

14. Neerven RJJ van, Knol EF, Heck JML, Savelkoul HFJ. (2012) Which factors in raw cow's milk contribute to protection against allergies? J Allergy Clin Immunol 130(4): 853-858.

15. Cameron SB, Stolte EH, Chow AW, Savelkoul HFJ (2003) T helper cell polarisation as a measure of the maturation of the immune response. Mediators Inflammation 12:285-292.

16. House RV (1999) Theory and practice of cytokine assessment in immunotoxicology. Methods 17:17-27.

17. Sander B, Andersson J, Andersson U (1991) Assessment of cytokines by immunofluorescence and the paraformal- dehyde-saponin procedure. Immunol Rev 119:65-93.

18. Schauer U, Jung T, Krug N, Frew A (1996) Measurement of intracellular cytokines. Immunol Today 17:305-306. 
19. Arif S, Tree TI, Astill TP, Tremble JM, Bishop AJ, Dayan CM, Roep BO, Peakman M. (2004) Autoreactive T cell responses show proinflammatory polarization in diabetes but a regulatory phenotype in healthJ. Clin. Invest. 113:451-463.

20. Chanput W, Mes JJ, Savelkoul HFJ, Wichers HJ (2013) Characterization of polarized THP-1 macrophages and polarizing ability of LPS and food compounds. Food \& function 4 (2), 266-276. 


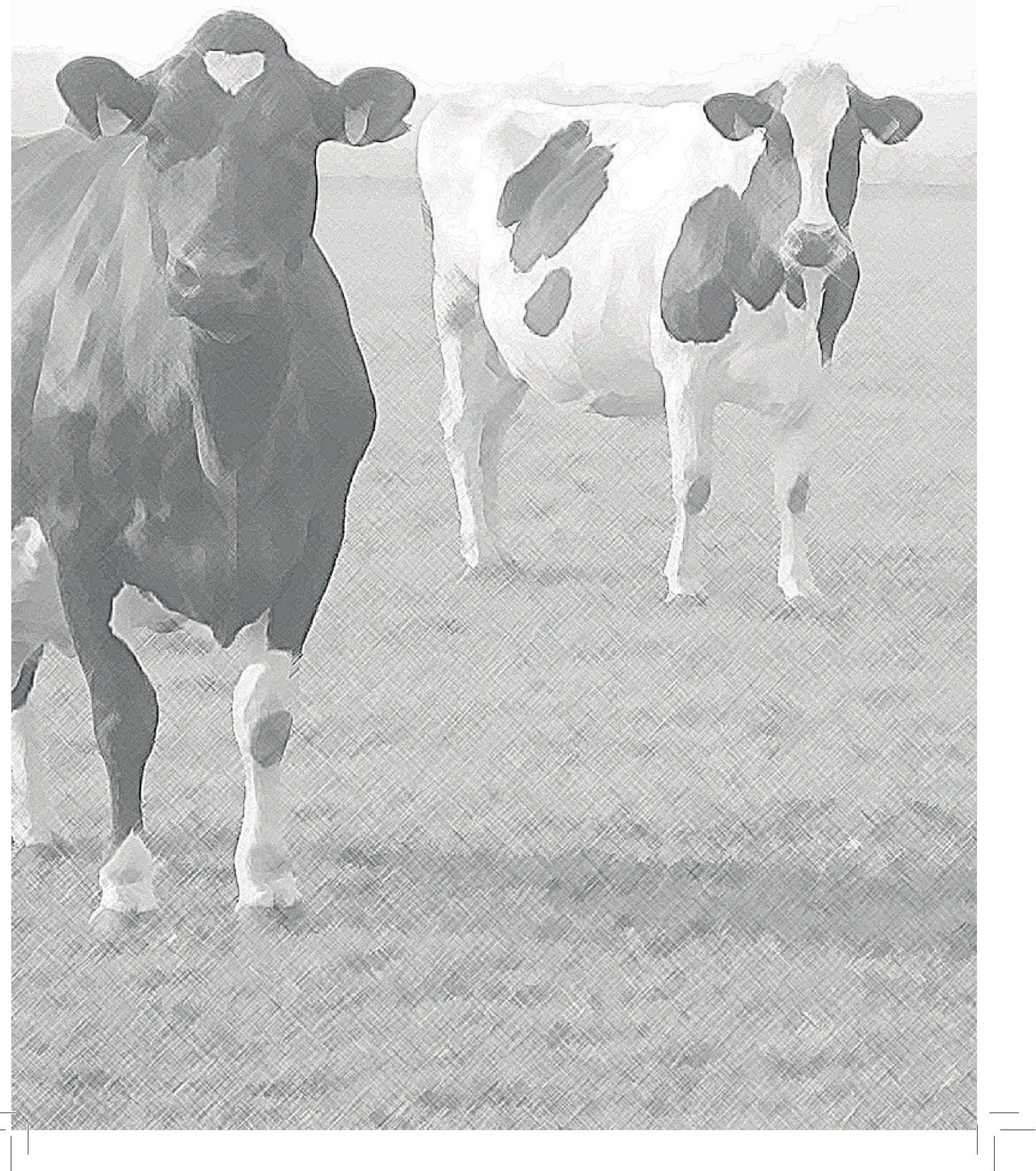




\section{Annex 2}

The Mucosal Factors Retinoic Acid and

TGF- $\beta 1$ Induce Phenotypically and Functionally Distinct

Dendritic Cell Types

Gerco den Hartog ${ }^{1}$, Christine van Altena ${ }^{1}$, Huub F.J. Savelkoul ${ }^{1}$, R.J. Joost van Neerven $^{1,2}$

${ }^{1}$ Cell Biology and Immunology Group, Department of Animal Sciences,

Wageningen University, P.O. Box 338, Wageningen, the Netherlands

${ }^{2}$ FrieslandCampina, Stationsplein 4, 3818 LE Amersfoort, the Netherlands

Int. Arch. Allergy Immunol. (2013) 162:225-236 


\section{Abstract}

Non-inflammatory dendritic cell (DC) subsets play an essential role in preventing massive inflammation in mucosal tissues. We investigated whether the mucosa-related factors retinoic acid (RA) and transforming growth factor- $\beta 1$ (TGF- $\beta 1$ ) can induce such DC types. DCs were differentiated from monocytes in the absence or presence TGF- $\beta 1$ and RA. The phenotype as well as responsiveness to bacterial ligands was studied in detail. Compared to monocyte-derived DCs (moDCs), the expression of co-stimulatory molecule CD86 and DC maturation marker CD83 were strongly reduced by RA and TGF- 31 . In addition, both RA and TGF- $\beta 1$ induced DCs showed strongly decreased responsiveness to stimulation with the bacterial ligands lipopolysaccharide and peptidoglycan, and produced significantly lower levels of the pro-inflammatory cytokines IL-12 and TNF- $\alpha$ compared to moDCs, whilst IL-10 production was not significantly reduced. DCs differentiated under the influence of RA uniquely expressed markers related to intestinal homing (CD103 and integrin B7). In addition, CCR7, which mediates homing to lymph nodes, was expressed by DCs differentiated in the presence of RA, and also to a lesser extent by the other DC types. Furthermore, whereas moDCs and TGF-B1-derived moDCs expressed high levels of CD32, RA-derived DCs lacked CD32 expression but expressed high levels of CD64, suggesting that RA-DC may primarily respond to soluble proteins, and moDC and TGF- $\beta$ DCs to immune complexes. The data presented here support the hypothesis that the mucosal factors TGF- $\beta 1$ and RA, which can also be provided through dietary intake of dairy products, result in functionally and phenotypically distinct DC types with non-inflammatory properties.

Key words: Dendritic cell, activation, CD103, CCR7, B7, mucosal factors, diet 


\section{Introduction}

A complex network of specialized dendritic cell (DC) subsets is involved in inducing acute inflammatory responses upon invasion by pathogens in the one hand, and on the other hand in inducing tolerance to harmless dietary and inhaled antigens as well as commensal microbiota [1,2]. Knowledge on the role of local mucosal and dietary factors that induce these different DC types is still limited.

Intestinal epithelial cells have been shown to be able to induce tolerogenic DCs expressing integrin alpha E (CD103) [3]. Transforming growth factor $\beta$ (TGF- $\beta$ ) and retinoic acid (RA) are important factors for conferring a tolerogenic environment in the mucosa by inducing regulatory $\mathrm{T}$ cells (Treg) and IgA-producing plasma cells [4,5]. Under specific conditions, RA is also able to induce more inflammatory CD4 T-cells $[6,7]$. Intestinal epithelial cells produce TGF- $\beta 1$ in steady state and can metabolize dietary vitamin A to retinoic acid [Reviewed by 8]. TGF- $\beta$ present in breast milk has been associated with development of gut homeostasis and prevention of allergy development in infants [9]. Several studies have indicated a role for the hematopoietic Fms-related tyrosine kinase 3 ligand (Flt31) for induction of CD103 DCs in mice, but this has not been confirmed for human $\mathrm{CD}_{103^{+}} \mathrm{DCs}[10,11]$. Other reports have demonstrated that RA is able to induce CD103 expression on human monocyte derived DCs [3] or mouse bone marrow cells [12] but data on responsiveness to bacterial ligands is lacking. RA has also been implicated in imprinting $T$ cells to migrate to the intestines [13] Both DCs and $\mathrm{CD}^{+} \mathrm{T}$ cells can display tolerogenic properties, which is reflected by expression of CD103 by DCs and forkhead box P3 (FoxP3) by Tregs $[1,3,5]$.

DC subsets exert different functional roles in the intestines, as evidenced by altered composition of the DC network in disease. Increased numbers of CD11 $\mathrm{b}^{+} \mathrm{DCs}$ and decreased numbers of $\mathrm{CD} 103^{+}$DCs were observed after sensitization with peanut allergens in a mouse peanut allergy model [14]. Tolerogenic CD $103^{+}$DCs are known for their different migratory capacity (homing to mesenteric lymph node; MLN) and capacity to induce peripheral tolerance by inducing FoxP3 $3^{+} \mathrm{CD} 4^{+}$Tregs $[1,5,15]$. Next to decreased numbers of $\mathrm{CD}_{103^{+}} \mathrm{DCs}$, Treg-inducing capacity by CD103 expressing DCs was lost in a mouse model of colitis [16]. Those studies in mice provide insight in how DC subsets may be involved in the prevention or pregression of disease, but the role of DC subsets still needs to be established in the human system [17]. Intestinal epithelial cells are also important in the maintenance of intestinal homeostasis as intestinal epithelial cells of patients suffering from colitis produce lower levels of thymic stromal lymphopoietin (TSLP), TGF- $\beta 1$ and aldehyde dehydrogenase (ALDH). ALDH is involved in synthesis of RA, and reduced expression of ALDH mat explain the altered RA-dependent induction of Tregs in those patients $[3,18]$.

Complete activation and differentiation of T cells in contact with antigen-presenting DCs is determined by expression levels of costimulatory molecules like CD80 and CD86, and the production of cytokines (TNF- $\alpha$, IL-10, IL-12) and other soluble factors (e.g. RA). Next to induction of Tregs, TGF- $\beta$ and the metabolite of Vitamin A, RA, have been shown to play a role in the induction of $\operatorname{IgA}$ in vitro and mouse models, which is a major contributor to the first line of mucosal defense $[4,19,20]$. Vitamin A deficiency is associated with pathological 
signs in epithelia, which could be restored after supplementation with vitamin A [21], but it is not known if the restoration of pathology was mediated by CD103+ DCs.

The currently established model for in vitro DC studies relies on differentiation of monocytes under the influence of GM-CSF and IL-4. In addition to the limitations in physiological functionality of differentiating DCs from monocytes in vitro, the conventional model generates only one subtype of DC whereas multiple DC subsets are found in vivo. As data on the direct effects of RA and TGF- $\beta 1$ on the DC phenotype and responses to bacterial ligands is limited, the current study aimed to identify how these mucosal factors affect DC phenotype and activation upon stimulation with bacterial ligands. Conventional monocyte-derived DCs (moDC) were compared to moDCs that were differentiated under the additional influence of TGF- $\beta 1$ or RA. The expression of DC subtype-specific cell surface markers, homing receptors, and $\mathrm{IgG}$ receptors was evaluated, as were their functional responses to stimulation by Toll-like receptor (TLR) ligands.

\section{Materials and Methods}

\section{Peripheral blood mononuclear cells and monocyte isolation}

Peripheral blood mononuclear cells (PBMCs) obtained from buffy coats of healthy blood donors (Sanquin Blood Bank Nijmegen, The Netherlands) were diluted 1:1 in IMDM (Gibco-BRL, Paisley, Scotland) and isolated by gradient centrifugation on FicollPaque PLUS (Amersham Biosciences, Uppsala, Sweden) for 5 minutes at 200g and subsequently for $15 \mathrm{~min}$ at $500 \mathrm{~g}$ (without brake at $20^{\circ} \mathrm{C}$ ). The PBMCs were harvested from the Ficoll layer, gently resuspended in IMDM and washed twice in IMDM.

Freshly isolated PBMCs were labelled with MicroBeads conjugated to mouse IgG2a monoclonal anti-human CD14 antibodies (130-050-201, Myltenyi Biotec, Bergisch Gladbach, Germany) and incubated for 15 minutes at $4^{\circ} \mathrm{C}$, washed with MACS buffer $(0.5 \%$ BSA, 2mM EDTA in PBS, pH 7.2), centrifuged (10 min, 200g) and resuspended in MACS buffer. The MACS columns were placed in the quadroMACS (Myltenyi Biotec) and rinsed with MACS buffer. Subsequently, the cell suspension was added, the columns were rinsed three times with MACS buffer and removed from the quadroMACS; labelled cells were collected in a new tube by rinsing with MACS buffer and the supplied plunger.

Purity of the $\mathrm{CD}_{1} 4^{+}$cell population was between 90 and $95 \%$, as determined by flow cytometric analysis (FACS Canto II BD Biosciences, San Jose, CA, USA) by labeling the cells with mouse IgG2a anti human CD14 APC or an isotype control (clone M5E2, 555399 or 555576, BD Biosciences).

\section{DC generation and stimulation}

Isolated monocytes were cultured in RPMI (Lonza, Basel, Switserland) containing 10\% standardized FCS (A15-551, PAA laboratories) and 1\% pen/strep (Gibco, 15140) at a concentration of $1 * 10^{6}$ cells $/ \mathrm{ml} .50 \mathrm{ng} / \mathrm{ml}$ recombinant human GM-CSF (Peprotech, 300-03) and IL-4 (Peprotech, 200-04) were added and refreshed every second or third day. On day 7 , expression of cell surface markers was analyzed using flow cytometry (FACS Canto II, BD Biosciences). Alternatively, DC subsets were generated by adding $10^{-5} \mathrm{M}$ all-trans retinoic 
acid (Sigma Aldrich) or $10 \mathrm{ng} / \mathrm{ml}$ recombinant human TGF-ß1 (Peprotech) in addition to Il-4 and GM-CSF. Like IL-4 and GM-CSF, RA and TGF- $\beta 1$ were refreshed every second or third day. Also TSLP (50 ng/ml, Peprotech) was tested as factor for CD103 induction.

After differentiation DCs were stimulated with $10 \mathrm{ng} / \mathrm{ml}$ recombinant human IL-1ß (Peprotech) or $2 \mu \mathrm{g} / \mathrm{ml}$ of LPS (S. typhimurium, L7261, Sigma, St Louis, USA), PGN (S. aureus, tlrl-pgnsa, InvivoGen, Toulouse, France) or flagellin (S. typhimurium, tlrl-stfla, InvivoGen). Cell free supernatants were collected and stored at $-80^{\circ} \mathrm{C}$ until analysis. DCs were collected and cell surface marker expression was analyzed.

\section{DC-T cell co-culture}

In order to evaluate the functional consequences of RA-induced-expression on $\mathrm{CD} 4^{+}$cells, DCs and autologous or allogeneic T-cells (CD14-depleted PBMCs) were co-cultured in a 1:10 ration (DC:T cell) [22]. At day 5 of DC differentiation, T-cells were added and incubated for another 5 days. Some T-cells were pre-incubated with $10^{-5} \mathrm{M}$ RA receptor antagonist LE136 (Tocris Bioscience, Bristol, UK) and/or during culture $150 \mathrm{ng} / \mathrm{ml}$ or $100 \mathrm{ng} / \mathrm{ml}$ of monoclonal antibodies to CD3 and CD28 (BD Biosciences) were added. Cells were harvested and stained for CD4 and CD127, followed by fixation and permeabilization and staining with FoxP3 according to the manufacturer`s descriptions (Treg staining kit 560131; BD Biosciences). Cells were gated on CD4-positivity, and the percentage of FoxP $3^{+} \mathrm{CD} 127^{-}$cells were extracted by batch processing using FlowJo.

\section{Cell Surface marker analysis}

DCs were stained with antibodies against CD14 (APC-H7, 560270, BD Biosciences), CD103 (PE, 550260, BD Biosciences), CX3CR1 (PerCP-eFluor710, 46-6099, eBioscience), HLA-DR (APC-eFluor780, 47-9956-41, eBioscience), CD11b (PE-Cy7, 25-0118, eBioscience), CD11c (V450, 560370, BD Biosciences), CD83 (FITC, 11-083942, eBioscience), CD86 (V450, 560357, BD Biosciences), 37 chain (APC, 551082, BD Biosciences), CCR7 (FITC, 561271, BD Biosciences), CD209 (PerCP-Cy5.5, 558263, BD Biosciences), CD16 (PE, 332779, BD Biosciences), CD32 (GTX74628, GeneTex. Irvine, USA), CD64 (305015, BioLegend), FcRn (sc-271745, Santa Cruz, California, USA). For FcRn, CD32 and CD64 a secondary antibody labeled with FITC was used (goat anti mouse IgG/IgM, 555988, BD Biosciences). Of each sample a control sample was analyzed, stained with control antibodies (same concentration as positive staining was used) of the same host species and isotype, conjugated with the same fluorochrome.

Cells were incubated at room temperature for 20 minutes in the dark. Subsequently, cells were centrifuged, supernatant discarded, $200 \mu \mathrm{l}$ FACS Buffer (BD Biosciences) added, and analyzed for surface marker expression by flow cytometric analysis (10 000 cells were analyzed using BD Canto II using DIVA software, BD). Data was batch processed and percentages and delta mean fluorescent intensity (MFI) values (surface marker staining isotype control staining) were obtained.

\section{Human cytokine measurements}

Human cytokine concentrations (IL-10, IL-12 and TNF- $\alpha, 558274,558283$ and 558273 
respectively, $\mathrm{BD}$ Biosciences) in cell culture supernatants were determined using the cytometric bead array flex sets (BD Biosciences) and incubations were performed in the recommended Protein Master Buffer Kit (BD Biosciences). Briefly, $50 \mu 1$ supernatant was incubated with capture beads diluted in $50 \mu \mathrm{l}$ Capture Bead Diluent for one hour at room temperature in the dark. Next, PE Detection Reagent was diluted in $50 \mu 1$ Detection Reagent Diluent, added and incubated for two hours at room temperature in the dark. For the standard curve, the provided lyophilized recombinant cytokines were used and assayed together with the samples. After incubation the samples were centrifuged, supernatant discarded and $200 \mu \mathrm{l}$ Wash Buffer was added. The samples were analyzed by flow cytometric analysis (FACS Canto II, BD Biosciences).

\section{Statistical analysis}

Statistical tests were performed in IBM SPSS Statistics v19. The independent samples t-test was used to test mean differences between DC types or treatments. Depending on equality of variances between test conditions, the p-value of equal or unequal variances assumed was reported.

\section{Results}

\section{Effects of RA and TGF-B on DC differentiation}

IL-4 and GM-CSF are generally used to generate DCs from monocytes. moDC are often used as model DC in studies on intestinal immunomodulation. As the intestines contain several DC subsets, of which tolerogenic subsets are crucial for maintaining homeostasis, we developed two additional DC subsets using the relevant mucosal factors RA and TGF- $\beta 1$. These factors were added to the differentiating DCs of at least 4 different donors in addition to IL-4 and GM-CSF.

All three DC subsets expressed HLA-DR and lacked CX3CR1 and CD14 expression (Table 1). Conventionally differentiated moDCs and TGF- $\beta 1$-derived DCs (TGFmoDCs) expressed CD1a, but RA-derived DCs (RAmoDCs) did not express CD1a (Table 1).

All three DC types expressed CD11b and CD11c (fig. 1). Analysis of the MFI of CD11b revealed that TGF- 31 -derived DCs and even more so the RA-derived DCs expressed reduced levels of $\mathrm{CD} 11 \mathrm{~b}$ compared to $\operatorname{moDC}(\mathrm{p}=0.006$ and $\mathrm{p}=0.001$, respectively). CD11c expression was also reduced $(p=0.001, p=0.006$, respectively; fig 1$)$. This was more prominent for TGF-derived moDCs than for RA-derived moDCs, resulting in a significantly reduced $\mathrm{CD} 11 \mathrm{~b} / \mathrm{CD} 11 \mathrm{c}$ ratio for RA-derived moDCs compared to moDCs ( $p$ $=0.020$, data not shown). 

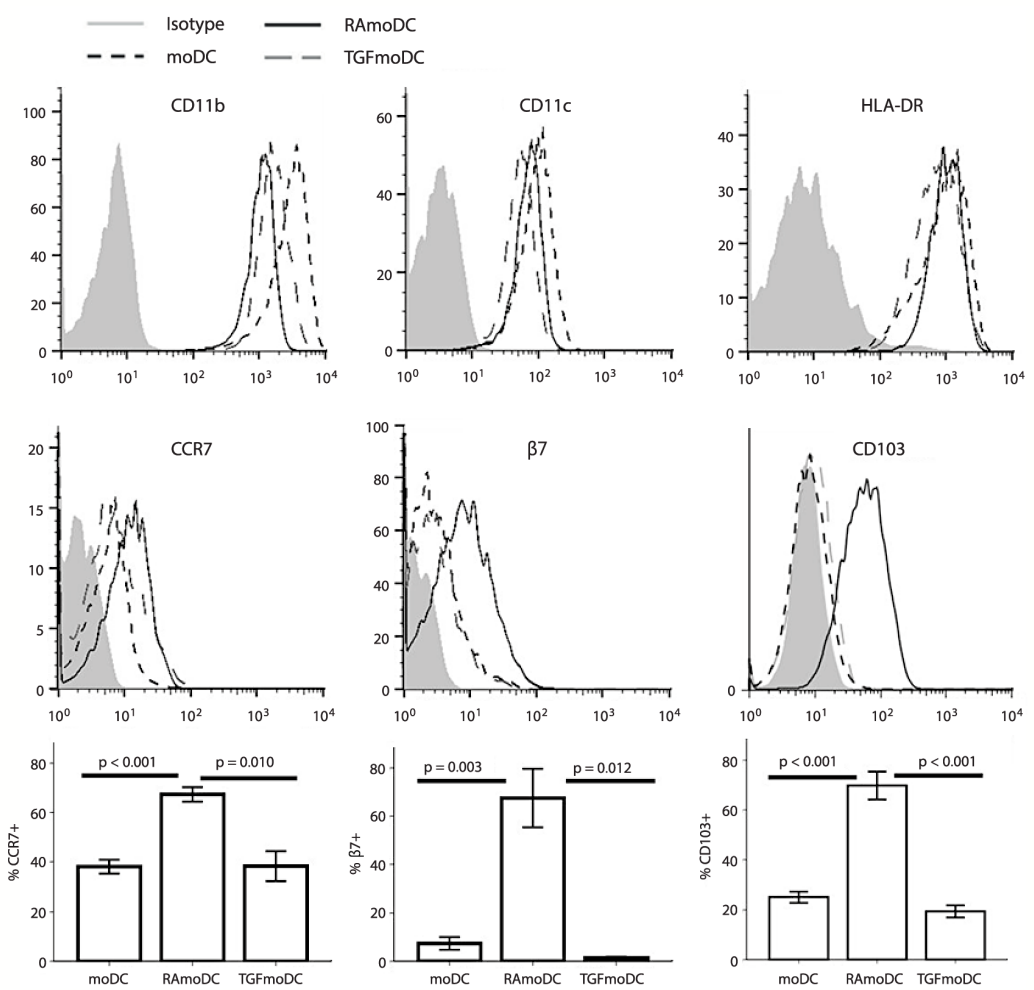

Figure 1. Surface marker expression by the moDCs differentiated under three different regimes. FACS histograms (above) show a representative example of at least 4 donors tested. The grey shaded area is isotype control, black dashed line is moDCs (IL-4 and GMCSF only), black line is RAmoDCs and grey long-dashed line is TGFmoDCs. Bar graphs (below) are shown indicating the average percentage of cells expressing those markers (isotype control values are subtracted) and standard error of 4 different donors. p values shown are based on double-sided t tests, performed after log transformation of the data.

As in vivo functionality of $\mathrm{CD} 103^{+} \mathrm{DCs}$ depends on co-expression of $(\alpha 4) B 7$ to adhere to E-cadherin and migrate to the intestine and on CCR7 for homing to the MLN, we assessed expression of those cell surface markers on the different DC types. The percentage of CCR7-expressing cells doubled under the influence of RA but not under the influence of TGF- $\beta 1$ (fig 1). The MFI level of CCR7 was significantly higher on RA-derived moDC compared to moDCs, but not compared to TGF-derived moDCs. In addition to the expression of CD103, the percentage of DCs expressing the integrin $B 7$ was significantly higher for RA compared to moDCs and TGF-ß-differentiated DCs (fig 1). TSLP and Flt3 ligand (implicated in CD103 induction in mice) did not induce expression of CD103 (data not shown). The basal expression data of the three DC subsets are summarized in table 1. We conclude that especially RA gave rise to moDCs resembling tolerogenic DCs observed in vivo in humans. 
Table 1. Basal expression (\%) of cell surface molecules on the three moDC types

\begin{tabular}{llll}
\hline & moDC & RAmoDC & TGFmoDC \\
CD14 & - & - & - \\
HLA-DR & ++ & ++ & ++ \\
CD1a & + & - & + \\
CD103 & - & + & - \\
CX3CR1 & - & - & - \\
CCR7 & $+/ \square$ & + & $+/ \square$ \\
$\beta 7$ & $+/ \square$ & + & $+/ \square$ \\
CD11b & ++ & ++ & ++ \\
CD11c & ++ & ++ & ++ \\
CD86 & + & $\square$ & $\square$ \\
CD83 & $+/ \square$ & $\square$ & $\square$ \\
FcRn & - & - & - \\
CD16 & - & $+/-$ & - \\
CD32 & + & - & + \\
CD64 & $\square$ & + & $\square$ \\
\hline
\end{tabular}

Data was calculated by subtracting isotype percentages and is based on at least 4 different donors, except for Fc receptor staining, which is based on 3 donors. $-=<5 \% ; \square=5-25 \% ;+/ \square=25-50 \% ;+=50-90 \%$; ++ $=>90 \%$.

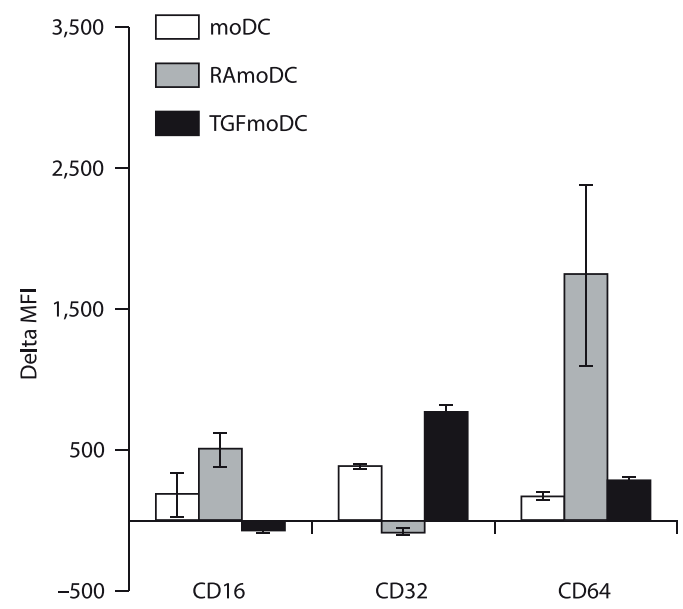

Figure 2. Fc $\gamma$ R expression by the three DC types. Mean MFI and standard errors are shown of 3 different donors. 


\section{Differential expression of $F c \gamma$ receptors}

$\mathrm{Fc} \gamma$ receptors (Fc $\gamma \mathrm{R})$ have different affinities for IgG. Low affinity Fc $\gamma \mathrm{R}(\mathrm{CD} 16)$ and high affinity Fc $\gamma \mathrm{R}$ (CD64) can bind to monomeric IgG, whereas low affinity Fc $\gamma \mathrm{R}$ (CD32) binds to immune complexes only [23]. CD32 expression was observed for moDCs and TGF-derived moDCs, but not for RA-derived moDCs (fig. 2). CD64nwas expressed by all DC types, but its expression wasnhighest on RA-derived moDCs. The Fc $\gamma$ R expression pattern is similar for moDCs and TGF-derived moDCs, although expression of CD32 and CD64 seems to be higher on TGF-derived moDCs. RA-derived moDCs have a different Fc $\gamma R$ expression profile by expressing low levels of CD16 and high levels of CD64, but no CD32. Expression of the neonatal receptor ( $\mathrm{FcRn}$ ) could not be shown on any of the DC types.

\section{Bacterial ligands reduce expression level of CD103 on RA-derived DCs}

$\mathrm{CD} 103^{+}$DCs are believed to migrate to the MLN upon activation, for which reduction of CD103 expression levels may be essential, next to upregulation of CCR7, which is responsible for homing to the MLN. To test if this also occurs in these in vitro-generated $\mathrm{CD}_{103}{ }^{+} \mathrm{DCs}, \mathrm{RA}-$ derived DCs were stimulated with several bacterial ligands and changes in CD103 expression level were measured after $48 \mathrm{~h}$. Addition of bacterial PGN (TLR 2/6 ligand) and LPS (TLR4 ligand) significantly reduced expression of CD103 (data not shown).

\section{DC subsets vary in expression of CD86 and CD83}

The expression of co-stimulatory molecules is essential for complete activation of $\mathrm{T}$ cells. Unstimulated conventional moDCs were slightly pre-activated as evidenced by increased CD83 and CD86 expression, but this was not observed for RAmoDCs or TGFmoDCs. Even so, CD83 and CD86 expression increased significantly after stimulation with bacterial ligands. The percentage of CD86-expressing cells was reduced in RA- and TGF-derived moDCs relative to moDCs $(p=0.013$ and $p=0.007$, respectively), whereas the MFI of CD86 was only reduced in RA-derived moDCs (not significant; fig. 3). All CD83-expressing cells also expressed CD86. RA- and TGF- $\beta 1$-derived moDCs showed a reduced percentage of CD83 + cells compared to moDCs ( $p=0.002$ and 0.004 , respectively), whereas the level of expression (MFI) was the same. Although the percentage of basal expression of CD86 on TGF- $\beta 1$ and RA-derived moDCs was reduced, the addition of bacterial ligands ( 3 donors, $24 \mathrm{~h}$, and 4 donors, $48 \mathrm{~h}$ ) resulted in a pronounced upregulation of CD86 expression on all DC types with the most significant changes induced by exposure to LPS (fig. 3; table 2). However, after stimulation with the TLR ligands PGN and LPS, the MFI of CD86 of RAand TGF-derived moDCs was still significantly lower compared to conventional moDCs, especially for RA-derived moDCs (fig. 3), indicating a state of non-responsiveness. Also, the percentage $\mathrm{CD} 83^{+} \mathrm{CD} 86^{+}$cells upon activation with bacterial ligands was significantly reduced when DCs were differentiated in the presence of TGF- $\beta 1$ and RA. However, no differences in MFI of CD83 were observed. 
A
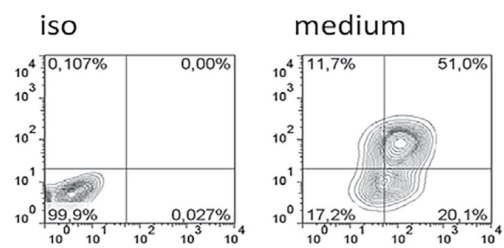

LPS
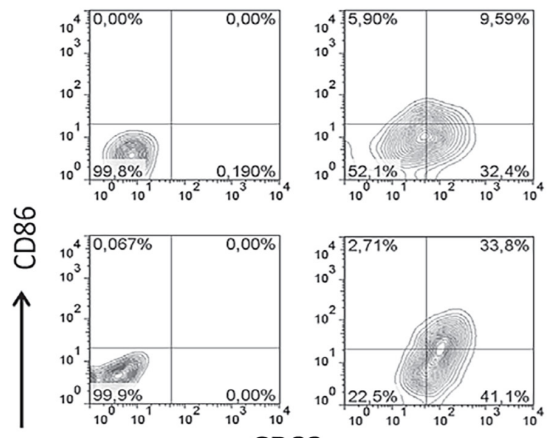

$\mathrm{CD} 83$
B
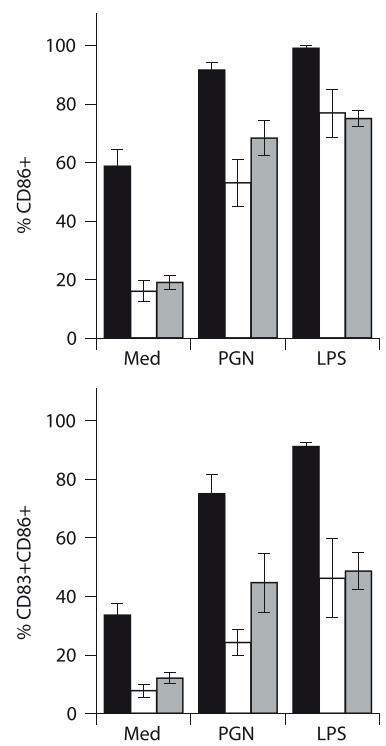

C

\begin{tabular}{|c|c|c|c|c|c|c|c|c|c|c|c|c|}
\hline & \multicolumn{4}{|c|}{ moDC versus RAmoDC } & \multicolumn{4}{|c|}{ moDC versus TGFmoDC } & \multicolumn{4}{|c|}{ RAmoDC versus TGFmoDC } \\
\hline & \multicolumn{2}{|l|}{ CD86 } & \multicolumn{2}{|l|}{ CD83 } & \multicolumn{2}{|l|}{ CD86 } & \multicolumn{2}{|l|}{ CD83 } & \multicolumn{2}{|l|}{ CD86 } & \multicolumn{2}{|l|}{ CD83 } \\
\hline & $\%$ & MFI & $\%$ & MFI & $\%$ & MFI & $\%$ & MFI & $\%$ & MFI & $\%$ & MFI \\
\hline PGN & 0.004 & 0.002 & 0.001 & 0.113 & 0.012 & 0.049 & 0.049 & 0.503 & 0.172 & 0.158 & 0.117 & 0.301 \\
\hline LPS & 0.072 & 0.053 & 0.017 & 0.13 & 0.000 & 0.087 & 0.005 & 0.112 & 0.826 & 0.194 & 0.876 & 0.511 \\
\hline
\end{tabular}
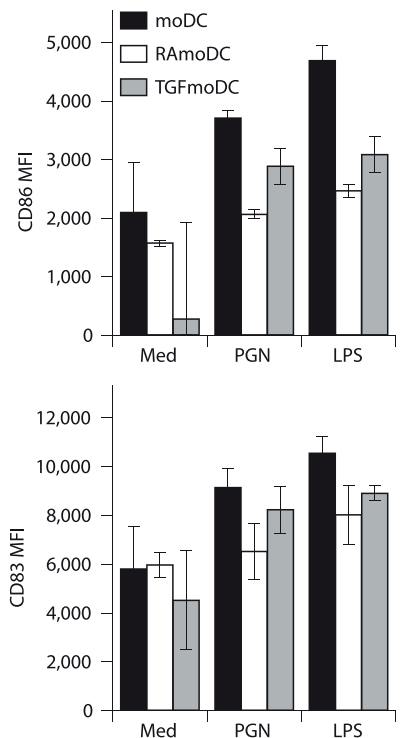

$\begin{array}{llll}0.1726 & 0.194 & 0.876 & 0.511\end{array}$
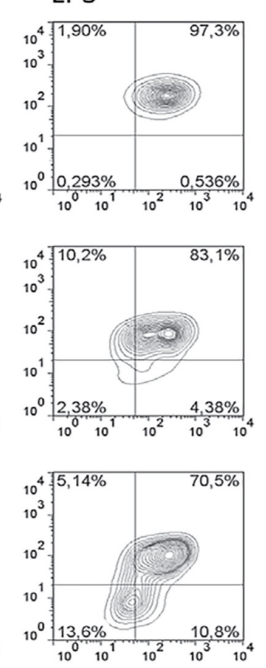

TGFmoDC

moDC

RAmoDC 
4 Figure. 3. Expression of maturation and activation marker CD 83 and CD 86 by the three DC types. (A) Isotype control staining (left column), followed by surface marker staining of non-stimulated (medium, shown in the middle) or LPS-stimulated (right column) moDCs (top), RAmoDCs (middle) and TGFmoDCs (bottom) are displayed. (B) Mean percentage, MFI and standard error are shown of 4 different donors after $48 \mathrm{~h}$ of incubation with medium or bacterial ligands. (C) $\mathrm{p}$ values of t test between DC subsets after activation with bacterial ligands. Statistical differences between DC subtypes are shown ( $t$ test). Similar results (not shown) were obtained with DCs stimulated for $24 \mathrm{~h}$ from 3 independent donors.

\section{Production of the proinflammatory cytokines TNF- $\alpha$ and IL-12 is reduced in RA and TGF-B1 - derived DCs}

After stimulation with the bacterial ligands LPS and PG for 48 hours, cell culture supernatants were collected and cytokine production levels (TNF- $\alpha$, IL-10, IL-12) were determined. Production levels of all cytokines were decreased in cultures with DCs differentiated in the presence of RA and TGF- $\beta 1$ (fig 4). RA and TGF-ß1-derived moDCs, showed significantly reduced production of the pro-inflammatory cytokines TNF- $\alpha$ and IL-12 compared to moDC (RA: $p=0.017$ and $p=0.021$ respectively; TGF- $\beta 1: p=0.013$ and $\mathrm{p}=0.017$, respectively). TGF-derived moDC did not produce detectable IL-12, and strongly reduced amounts of IL-12 were produced by RA-derived moDCs when PGN or LPS was added. IL-10 production by RA- and TGF-derived DCs had a tendency to reduction upon stimulation with PGN, but this did not reach significance.

A

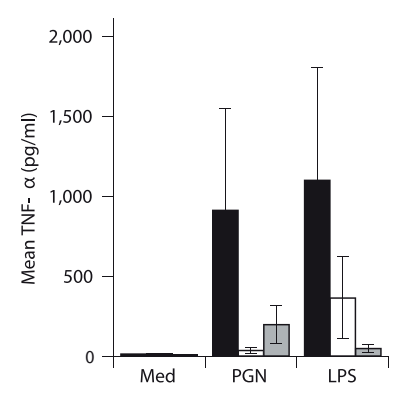

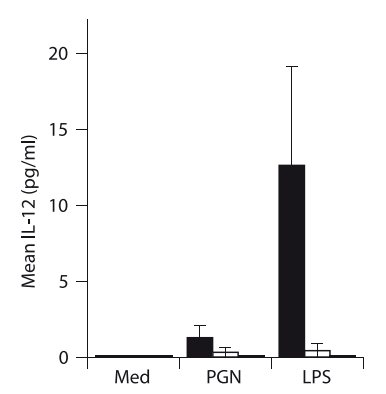

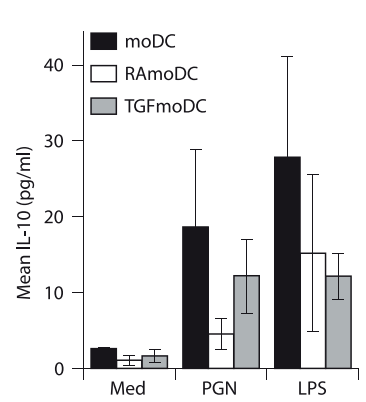

B

\begin{tabular}{|c|c|c|c|c|c|c|c|c|}
\hline \multicolumn{3}{|c|}{$\begin{array}{l}\text { moDC versus } \\
\text { RAmoDC }\end{array}$} & \multicolumn{3}{|c|}{$\begin{array}{l}\text { moDC versus } \\
\text { TGFmoDC }\end{array}$} & \multicolumn{3}{|c|}{$\begin{array}{l}\text { RAmoDC versus } \\
\text { TGFmoDC }\end{array}$} \\
\hline TNF- $a$ & IL-12 & IL-10 & TNF- a & IL-12 & IL-10 & TNF- $a$ & IL-12 & IL-10 \\
\hline 0.085 & 0.340 & 0.054 & 0.168 & 0.315 & 0.497 & 0.006 & 0.391 & 0.049 \\
\hline 0.018 & $<0.001$ & 0.100 & 0.020 & 0.002 & 0.124 & 0.040 & 0.391 & 0.602 \\
\hline
\end{tabular}

Figure 4. Cytokine production by the three DC types upon $48 \mathrm{~h}$ of incubation with medium or bacterial ligands. aean cytokine concentration $(\mathrm{pg} / \mathrm{ml})$ and standard error of 4 different donors after $48 \mathrm{~h}$ of incubation with medium or bacterial ligands. $\mathrm{b} p$ values of $\mathrm{t}$ tests between DC subsets after activation with bacterial ligands (relative cytokine levels). Statistical differences between DC subtypes are shown ( $t$ test). 


\section{Induction of FoxP3 Expression}

As CD103+ DCs have been implicated in inducing FoxP3+ Tregs, moDCs and RAmoDCs were co-cultured with autologous or allogeneic PBMCs that were depleted of monocytes and B cells for 5 days at a ratio of 1:10. Cells were stimulated with suboptimal concentrations of monoclonal antibodies to CD3 and CD28 (150 and $100 \mathrm{ng} / \mathrm{ml}$ ) or medium. The cells were harvested and stainedfor CD4 and CD127 (which should be absent on Tregs) followed by fixation and permeabilization and staining for FoxP3. The percentage of $\mathrm{CD}^{2} 27^{-} \mathrm{FoxP} 3^{+} \mathrm{CD} 4^{+}$cells was determined by flow cytometric analysis. PBMCs cultured in the presence of allogeneic RAmoDCs and CD3 and CD28-specific antibodies showed increased percentage of $\mathrm{FoxP}^{+} \mathrm{CD} 127^{+} \mathrm{CD} 4^{+}$cells (fig. 5). This could be abrogated when PBMCs were pre-incubated with RA receptor antagonist LE135 $\left(10^{-5}\right.$ $\mathrm{M})$. This increased percentage of FoxP $3^{+} \mathrm{CD} 127^{-}$cells was not observed when autologous RAmoDCs or autologous or allogeneic moDCs were used. 
A

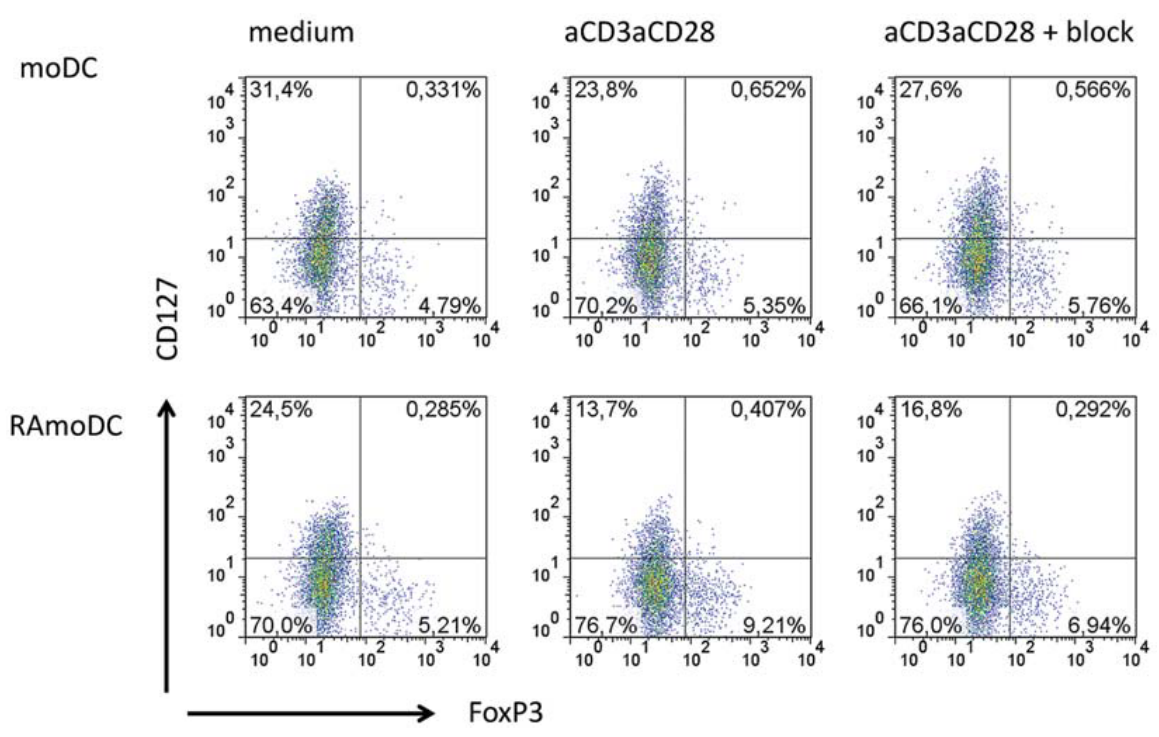

B

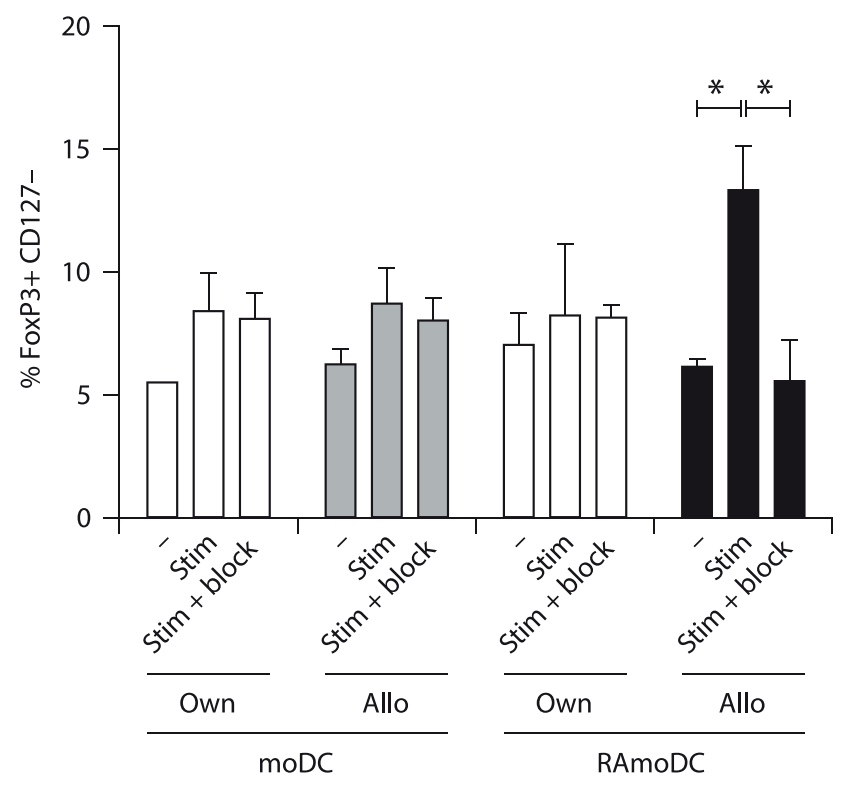

Figure 5. Induction of FoxP3 expression by CD4+ T cells. T cells were added at day 5 of differentiation and incubated for another 5 days before cells were harvested for FACS staining. (A) CD4+ cells are gated on CD127 (y-axes) and FoxP3 (x-axes); medium (left), $\alpha \mathrm{CD} 3 \alpha \mathrm{CD} 28$ (middle) and $\alpha \mathrm{CD} 3 \alpha \mathrm{CD} 28$ plus RA block (LE135) and $\alpha$ TGF- $\beta$ (right) for moDCs (top) and RAmoDCs (bottom) are presented. (B) Mean and standard error of 3 donors are shown for percentage FoxP3+CD127-CD4 cells. Own $=$ Autologous; Allo $=$ allogeneic. $*$ p $<0.05$. 


\section{Discussion}

The generation of moDCs is well established, whilst moDCs do not fully reflect the complex network of mucosal DCs found in vivo, that is partly conditioned by local factors in the mucosa. In this report we describe two DC subsets that can be induced by the mucosal ligands RA and TGF- $\beta 1$. RA- and TGF- $\beta 1$-derived DCs were compared to the commonly used moDCs that are differentiated with IL-4 and GM-CSF only. Addition of RA gave rise to a CD103 and integrin $\beta 7$-expressing subset that also expressed CCR 7 and resembles non-inflammatory DCs observed in vivo. Expression of CCR7 was also found to be increased on $\mathrm{CD} 11 \mathrm{c}^{+} \mathrm{CD} 103^{+} \mathrm{DCs}$ isolated from human MLN, compared to

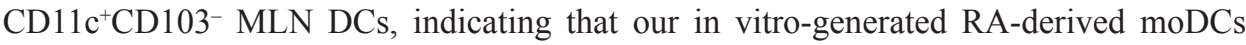
might be a relevant model for $\mathrm{CD} 11 \mathrm{c}^{+} \mathrm{CD} 103^{+} \mathrm{CCR} 7^{+}$DCs found in vivo [3]. DCs differentiated under the influence of IL- 4 and GM-CSF in the presence or absence of TGF- $\beta$ did not express CD103 and integrin $\beta 7$. Differentiation in the presence of RA or TGF- $\beta 1$ resulted in reduced responsiveness to bacterial ligands.

All three regimens used to differentiate peripheral monocytes seem to result in differentiation of immature DC types as expression of CD14 was lost and HLA-DR, CD11b and CD11c were upregulated. CD103- and CD103 ${ }^{+}$DCs expressed CD209, but $\mathrm{CD} 103^{+}$DCs lacked CD1a. The in vitro-differentiated CD $103^{+}$DCs expressed CD11b, but at lower levels compared to CD103- moDCs. The cytokine TSLP did not induce expression of CD103. Although much progress has been made, the precise factors differentially inducing $\mathrm{CD} 11 \mathrm{c}^{+} \mathrm{CD} 103^{+}$and $\mathrm{CD} 11^{1{ }^{\circ}} \mathrm{CD} 103^{-}$DCs have not been revealed to date [24]. Even though functional consequences of different expression levels of CD11b and CD11c by DCs are not understood well, CD11b may correlate with more inflammatory DC subsets, whereas $\mathrm{CD} 11 \mathrm{c}$ might be more expressed on tolerogenic $\mathrm{CD} 103^{+}$subsets in vivo [25]. None of the moDCs generated, neither basally, nor after addition of bacterial ligands, expressed CX3CR1. CX3CR1 expression could also not be induced by differentiation of DCs in the presence of IL-1 $\beta$. This might be explained by the finding that HLA-DRpositive colonic cells that expressed CX3CR1 also expressed CD14, which suggests that CX3CR1 expression in humans might be limited to macrophages and is lacking on DCs [26].

Compared to moDCs, differentiation using additional RA and TGF- $\beta 1$ resulted in reduced expression of CD86 and CD83, and reduced production of cytokines, indicating that these cells may have tolerogenic properties, which was confirmed by their reduced activation by TLR ligands. Those findings are similar to data obtained after co-culturing moDCs with CaCo-2 cells for $24 \mathrm{~h}[3,27]$.

CD103 ${ }^{+}$DCs are believed to migrate to the lymph node upon activation in a CCR7dependent manner [28]. CD103 ${ }^{+}$DCs present in the MLN express CCR7 [3, 24], which was also found in a significant proportion of RA-derived moDCs. Expression of ALDH does not depend on TLR-signaling [29], which is in line with our finding that expression of CD103 was downregulated after stimulation with bacterial ligands. It can be envisaged that CCR7-dependent migration is more efficient when expression of CD103 is reduced upon activation. An effect of the downregulation of CD103 expression upon stimulation with bacterial ligands may be that $\mathrm{CD} 103^{+} \mathrm{DCs}$ lose their non-inflammatory properties 
[16]. The functional relevance of CCR7 expression by RAmoDCs is not clear yet. CCR7 expression by $\mathrm{CD}_{103}{ }^{+}$DCs may allow induction of peripheral tolerance, or enhance inflammation as CCR7-expressing DCs were observed in the colon of Crohn's disease patients, which were absent in healthy individuals [30].

Another interesting difference observed between the three DC types was the level of expression of Fc $\gamma \mathrm{R}$ on the cell membrane. Addition of TGF- $\beta 1$ during differentiation resulted in a similar pattern of Fc $\gamma R$ expression as on moDCs $\left(\mathrm{CD} 32^{\mathrm{hi}}, \mathrm{CD} 16^{\mathrm{lo}}, \mathrm{CD} 32^{\mathrm{lo}}\right)$ but expression levels of low affinity CD32 and high affinity Fc $\gamma R$ CD64 were increased. RA, however, resulted in a lack of CD32 expression and relatively high expression of CD64. This may imply that moDCs and TGF-derived moDCs have a higher capacity to bind to immune complexes, including bacteria, whereas RA-derived moDCs may be specialized in binding soluble antigens (e.g. dietary proteins). Immune complex binding (e.g. bacteria) by moDCs may preferentially result in the activation of $\mathrm{T}$ cells, whereas those complexes bound by non-inflammatory TGF-derived DCs may result in tolerance to those bacteria. It has been established that ligation of CD64 by antigen-IgG complexes could result in activation of $\mathrm{T}$ cells by DCs [31]. As RA-derived DCs show noninflammatory characteristics, ligation of CD64 on RA-derived DCs $\left(\mathrm{CD}_{103}{ }^{+}\right)$may result in induction of oral tolerance as those cells migrate to the MLN and induce Tregs in vivo. Currently, data describing Fc $\gamma R$ expression of DC subsets is limited. As IL-4 downregulates Fc $\gamma R$ expression, it is worthwhile evaluating the effect of RA and TGF- $\beta 1$ on Fc $\gamma R$ expression in the absence of IL-4 [32].

Like $\mathrm{CD} 103^{+} \mathrm{DCs}$ found in vivo, the RA-differentiated DCs described here could induce increased percentages of $\mathrm{FoxP}^{+}$in allogeneic $\mathrm{CD}^{+}$cells under the influence of suboptimal doses of anti-CD3 and anti-CD28 monoclonal antibodies (fig. 5). This increased expression was not observed when T cells were co-cultured with conventional moDCs, and could be abrogated by blocking TGF- $\beta$ and RA simultaneously (fig. 5). It was previously shown that the RA- and TGF- $\beta$-dependent induction of FoxP3 expression by $\mathrm{CD} 4^{+} \mathrm{T}$ cells is abrogated when IL-15 is also present, and RA even enhances IFN-y production by $\mathrm{CD} 4^{+} \mathrm{T}$ cells in the presence of RA [6]. The different levels of cytokines produced by the DC types may result in differential skewing of $\mathrm{T}$ helper cells, as was observed for the induction of Th2 cells by DCs conditioned by epithelial cells [33]. The absence of production of Th1 inducing IL- 12 by TGF-derived DCs may promote the development of Th2 cells, especially since IL-10 expression was largely maintained $[34,35]$. Recently, DCs have been identified as important players in induction of mucosally produced IgA. CD103+ DCs are a candidate IgA-inducing DC subset [12] as these cells are able to produce the major IgA switch factor TGF- $\beta$, and RA which induces IgA plasma cell homing to the intestines [3, 4]. For synthesis of RA, humans depend on dietary intake of RA precursors. These precursors are present in several dietary ingredients, including a number of vegetables like carrot ( $\beta$-carotene) and cow's milk. Induction of peripheral antigen-specific FoxP $3^{+}$Tregs may indirectly depend on dietary intake of RA. Also, TGF- $\beta$ is present in physiologically relevant amounts (several nanograms per mililiter) in cow's milk. The bioactive form of TGF- $\beta 1$ found in milk is largely conserved and TGF- $\beta 2$ is identical to human TGF- $\beta$, and, interestingly, TGF- $\beta$ bioactivity is induced by acidic conditions in the stomach rather than inhibited 
[36]. Also, bovine IL-10 is cross-reactive with the human IL-10R, though IL-10 is mainly present in colostrum and lacking in the majority of commercially available dairy products [37]. Presence of IL-10 during terminal differentiation into immature DCs gives rise to DCs with increased capacity to induce type 1 regulatory T cells $[38,39]$. Tus, several mucosal and dietary factors may contribute to a noninflammatory intestinal milieu.

In conclusion, the RA- and TGF- $\beta 1$-differentiated DCs described here induce distinct mucosal DC subsets, including $\mathrm{CD} 103^{+}$DCs. The phenotype of $\mathrm{CD} 103^{+} \mathrm{DCs}$ resembles the $\mathrm{CD} 103^{+} \mathrm{DCs}$ described in in vivo studies, and can advance widely used DC-type in vitro models with a different functional response to bacterial ligands. However, it still needs to be further established to what extent those CD103+ moDCs resemble the functionality of $\mathrm{CD}_{103^{+}} \mathrm{DCs}$ in vivo. Importantly, the expression of homing markers and Fc $\gamma \mathrm{R}$ differed between the DC types, suggesting different functional roles in intestinal immunity. Induction of these non-inflammatory DC types may very well be modulated by the dietary intake of vitamin A and TGF- $\beta$.

\section{Acknowledgements}

The authors thank Talitha de Ruiter, Elise van de Weg-Schrijver and Anouk L. Feitsma for technical assistance and stimulating discussions. This study was funded by Wageningen University. The authors declare no conflict of interest. 


\section{References}

1. Sun C-M, Hall JA, Blank RB, Bouladoux N, Oukka M, Mora JR, Belkaid Y: Small intes. tine lamina propria dendritic cells promote de novo generation of Foxp3 T reg cells via retinoic acid. J Exp Med 2007; 204: 1775-1785.

2. Pabst O, Mowat AM: Oral tolerance to food protein. Mucosal Immunol 2012; 5: 232-239.

3. Iliev ID, Spadoni I, Mileti E, Matteoli G, Sonzogni A, Sampietro GM, Foschi D, Caprioli F, Viale G, Rescigno M: Human intestinal epithelial cells promote the differentiation of tolerogenic dendritic cells. Gut 2009; 58: 1481-1489.

4. Mora JR, von Andrian UH: Role of retinoic acid in the imprinting of gut-homing IgA-secreting cells. Semin Immunol 2009; 21: 28-35.

5. Coombes JL, Siddiqui KRR, Arancibia-Carcamo CV, Hall J, Sun C-M, Belkaid Y, Powrie F: A functionally specialized population of mucosal CD103 + DCs induces Foxp3 + regulatory T cells via a TGF- $\beta$ - and retinoic acid-dependent mechanism. J Exp Med 2007; 204 : 1757-1764.

6. DePaolo R, Abadie V, Tang F, Fehlner-Peach H, Hall J, Wang W, Marietta E, Kasarda D, Waldmann T, Murray J: Co-adjuvant effects of retinoic acid and IL-15 induce inflammatory immunity to dietary antigens. Nature $2011 ; 471: 220-224$.

7. Hall JA, Grainger JR, Spencer SP, Belkaid Y: The role of retinoic acid in tolerance and immunity. Immunity 2011; 35: 13-22.

8. Mora JR, Iwata M, von Andrian UH: Vitamin effects on the immune system: vitamins a and d take centre stage. Nat Rev Immunol 2008; 8:685-698.

9. Oddy WH, Rosales F: A systematic review of the importance of milk TGF- $\beta$ on immunological outcomes in the infant and young child. Pediatr Allergy Immunol 2010; 21: 47-59.

10. Varol C, Vallon-Eberhard A, Elinav E, Aychek T, Shapira Y, Luche H, Fehling HJ, Hardt W-D, Shakhar G, Jung S: Intestinal lamina propria dendritic cell subsets have different origin and functions. Immunity 2009; 31: 502-512.

11. Waskow C, Liu K, Darrasse-Jeze G, Guermonprez P, Ginhoux F, Merad M, Shengelia T, Yao K, Nussenzweig M: The receptor tyrosine kinase Flt3 is required for dendritic cell development in peripheral lymphoid tissues. Nat Immunol 2008; 9: 676-683.

12. Feng T, Cong Y, Qin H, Benveniste EN, Elson CO: Generation of mucosal dendritic cells from bone marrow reveals a critical role of retinoic acid. J Immunol 2010; 185: 59155925.

13. Iwata M, Hirakiyama A, Eshima Y, Kagechika H, Kato C, Song S-Y: Retinoic acid imprints gut-homing specificity on T cells. Immunity 2004; 21: 527-538.

14. Smit JJ, Bol-Schoenmakers M, Hassing I, Fiechter D, Boon L, Bleumink R, Pieters RHH: The zrole of intestinal dendritic cells subsets in the establishment of food allergy. Clin Exp Allergy 2011; 41: 890-898.

15. Schulz O, Jaensson E, Persson EK, Liu X, Worbs T, Agace WW, Pabst O: Intestinal CD103 + , but not CX3CR1 + , antigen sampling cells migrate in lymph and serve classical dendritic cell functions. J Exp Med 2009; 206: 3101-3114.

16. Laffont S, Siddiqui KRR, Powrie F: Intestinal inflammation abrogates the tolerogenic properties of MLN CD103+ dendritic cells. Eur J Immunol 2010; 40: 1877-1883.

17. Gibbons DL, Spencer J: Mouse and human intestinal immunity: same ballpark, different players; different rules, same score. Mucosal Immunol 2011; 4: 148-157.

18. Duester G: Involvement of alcohol dehydrogenase, short-chain dehydrogenase/reductase, aldehyde dehydrogenase, and cytochrome P450 in the control of retinoid signalling by activation of retinoic acid synthesis. Biochemistry 1996; 35: 12221-12227.

19. Tokuyama H, Tokuyama Y: The regulatory effects of all-trans-retinoic acid on isotype 
switching: retinoic acid induces IgA switch rearrangement in cooperation with IL-5 and inhibits IgG1 switching. Cell Immunol 1999; 192: 41-47.

20. Zan H, Cerutti A, Dramitinos P, Schaffer A, Casali P: CD40 engagement triggers switching to IgA1 and IgA2 in human B cells through induction of endogenous TGF- $\beta$ : evidence for TGF- $\beta$ but not IL-10-dependent direct $\mathrm{S} \mu \rightarrow \mathrm{S} \alpha$ and sequential $\mathrm{S} \mu \rightarrow \mathrm{S} \gamma, \mathrm{S} \gamma \rightarrow \mathrm{S} \alpha$ DNA recombination. J Immunol 1998; 161: 5217- 5225.

21. Villamor E, Fawzi WW: Effects of vitamin A supplementation on immune responses and correlation with clinical outcomes. Clin Microbiol Rev 2005; 18: 446-464.

22. Bernardo D, Al-Hassi HO, Mann ER, Tee CT, Murugananthan AU, Peake STC, Hart AL, Knight SC: T cell proliferation and forkhead box P3 expression in human T cells are dependent on T cell density: physics of a confined space? Hum Immunol 2012; 73: 223-231.

23. Ravetch JV, Bolland S: IgG Fc receptors. Annu Rev Immunol 2001; 19: 275-290.

24. Bogunovic M, Ginhoux F, Helft J, Shang L, Hashimoto D, Greter M, Liu K, Jakubzick C, Ingersoll MA, Leboeuf M, Stanley ER, Nussenzweig M, Lira SA, Randolph GJ, Merad M: Origin of the lamina propria dendritic cell network. Immunity 2009; 31: 513-525.

25. del Rio M-L, Rodriguez-Barbosa J-I, Kremmer E, Forster R: CD103 - and CD103 + bronchial lymph node dendritic cells are specialized in presenting and cross-presenting innocuous antigen to CD4 + and CD8 + T cells. J Immunol 2007; 178: 6861-6866.

26. Mann ER, Landy JD, Bernardo D, Peake STC, Hart AL, Al-Hassi HO, Knight SC: Intestinal dendritic cells: their role in intestinal inflammation, manipulation by the gut microbiota and differences between mice and men. Immunol Lett 2013; 150: 30-40.

27. Butler M, Ng CY, van Heel DA, Lombardi G, Lechler R, Playford RJ, Ghosh S: Modulation of dendritic cell phenotype and function in an in vitro model of the intestinal epithelium. Eur J Immunol 2006; 36: 864-874.

28. Hintzen G, Ohl L, del Rio M-L, Rodriguez-Barbosa J-I, Pabst O, Kocks JR, Krege J, Hardtke S, Forster R: Induction of tolerance to innocuous inhaled antigen relies on a CCR7-dependent dendritic cell-mediated antigen transport to the bronchial lymph node. J Immunol 2006; 177: 7346-7354.

29. Molenaar R, Knippenberg M, Goverse G, Olivier BJ, de Vos AF, O’Toole T, Mebius RE: Expression of retinaldehyde dehydrogenase enzymes in mucosal dendritic cells and gutdraining lymph node stromal cells is controlled by dietary vitamin A. J Immunol 2011; 186: 1934-1942.

30. Al-Hassi HO, Bernardo D, Murugananthan AU, Mann ER, English NR, Jones A, Kamm MA, Arebi N, Hart AL, Blakemore AIF, Stagg AJ, Knight SC: A mechanistic role for leptin in human dendritic cell migration: differences between ileum and colon in health and Crohn's disease. Mucosal Immunol 2013; 6:751-761.

31. Fanger NA, Voigtlaender D, Liu C, Swink S, Wardwell K, Fisher J, Graziano RF, Pfefferkorn LC, Guyre PM: Characterization of expression, cytokine regulation, and effector function of the high affinity IgG receptor Fc gamma RI (CD64) expressed on human blood dendritic cells. J Immunol 1997; 158: 3090-3098.

32. Boross P, Poel K, Winkel JG, Leusen JH: Fc receptors. eLS 2008, DOI: 10.1002/9780470015902.a0000916.pub2.

33. Rimoldi M, Chieppa M, Salucci V, Avogadri F, Sonzogni A, Sampietro GM, Nespoli A, Viale G, Allavena P, Rescigno M: Intestinal immune homeostasis is regulated by the crosstalk between epithelial cells and dendritic cells. Nat Immunol 2005; 6: 507-514.

34. Jankovic D, Kullberg MC, Hieny S, Caspar P, Collazo CM, Sher A: In the absence of IL$12, \mathrm{CD} 4+\mathrm{T}$ cell responses to intracellular pathogens fail to default to a Th2 pattern and are host protective in an IL-10 -/- setting. Immunity 2002; 16: 429-439.

35. D'Andrea A, Aste-Amezaga M, Valiante NM, Ma X, Kubin M, Trinchieri G: Interleukin 10 (IL-10) inhibits human lymphocyte interferon $\gamma$-production by suppressing natural 
killer cell stimulatory factor/IL-12 synthesis in accessory cells. J Exp Med 1993; 178: 1041-1048.

36. Rogers M-L, Goddard C, Regester GO, Ballard FJ, Belford DA: Transforming growth factor $\beta$ in bovine milk: concentration, stability and molecular mass forms. J Endocrinol 1996; 151: 77-86.

37. den Hartog G, Savelkoul HFJ, Schoemaker R, Tijhaar E, Westphal AH, de Ruiter T, van de Weg-Schrijver E, van Neerven RJJ: Modulation of human immune responses by bovine interleukin-10. PLoS ONE 2011; 6:e18188.

38. Gregori S, Tomasoni D, Pacciani V, Scirpoli M, Battaglia M, Magnani CF, Hauben E, Roncarolo M-G: Differentiation of type $1 \mathrm{~T}$ regulatory cells $(\operatorname{Tr} 1)$ by tolerogenic DC-10 requires the IL-10-dependent ILT4/HLA-G pathway. Blood 2010; 116: 935-944.

39. Steinbrink K, Wolfl M, Jonuleit H, Knop J, Enk AH: Induction of tolerance by IL- 10-treated dendritic cells. J Immunol 1997; 159: 4772-4780. 


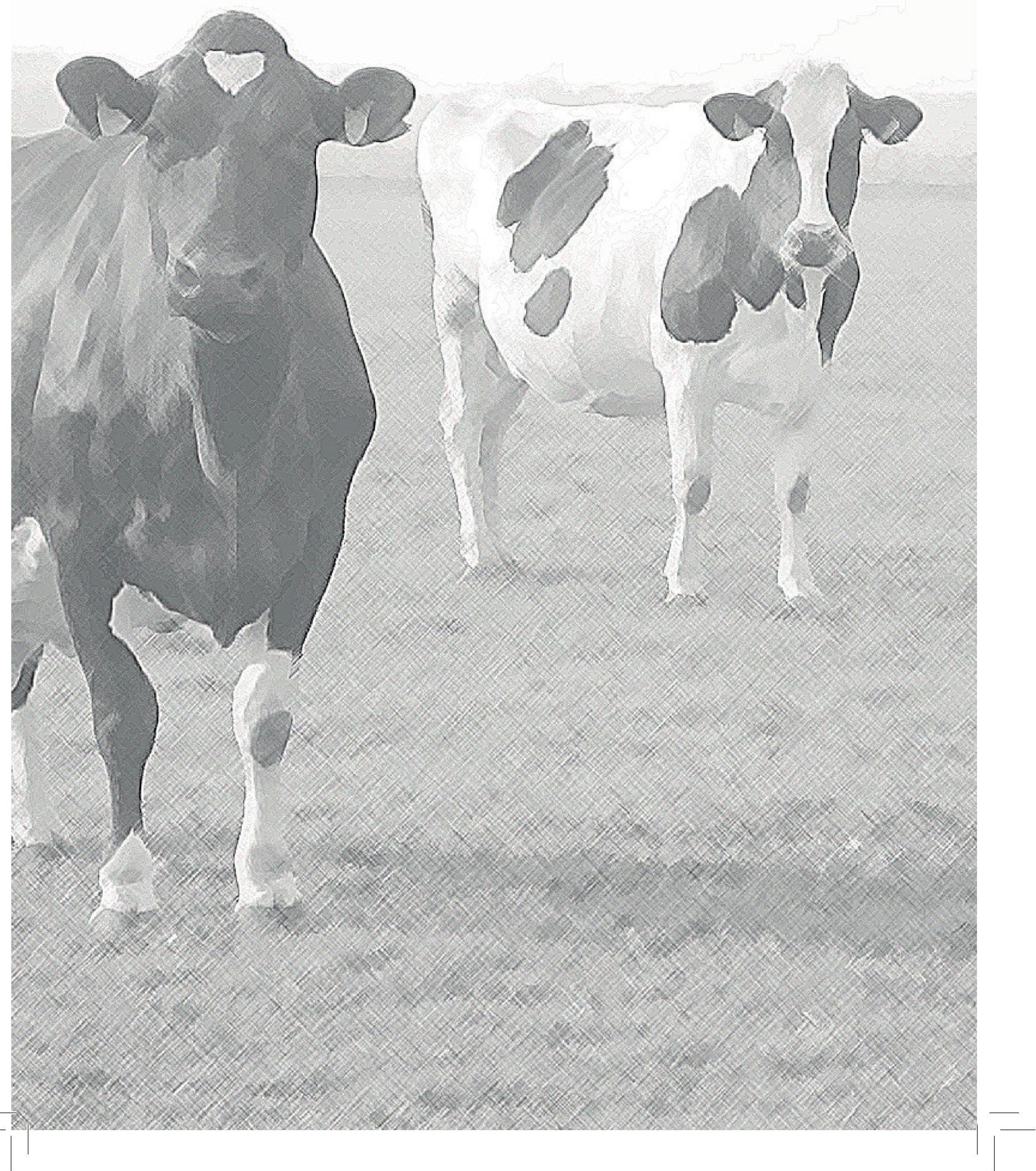




\section{About the Author}

List of Publications

Training Activities

Dankwoord

CV 


\section{List of publications}

Identification of $B-1$ cells in cows

S.E. Christine van Altena, Ben Meijer, Ad P. Koets, Huub F.J. Savelkoul, Edwin J. Tijhaar.

Submitted for publication

$B-1$ cells in veterinary species

S.E. Christine van Altena, Huub F.J. Savelkoul, Edwin J. Tijhaar.

Submitted for publication

A proteomics-based identification of putative biomarkers for disease in bovine milk

S.E. Christine van Altena, Britt de Klerk, Kasper A. Hettinga, R.J. Joost van Neerven, Sjef Boeren, Huub F.J. Savelkoul, Edwin J. Tijhaar. Veterinary Immunology and Immunopathology 2016;174:11-18

Bovine natural antibodies in antibody-dependent bactericidal activity against E. coli and S. typhimurium and risk of mastitis

S.E. Christine van Altena, Manon A. Peen, Franka H. van der Linden, Henk K. Parmentier, Huub F.J. Savelkoul, Edwin J. Tijhaar. Veterinary Immunology and Immunopathology 2016;171:21-27

Maturation of the immune response

S.E. Christine van Altena, Ben Meijer, Huub F. J. Savelkoul. Encyclopedia of Immunotoxicology 2014; 1-11

The mucosal factors retinoic acid and TGF- $\beta 1$ induce phenotypically and functionally distinct dendritic cell types

Gerco den Hartog, Christine van Altena, Huub F. J. Savelkoul, R. J. Joost van Neerven.

International Archives of Allergy and Immunology 2013;162:225-236

Culicoides obsoletus extract relevant for diagnostics of insect bite hypersensitivity in horses

Nathalie M. A. van der Meide, Chantal Meulenbroeks, Christine van Altena, Anouk Schurink, Bart J. Ducro, Bettina Wagner, Wolfgang Leibold, Jens Rohwer, Frans Jacobs, Marianne M. Sloet van Oldruitenborgh-Oosterbaan, Huub F.J. Savelkoul, Edwin Tijhaar. Veterinary Immunology and Immunopathology 2012;149:245-254 


\section{Training and Supervision Plan}

\section{(Inter)national conferences}

BSI European Veterinary Immunology Workshop, Edinburgh, UK International Veterinary Immunology Symposium, Milan, Italy NVVI, Kaatsheuvel, the Netherlands

BSI European Veterinary Immunology Workshop, Vienna, Austria

\section{Seminars and workshops}

WIAS Science Day

Summer Frontiers: Training the innate immunity: Immunological memory in innate host defense

International Dairy Nutrition Symposium: Nutritional management in early lactation How to write a world-class paper?

International Dairy Nutrition Symposium 2013: Feed efficiency in dairy cattle Feed4foodure: Maternal and neonatal interventions

Nutrition, health and welfare of calves

Symposium Droogstand: Why dry?

Wageningen PhD Symposium

\section{Presentations}

Biomarkers voor weerstand in koeien, NRM Zwolle

Biomarkers for natural resistance, Wageningen and Meppel

WIAS Science Day

Weerbaar Vee, Drachten, Hoogeveen, Deventer and Houten

BSI European Veterinary Immunology Workshop, Vienna, Austria

Weerbaar Vee Symposium, Ede

\section{Disciplinary and interdisciplinary courses}

Fish Immunology Workshop, Wageningen

Advanced Immunology, Utrecht

Advanced Proteomics, Wageningen

Statistics for the Life Sciences, Wageningen

Scientific Writing, Wageningen

Efficient writing strategies, Wageningen

BD Flow Cytometry course, Erembodegem, Belgium

Data-mining, Lelystad

\section{Didactic Skills Training}

Cell Biology 1 practicals

Cell Biology 1 discussion groups

Supervision $2 \mathrm{BSc}$ and $2 \mathrm{MSc}$ students

Total study load: 58 ECTS 


\section{Dankwoord}

Een $\mathrm{PhD}$ doen stond niet bepaald op mijn "wish list" en mijn $\mathrm{PhD}$ verliep niet altijd even gemakkelijk, toch heb ik er geen spijt van. Ik kijk vooral terug op een bijzondere tijd waarin ik veel heb geleerd, veel lol heb gehad met de mensen om me heen en de scheiding tussen werk en privé door de jaren heen steeds vager werd.

Allereerst wil ik de mensen uit de stuurgroep en projectgroep van Weerbaar Vee bedanken voor de meetings, de gezelligheid tijdens de bedrijfsbezoeken en natuurlijk het mogelijk maken van mijn $\mathrm{PhD}$ project.

Huub, bedankt voor je enthousiasme, vertrouwen en vooral de steun om ook het laatste stuk van mijn PhD door te komen. Edwin, bedankt voor je begeleiding, humor, vertrouwen en het feit dat ik altijd bij je kon binnenlopen. Van je positiviteit, flexibiliteit en creativiteit kan ik nog wat van leren. Je opruim-skills daarentegen...

Paranimfen Lieke en Carmen. Naast kamergenootjes zijn we ook vriendinnen geworden. Ik heb veel gezelligheid en steun aan jullie gehad (en dat zal hopelijk ook in de toekomst zo blijven). Door jullie goede kookkunsten heb ik afgelopen 4 jaar meer vegetarisch gegeten dan in de 25 jaar daar voor heb gedaan... en ik leef nog steeds...;-) Van jullie enorme chaos en verzamelwoede werd ik wel eens een beetje bang, maar gelukkig was het niet besmettelijk ;-) Nathalie, ik begon als jouw student bij CBI, maar gaandeweg werden we collega`s, vriendinnen en was ik jouw paranimf. Dank daarvoor! @Joeri. Er is inderdaad licht aan het einde van de PhD-tunnel, maar het was wel even zoeken... (Kon niemand een paar lampen ophangen?!?) Dank voor de gesprekken en, vooruit, een klein beetje sorry voor alle grappen ten koste van jou. Kantoorgenootjes Nathalie, Lieke, Inge, Carmen, Esther, Sem en Luca. Thanks for everything! Ben, Marleen en Trudi. Jullie bedankt voor de hulp en gezelligheid. Helaas kunnen we nu niet meer over de kast roepen om een bakkie koffie te doen, een voordeel is dat de "buurvrouw" geen flauwe grapjes meer uit kan halen ;-) Mijn studenten Daria, Manon, Joost en Franka, bedankt voor jullie inzet en bijdrage aan mijn onderzoek.

Verder wil ik de mensen van CBI, EZO en HMI bedanken voor de leuke tijd! De koffiepauzes en lunches met "interessante" discussies, labuitjes, deelname aan de WEday in thema-outfits, de (Rijn-) barbecues, de weekendje weg, de Nieuwjaarsduik en alle andere dingen die mijn $\mathrm{PhD}$ bijzonder maakten. 


\section{Curriculum vitae (EN)}

Stefanie Elisabeth Christine van Altena was born on the 26th of July 1986 in De Wilp, the Netherlands. She grew up in Amerongen attended highschool at the Revius Lyceum in Doorn. In 2005 Christine enrolled in the bachelor Biomedical Sciences at the Utrecht University. After graduation of her Bachelor in 2008, she enrolled in the master program Biology of Disease at the same university. During her master she studied various subjects during her internships. First she was at the Pathology group of the University Medical Centre in Utrecht where she studied bone

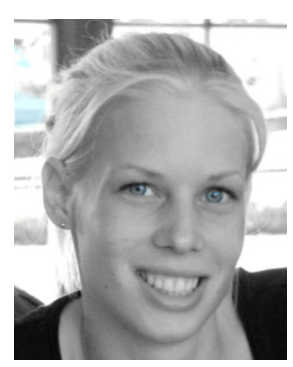
morphogenetic protein (BMP) signalling in response to injury in the kidneys of diabetic mice. Next, she travelled to Wageningen, where she studied insect bite hypersensitivity in horses at the Cell Biology and Immunology group of Wageningen University. For her master thesis Christine wrote a discourse about the interplay between the immune system and tumour cells. After graduation from the master program in 2011, she started working as a laboratory assistant at the Cell Biology and Immunology group in Wageningen. Here she was offered a $\mathrm{PhD}$ project aimed at discovery of novel biomarkers for disease resistance in cows, the result of which lies before you. After finishing her $\mathrm{PhD}$ project, Christine was offered a job at Future Diagnostics Solutions in Wijchen, where she now works as Development Technician. 
The research described in this thesis was part of a joint project "Weerbaar Vee", which was financially supported by the Dutch Ministry of Economic Affairs (The Hague, the Netherlands), Dutch Dairy Product Board ("Productschap Zuivel", Zoetermeer, the Netherlands), Dutch Cooperative Cattle Improvement (CRV, Arnhem, the Netherlands), Dutch Federation of Agriculture and Horticulture ("LTO-Noord Fondsen", Zwolle, the Netherlands) and GD Animal Health (Deventer, the Netherlands). Also special thanks to the herd owners for their collaboration.

Cover: Maurijn Kessels

Lay-out: Fenke Fros

Printing: Digiforce 